EVOLUTION OF FUTURE ENERGY DEMANDS TILL 2030 IN DIFFERENT WORLD REGIONS: AN ASSESSMENT MADE FOR THE TWO IIASA SCENARIOS

Arshad M. Khan and Alois Hölzl

International Institute for Applied Systems Analysis, Laxenburg, Austria

RR-82-14

April 1982

INTERNATIONAL INSTITUTE FOR APPLIED SYSTEMS ANALYSIS

Laxenburg, Austria 
International Standard Book Number 3-7045-0034-8

Research Reports, which record research conducted at IIASA, are independently reviewed before publication. However, the views and opinions they express are not necessarily those of the Institute or the National Member Organizations that support it.

\section{Copyright $\odot 1982$}

International Institute for Applied Systems Analysis

All rights reserved. No part of this publication may be reproduced or transmitted in any form or by any means, electronic or mechanical, including photocopy, recording, or any information storage or retrieval system, without permission in writing from the publisher. 


\section{FOREWORD}

Assessment of future global energy demand was an essential element of the recently completed work of the IIASA Energy Systems Program. This report outlines the main features of the estimates for six out of the seven world regions considered in the IIASA study.

This final energy demand analysis was based on a model, MEDEE-2, that IIASA adopted for projecting the medium- to long-term energy demand at the regional level. The approach used in MEDEE-2 involves specifying fairly detailed scenarios for the expected evolution of socioeconomic activities and technological developments in the world regions over the five decades 1980-2030, during which the related parameters are expected to undergo considerable change.

This report elaborates on and documents the IIASA work on final energy demand. It describes in some detail the derivation of the base year (1975) values of the MEDEE-2 parameters, indicates the relevant sources of information, and spells out the major assumptions and considerations underlying the projected values of various groups of parameters.

Although this report is mainly concerned with evaluating final energy demand, i.e., energy demand by final consumers, it should be stressed that the assumptions in the MEDEE- 2 model and the results it generates must be seen in the context of a set of other models covering energy supply, oil price and trade, and energy-related macroeconomic issues. Together these models enabled us to specify and evaluate two global scenarios to 2030 . as well as some sensitivity cases.

The scenario approach and results, as well as further information on the models, are reported in Part IV of Energy in a Finite World: Volume 2, A Global Systems Analysis, report by the Energy Systems Program Group of IIASA, Wolf Häfele, Program Leader (Cambridge, Massachusetts: Ballinger Publishing Co., 1981). Energy in a Finite World: Volume 1, Paths to a Sustainable Future, issued by the same publisher, gives a shorter account of the study's findings for the general reader. A very short overview is also available from IIASA: Energy in a Finite World: Executive Summary. A list of other IIASA publications supporting this work is given at the end of this report.

WOLF HÄFELE

Leader

Energy Systems Program 



\section{CONTENTS}

SUMMARY

1 INTRODUCTION 3

2 SOME DEFINITIONS

3 THE MEDEE-2 MODEL FOR ENERGY DEMAND ASSESSMENT 8

3.1 Methodological Approach $\quad 8$

3.1.1 Industry 11

3.1.2 Transportation 11

$\begin{array}{ll}3.1 .3 \text { Households and Services } & 13\end{array}$

3.2 Input Data Requirements 14

4 TWO SCENARIOS: BASIC ELEMENTS 14

5 APPLICATION OF MEDEE-2 TO IIASA REGIONS I TO VI 16

5.1 Base Year Data/Inputs 16

$\begin{array}{ll}\text { 5.1.1 Demography } & 19\end{array}$

$\begin{array}{ll}5.1 .2 \text { Macroeconomics } & 21\end{array}$

5.1.3 Energy Consumption in Sectors $\quad 21$

5.2 Detailed Scenario Assumptions 31

5.2.1 Demography $\quad 32$

$\begin{array}{ll}\text { 5.2.2 Macroeconomics } & 32\end{array}$

5.2.3 Energy Consumption in Sectors $\quad 35$

5.3 Projected Final Energy Demand $\quad 49$

5.3.1 Shares of Sectors in Final Energy Demand $\quad 52$

5.3.2 Electricity Demand $\quad 69$

6 CONCLUDING REMARKS $\quad 72$

$\begin{array}{ll}\text { ACKNOWLEDGMENTS } & 78\end{array}$

$\begin{array}{lc}\text { REFERENCES } & 78\end{array}$

APPENDIX A: The Seven World Regions of the IIASA Energy Systems Program 83

APPENDIX B: Equations and Variable Definitions of MEDEE-2 (IIASA version) 86

B1: Calculation of Energy Demand in MEDEE-2 86

B2: Definition of Parameter Variables 114

B3: Definition of Derived Variables 122

APPENDIX C: Definitions of Macroeconomic Sectors in Terms of ISIC Categories 



\title{
EVOLUTION OF FUTURE ENERGY DEMAND TILL 2030 IN DIFFERENT WORLD REGIONS: AN ASSESSMENT MADE FOR THE TWO IIASA SCENARIOS
}

\author{
Arshad M. Khan and Alois Hölzl \\ International Institute for Applied Systems Analysis, Laxenburg, Austria
}

\section{SUMMARY}

This report describes the essential features and the results of a final energy demand assessment made at the International Institute for Applied Systems Analysis (IIASA), cover-ing six of the seven world regions considered in the recently completed global study of IIASA 's Energy Systems Program. The assessment was made using the scenario-development approach embodied in a model called MEDEE-2 that was adopted at IIASA for projecting the medium- to long-term energy demand at the level of world regions. This approach first analyzes the base year energy demand for different sectors in a region in terms of useful/final energy requirements for a large number of activities in each sector, and then projects this demand for later periods by identifying the plausible evolution of various socioeconomic activities and by estimating the probable technological improvements and lifestyle changes in the coming decades.

The starting point for the assessment was a set of basic scenario assumptions concerning population growth and economic development (measured in terms of GDP growth). Two different scenarios were analyzed: they are labelled High and Low with respect to two different sets of assumptions implying relatively high and relatively low economic growth rates. They cover a plausible range of values for world economic growth during the next 50 years. The population growth rate assumptions are common to both the scenarios.

This assessment involved estimating the base year (1975) values of some 180 parameters for each region and projection of the values of these parameters to the years 2000 and 2030 in a manner consistent with the basic scenario assumptions, while incorporating feasible technological improvements and plausible lifestyle changes. The report lists the estimated base year values of the various parameters, describes how they were estimated, and gives sources of information. Similarly, it lists the projected values of these parameters, and describes the underlying reasoning. Finally, it discusses the requirements of final energy for various sectoral activities and the extent of conservation incorporated in the projections. 
Some of the main results of this assessment are:

1. By 2030 the final energy demand in the developed regions (IIASA Regions I North America; II - The Soviet Union and Eastern Europe, and III - Western Europe, Japan, Australia etc.) will increase by a factor of 1.8 to 2.6 as compared to that in 1975 , whereas that in the three developing regions considered in the present assessment (i.e., IIASA Regions IV - Latin America; V - Africa, except Northern Africa and South Africa, and South East Asia, and VI - Middle East and Northern Africa) will increase by a factor of 7 to 12. The projected demand in the various regions will, however, be lower than that estimated on the basis of historical final energy-to-GDP elasticity of each region by 16 percent to 40 percent in the Low scenario and 23 percent to 54 percent in the High scenario.

2. The per capita final energy consumption in the developed regions $I, I I$, and $I I I$ will increase from a level of $2.8-7.9 \mathrm{~kW}$ in 1975 to a level of $3.9-11.6 \mathrm{~kW}$ by 2030 , whereas that in the developing regions $I V, V$, and $V I$ will increase from $0.2-0.8 \mathrm{~kW}$ to $0.5-4.6 \mathrm{~kW}$ over the same period. Among the developing regions the largest increase will occur in the resource-rich Region VI and the smallest increase will occur in the resourcepoor Region $V$.

3. The sectoral shares of final energy demand in various world regions will not undergo major changes during the next 50 years, so that the regional differences in the sectoral distribution of final energy will persist. In particular, the transportation sector in the de. veloping regions and the household/service sector in the developed regions will continue to have relatively higher shares in the final energy demand than those commanded by the corresponding sectors in other regions.

4. The share of electricity in final energy will increase everywhere - from 10-13 percent in 1975 to $20-23$ percent in 2030 in the developed regions, and from 4-10 percent in 1975 to $15-17$ percent in 2030 in the developing regions.

5. The specific liquid fuel requirements as motor fuel or petrochemical feedstocks will, in 2030, account for a 34 percent to 43 percent share of final energy in the developed regions and 45 percent to 57 percent in the developing regions. The corresponding shares in 1975 in the developed and the developing regions are in the range of 24-37 percent and 32-52 percent respectively.

6. Manufacturing activities will continue to dominate the industrial final energy demand (i.e., the demand from the manufacturing, mining, agriculture, and construction sectors) in all regions. The share of manufacturing in the industrial final energy demand in 2030 for different regions will be in the range of $76-90$ percent, as compared to 62 92 percent in 1975 .

7. The automobile share of transportation energy demand will decrease in the developed regions and increase in the developing regions. The most notable change will occur in Region I, where this share will decline from 67 percent in 1975 to 19-29 percent in 2030. The automobile share in the transportation sector's final energy demand for different regions will lie in the range of $8-36$ percent in 2030 , as against $6-67$ percent in 1975 .

8. In 2030 soft solar devices will be able to meet about $1-3$ percent of the useful thermal energy requirements of the manufacturing sector and 5-13 percent of those of the household/service sector in the developed regions. The corresponding shares in the developing regions will be in the ranges of 4-5 percent and 2-12 percent, respectively. 
9. In spite of gradually increasing penetration of electricity, heat pumps, soft solar, and district heat in the heat markets of the manufacturing and household/service sectors, fossil fuels will continue to be the most important source of thermal energy in these sectors in all regions except Region II. In 2030 the shares of substitutable fossil fuels (i.e., fossil fuels for thermal uses) in developed Regions I and III and the developing regions will be in the range 80-90 percent for the manufacturing sector and 55-85 percent for the household/service sector. The corresponding shares in Region II will be about 30 and 25 percent, respectively, due to continued heavy reliance on district heating systems in this region

\section{INTRODUCTION}

IIASA's Energy Systems Program deals with the medium- to long-term aspects of global energy supply and demand. It concentrates on a period of 15-50 years from now, during which the world energy system will have to undergo a major transition. This transition will result from a large increase in world population, the expected industrialization and relatively fast economic growth of the developing countries, and the worldwide scarcity of the hitherto cheap conventional forms of energy, particularly of conventional oil and natural gas. The major findings of this study have recently been reported in Energy in a Finite World: A Global Systems Analysis (Energy Systems Program Group 1981).

This current report gives an assessment of final energy demand in various world regions that was carried out as a part of the above program by using an energy demand model called MEDEE-2.

For the purpose of IIASA's energy systems study, the world was divided into seven regions, as illustrated in Figure 1. (For a complete listing of the countries in each region see Appendix A.) The grouping of countries in these regions was based not on their geographical proximity but on considerations of similarities in social, economic, and demographic structures, and on prospects of economic growth and availability of energy re sources. The work described in this report covers only the first six of the seven world regions shown in Figure 1. The energy demand assessment for Region VII (China and Centrally Planned Asian Economies) was not carried out with MEDEE-2 due to the lack of data. A simplified model called SIMCRED (Parikh 1978) was used for this region; this report does not discuss the assessment nor results.

The long-term projection of energy demand and supply in various world regions can be made only in the light of mutually consistent projections of population, economic growth, availability of energy, material, and other resources, some perception of technological innovation and development, and in the wake of various physical, social, and environmental constraints. In order to obtain a consistent picture, one has to look at all these factors both individually and collectively, and through an iterative procedure try to eliminate internal inconsistencies.

Such an analysis was carried out at IIASA using a set of mathematical models as the major analytical tool (Basile 1980). The flow of information between these models is schematically shown in Figure 2. It begins with some initial scenario definitions of the economic and population growth rates in the various world regions. The demand of final energy in each region is then evaluated with the energy demand model MEDEE-2 projecting 


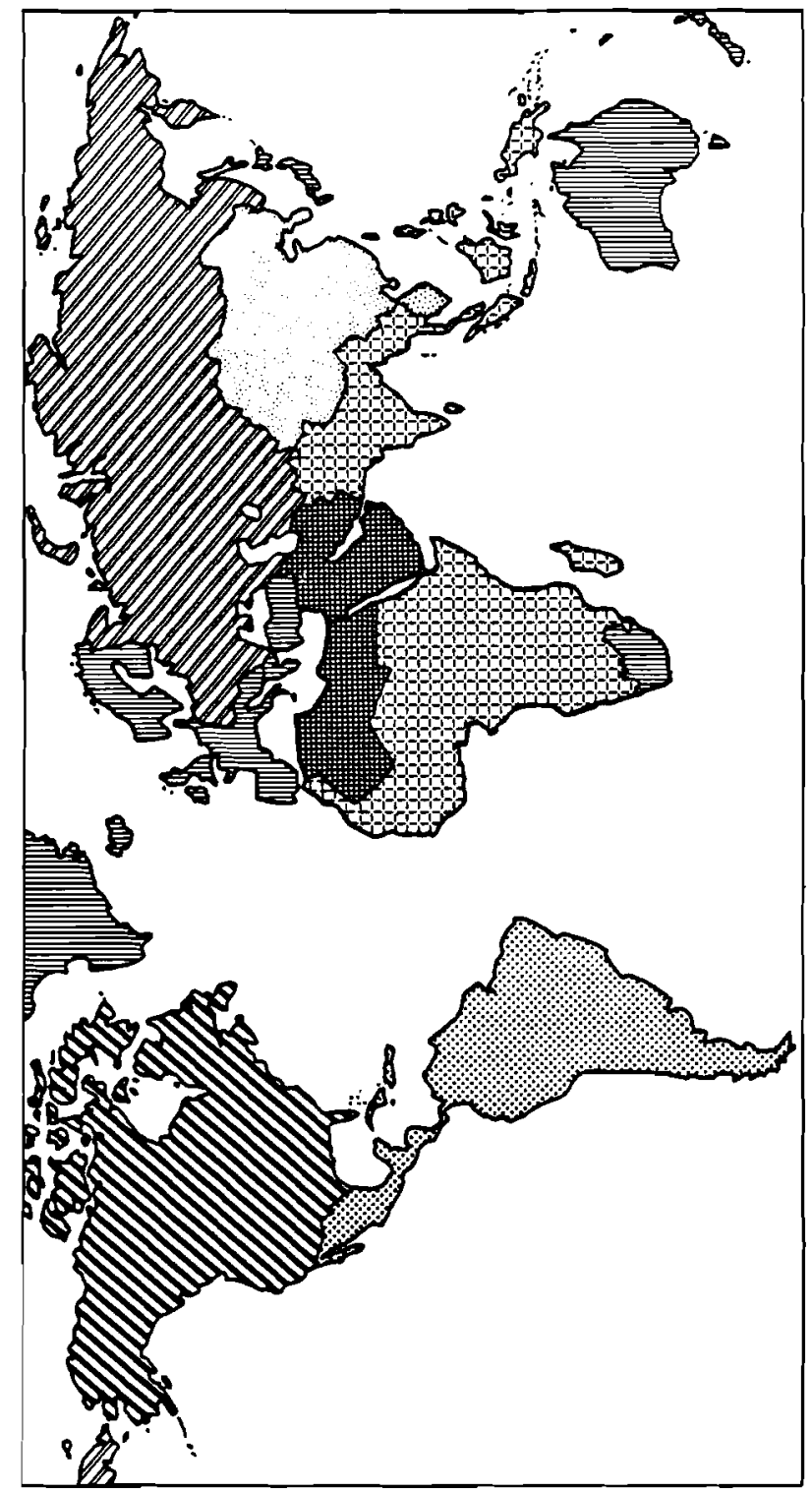

苍 $\frac{\pi}{4}$

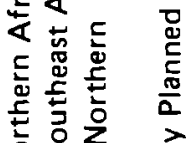

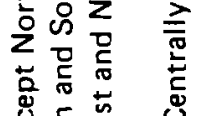

造䓵

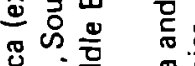

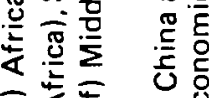

选安焉

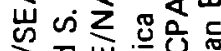

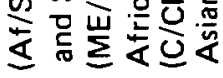

$>\quad \overline{5}$

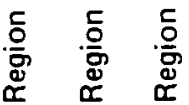

国

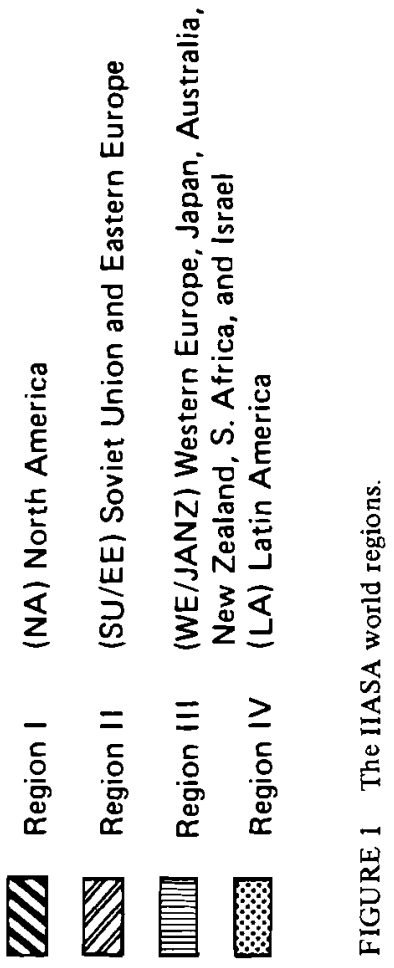




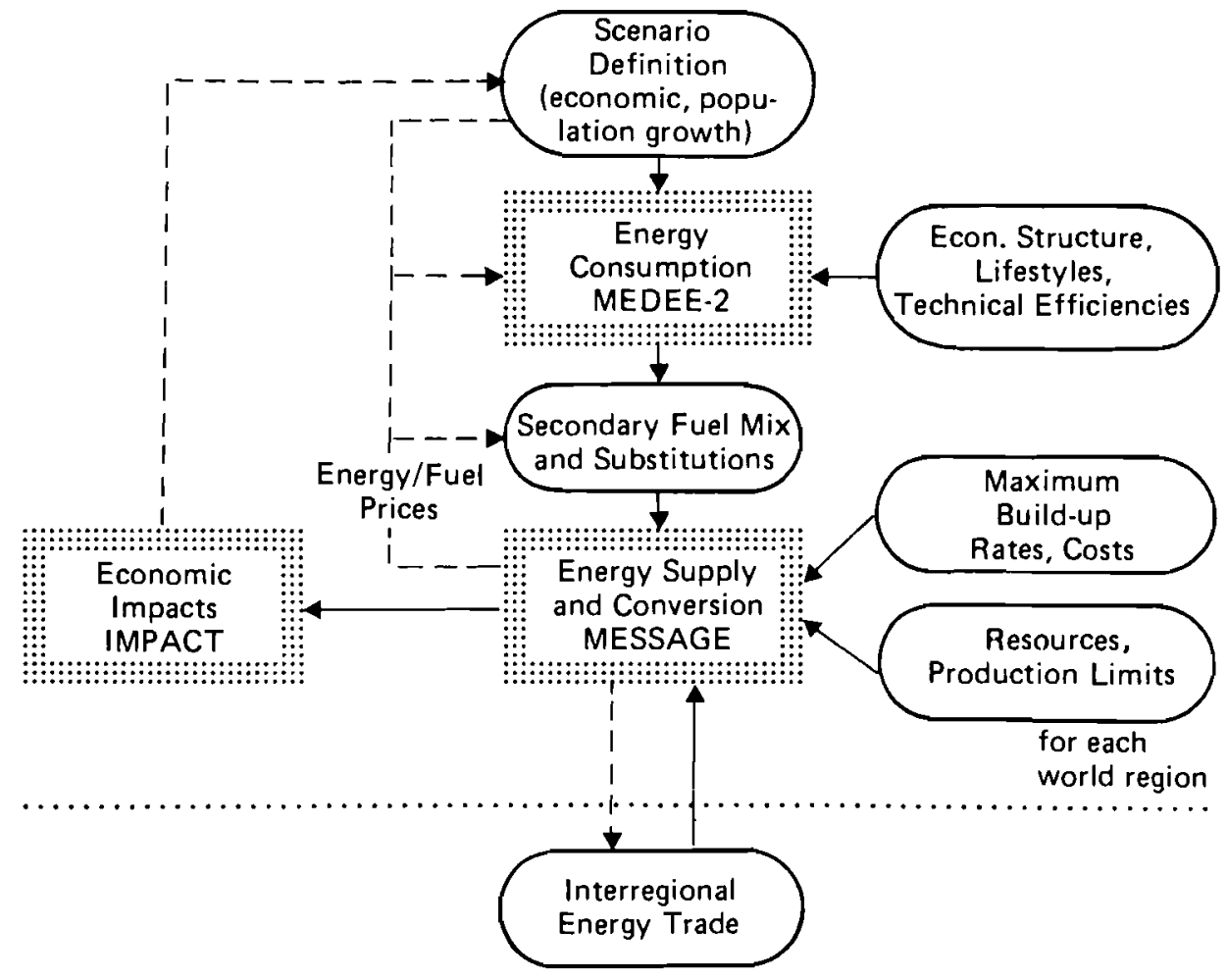

Assumptions, judgments, manual calculations

:::::::::::

Formal mathematical models

$\longrightarrow$ Direct flow of information (only major flows shown)

$-\rightarrow$ Feedback flow of information (only major flows shown)

FIGURE 2 IIASA's set of energy models: a simplified representation.

changes in economic structure, lifestyles, technical efficiencies, etc., that could be expected under the basic scenario conditions. The energy supply model MESSAGE then calculates optimal supply strategies consistent with the availability of energy resources and subject to various constraints encompassing technological, environmental, and other related issues. Consideration of the interregional energy trade calls for iteration of the MESSAGE runs for various regions until a globally consistent picture emerges. The economic impacts of the regional supply strategies are then analyzed in the energy-economy interaction model IMPACT. The corresponding implications and the estimates of energy and fuel prices, obtained from the MESSAGE runs, are used to modify - if necessary - the scenario 
definitions of regional economic growth and the projections of some of the parameters used in the MEDEE-2 runs of the preceding iteration of the modeling loop. This procedure is repeated until the demand and supply projections are considered to be "reasonable" and consistent.

This report is concerned mainly with the assessment of final energy demand, based on a MEDEE-2 analysis, for the IIASA Regions I through VI. In order to provide a proper appreciation of the assessment procedure, we also briefly describe the energy accounting and the analytical approach used in the MEDEE-2 analysis. (A formal description is given in Appendix B.) A description follows of the input data actually used for the base year (1975), of the values assigned to the scenario variables for the years 2000 and 2030 in the various world regions, and of the underlying assumptions. The results of the MEDEE-2 analysis are then discussed in terms of the projected energy requirements for various sectoral activities and the extent of "conservation" incorporated in these projections.

\section{SOME DEFINITIONS}

In discussing the issues related to energy demand and supply, a distinction must be made between the different forms of energy usually referred to as primary energy, secondary energy, final energy, and useful energy. The difference between these various forms is illustrated in Figure 3.

Primary energy* represents the energy content of extracted raw fuels, e.g., crude oil or natural gas at the wellhead, coal at the minemouth. Some primary fuels need to be refined or converted to secondary energy, in oil refineries or power plants, with typically rather large conversion losses (at least 60 percent losses in the case of coal converted to electricity); others can be transported and used directly as secondary energy.

Secondary energy, after transmission and distribution through major networks (e.g., oil/gas pipelines, delivery trucks, high and low voltage lines), becomes final energy. Electricity at the output, or busbar, of a power station is secondary energy; electricity at the home wallplug is final energy.

Final energy is energy delivered to final consumers - oil delivered to burners in the basement, or to industrial boilers. Final energy is what the consumer buys.

Useful energy is what one actually benefits from - the heat that warms living rooms, for example. Produced photons, heated air, kinetic energy are useful energy. All conversion processes from primary energy through useful energy involve varying amounts of losses due to conversion and/or transmission, storage, and distribution (see Figure 3). After providing the required energy services, in combination with other inputs such as capital, know-how, and labor, the useful energy is ultimately rejected to the environment. The amount of useful energy needed to obtain a given amount of energy services depends

*Primary energy also includes fossil fuel equivalents, for example, of nuclear energy and hydropower converted to electricity; and the energy obtained from new sources such as solar, geothermal, wind, ocean thermal gradients, charcoal and fuelwood from forests, planned wood plantations, biogas, etc. Except where indicated, primary energy excludes noncommercial use of fuels such as firewood, farm wastes, and animal wastes. 


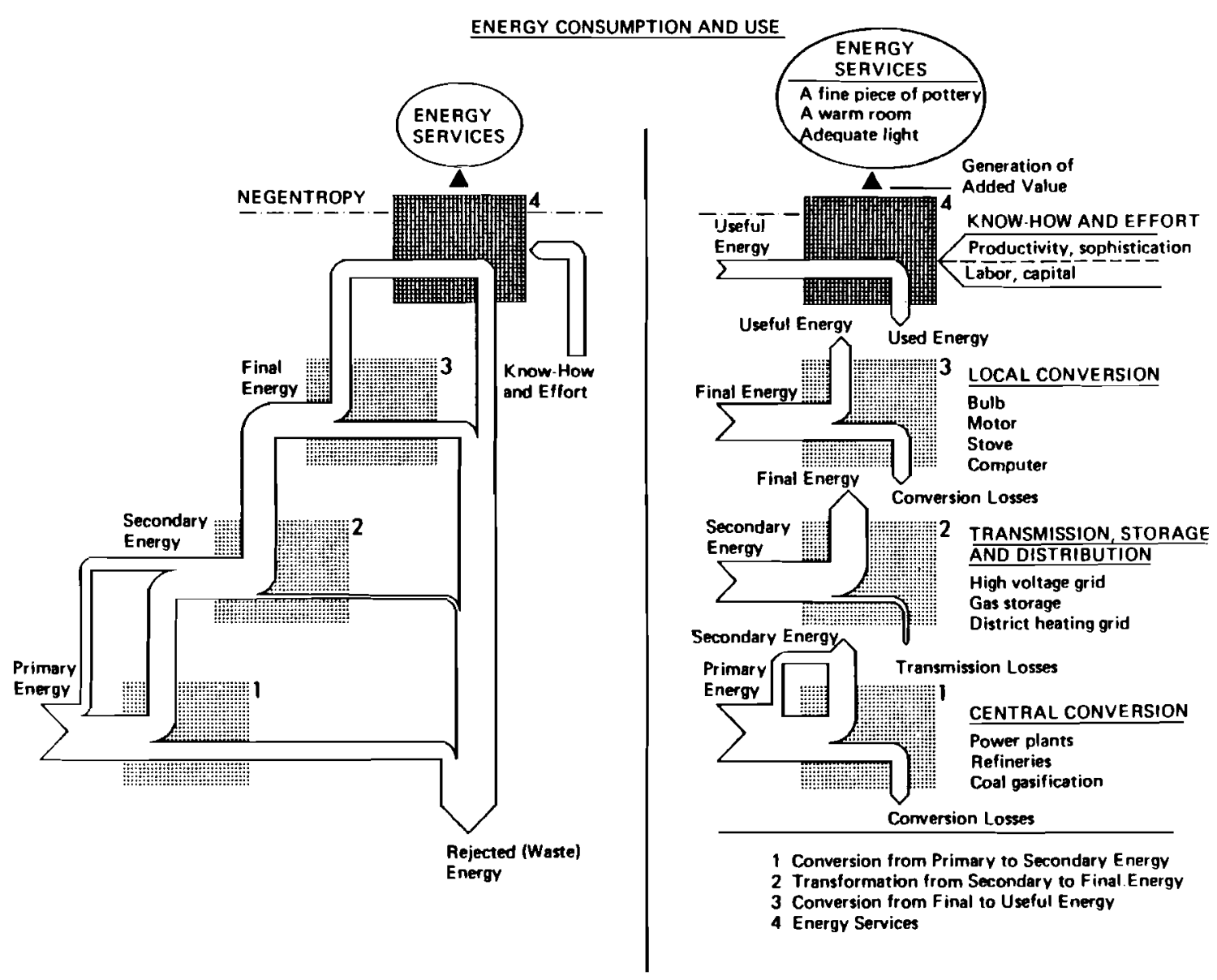

FIGURE 3 Energy conversion and use. 
on the relative magnitudes of these other inputs (Häfele 1977), and this leads to the ultimate potential of energy conservation.

The energy demand projections discussed in this report were made only in terms of useful and/or final energy forms. The evaluation of secondary and primary energy require ments, based on these demand projections, was made in the MESSAGE model runs and has been described in Energy Systems Program Group (1981).

\section{THE MEDEE-2 MODEL FOR ENERGY DEMAND ASSESSMENT}

\subsection{Methodological Approach}

MEDEE-2 is a simulation model for evaluating the energy demand implications of a scenario describing a hypothetical evolution of economic activities, changes in the lifestyle of the population, and technological improvements. ${ }^{*}$ It is based on a disaggregation of total energy demand into a multitude of end-use categories - such as heating or cooling of dwellings, passenger transportation by mode, or steam generation in industry. For thermal uses of energy, where the useful energy demand can be provided by various enery sources (e.g., fossil fuels, district heat, electricity, or solar systems), the energy demand is calculated first in terms of useful energy** and then converted to final energy terms based on assumptions about the penetration of various energy sources into their potential end-use markets and about their end-use efficiency. For all other energy use categories, such as motor fuel for automobiles or electricity for electrolysis, lighting, various household appliances, etc., the energy demand is directly calculated in final energy terms, they are called "nonsubstitutable uses," in the sense that substitutions would be difficult and are therefore unlikely.

For each end-use category, energy demand (useful or final) is related to a set of determining factors, which may be macroeconomic aggregates, physical quantities, or technological coefficients. The energy demand projections result from the evolution assumed for these factors. Because of this high level of disaggregation and the relatively few structural assumptions built into the model, it can be viewed as an accounting framework of the energy uses in a country or a region.

Figure 4 shows the scheme for projecting useful and/or final energy demand used in MEDEE-2. The starting point is a scenario that defines an environment of population growth, economic development, energy availability, and prices envisaged for the future. These general scenario parameters must be disaggregated in terms of economic structure, demographic structure and lifestyles, and technological structure. Various elements make up these factors - gross domestic product (GDP) expenditure and formation and production of certain energy intensive basic industry products, labor force participation, urban/rural

\footnotetext{
*MEDEE-2 is a simplified version of a more general approach developed by Chateau and Lapillonne (1977) at the Institute des Etudes Juridiques et Economiques, University of Grenoble, France. 1t was adapted by Lapillonne (1978a) for the global energy demand assessment in IIASA's Energy Systems Program. In the course of the study, several changes were made to the program. The main equations and variable definitions corresponding to the present state of the model are listed in Appendix B. It may also help to understand how the various parameters affect the results, and dispel ambiguities about the scope.

**For this assessment, useful energy for thermal processes is expressed as equivalent requirements of electricity. This implies that all efficiencies are specified relative to the efficiencies of electricity.
} 


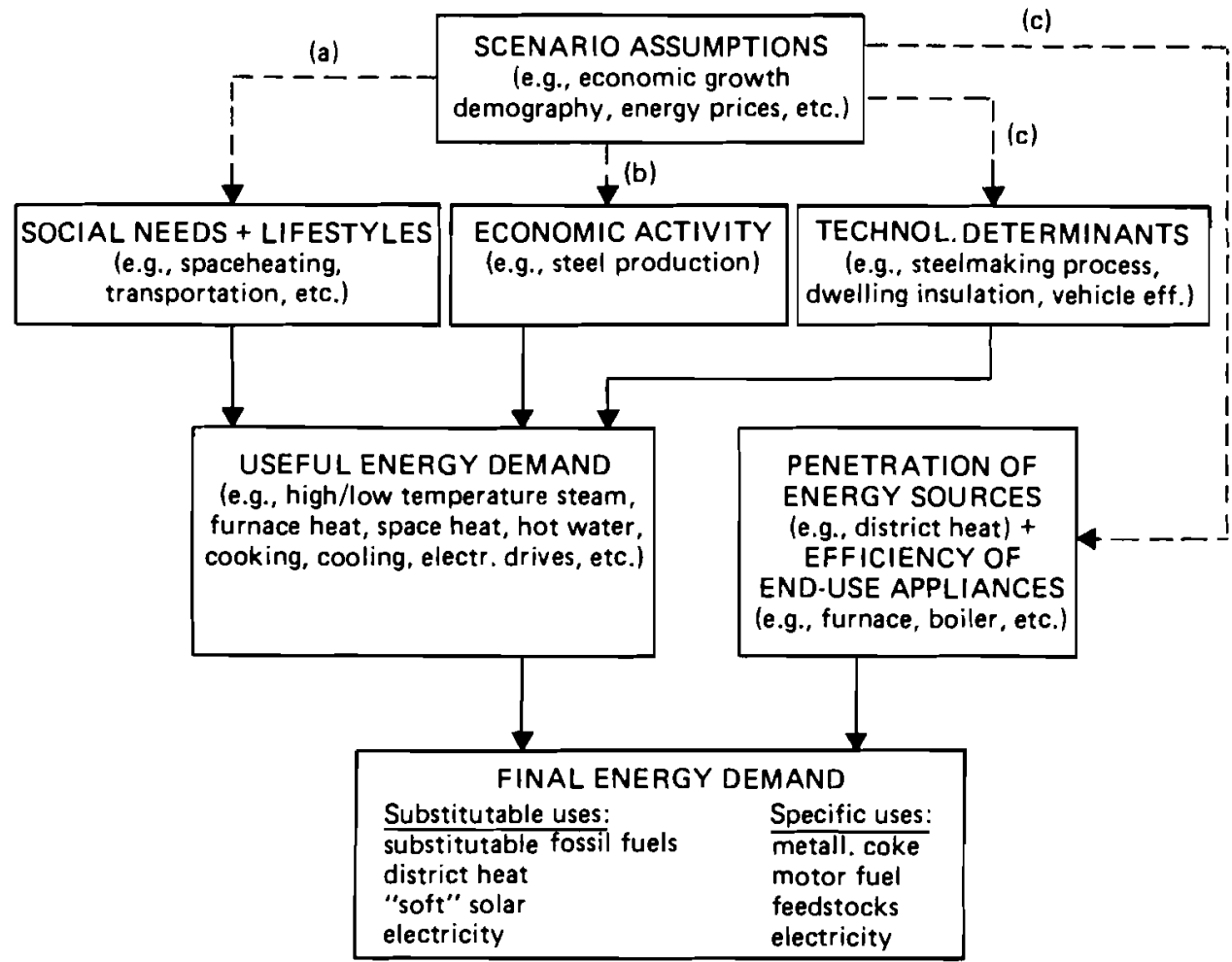

Scenario Assumptions: (a) socioeconomic

(b) macroeconomic

(c) technologica!

FIGURE 4 Schematic description of MEDEE-2.

split, household size, type and size of dwellings, energy-using equipment, travel distances, automobile ownership, preferences for certain modes of travel, energy intensity of industrial sectors, dwelling insulation, fuel economy of vehicles and many others.

Each of the factors mentioned would merit detailed investigation, or at least a survey of relevant studies. The fact that the various assumptions - though not formally interrelated in MEDEE-2 - are not independent from each other, raises the question of consistency. For example, energy prices are only judgmentally incorporated into the model; import-export relations are not explicitly treated (for small countries, trade of energy-intensive products can have a significant influence on the average energy intensity, but the effect will be small on the level of world regions considered in this study); the relation between lifestyle changes and purchasing power is not formalized; the relation between economic growth and turnover of capital stock is not modeled. All these factors enter only judgmentally, where one assigns future time trends to parameters, such as sectoral GDP shares, electricity consumption per dwelling, car ownership, change of energy 
intensity in various industry branches, etc. On the other hand, it is questionable whether one can develop a model that is general and flexible enough to be applied to a macro region and that rigorously treats the aspects mentioned above. In the scenario approach adopted for this study, the question of consistency could not be resolved in every detail. However, a cross-check of the MEDEE-2 results with the shadow prices obtained from the energy supply optimization model MESSAGE as well as an ex post interpretation of sectoral energy demand projections in terms of income and price elasticities ensure a certain degree of consistency on an aggregated level.

As mentioned above, MEDEE-2 calculates thermal energy demand in terms of useful energy, and the energy demand for nonsubstitutable uses in terms of final energy. However, the supply optimization model used in the present global energy demand assessment accepts energy demand inputs only in the form of secondary energy. The first part of the missing link between useful thermal energy and secondary energy by source, namely the conversion from useful to final energy, is done by MEDEE- 2 on the basis of specified values of the expected penetrations of different energy sources (e.g., noncommercial fuels, electricity, district heat, solar systems, heat pumps), into their respective potential heat markets and the end-use efficiencies (relative to the efficiency of electricity) of various final energy forms.* The main output of MEDEE-2 is final energy demand by sector (industry, transportation, household/service) and by energy source/category of use (substitutable fossil fuels for thermal uses; centralized heat supply; soft, i.e., decentralized solar systems; electricity; motor fuel; coke; feedstocks, i.e., fossil fuels used as raw material; and noncommercial fuels). In order to obtain the associated primary energy demand, one must (1) determine the shares of coal, oil, gas, charcoal, and biogas in the substitutable fossil fuel demand for thermal uses and in the feedstock requirements**;(2)add transport/ distribution losses and internal energy consumption by energy producing industries (which gives secondary energy demand), and (3) determine the supply mix of the primary energy sources and the associated conversion losses. Only step (3) was handled by the supply optimization model MESSAGE; steps (1) and (2) required a "human interface."

The choice of fossil fuels is left open in MEDEE-2 because it is mainly a matter of availability and price, and shifts may occur rather quickly. (The conversion from useful thermal to final energy demand should in fact also be treated in some optimization framework, so that relative costs of competing technologies/energy sources are formally included in the calculations.) Determination of transport/distribution losses and internal consumption by energy producers is in principle a task for the supply model, because they depend on the locations selected, the choice between import and domestic production, and the technological characteristics of energy production facilities and distribution networks. Efforts are being made in IIASA's Energy Systems Program to improve the treatment of these parts of the energy chain.

The remainder of this section gives an overview of the energy demand calculations in each sector. A formal description with the equations is given in Appendix B.

\footnotetext{
*Final energy in the form of coal, oil, gas, and the organized supply of charcoal and biogas, used for meeting useful thermal energy demand, is treated in MEDEE-2 as a single category (called substitutable fossil fuels) and only the average efficiency for this category of fuels is specified.

**Charcoal and biogas were considered as alternatives only for the developing regions; only liquid fuels were assumed to be used as feedstocks in all regions except Region II.
} 


\subsubsection{Industry}

All economic activities, except for those of the service sector, are included under this label in MEDEE-2. Specifically, these are agriculiure, construction, mining, three manufacturing subsectors, and energy. The energy consumption of this last sector (covering electricity gas and water supply, and other energy-related activities that can be isolated) is neglected because it is related to conversion activities as calculated at a later stage by the MESSAGE model.

Three types of end-use categories are considered: specific uses of electricity (for lighting, motive power, electrolysis, etc.); thermal uses (space and water heating, low/high temperature steam generation, furnace/direct heat); and motor fuel use (mainly for motive power in nonstationary uses such as in agriculture, construction, and mining).

Because it is mostly impossible to obtain energy balances in such detail, all present uses of electricity in industry are considered "specific" (in the sense that they are unlikely to be replaced by other energy sources) and all fossil fuels, except for motor fuel, are assumed to be consumed for thermal uses. This implies that electricity penetration into thermal uses must be interpreted as incremental penetration above the levels reached today.

For the energy demand calculations, knowledge of the activity level (value added) and energy intensities (per unit value added) in each sector is required. Energy intensities must be specified in terms of final energy for motor fuel and electricity, and in terms of "electricity equivalent" for thermal uses. The breakdown of thermal uses (space and water heating, low and high temperature steam generation, furnace/direct heat) is assumed to be constant. If the breakdown is not known for each subsector, an average split must be specified.

The energy consumption of manufacturing industries depends on the activity level and on the energy demand per unit of output in each sector. Since the sectors are highly aggregated and therefore inhomogeneous, the energy intensity may change with a modi. fied product mix as well as with increased process integration and other operational improvements. Also the energy use pattern changes as a result of substitutions of other energy sources for fossil fuels, especially with regard to thermal uses.

For thermal uses, the penetration of electricity, district heat, cogeneration, heat pump, and soft solar technologies must be estimated. The remaining energy demand is assumed to be met by fossil fuels, and is converted to final energy demand using exogenously specified end-use efficiencies for heating systems, boilers, and furnaces (these must be given relative to electricity). Electricity can penetrate into virtually all thermal uses; the potential market of the other alternatives is restricted to steam and low-temperature uses.

The demand for coke and for petrochemical feedstocks is calculated separately in MEDEE-2, since they account for a major share of total industrial energy consumption. Coke demand is related to pig-iron production, which in turn is related to steel production. Steel production as well as petrochemical feedstock demand is directly related to the value added of basic materials industries, which include these two industry branches.

\subsubsection{Transportation}

Three types of transportation are distinguished in MEDEE-2: passenger, freight, and international and military transportation. Passenger transportation is broken down into urban and intercity categories (Table 1). 
TABLE 1 Categories of energy end use considered in MEDEE-2. Energy sources are coal (CL); motor fuel - gasoline, diesel, jet fuel (MF); electricity (EL). $F$ is basic energy demand calculated in final energy forms; $U$ is basic energy demand calculated in useful energy forms.

\begin{tabular}{|c|c|c|c|}
\hline Transportation module $(\mathrm{F})$ & Industry module & & Household/service module \\
\hline 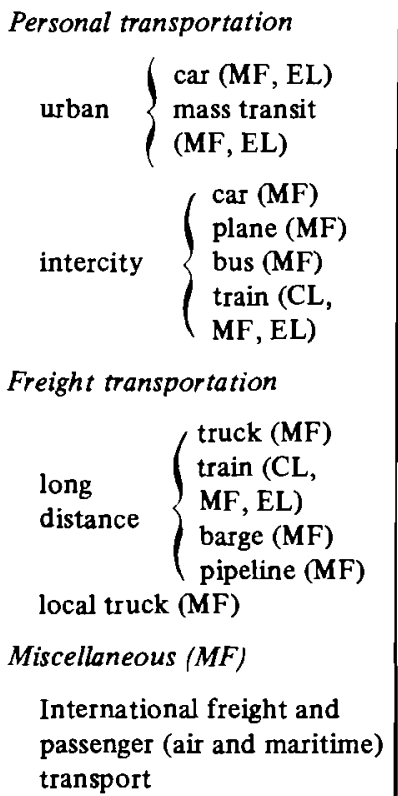 & $\begin{array}{l}\text { Sectors } \\
\text { Agriculture } \\
\text { Construction } \\
\text { Mining } \\
\text { Manufacturing } \\
\quad \text { Basic materials } \\
\text { Machinery and equipment } \\
\text { Food textiles, and other } \\
\text { Energy** }\end{array}$ & $\begin{array}{l}\text { Processes } \\
\text { Motor fuel use (F) } \\
\text { Specific* electricity uses (F) } \\
\text { Thermal uses (U) } \\
\quad \text { Steam generation } \\
\text { Furnace/direct heat } \\
\text { Space and water heating } \\
\text { Coke for iron-ore reduction (F) } \\
\text { Use of energy products as } \\
\text { feedstocks (F) }\end{array}$ & $\begin{array}{l}\text { Household } \\
\text { Space heating (U) }\left\{\begin{array}{l}\text { pre-/post-1975 dwellings } \\
\text { multifamily/single family } \\
\text { central heating/other }\end{array}\right. \\
\text { Water heating (U) } \\
\text { Cooking (U) } \\
\text { Cooling (U) } \\
\text { Electrical appliances (F) } \\
\text { Service } \\
\text { Thermal uses (U) } \\
\text { Cooling (U) } \\
\text { Electrical appliances (F) }\end{array}$ \\
\hline
\end{tabular}

* By definition in the model, all present uses of electricity are included here.

** The energy sector should be considered separately if statistics permit. Its energy consumption should be determined in relation to conversion from primary to secondary energy.

NOTE: The restriction of certain categories here to just one or two fuel types misses other possibilities. For instance, pipelines may also use electricity or gas. 
For international and military transportation only the use of liquid fuels is considered feasible. Data for this category are often difficult to find, and the motor fuel demand of this type of transportation is therefore treated simplistically as a function of GDP.

The demand for domestic freight transportation (measured in net ton-kilometers) is calculated as a function of the GDP contribution by the agricultural, mining, manufacturing, and energy sectors. The modal split, i.e., the allocation to the various modes (rail, truck, inland waterways or coastal shipping, pipeline), must be specified exogenously, as well as the energy intensity (per ton-kilometer) of each mode. Except for rail, where electricity and coal can also be used as an energy source, only liquid fuels are assumed to be used.

Passenger transportation is treated in more detail, because in most countries it accounts for a major share of energy consumption.

Total demand for intercity passenger transportation (measured in passenger-kilometers) is calculated in MEDEE-2 from data on population and average distance travelled per person per year. Automobile travel is calculated from data on population, automobile ownership, average distance traveled per automobile per year, and an average load factor (passenger-kilometer per vehicle-kilometer). The remainder is allocated to public transportation modes (rail, bus, airplane) according to exogenously specified shares. The corresponding vehicle-kilometers are calculated from average load factors for each mode. The energy intensities (per vehicle-kilometer) also have to be specified. For freight transportation, except for railways, only liquid fuels are assumed to be used.

Total demand for urban transportation is related to the population in large cities* where mass transportation is feasible. It is calculated from data on the average distance traveled per day and per person in urban areas and on the total population living in these areas. The energy consumption related to this demand is determined from exogenously specified shares of various modes (private automobiles and mass transportation powered by motor fuel or electricity), together with average load factors and energy intensities of each mode.

All energy demand in the transport sector is calculated only in terms of final energy.

\subsubsection{Households and Services}

Currently, in the developed countries space heating accounts for the major share of energy consumption in the household sector, and with improved insulation this energy demand could be reduced considerably. Buildings constructed after the world's acknowledgment of the energy crisis in 1973 have better insulation. To allow for this difference, pre-1975 and post-1975 buildings are treated separately in MEDEE-2. In addition, three types of dwellings are considered: single housing units with central heating, apartments with central heating, and dwellings with room heating only. This is in order to allow for the large differences in the average heat loss of these dwelling types.

The change in the housing stock of the residential sector is determined from data on average family size and population, on demolition of existing dwellings by type, and on construction of new dwellings by type. Allowance is made for the reduction of heat

*Cities with more than 50,000 inhabitants in Regions I, III, and those with more than 100,000 inhabitants in the developing Regions IV, V, VI. For Region Il all urban population has been included in this category. 
loss in old dwellings through retrofitting; the heat loss of post.1975 dwellings is calculated from data on the average size and the specific heat loss (per $\mathrm{m}^{2}$ ) for each type of dwelling.

Energy demand for water heating, cooking, air-conditioning, and the electricity consumption of secondary appliances (such as washing machine, refrigerator, freezer, dishwasher, clothes dryer, vacuum cleaner) is calculated from exogenously specified ownership fractions and/or average annual consumption rates.

The change in the building stock of the commercial/service sector is calculated from data on the average floor area per worker and labor force, and on the demolition of existing floor area. Allowance is made for improving the insulation of old buildings. Besides thermal uses (space/water heating), two other end-use categories are distinguished, namely air-conditioning and specific electricity uses, for which penetration and/or average consumption rates must be given.

The energy demand calculations for this sector are generally made in terms of "electricity equivalent." For air-conditioning, electricity is considered the only energy source; this is also true for heat pumps. In all other instances, the penetration of alternative sources, such as electricity, district heat, heat pumps, or soft solar technology, must be estimated. The remaining energy demand is assumed to be met by fossil fuels and converted to final energy demand using exogenously specified end-use efficiencies. The potential market for district heat is restricted to large cities, and the potential market for solar is restricted to post-1975 single housing units in the case of space heating; penetration of solar technology for thermal uses in the commercial/service sector is also assumed to be feasible only in low-rise buildings.

\subsection{Input Data Requirements}

There are some 180 parameters in the input data files of MEDEE-2 serving to capture such essential features of the economy, demography, technology, lifestyle, and various social and industrial activities of a country or region that have, or may have in the foreseeable future, some effect on the amount and pattern of final energy consumption. These parameters are constants or variables. Constants are understood to comprise initial values as well as coefficients held constant in the model calculations. Variables are timedependent parameters for which scenario values have to be assigned for each model year. A complete listing of all the parameters and their definition is given in Appendix B.

\section{TWO SCENARIOS: BASIC ELEMENTS}

The future evolution of world energy demand is governed essentially by three basic elements: population growth, economic growth, and technological developments. The last two elements, which are to a certain extent interdependent, are also influenced by the relative availability of energy as a source of power, and its price.

The starting point for IIASA's energy demand projections 1975-2030 is the definition of two scenarios (Chant 1981) describing the evolution over time of population and economic growth in the seven world regions specified in Figure 1. The population projections common to both scenarios are based on Keyfitz (1977). These scenarios are labeled 
High and Low in terms of two different levels of world economic growth, which cover a range of plausible economic developments in the regions in a mutually consistent manner. The figures for economic growth projections have been arrived at after several iterations through the modeling loop of Figure 2, until the energy prices and the investment requirements of the energy sector obtained for the various world regions were considered to be consistent with their envisaged economic growth rates. (See Basile 1980, Chant 1981, Energy Systems Program Group 1981, for a more detailed discussion.)

Tables 2, 3, and 4 list the projections of population and GDP in various world regions that serve as basic inputs to the energy demand assessment to be discussed. The

TABLE 2 Population projections by region $\left(10^{6}\right)$.

\begin{tabular}{lrrr}
\hline & & \multicolumn{2}{c}{ Projections } \\
\cline { 3 - 4 } Region & 1975 & 2000 & 2030 \\
\hline I (NA) & 237 & 284 & 315 \\
II (SU/EE) & 363 & 436 & 480 \\
III (WE/JANZ) & 560 & 680 & 767 \\
IV (LA) & 319 & 575 & 797 \\
V (Af/SEA) & 1,422 & 2,528 & 3,550 \\
VI (ME/NAf) & 133 & 247 & 353 \\
VII (C/CPA) & 912 & 1,330 & 1,714 \\
World & & & \\
\hline
\end{tabular}

NOTE: 1975 data are mid-year estimates from United Nations Monthly Bulletin of Statistics, January 1978.

The same population projection is chosen for both High and Low scenarios.

SOURCE: Keyfitz (1977).

population projections for the world as a whole as well as by groups of developed (I, Il and III) and developing (IV,V,VI, and VII) regions are plotted in Figure 5. Note that the period of consideration is one in which the world population is expected to undergo a major transition, with a predominant increase occurring in the areas of the currently developing economies.

Depletion of energy resources, increasing production costs and rising prices of energy commodities traded internationally over the next 50 years are only qualitatively accounted for in this assessment. (For a detailed discussion with respect to the two IIASA scenarios, see Energy Systems Program Group 1981.) These issues influenced the projections of some scenario parameters of the MEDEE-2 model, and occasionally required a modification of the values used in a previous iteration of the modeling loop of Figure 2. For our purpose, it should suffice to point out two important results of the supply analysis of the two scenarios. The biggest difficulty in energy supply, which is to be felt worldwide, will be to meet the demand for liquid fuel. Further, by 2030 , the average final energy production costs will increase to about 2.9 to 4.2 times the 1972 values (with the corresponding prices probably increasing to 2.4 to 3.0 times the 1972 prices) in the various world regions (Chant 1981). 
TABLE 3 GDP projections by region $\left(10^{9} \$ 1975\right)$.

\begin{tabular}{|c|c|c|c|c|c|}
\hline \multirow[b]{3}{*}{ Region } & \multirow[b]{3}{*}{1975} & \multicolumn{4}{|c|}{ Projections } \\
\hline & & \multicolumn{2}{|c|}{ High scenario } & \multicolumn{2}{|c|}{ Low scenario } \\
\hline & & 2000 & 2030 & 2000 & 2030 \\
\hline $1(\mathrm{NA})$ & 1,670 & 4126 & 7,926 & 3049 & 4,170 \\
\hline II (SU/EE) & 930 & 2729 & 7.658 & 2,420 & 4,713 \\
\hline III (WE/JANZ) & 2,385 & 5,999 & 11693 & 4452 & 6,656 \\
\hline IV (LA) & 340 & 1,272 & 3,569 & 918 & 2,229 \\
\hline V (Af/SEA) & 340 & 1.207 & 3,488 & 924 & 1,995 \\
\hline V1 (ME/NAf) & 190 & 900 & 2,918 & 643 & 1,310 \\
\hline VII (C/CPA) & 320 & 939 & 2,450 & 690 & 1,345 \\
\hline World & 6,175 & 17,172 & 39,702 & 13,096 & 22,418 \\
\hline
\end{tabular}

NOTE: GDP in constant 1975 US dollars. Base year data are estimates from UN (1977c), World Bank (1977) and OECD (1979a).

TABLE 4 GDP per capita projections by region $\left(10^{3} \$ 1975\right)$.

\begin{tabular}{|c|c|c|c|c|c|}
\hline \multirow[b]{3}{*}{ Region } & \multirow[b]{3}{*}{1975} & \multicolumn{4}{|c|}{ Projections } \\
\hline & & \multicolumn{2}{|c|}{ High scenario } & \multicolumn{2}{|c|}{ Low scenario } \\
\hline & & 2000 & 2030 & 2000 & 2030 \\
\hline I (NA) & 7.05 & 14.53 & 25.16 & 10.74 & 13.24 \\
\hline Il (SU/EE) & 2.56 & 6.26 & 15.95 & 5.55 & 9.82 \\
\hline III (WE/JANZ) & 4.26 & 8.82 & 15.25 & 6.55 & 8.68 \\
\hline IV (LA) & 1.07 & 2.21 & 4.48 & 1.60 & 2.80 \\
\hline $\mathrm{V}(\mathrm{Af} / \mathrm{SEA})$ & 0.24 & 0.48 & 0.98 & 0.37 & 0.56 \\
\hline VI (ME/NAf) & 1.43 & 3.64 & 8.27 & 2.60 & 3.71 \\
\hline VIl (C/CPA) & 0.35 & 0.71 & 1.43 & 0.52 & 0.78 \\
\hline World & 1.56 & 2.82 & 4.98 & 2.15 & 2.81 \\
\hline
\end{tabular}

NOTE: Based on Tables 2 and 3.

\section{APPLICATION OF MEDEE-2 TO IIASA REGIONS I TO VI}

\subsection{Base Year Data/Inputs}

As is evident from Section 3, assessment of future energy demand following the MEDEE-2 approach requires base year data of a large number of parameters as well as projected values of these parameters that are consistent with the basic scenario elements (Section 4) for each world region. For some of these parameters, statistical information detailed by countries or by groups of countries is available from United Nations (UN), International Bank for Reconstruction and Development (IBRD), Food and Agriculture Organization (FAO), International Road Federation (IRF), Organization for Economic Cooperation and Development (OECD), Economic Commission for Europe (ECE) etc., while for others the information is either limited to only a few countries (mostly contained in national statistical bulletins) or is not documented at all. 


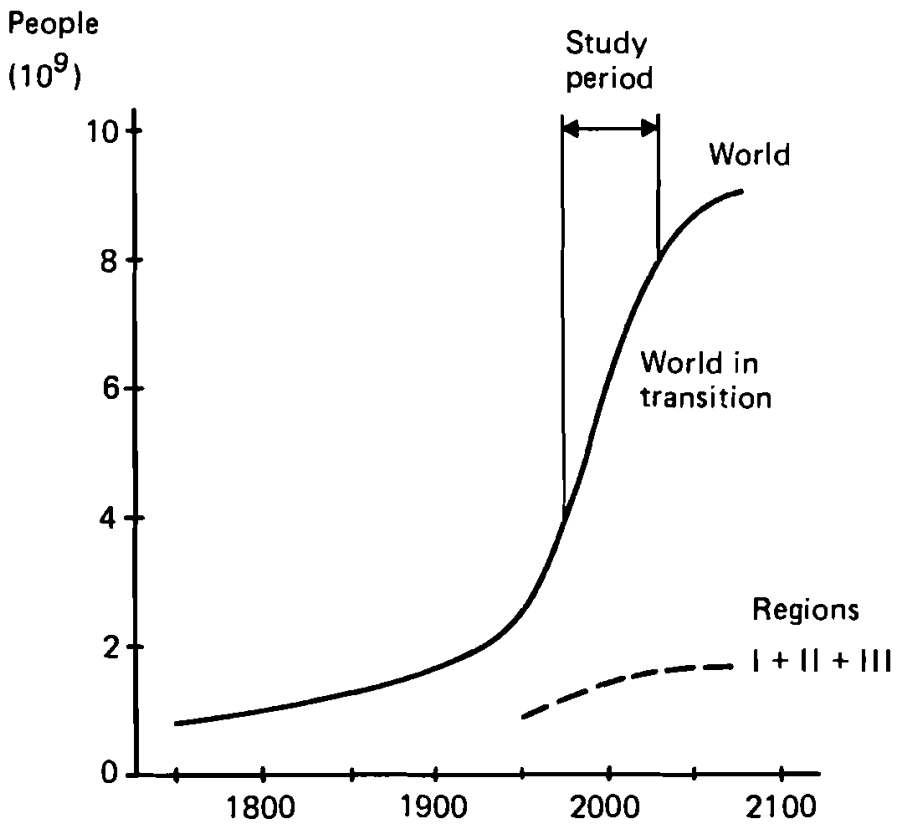

FIGURE 5 World population - historical and projected.

Overall, the data base situation is considerably more satisfactory for the developed Regions I, II and III than it is for the developing Regions IV, V, and VI. In some cases we had to rely on extrapolation of regional averages from information on just a few coun. tries (sometimes only on one) in a given region, or on estimates we made on the basis of scattered material in the literature and from discussion with knowledgable persons from countries in these regions.

In spite of these difficulties, we feel that the base year data for all the regions represent fairly well the regional average situations prevailing in 1975. One should keep in mind, however, that the purpose of this project was to conceptualize the present energy demand pattern in each world region and to arrive at projections of the demands for specific and substitutable energy forms. This was achieved while considering the likely evolution of various socioeconomic activities in line with the basic assumptions of the two IIASA scenarios. This report documents the complete set of input data for the base year (1975) for each world region as it was used in the IIASA analysis (Energy Systems Program Group 1981). It is hoped that some of these data will be refined in due course, as improved and/or more complete information becomes available. We now briefly describe how the base year data related to various groups of parameters were obtained.

The starting point for this exercise was to determine primary energy consumption in the form of both commercial and noncommercial fuels. These data are listed in Table 5. The data on commercial energy consumption in Regions II, IV, V, and VI are based on World Energy Supplies (UN 1977a, 1978a), and those of Regions I and III are derived hasically from OECD Energy Statistics (OECD 1977). For noncommercial energy, the data on fuelwood are based on World Energy Supplies (UN 1977a, 1978a), and those for 
TABLE 5 Primary energy consumption, electricity generation and noncommercial energy use in the base year (1975) by region.

\begin{tabular}{|c|c|c|c|c|c|c|}
\hline & \multicolumn{6}{|l|}{ Kegion } \\
\hline & I & II & III & IV & $\mathrm{V}$ & VI \\
\hline \multicolumn{7}{|c|}{ Primary energy consumption (GWyr) } \\
\hline Solid & 484 & 770 & 541 & 16 & 119 & 3 \\
\hline Liquid & 1,167 & 635 & 1,252 & 228 & 159 & 77 \\
\hline Natural gas & 763 & 374 & 238 & 48 & 20 & 43 \\
\hline Hydro (primary equiv.) & 174 & 50 & 180 & 45 & 29 & 5 \\
\hline Nuclear (primary equiv.) & 66 & 6 & 45 & 1 & 1 & 0 \\
\hline Total & 2,654 & 1,835 & 2,256 & 338 & 328 & 128 \\
\hline \multicolumn{7}{|l|}{ Electricity generation $(\mathrm{GWy})$} \\
\hline Hydro & 58 & 17 & 59 & 15.1 & 9.9 & 1.5 \\
\hline \multicolumn{7}{|l|}{ Conventional thermal (from } \\
\hline fossil fuels) & 181 & 139 & 167 & 12.6 & 16.0 & 3.9 \\
\hline Nuclear & 21 & 2 & 15 & 0.3 & 0.4 & 0 \\
\hline Total & 260 & 158 & 241 & 28 & 26 & 5 \\
\hline \multicolumn{7}{|l|}{ Noncommercial fuels (GWyr) } \\
\hline Wood & - & 44 & - & 84 & 229 & 2 \\
\hline Agricultural and animal wastes & - & - & - & 25 & 115 & 8 \\
\hline Total & - & 44 & - & 109 & 344 & 10 \\
\hline
\end{tabular}

agricultural and animal wastes on the estimates by Parikh (1978) together with informa. tion on agricultural production given in FAO (1977). The noncommercial energy use in Regions I and III, as compared to the use of commercial fuels, is insignificantly small and has been ignored.

The MEDEE-2 calculations lead to only final energy and not to primary energy. Thus, in adjusting the various base year parameters to match the actual energy consump tion, one needs to know the final consumption in terms of electricity as well as in nonelectric energy forms. Such information is readily available for Region I, for most of Region III, and for part of Region II (Eastern Europe) in OECD (1977) and ECE (1977). The missing information on these and other regions is obtained by assuming appropriate conversion (primary to secondary) and distribution (secondary to final) losses typical of different fuels, as well as an appropriate fuel mix for thermal electricity (and, in the case of Region II, district heat) generation in the various regions. The final energy estimates for the base year are listed in Table 6 .

Information on the sectoral distribution of final energy in Region I, in the Eastern Europe part of Region II, and in the OECD section of Region III is also available in OECD (1977) and ECE (1977). Similar information on the developing regions is derived partly from sectoral primary energy consumption data for certain countries - Brazil, Mexico. India, Pakistan, Egypt. Saudi Arabia (Vieira 1978, WAES 1976, Parikh 1976, Henderson 1975, Pakistan 1977. Elshafei 1978, Saudi Arabia 1977) - and partly by adjusting the less certain MEDEE-2 parameters to match the total final energy demand.* These estimates

*A recent publication by OECD (1979b) giving information on energy consumption data for sectoral activities in sixteen developing countries was not available at the time of the assessment. 
TABLE 6 Estimate of final energy use by energy form and by region in the base year (1975).

\begin{tabular}{lcccrrr}
\hline & \multicolumn{2}{l}{ Region } & & & \\
\cline { 2 - 6 } Fnergy form (GWyr) & I & II & III & IV & V & VI \\
\hline Coal $^{a}$ & 108 & 353 & 232 & 12 & 81 & 2 \\
Oil $^{b}$ & 951 & 428 & 979 & 189 & 138 & 70 \\
Gas $^{c}$ & 584 & 148 & 177 & 29 & 12 & 29 \\
Electricity & 228 & 130 & 201 & 24 & 22 & 5 \\
District heat & - & 218 & - & - & - & - \\
Total & 1,871 & 1,277 & 1,589 & 254 & 253 & 106 \\
\hline
\end{tabular}

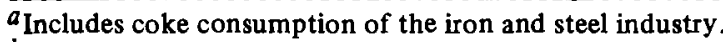

$b$ Includes feedstocks derived from crude oil.

$c_{\text {Includes manufactured gas. }}$

TABLE 7 Estimate of sectoral distribution of final energy use in the base year (1975).

\begin{tabular}{|c|c|c|c|c|c|c|}
\hline & \multicolumn{6}{|c|}{ Region } \\
\hline & I & II & III & IV & V & VI \\
\hline Total final energy $(\mathrm{GWy})$ & 1,871 & 1,277 & 1,589 & 254 & 253 & 106 \\
\hline$\%$ electricity & 12.2 & 10.2 & 12.7 & 9.6 & 8.1 & 4.4 \\
\hline$\%$ district heat & - & 17.7 & - & - & - & - \\
\hline Industry (GWyr) & 757 & 759 & 805 & 119 & 149 & 49 \\
\hline$\%$ electricity & 12.5 & 13.3 & 14.0 & 14.5 & 11.9 & 7.5 \\
\hline$\%$ district heat & - & 22.4 & - & - & - & - \\
\hline Transport $(\mathrm{GWyr})$ & 541 & 224 & 313 & 105 & 76 & 42 \\
\hline$\%$ electricity & 0.1 & 4.0 & 1.9 & 0.2 & 0.5 & 0.1 \\
\hline Household/service (GWyr) & 573 & 293 & 471 & 31 & 28 & 15 \\
\hline$\%$ electricity & 23.3 & 6.9 & 17.6 & 22.7 & 13.6 & 6.6 \\
\hline \% district heat & - & 16.4 & - & - & - & - \\
\hline $\begin{array}{l}\text { Noncommercial energy hol } \\
\text { holds only) (GWyr) }\end{array}$ & - & 44 & - & 109 & 344 & 10 \\
\hline
\end{tabular}

are summarized in Table 7.

The base year input parameters (see Appendix B for definitions) for MEDEE-2 are discussed; the groups covered are (1) demography; (2) macroeconomics; and (3) energy consumption by the industry, transportation, and household/service sectors. They are listed in Table 8, and the corresponding sources of information are given below. In order to obtain the appropriate regional values, additional calculations and/or extrapolations were necessary in most cases.

\subsubsection{Demography}

Parameters in Group 1 of Table 8. The sources of information for the various parameters were as follows: 
Variable

$P O$ (population)

$P L F$ (potential labor force)

PARTLF (participation rate of the potential labor force)

POLC (population outside large cities)

PRUR (rural population)

$C A P H$ (persons per dwelling)
Reference

UN (1977b, 1978b)

UN (1976a)

US (1976a) and Canada (1975) for Region I

CMEA (1976) for Region II

ILO (1976) for Region III

FAO (1977) for Regions IV, V, VI

UN (1976b) for Regions IV, V, VI; Paxton (1976)

for Regions I and III. CMEA (1976) for Region II $\mathrm{UN}(1976 \mathrm{~b})$

ECE (1978a) for Regions I, II, III

UN (1974) for Regions IV, V, VI

TABLE 8 Base year data/inputs.

\begin{tabular}{|c|c|c|c|c|c|c|}
\hline \multirow[b]{2}{*}{ Variable } & \multicolumn{6}{|l|}{ Region } \\
\hline & $\mathbf{I}$ & II & III & IV & $\mathbf{V}$ & VI \\
\hline \multicolumn{7}{|c|}{ Group 1: Demography } \\
\hline$P O$ & 237 & 363 & 560 & 319 & 1,422 & 133 \\
\hline$P L F$ & 0.64 & 0.64 & 0.63 & 0.542 & 0.538 & 0.523 \\
\hline PARTLF & 0.69 & 0.61 & 0.72 & 0.59 & 0.708 & 0.512 \\
\hline POLC & 0.64 & 0.42 & 0.51 & 0.63 & 0.87 & 0.71 \\
\hline$P R U R^{*}$ & 0.24 & 0.41 & 0.29 & 0.40 & 0.78 & 0.55 \\
\hline$C A P H$ & 2.98 & 3.7 & 3 & 5.1 & 5.24 & 5.25 \\
\hline \multicolumn{7}{|c|}{ Group 2: Macroeconomics } \\
\hline$Y$ & 1,670 & 930 & 2,385 & 340 & 340 & 190 \\
\hline$P Y A G$ & 0.028 & 0.107 & 0.058 & 0.122 & 0.361 & 0.07 \\
\hline$P Y B$ & 0.041 & 0.079 & 0.075 & 0.057 & 0.058 & 0.065 \\
\hline$P Y M I N^{* *}$ & 0 & 0 & 0 & 0.025 & 0.015 & 0.51 \\
\hline PYMAN & 0.245 & 0.382 & 0.336 & 0.248 & 0.166 & 0.078 \\
\hline$P Y E N$ & 0.038 & 0.042 & 0.046 & 0.025 & 0.016 & 0.007 \\
\hline PYSER & 0.648 & 0.39 & 0.485 & 0.523 & 0.384 & 0.27 \\
\hline$P V A I G$ & 0.248 & 0.233 & 0.33 & 0.308 & 0.264 & 0.2 \\
\hline$P Y A M$ & 0.432 & 0.476 & 0.42 & 0.264 & 0.176 & 0.1 \\
\hline$P V A C$ & 0.32 & 0.291 & 0.25 & 0.429 & 0.56 & 0.7 \\
\hline$I^{*}$ & 0.18 & 0.3 & 0.25 & 0.23 & 0.2 & 0.215 \\
\hline$P^{*}$ & 0.65 & 0.45 & 0.58 & 0.7 & 0.71 & 0.325 \\
\hline$P C D G^{*}$ & 0.19 & 0.1 & 0.1 & 0.1 & 0.07 & 0.1 \\
\hline$P C N D G^{*}$ & 0.42 & 0.6 & 0.56 & 0.6 & 0.73 & 0.6 \\
\hline$P C S E R^{*}$ & 0.39 & 0.3 & 0.34 & 0.3 & 0.2 & 0.3 \\
\hline
\end{tabular}

*The values for these variables do not directly affect the calculations of the version of the MEDEE-2 model used for the present assessment, but they are used for projecting the evolution of other variables, outside the model calculations.

**For Regions I, II, and III, mining of coal, oil, and gas is included in the energy sector and that of other materials is included under manufacturing of basic materials. (See definition of sectors in Appendix C.)

NOTE: See definition of variables in Appendix B, Part 2. 


\subsubsection{Macroeconomics}

Parameters in Group 2 of Table 8. The sources of data were the following:

Variable

$Y$ (total GDP)

All other data

\author{
Reference \\ UN (1977c), World Bank (1977), OECD (1979a) \\ UN (1977b) for Regions I, II, III \\ UN (1977c) and data supplied by Arab Fund (1979) \\ for Regions IV, V, VI
}

\subsubsection{Energy Consumption in Sectors}

\section{Industry (Agriculture, Construction, Mining, and Manufacturing)}

(i) Parameters in Groups 3.1a and 3.1b in Table 8. The data for Region I are based on estimates for the US made by Lapillonne (1978b) using the information given in WAES (1976) and Doblin (1978). The values estimated for Region III are based on data for Austria (Foell et al. 1979), France (Lapillonne 1978c) and the US. The estimates for Region II were made partly on the basis of data contained in Vigdorchik (1976), USSR

TABLE 8 Base year data/inputs (continued).

\begin{tabular}{|c|c|c|c|c|c|c|}
\hline \multirow[b]{2}{*}{ Variable } & \multicolumn{6}{|c|}{ Region } \\
\hline & I & II & III & IV & $\mathrm{V}$ & VI \\
\hline \multicolumn{7}{|c|}{ Group 3: Energy Consumption } \\
\hline \multicolumn{7}{|c|}{ Group 3.1: Industry (Agriculture, Construction, Mining, Manufacturing) } \\
\hline \multicolumn{7}{|c|}{ Group 3.1a: Energy Intensity of Agriculture, Construction, Mining } \\
\hline EI.AGR.MF & 5.07 & 1.36 & 1.49 & 0.132 & 0.165 & 0.252 \\
\hline$E I . A G R . E L$ & 0.56 & 0.88 & a & 0.062 & 0.1 & 0.065 \\
\hline EI.AGR.TH & $\mathrm{a}$ & $\mathbf{a}$ & $\mathbf{a}$ & a & $\mathrm{a}$ & a \\
\hline EI.CON.MF & 2.53 & 2.56 & 1.97 & 1.44 & 0.05 & 0.25 \\
\hline EI.CON.EL & $\mathrm{a}$ & 0.95 & $a$ & 0.065 & a & $\mathbf{a}$ \\
\hline EI.CON.TH & a & $\mathrm{a}$ & $a$ & a & $\mathrm{a}$ & a \\
\hline$E I . M I N . M F$ & $\mathrm{~b}$ & $\mathrm{~b}$ & $\mathrm{~b}$ & 5.1 & 1.47 & a \\
\hline$E I . M I N . E L$ & $\mathrm{~b}$ & $\mathrm{~b}$ & b & 1.82 & $\mathrm{a}$ & $\mathrm{a}$ \\
\hline EI.MIN.TH & $\mathrm{b}$ & $\mathrm{b}$ & b & $\mathrm{a}$ & a & 1.366 \\
\hline \multicolumn{7}{|c|}{ Group $3.1 \mathrm{~b}$ : Energy Intensity of Manufacturing Industries } \\
\hline$E I . B M . M F$ & 0.14 & a & a & $\mathbf{a}$ & a & $\mathbf{a}$ \\
\hline$E L, B M, E I$ & 4.62 & 5 & 1.27 & 2.35 & 5.5 & 4.4 \\
\hline EI.BM.US & 18.05 & 17.286 & 5.81 & 7.38 & 12.5 & 11.74 \\
\hline EI.ME.MF & $\mathbf{a}$ & a & a & $\mathbf{a}$ & $\mathbf{a}$ & a \\
\hline EI.ME.EL & 0.9 & 1.5 & 1.87 & 0.68 & 1.85 & 0.66 \\
\hline EI.ME.US & 1.14 & 4.4 & 0.81 & 0.576 & 1.025 & 1.89 \\
\hline EI.ND.MF & $\mathrm{a}$ & $\mathrm{a}$ & $a$ & $\mathrm{a}$ & a & $\mathrm{a}$ \\
\hline EI.ND.EL & 1.32 & 0.58 & 0.23 & 1.54 & 1.38 & 1.69 \\
\hline EI.ND.US & 2.48 & 5 & 1.06 & 2.868 & 6.85 & 3.19 \\
\hline
\end{tabular}


TABLE 8 Base year data/inputs (continued).

\begin{tabular}{|c|c|c|c|c|c|c|}
\hline \multirow[b]{2}{*}{ Variable } & \multicolumn{6}{|c|}{ Region } \\
\hline & I & II & III & IV & $\mathrm{V}$ & VI \\
\hline \multicolumn{7}{|c|}{ Group 3.1c: Change of Energy Intensity of Agriculture, Construction, Mining } \\
\hline CH.AGR.MF & 1 & 1 & 1 & 1 & 1 & 1 \\
\hline CH.AGR.EL & 1 & 1 & 1 & 1 & 1 & 1 \\
\hline CG.AGR.TH & 1 & 1 & 1 & 1 & 1 & 1 \\
\hline CH.CON.MF & 1 & 1 & 1 & 1 & 1 & 1 \\
\hline CH.CON.EL & 1 & 1 & 1 & 1 & 1 & 1 \\
\hline CH.CON.TH & 1 & 1 & 1 & 1 & 1 & 1 \\
\hline$C H . M I N . M F$ & 1 & 1 & 1 & 1 & 1 & 1 \\
\hline CH.MIN.EL & 1 & 1 & 1 & 1 & 1 & 1 \\
\hline CH.MIN.TH & 1 & 1 & 1 & 1 & 1 & 1 \\
\hline \multicolumn{7}{|c|}{ Group 3.1d: Change of Energy Intensity of Manufacturing Industries } \\
\hline$C H . M A N . M F$ & 1 & 1 & 1 & 1 & 1 & 1 \\
\hline CH.MAN.EL & 1 & 1 & 1 & 1 & 1 & 1 \\
\hline CH.MAN.US & 1 & 1 & 1 & 1 & 1 & 1 \\
\hline
\end{tabular}

a: Separate data were not available; the corresponding requirements are accounted for elsewhere. b: The mining sector is not considered separately for Regions I, II, and III (see definition of PYMIN, PYEN, PYMAN and PVAIG in Appendix C).

(1976), and partly by comparison with Regions I and III. For Regions IV and V, the values were in general derived by combining the sectoral energy consumption data of a few countries, i.e., of Brazil (Vieira 1978) for Region IV, and of India (Parikh 1976) and Pakistan (1977) for Region $\mathrm{V}$ for recent years, and the corresponding value-added contributions to respective national GDPs (UN 1977c). The data for Region VI were estimated by adjusting the values obtained for Egypt from the energy consumption data given by Elshafei (1978) in the light of those for Regions IV and V.

The energy intensity values for agriculture (EI.AGR.MF for motor fuel and EI.AGR. $E L$ for electricity) in Regions IV, V, and VI were also adjusted taking into account the extent of farm mechanization and irrigation in these regions (FAO 1977). The energy intensity of mining in Region VI was estimated from the data given by Chapman and Hemming (1976) and Saudi Arabia (1977).

(ii) Parameters in Group 3.1c and 3.1d in Table 8. These parameters are used to project future changes in energy intensity of various industrial activities relative to the base year values. Each of the parameters is by definition equal to unity in the base year.

(iii) Parameters in Group 3.1e in Table 8. At the time the present set of model runs was carried out, detailed information on these parameters was available to us only for the US (APS 1975; Lovins 1977), but we had some partial information on the USSR (Vigdorchik 1976). This is the basic information used for the estimates of these parameters in all regions, although some adjustments were made to account for the different climatic conditions in the regions. Detailed information recently published for the UK (Leach et al. 1979) indicates slightly higher values for STSHI (share of steam and low temperature heat) and $S T I$ (share of steam only), but the differences are not significant for our results. 
TABLE 8 Base year data/inputs (continued).

\begin{tabular}{|c|c|c|c|c|c|c|}
\hline \multirow[b]{2}{*}{ Variable } & \multicolumn{6}{|c|}{ Region } \\
\hline & I & II & III & IV & V & VI \\
\hline \multicolumn{7}{|c|}{ Group 3.1e: Breakdown of Useful Thermal Energy in Manufacturing Industries } \\
\hline STSHI & 0.5 & 0.69 & 0.5 & 0.42 & 0.4 & 0.4 \\
\hline$S T I$ & 0.4 & 0.6 & 0.4 & 0.4 & 0.4 & 0.4 \\
\hline$L T H$ & 0.2 & 0.3 & 0.2 & 0.15 & 0.15 & 0.15 \\
\hline \multicolumn{7}{|c|}{ Group 3.1f: Penetration of Alternative Energy Sources and Efficiences ${ }^{\dagger}$} \\
\hline$E L P I N D(4)^{*}$ & 0 & 0 & 0 & 0 & 0 & 0 \\
\hline$(H P I)$ & $(0)$ & (0) & (0) & $(0)$ & $(0)$ & $(0)$ \\
\hline$E F F H P I$ & 2 & 2 & 2 & 2 & 2 & 2 \\
\hline$I D H$ & 0 & 0.69 & 0 & 0 & 0 & 0 \\
\hline$S P L T$ & 0 & 0 & 0 & 0 & 0 & 0 \\
\hline$S P H T$ & 0 & 0 & 0 & 0 & 0 & 0 \\
\hline$F I D S$ & 0.7 & 0.3 & 0.7 & 0.8 & 0.8 & 0.8 \\
\hline ICOGEN & 0 & 0 & 0.3 & 0 & 0 & 0 \\
\hline$E F F C O G$ & 0.65 & 0.65 & 0.65 & 0.65 & 0.65 & 0.65 \\
\hline$H E L R A T$ & 5 & 5 & 5 & 5 & 5 & 5 \\
\hline $\operatorname{EFFIND}(4)^{* *}$ & 0.85 & 0.605 & 0.65 & 0.8 & 0.6 & 0.55 \\
\hline
\end{tabular}

*Zero by definition, i.e., only penetration above levels reached today is considered. **Efficiency of fossil fuel use relative to electricity.

Values in parentheses are to be interpreted as fractions of the preceding category.

(iv) Parameters in Group 3.1f in Table 8. Among these parameters, relating to the penetration of alternative energy sources in to the thermal energy market, ELPIND (electricity) is by definition zero for the base year. HPI (heat pump), SPLT (solar/low temperature uses), and SPHT (solar/high temperature uses) are zero in 1975 in all regions, and consequently EFFHPI (efficiency of heat pumps) and FIDS (load factor of solar installations) are ineffective. IDH (district heat) has a large value for Region II (Vigdorchik 1976), but was considered negligible for other regions. ICOGEN (cogeneration of steam and electricity within industry) applies, as a significant base year parameter, only to Region III where cogeneration is used appreciably in certain countries (in particular UK, FRG, Sweden). EFFCOG (system efficiency of cogeneration) and $H E L R A T$ (heat to electricity ratio) are significant only when ICOGEN has a nonzero value. The listed values for these parameters are based on Leach et al. (1979).

EFFIND represents the average value of the fossil fuel efficiency for all fossil fuels (oil, gas, coal) and all thermal processes (low temperature heat, steam, furnace heat). It is difficult to specify a regional value of this parameter as the combustion efficiencies of gas, oil, and coal differ greatly among each other and since the shares of these sources vary between countries. EFFIND, therefore, is largely of indicative value. The fossil fuel efficiency values in the literature (e.g., Eurostat 1978; Beschinsky and Kogan 1976), expressed relative to the efficiency of electricity, vary between 30 and 80 percent for the developed regions. They are in the lower range for high-temperature processes and in the upper range for low-temperature processes. The values are generally expected to be lower for the developing regions, where the equipment is not the most modern and is often not well maintained. The efficiency would be the lowest in Region V, where coal is still used 
TABLE 8 Base year data/inputs (continued).

\begin{tabular}{|c|c|c|c|c|c|c|}
\hline \multirow[b]{2}{*}{ Variable } & \multicolumn{6}{|l|}{ Region } \\
\hline & I & II & III & IV & $\mathrm{v}$ & VI \\
\hline \multicolumn{7}{|c|}{ Group 3.1g: Constants for Projection of Feedstock Use and Steel Production } \\
\hline CFEED (1) & 0 & -44.3 & 0 & 0 & 0 & 5.6 \\
\hline CFEED (2) & 0.77 & 1 & 0.36 & 0.488 & 0.553 & 0.4 \\
\hline CPST (1) & 0 & 71.4 & 0 & 0 & 0 & 0 \\
\hline CPST (2) & 0.49 & 1.33 & 0.83 & 0.732 & 0.606 & 0.304 \\
\hline \multicolumn{7}{|c|}{ Group 3.1h: Coke Use in Iron and Steel Industry } \\
\hline$B O F$ & 0.8 & 0.8 & 0.8 & 1 & 1 & 1 \\
\hline IRONST & 0.97 & 0.9 & 0.97 & 0.6 & 0.95 & 1.2 \\
\hline EICOK & 600 & 700 & 500 & 600 & 900 & 1,000 \\
\hline
\end{tabular}

in large proportions. The values listed for EFFIND in Table 8 were estimated and, if necessary, adjusted in the light of the above consideration.

(v) Parameters in Groups 3.1g and 3.1h in Table 8. As indicated in Appendix B, the parameters of Group $3.1 \mathrm{~g}$ are the fixed coefficients $\mathrm{C}(1)$ and $\mathrm{C}(2)$ of the expressions $\mathrm{C}(1)+$ $\mathrm{C}(2) \mathrm{X} X$ relating the use of petrochemical feestocks (CFEED) and the production of steel (CPST) to the value-added contribution of the basic materials industries in each region. In principle, these coefficients can be determined on the basis of the actual production data over the last few years, if in the scenarios the past trends are assumed to continue. Alternatively, one could define the coefficients independently of the past data and only adjust them to the base year production and future target values.

In the present set of MEDEE-2 runs, CFEED (1) is assumed to be zero in all the regions except for Regions II and VI, and CFEED (2) was determined solely on the basis of the 1975 values. For Regions II and VI, the coefficients were fixed in a similar manner; they were assumed to constitute an increasing proportion of the petrochemical component in the value added of basic material industries of Region II and a declining proportion in Region VI. Coefficients CPST (1) and CPST (2) were determined likewise for all regions, except for Region II, by assuming CPST (1) to be zero. For Region II, the two coefficients were adjusted to the base year data under the assumption that the proportion of the steelmaking component of the basic material industries decreases with time. The base year consumptions of (liquid fuel based) petrochemical feedstocks and of steel in the various regions were estimated basically from the data given by the following sources:

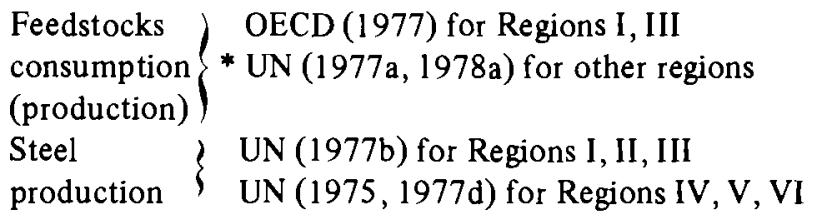

*Feedstock consumption data were available only for Regions 1 and III; for other regions, production data were used, assuming that trade would be negligible. 
The parameter IRONST (ratio of pig-iron to steel production) was estimated for all the regions from the data on pig-iron and steel production (UN 1975, 1977b, 1977d). The EICOK (coke rate of blast furnaces) and BOF (share of steel produced in nonelectric furnaces) estimates for Regions I and III are based on the data for the US and Japan (Doernberg 1977), and France (Lapillonne 1978c). For Region II, such estimates were obtained by comparison with the values for Regions I and III and taking into account the coke production data given in (UN 1977b). For Regions IV, V, and VI, BOF was assumed to be unity in 1975 , whereas the estimates for EICOK were based essentially on the data on pig-iron production and coke consumption of a few countries (UN 1975, 1977d, Vieira 1978, Parikh 1976, Elshafei 1978).

\section{Transportation}

(i) Parameters in Group 3.2a in Table 8. The coefficients CTKFRT (1) and CTKFRT (2) (demand for freight ton-kilometers) for Region I have been taken to be the same as derived by Lapillonne (1978b) for the US, on the basis of the historical data for 19501975 (US 1976a, b). For Region II, these coefficients were estimated by assuming a slower growth of freight transportation activity in relation to the growth of value added from the nonservice sectors and by adjusting them to match the base year data on freight

TABLE 8 Base year data/inputs (continued).

\begin{tabular}{|c|c|c|c|c|c|c|}
\hline \multirow[b]{2}{*}{ Variable } & \multicolumn{6}{|l|}{ Region } \\
\hline & I & II & III & IV & V & VI \\
\hline \multicolumn{7}{|c|}{ Group 3.2: Transportation } \\
\hline \multicolumn{7}{|c|}{ Group 3.2a: Constants for Projecting Freight and Miscellaneous Transportation } \\
\hline$C T K F R T(1)$ & -118.45 & 1,120 & 0 & 0 & 0 & 0 \\
\hline CTKFRT (2) & 6.125 & 7.12 & 1.45 & 6.19 & 2.83 & 4.353 \\
\hline CMISMF (1) & 0 & 560 & 0 & 0 & 0 & 0 \\
\hline CMISMF (2) & 0.225 & 0.3 & 0.07 & 0.16 & 0.16 & 0.2 \\
\hline
\end{tabular}

transportation (CMEA 1976) and GDP formation. For Regions III, IV, V, and VI, CTKFRT (1) was assumed to be zero; the values of CTKFRT (2) were worked out on the basis of estimated total freight transportation activity in 1975 in each region and the corresponding GDP formation data. Freight transportation on trains is given in detail in UN (1977b). Information on freight transportation by truck, barge, and pipeline for several countries in each region was gathered from various national statistics and other sources, in particular IRF (1976), WAES (1976), Europa (1974), and WFB (1974). This information served to estimate the total freight transportation activity in groups of countries in each region; the latter values were then extrapolated to the regional level by GDP weighting. Often, data on freight transportation were not given in ton $\mathrm{km}$ but had to be estimated from information on total tons transported, number of vehicles, vehicle-km, average distance travelled per vehicle, lengths and diameters of pipelines, etc.

Coefficients CMISMF (1) and CMISMF (2) refer to motor fuel consumption for miscellaneous transportation activities including military and international transportation. 
In MEDEE-2, these activities are assumed to vary linearly with GDP. Data necessary for estimating these coefficients are generally not available except for the US in Region I. The coefficients for Region I used here are based on the estimates made by Lapillonne (1978b) and are in agreement with the information given in WAES (1976). For other market economy regions, CMISMF (1) is assumed to be zero, as for Region I, and the values of CMISMF (2) have been chosen in the light of information on international travel/freight transportation and the expenditures (as fraction of GDP) on military activities in different regions relative to that in the US (US 1976a). For Region II, it is assumed that the present per capita level of motor fuel consumption for these activities is comparable to that in Region I. It is further assumed that the absolute demand for such activities will grow more slowly than GDP, in view of the relatively faster growth of GDP expected for this region among the developed regions. We realize that our input values of CMISMF (1) and CMISMF (2) for various regions are particularly uncertain, but this is due to the present limitations of data availability.

(ii) Parameters in Group 3.2b in Table 8. These parameters refer to fractional shares of different modes in total freight transportation. The parameters in parentheses represent certain subcategories of the preceding mode. The values for these parameters were obtained simultaneously with those of total freight ton-km discussed earlier in connection with the CTKFRT coefficient, and the same sources of data apply. Subcategory TRUL (local truck transport) was not considered separately except for Region I.

(iii) Parameters in Group 3.2c in Table 8. The values of the first four of these parameters for Region I are the same as those derived by Lapillonne (1978b) on the basis of data given in US (1976a), ATA (1975), and FEA (1974a). Estimates of these parameters for Region III were obtained on the basis of data given in WAES (1976), Goen (1975),

TABLE 8 Base year data/inputs (continued).

\begin{tabular}{|c|c|c|c|c|c|c|}
\hline \multirow[b]{2}{*}{ Variable } & \multicolumn{6}{|l|}{ Region } \\
\hline & I & II & IlI & IV & V & VI \\
\hline \multicolumn{7}{|c|}{ Group 3.2b: Distribution of Freight Transportation by Mode* } \\
\hline$T R U$ & 0.234 & 0.025 & 0.55 & 0.615 & 0.45 & 0.426 \\
\hline (TRUL) & $(0.15)$ & (0) & (0) & (0) & (0) & (0) \\
\hline FTRA & 0.39 & 0.775 & 0.3 & 0.175 & 0.35 & 0.024 \\
\hline$(T R A E F)$ & (0) & $(0.35)$ & $(0.3)$ & $(0.01)$ & $(0.15)$ & $(0.05)$ \\
\hline$(T R A S T F)$ & (0) & $(0.055)$ & (0) & (0) & $(0.55)$ & (0) \\
\hline$B A$ & 0.164 & 0.05 & 0.1 & 0.15 & 0.08 & 0.03 \\
\hline$P I P$ & 0.212 & 0.15 & 0.05 & 0.06 & 0.12 & 0.52 \\
\hline \multicolumn{7}{|c|}{ Group 3.2c: Energy Intensity of Freight Transportation Modes } \\
\hline$D T R U$ & 400 & 800 & 800 & 800 & 800 & 800 \\
\hline DTRUL & 1,100 & 0 & 0 & 0 & 0 & 0 \\
\hline$D T R A F$ & 110 & 100 & 200 & 200 & 200 & 200 \\
\hline$D B A$ & 80 & 100 & 200 & 200 & 200 & 200 \\
\hline$D P I P$ & 0 & 0 & 0 & 0 & 0 & 70 \\
\hline
\end{tabular}

*Values in parentheses are to be interpreted as fractions of the preceding category. 
Japan (1978), CEC (1978), and Lapillonne (1978c). The values chosen for Region II are similar to those for Region I as the average distance per freight movement is similar. The values used for Regions IV, V, and VI are identical with those for Region III.

Parameter DTRUL (energy intensity of local truck transport) applies only to Region I, where local truck movements are considered separately from long-distance hauls. The value of parameter DPIP is based on information given in ECE (1976). Energy consumption due to pipeline transportation is significant only in Region VI, and was neglected for other regions.

Not included in Group $3.2 \mathrm{c}$ are the efficiencies of electric and steam-operated trains. These efficiencies were internally fixed within the model respectively as one-third and three times the efficiency of diesel trains.

(iv) Parameters in Groups $3.2 \mathrm{~d}$ to $3.2 \mathrm{~g}$ in Table 8. The parameter values for Region I in these four groups were obtained on the basis of data in US (1976a), Hirst (1974a, b), IEA (1976), ATA (1975) FEA (1974a), WAES (1976), and Hittman (1974), and are, in general, the same as used for the US study (Lapillonne 1978b). The information for Region III was derived on the basis of Goen (1975), Japan (1978), WAES (1976), UN (1977b), IRF (1976), and by comparison with the data for Region I. The input data for Region II are based partly on UN (1977b), CMEA (1976), USSR (1976), Styrikovich (1979), and partly on comparison with Regions I and III.

For Regions IV, V, and VI the main sources of information in addition to a few national statistical publications, were UN (1977b), IRF (1976), Europa (1974), WFB (1974), and Arab Fund (1979). Some of the information available was limited to a few countries in each of the developing regions, and was extrapolated to obtain representative regional values also on the basis of other parameters and under consideration of similarities between countries or groups of countries.

For most regions, except for Region I and partly Region III, load factors and urban travel were estimated essentially on a judgmental basis in consultation with some experts from various regions. The load factors for the developing regions were chosen to correspond to trains and vehicles of similar average sizes as are used in Region III. This was necessary in order to make use of the vehicle efficiency data established for Region III as the corresponding information for Regions IV, V, and VI was not readily available.

\section{Households and Services}

(i) Parameters in Group 3.3a to 3.3e in Table 8. Detailed information on the distribution of energy consumption in the household and service sectors is generally scarce, except for the US and a few countries in Region III. Still, a large number of parameters are needed to conceptualize the patterns of energy consumption in these sectors and to project the future energy demand by assuming a plausible evolution of various activities in relation to the projected population and economic growth. The values for the parameters in Table 8 , Group 3* are based on available data wherever possible, on extrapolations from the data of certain countries, and on more general studies related to energy consumption.

\footnotetext{
${ }^{*}$ Except for subgroup 3.3c, which is only relevant for the projections.
} 
TABLE 8 Base year data/inputs (continued).

\begin{tabular}{|c|c|c|c|c|c|c|}
\hline \multirow[b]{2}{*}{ Variable } & \multicolumn{6}{|l|}{ Region } \\
\hline & I & II & III & IV & V & VI \\
\hline \multicolumn{7}{|c|}{ Group 3.2d: Total Distance Traveled per Person (Intercity/Urban) } \\
\hline$D I$ & 10,000 & 2,650 & 7,500 & 1,850 & 500 & 1,050 \\
\hline$D U$ & 56 & 10 & 9.7 & 16.5 & 11 & 11 \\
\hline \multicolumn{7}{|c|}{ Group 3.2e: Car Travel* } \\
\hline $\mathrm{CO}$ & 2 & 40 & 5.21 & 25.64 & 268 & 59.5 \\
\hline$D I C$ & 7,000 & 5,000 & 5,000 & 6,300 & 6,700 & 6,000 \\
\hline$L F I C$ & 2.6 & 3 & 2.3 & 3.5 & 3.5 & 3 \\
\hline$U C$ & 0.966 & 0.4 & 0.7 & 0.3 & 0.33 & 0.3 \\
\hline (UCE) & (0) & $(0)$ & $(0)$ & $(0)$ & $(0)$ & $(0)$ \\
\hline$L F U C$ & 1.6 & 2.5 & 1.5 & 2.5 & 2.5 & 2 \\
\hline \multicolumn{7}{|c|}{ Group 3.2f: Public Transportation* } \\
\hline$P B U$ & 0.153 & 0.15 & 0.35 & 0.845 & 0.67 & 0.844 \\
\hline PTRA & 0.051 & 0.62 & 0.6 & 0.107 & 0.314 & 0.132 \\
\hline$(T R A E P)$ & $(0.01)$ & $(0.5)$ & $(0.3)$ & $(0.01)$ & $(0.15)$ & $(0.05)$ \\
\hline$T R A S T P$ ) & (0) & $(0.02)$ & $(0)$ & $(0)$ & $(0.55)$ & (0) \\
\hline$P L A$ & 0.796 & 0.23 & 0.05 & 0.048 & 0.016 & 0.024 \\
\hline$L F B U$ & 22 & 45 & 25 & 40 & 40 & 40 \\
\hline$L F T R A$ & 140 & 400 & 140 & 500 & 500 & 500 \\
\hline$L F P$ & 0.5 & 0.9 & 0.6 & 0.6 & 0.8 & 0.75 \\
\hline$U M T$ & 0.034 & 0.6 & 0.3 & 0.7 & 0.67 & 0.7 \\
\hline (UMTE) & $(0.4)$ & $(0.8)$ & $(0.4)$ & $(0.05)$ & $(0.03)$ & $(0.02)$ \\
\hline$L F M T B$ & 17.6 & 40 & 20 & 50 & 50 & 50 \\
\hline$L F M T E$ & 20.5 & 50 & 30 & 60 & 60 & 60 \\
\hline \multicolumn{7}{|c|}{ Group 3.2g: Specific Energy Consumption of Passenger Transportation Modes } \\
\hline GIC & 14 & 12 & 9 & 9 & 9 & 11.5 \\
\hline$G U C$ & 19.6 & 14 & 11 & 12 & 12 & 14.5 \\
\hline ELUC & 0.25 & 0.25 & 0.25 & 0.25 & 0.25 & 0.25 \\
\hline$D B U$ & 39 & 35 & 40 & 40 & 40 & 40 \\
\hline$D T R A P$ & 42,790 & 22,750 & 20,000 & 20,000 & 20,000 & 20,000 \\
\hline$D P L A$ & 691 & 800 & 700 & 700 & 700 & 700 \\
\hline$D M T$ & 50 & 40 & 60 & 60 & 60 & 60 \\
\hline$E L M T$ & 3.4 & 3.4 & 3.4 & 3.4 & 3.4 & 3.4 \\
\hline
\end{tabular}

*Values in parentheses are to be interpreted as fractions of the preceding category.

Specifically, the values of these parameters for Region I are based on the estimates made by Lapillonne (1978b) for the US from data given in US (1976b), FEA (1974b), SRI (1972), SPP (1975), and Hirst and Jackson (1977), Beller (1975), Salter et al. (1976), and on additional data given for Canada in WAES (1976). The corresponding estimates for Region III were made by extrapolation from the information in some Region III countries given in CEC (1978), Lapillonne (1978c), WAES (1976), Foell et al. (1979), and by comparison with the values found for Region I - taking into account similarities and differences in lifestyles and technology as described in various comparative studies between the US and Japan, US and FRG, and US and Sweden in Doernberg (1977), Goen (1975), and Schipper and Lichtenberg (1976), respectively. For Region II, some 
TABLE 8 Base year data/inputs (continued).

\begin{tabular}{|c|c|c|c|c|c|c|}
\hline \multirow[b]{2}{*}{ Variable } & \multicolumn{6}{|l|}{ Region } \\
\hline & 1 & 11 & 1II & IV & $\mathrm{V}$ & VI \\
\hline \multicolumn{7}{|c|}{ Group 3.3: Household and Service Sector } \\
\hline \multicolumn{7}{|c|}{ Group 3.3a: Important Constants/Initial Values } \\
\hline$D D$ & 2,600 & 4,000 & 2,200 & 1,200 & 300 & 500 \\
\hline$D W S H, A R S H$ & 1 & 1 & 1 & 0.25 & 0.15 & 1 \\
\hline$D W \cdot 75$ & 79.4 & 98 & 187 & 62.6 & 271.4 & 25.3 \\
\hline SHDWO (1) & 23,500 & 17,750 & 17,000 & 5,000 & 0 & 2,700 \\
\hline SHDWO (2) & 12,800 & 11,500 & 11,000 & 3,500 & 0 & 1,800 \\
\hline SHDWO (3) & 9,600 & 6,300 & 4,000 & 1,250 & 450 & 900 \\
\hline$T A R E A .75$ & 2,720 & 1,500 & 3,000 & 600 & 1,250 & 180 \\
\hline CPLSER & 1.2 & 1.028 & 1.2 & 1.534 & 1.536 & 0.824 \\
\hline$H A R E A O$ & 290 & 220 & 135 & 50 & 15 & 25 \\
\hline$B Y R N C F$ & a & 47.5 & a & 117 & 370 & 10.5 \\
\hline \multicolumn{7}{|c|}{ Group 3.3b: Other Factors Determining Present Useful Energy Consumption } \\
\hline COOKDW & 1,000 & 1,000 & 1,100 & 1,600 & 1,000 & 1,600 \\
\hline$D W H W$ & 1 & 0.6 & 0.7 & 0.2 & 0.1 & 0.6 \\
\hline$H W C A P$ & 1,500 & 700 & 700 & 400 & 40 & 60 \\
\hline$D W A C$ & 0.39 & 0 & 0 & 0 & 0 & 0.01 \\
\hline$A C D W$ & 4,472 & 2,000 & 3,000 & 1,500 & 1,500 & 2,000 \\
\hline$E L A P D W$ & 3,850 & 880 & 1,950 & 700 & 50 & 200 \\
\hline PREDW (1) & 0.48 & 0.05 & 0.1 & 0.08 & 0 & 0.01 \\
\hline PREDW (2) & 0.32 & 0.35 & 0.2 & 0.16 & 0 & 0.05 \\
\hline PREDW (3) & 0.2 & 0.6 & 0.7 & 0.56 & 0.35 & 0.4 \\
\hline$A R E A H$ & 0.8 & 1 & 0.7 & 0.8 & 0.35 & 0.7 \\
\hline$E L A R O$ & 120 & 40 & 40 & 25 & 15 & 15 \\
\hline$A R E A A C$ & 0.55 & 0 & 0.05 & 0.05 & 0 & 0.04 \\
\hline$A C A R E A$ & 70 & 70 & 70 & 70 & 70 & 70 \\
\hline$E F F A C$ & 2 & 2 & 2 & 2 & 2 & 2 \\
\hline
\end{tabular}

Group 3.3c: Factors Relevant for Projection of Useful Energy Consumption $D E M D E$ $N E W D W(1)$ $N E W D W(2)$ NEWDW (3) $D W S(1)$

DWS (2)

$D W S(3)$

$K(1)$

$K(2)$

$K(3)$

$I S O(1)$

$I S O(2)$

$I S O(3)$

AREAL

DEMAR

HAREAN

ELARN

ISOSV

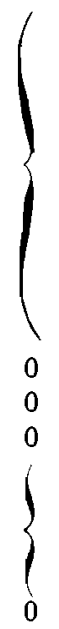

not applicable for base year
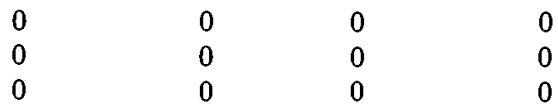

0

0

not applicable for base year

0

0

0

0

0

a: Noncommercial fuels are not considered in Regions I and III. 
TABLE 8 Base year data/inputs (continued).

\begin{tabular}{|c|c|c|c|c|c|c|}
\hline \multirow[b]{2}{*}{ Variable } & \multicolumn{6}{|c|}{ Region } \\
\hline & I & II & III & IV & V & VI \\
\hline \multicolumn{7}{|c|}{ Group 3.3d: Penetration of Alternative Energy Sources** } \\
\hline ELP.H.SH & 0.12 & 0 & 0.04 & 0.01 & 0.01 & 0.01 \\
\hline ELP.H.HW & 0.3 & 0.07 & 0.24 & 0.01 & 0.01 & 0.01 \\
\hline ELP.H.CK & 0.47 & 0.15 & 0.36 & 0.005 & 0 & 0 \\
\hline ELP.S.TH & 0.05 & 0 & 0.04 & 0.01 & 0.3 & 0.01 \\
\hline (HPHS) & $(0)$ & (0) & $(0)$ & $(0)$ & $(0)$ & $(0)$ \\
\hline EFFHPR & 2 & 2 & 2 & 2 & 2 & 2 \\
\hline$D H P H$ & 0 & 0.467 & 0 & 0 & 0 & 0 \\
\hline$S P S H^{*}$ & 0 & 0 & 0 & 0 & 0 & 0 \\
\hline FDSHS & 0.7 & 0.4 & 0.5 & 0.8 & 0.8 & 0.8 \\
\hline$S P H W$ & 0 & 0 & 0 & 0 & 0 & 0 \\
\hline$F D H W S$ & 0.7 & 0.6 & 0.7 & 0.8 & 0.8 & 0.8 \\
\hline$P L B$ & 0.3 & 0.3 & 0.3 & 0.3 & 0.7 & 0.7 \\
\hline$S P S V^{*}$ & 0 & 0 & 0 & 0 & 0 & 0 \\
\hline$F D H S$ & 0.7 & 0.4 & 0.55 & 0.8 & 0.8 & 0.8 \\
\hline CHGNCF & a & 1 & $\mathbf{a}$ & 1 & 1 & 1 \\
\hline \multicolumn{7}{|c|}{ Group 3.3e: Fossil Fuel Efficiencies (relative to electricity) } \\
\hline EFF.H.SH & 0.63 & 0.59 & 0.63 & 0.6 & 0.5 & 0.6 \\
\hline EFF.H.HW & 0.57 & 0.49 & 0.57 & 0.55 & 0.5 & 0.55 \\
\hline$E F F . H C K$ & 0.41 & 0.4 & 0.51 & 0.5 & 0.5 & 0.5 \\
\hline EFF.S.TH & 0.7 & 0.59 & 0.7 & 0.65 & 0.55 & 0.6 \\
\hline EFFNCF & a & 0.3 & $a$ & 0.075 & 0.075 & 0.075 \\
\hline
\end{tabular}

a; Noncommercial fuels are not considered in Regions I and III.

*Only relevant for post-1975 buildings.

**Values in parentheses are to be interpreted as fractions of the preceding category.

values were established from UN (1977b), ECE (1978a), ECE (1978b), CMEA (1976), and USSR (1976). Others were derived by comparison with Regions I and III and by crosschecking against the useful energy balance by process and energy source given for the USSR in Vigdorchik (1976), against the final energy consumption statistics given in ECE (1977), Melentiev (1977) and Petro Studies (1978), and against typical efficiencies given in Eurostat (1978), and Beschinsky and Kogan (1976).

For the developing regions, our estimates were based on the geographical locations of these regions, sizes of dwellings in various countries (IBRD 1976), scattered information on the pattern of energy use in the domestic sector and on the sectoral distribution of energy consumption in various countries, (e.g., Makhijani and Poole 1975, Parikh 1978, McGranahan and Taylor 1977, WAES 1976, Vieira 1978, Parikh 1976, Henderson 1975, Revelle 1976, Pakistan 1977, Elshafei 1978)*; discussions with persons from these regions, and comparison with data for other regions.

The values for $D W-75$ (stock of dwellings in 1975) listed in Table 8 correspond to the data on population $(P O)$ and average household size $(C A P H)$. The value of CPLSER is determined on the basis of the value of PYSER (service sector share of GDP) and PLSER

*Some useful information is algo given in Cecelski et al. (1979). 
(fraction of labor force employed in the service sector): CPLSER $=\ln$ PLSER/ln PYSER. Information on the share of the service sector in the labor force was derived from the data in IBRD (1976), CMEA (1976), and ILO (1976).

Parameter TAREA-75 corresponds to the service sector area in 1975. For Regions I and III, it represents the area of establishments related to trade and catering, business and social, and governmental services. For other regions, this definition was not applied due to the complete lack of data. Instead the values used for this parameter are, in combination with those of some other parameters, only a way to conceptualize the present energy requirements of the service sector.

The parameters in Group $3 c$ of Table 8 are intended exclusively for projections and do not serve to describe the pattern of energy consumption in the base year.

\subsection{Detailed Scenario Assumptions}

The projection of final energy demand in the two IIASA scenarios is based on the formulation of detailed scenarios describing plausible evolutions of the variable parameters of MEDEE-2 listed in Appendix B. There is no universally accepted method for projecting the evolution of various socioeconomic indicators and related technological parameters over a period of several decades. The econometric approach based on extrapolations from past trends usually works well for short-term projections, but cannot be usefully applied over such long intervals. Fifty years is a short period in the history of mankind but a fairly long time when one considers that in such a period certain economies will probably change their status from developing countries to developed countries. Some others may be forced to substantially reorientate their economic structures and the lifestyles of their populations in the face of a growing scarcity of natural resources (including energy), and under tightening environmental constraints.

In our opinion, the past trends, although useful guidelines, cannot be relied upon to make medium- to long-term projections in a rapidly changing world situation. Also there is an acute shortage of disaggregated relevant data; sufficiently detailed data are available only for a few countries (mostly developed) and, even then, such data have been compiled only in recent years. The approach followed here is, therefore, one of scenario assumptions - developed on the basis of judgments guided by past trends, interregional and intercountry comparisons whenever appropriate, estimated relationships reflecting the interdependence between various economic and social activities, and estimated prospects of technological developments. Of course, these scenario assumptions and the resulting sectoral and subsectoral energy demand projections are not deterministic; they should simply be considered as guidelines for understanding the nature of future energy demand.

The detailed scenario assumptions described in this section are the final set of MEDEE-2 inputs we arrived at after going through the iterations of the IIASA modeling loop described earlier (see Section 1). In the final stages of these iterations, the energy demand - total as well as for some broad sectors, such as transportation, household. agriculture, and industry - was also analyzed (Chant 1982) in terms of the elasticities implied - energy price elasticity, income elasticity, and elasticity of substitution - in order to ensure consistency of the aggregate results. 
In Tables 9.1-9.3, the values of variable scenario parameters of MEDEE-2 used in the present assessment are listed for the years 2000 and 2030, along with those for 1975 . The parameters are presented in several groups to aid understanding of the assumed variations of related parameters within each region, and also to allow interregional comparisons. (Although the values for the intermediate years 1985 and 2015 were also specified in the actual model runs, for the sake of brevity they are not listed here.) We continue with some general comments about the considerations underlying the assignment of specific values to the parameters in these different groups.

\subsubsection{Demography (Table 9.1)}

The parameter projections in this group are based on Keyfitz (1977) and on extrapolation of past trends and the available UN projections for the next 10 to 25 years (UN 1974, 1976b).

\subsubsection{Macroeconomics (Table 9.2)}

In order to project the GDP formation structure and the composition of the value added by manufacturing industries for the developing regions (IV, V, VI), we have obtained guidance from the observed evolution patterns in the historical data, 1960-75, for a number of countries and groups of countries at different stages of development (UN $1977 \mathrm{~b}, \mathrm{c})$. The analysis of past data, 1950-70, for several countries made by Chenery and Syrquin (1975), and the short-term development plans of a few countries have also provided information.

The main features of the assumptions concerning GDP formation in these regions are the following: the share of agriculture decreases while still allowing a slow gradual improvement in per capita agricultural GDP with increasing per capita total GDP; the share of manufacturing increases, the increase being relatively higher in the High scenario than in the Low scenario; and the service sector share increases in Regions V and VI (where it was quite low in the base year), but decreases slightly in Region IV. The mining sector contributes only 2-3 percent to the GDP of Region IV and V, whereas its share in the GDP of Region VI is projected to decrease from 51 percent in 1975 to 9 percent in the High scenario and about 18 percent in the Low scenario by 2030 . The value added by the mining sector in this region is mainly governed by the oil and gas extraction activities; it has been adjusted accordingly in each scenario to correspond to the envisaged production rate necessary for meeting both the domestic consumption and the export demand. It is also assumed that Region VI will undergo major industrialization within the next 10 to 25 years with the help of its oil revenues. With respect to the composition of the manufacturing industries, our projections are based on the hypothesis that the countries at a low level of industrial development have a high share of consumer goods industries, but as the industrial infrastructure develops, more emphasis is placed first on expanding the basic material and later on promoting the sophisticated machinery and equipment industries. This hypothesis is based on the observed pattern of manufacturing activities in various countries at different stages of development.

The situation is different in the developed Regions I and III. Here the GDP formation structure, as it appears on the aggregated level considered in MEDEE-2, remained practically unchanged during the period 1960-75, whereas in Region II the only significant 
TABLE 9.1 Detailed scenario assumptions - demography (Group 1).

\begin{tabular}{|c|c|c|c|c|c|c|c|c|c|c|c|c|c|c|c|}
\hline \multirow[b]{2}{*}{ Variable } & \multirow[b]{2}{*}{1975} & \multicolumn{2}{|l|}{2000} & \multicolumn{2}{|c|}{2030} & \multirow[b]{2}{*}{1975} & \multicolumn{2}{|c|}{2000} & \multicolumn{2}{|c|}{2030} & \multirow[b]{2}{*}{1975} & \multicolumn{2}{|l|}{2000} & \multicolumn{2}{|c|}{2030} \\
\hline & & Low & High & Low & High & & Low & High & Low & High & & Low & High & Low & High \\
\hline & Region I & & & & & Region II & & & & & Region III & & & & \\
\hline$P O$ & 237 & \multicolumn{2}{|c|}{284} & \multicolumn{2}{|c|}{315} & 363 & \multicolumn{2}{|c|}{436} & \multicolumn{2}{|c|}{480} & 560 & \multicolumn{2}{|c|}{680} & \multicolumn{2}{|c|}{767} \\
\hline$P L F$ & 0.64 & \multicolumn{2}{|c|}{0.64} & \multicolumn{2}{|c|}{0.64} & 0.64 & \multicolumn{2}{|c|}{0.64} & \multicolumn{2}{|c|}{0.64} & 0.63 & \multicolumn{2}{|c|}{0.65} & \multicolumn{2}{|c|}{0.65} \\
\hline PARTLF & 0.69 & 0.69 & 0.75 & 0.69 & 0.8 & 0.61 & 0.66 & 0.7 & 0.7 & 0.8 & 0.72 & 0.75 & 0.77 & 0.77 & 0.8 \\
\hline$P O L C$ & 0.64 & \multicolumn{2}{|c|}{0.635} & \multicolumn{2}{|c|}{0.625} & 0.42 & \multicolumn{2}{|c|}{0.3} & \multicolumn{2}{|c|}{0.2} & 0.51 & \multicolumn{2}{|c|}{0.48} & \multicolumn{2}{|c|}{0.45} \\
\hline$P R U R^{*}$ & 0.24 & \multicolumn{2}{|c|}{0.14} & \multicolumn{2}{|c|}{0.07} & 0.41 & \multicolumn{2}{|c|}{0.25} & \multicolumn{2}{|c|}{0.12} & 0.29 & \multicolumn{2}{|c|}{0.18} & & \\
\hline$C A P H$ & 2.98 & & & & & 3.7 & 3 & & & & 3 & & & & \\
\hline & Region IV & & & & & Region $V$ & & & & & Region VI & & & & \\
\hline$P O$ & 319 & 57 & & & & 1,422 & & & & & 133 & & & & \\
\hline$P L F$ & 0.542 & & & & & 0.538 & & & & & 0.523 & & & & 98 \\
\hline PARTLF & 0.59 & & & & & 0.708 & & & & & 0.512 & & & & 12 \\
\hline POLC & 0.63 & & & & & 0.87 & & & & & 0.71 & & & & \\
\hline$P R U R^{*}$ & 0.40 & & & & & 0.78 & & & & & 0.55 & & & & \\
\hline$C A P H$ & 5.1 & 4. & & & & 5.24 & & & & & 5.25 & 4. & & & \\
\hline
\end{tabular}

*The values for this variable do not directly affect the calculations of the version of the MEDEE-2 model used for the present assessment, but they are used for projecting the evolution of other variables, outside the model calculations.

NOTE: See definition of variables in Appendix B, Part 2. 
TABLE 9.2 Detailed scenario assumptions - macroeconomics (Group 2).

\begin{tabular}{|c|c|c|c|c|c|c|c|c|c|c|c|c|c|c|c|}
\hline \multirow[b]{2}{*}{ Variable } & \multirow[b]{2}{*}{1975} & \multicolumn{2}{|l|}{2000} & \multicolumn{2}{|l|}{2030} & \multirow[b]{2}{*}{1975} & \multicolumn{2}{|l|}{2000} & \multicolumn{2}{|l|}{2030} & \multirow[b]{2}{*}{1975} & \multicolumn{2}{|l|}{2000} & \multicolumn{2}{|l|}{2030} \\
\hline & & Low & High & Low & High & & Low & High & Low & High & & Low & High & Low & High \\
\hline & \multicolumn{5}{|l|}{ Region I } & \multicolumn{5}{|l|}{ Region II } & \multicolumn{5}{|c|}{ Region III } \\
\hline$Y$ & 1,670 & 3,049 & 4,126 & 4,170 & 7,926 & 930 & 2,420 & 2,729 & 4,713 & 7,658 & 2,385 & 4,452 & 5,999 & 6,656 & 11,693 \\
\hline$P Y A G$ & 0.028 & 0.023 & 0.021 & 0.02 & 0.015 & 0.107 & 0.086 & 0.074 & 0.07 & 0.04 & 0.058 & 0.044 & 0.045 & 0.03 & 0.025 \\
\hline$P Y B$ & 0.041 & 0.044 & 0.043 & 0.046 & 0.045 & 0.079 & 0.08 & 0.075 & 0.08 & 0.07 & 0.075 & 0.073 & 0.071 & 0.07 & 0.065 \\
\hline$P Y M I N^{*}$ & 0 & & & & & 0 & & & & & 0 & & & & \\
\hline PYMAN & 0.245 & 0.24 & 0.223 & 0.238 & 0.207 & 0.382 & 0.335 & 0.337 & 0.3 & 0.29 & 0.336 & 0.317 & 0.313 & 0.297 & 0.281 \\
\hline PYEN & 0.038 & & & & & 0.042 & 0. & 46 & 0. & & 0.046 & 0.05 & 0.049 & 0.053 & 0.05 \\
\hline PYSER & 0.648 & 0.655 & 0.675 & 0.658 & 0.695 & 0.39 & 0.453 & 0.468 & 0.5 & 0.55 & 0.485 & 0.516 & 0.522 & 0.55 & 0.58 \\
\hline$P V A I G$ & 0.248 & 0.237 & 0.232 & 0.232 & 0.212 & 0.233 & 0.222 & 0.23 & 0.217 & 0.227 & 0.33 & 0.312 & 0.311 & 0.294 & 0.282 \\
\hline$P V A M$ & 0.432 & 0.458 & 0.47 & 0.47 & 0.517 & 0.476 & 0.514 & 0.521 & 0.53 & 0.568 & 0.42 & 0.445 & 0.46 & 0.471 & 0.512 \\
\hline$P V A C$ & 0.32 & 0.305 & 0.298 & 0.298 & 0.271 & 0.291 & 0.264 & 0.249 & 0.253 & 0.205 & 0.25 & 0.243 & 0.23 & 0.235 & 0.206 \\
\hline$I^{* *}$ & 0.18 & \multicolumn{2}{|c|}{0.195} & \multicolumn{2}{|c|}{0.21} & 0.3 & 0.265 & 0.29 & 0.25 & 0.28 & 0.25 & & & & \\
\hline$P^{* *}$ & 0.65 & \multicolumn{2}{|c|}{0.625} & \multicolumn{2}{|c|}{0.59} & 0.45 & 0.52 & 0.499 & \multicolumn{2}{|c|}{0.55} & 0.58 & & & & \\
\hline$P C D G^{* *}$ & 0.19 & 0.21 & 0.22 & 0.23 & 0.25 & 0.1 & 0.135 & 0.139 & 0.15 & 0.18 & 0.1 & 0.131 & 0.15 & 0.16 & 0.02 \\
\hline$P C N D G^{* *}$ & 0.42 & 0.38 & 0.36 & 0.35 & 0.3 & 0.6 & 0.53 & 0.502 & 0.5 & 0.4 & 0.56 & 0.503 & 0.47 & 0.45 & 0.38 \\
\hline \multirow[t]{2}{*}{ PCSER ** } & 0.39 & 0.41 & 0.42 & 0.42 & 0.45 & 0.3 & 0.335 & 0.359 & 0.35 & 0.42 & 0.34 & 0.366 & 0.38 & 0.39 & 0.42 \\
\hline & \multicolumn{5}{|c|}{ Region IV } & \multicolumn{5}{|l|}{ Region $V$} & \multicolumn{5}{|c|}{ Region $V I$} \\
\hline$Y$ & 340 & 918 & 1,272 & 2,229 & 3,569 & 340 & 924 & 1,207 & 1,995 & 3,488 & 190 & 643 & 900 & 1,310 & 2,918 \\
\hline$P Y A G$ & 0.122 & 0.095 & 0.076 & 0.065 & 0.046 & 0.361 & 0.296 & 0.255 & 0.232 & 0.162 & 0.07 & 0.05 & 0.041 & 0.04 & 0.023 \\
\hline$P Y B$ & 0.057 & \multicolumn{2}{|c|}{0.06} & \multicolumn{2}{|c|}{0.07} & 0.058 & 0. & & 0.0 & & 0.065 & 0.1 & & 0.091 & 0.076 \\
\hline$P Y M I N^{*}$ & 0.025 & o. & & 0.0 & & 0.015 & 0. & & 0.0 & & 0.51 & 0.155 & 0.2 & 0.175 & 0.09 \\
\hline PYMAN & 0.248 & 0.285 & 0.304 & 0.291 & 0.33 & 0.166 & 0.2 & 0.223 & 0.228 & 0.258 & 0.078 & 0.258 & 0.242 & 0.25 & 0.273 \\
\hline PYEN & 0.025 & 0.035 & 0.036 & 0.049 & 0.05 & 0.016 & 0.026 & 0.028 & 0.038 & 0.042 & 0.007 & 0.024 & 0.023 & 0.0 & \\
\hline PYSER & 0.523 & 0.505 & 0.504 & 0.505 & 0.484 & 0.384 & 0.4 & 0.417 & 0.42 & 0.456 & 0.27 & 0.407 & 0.388 & 0.416 & 0.51 \\
\hline PVAIG & 0.308 & 0.344 & 0.356 & 0.364 & 0.352 & 0.264 & 0.297 & 0.319 & 0.311 & 0.367 & 0.2 & 0.3 & & 0.4 & 0.35 \\
\hline$P V A M$ & 0.264 & 0.333 & 0.356 & 0.386 & 0.42 & 0.176 & 0.22 & 0.242 & 0.256 & 0.3 & 0.1 & 0.12 & 0.15 & 0.2 & 0.4 \\
\hline$P V A C$ & 0.429 & 0.322 & 0.289 & 0.25 & 0.227 & 0.56 & 0.484 & 0.44 & 0.433 & 0.333 & 0.7 & 0.53 & 0.5 & 0.4 & 0.25 \\
\hline$I^{* *}$ & 0.23 & & & & & 0.2 & 0.2 & & 0.2 & & 0.215 & 0.3 & & 0.3 & 0.25 \\
\hline$P^{* *}$ & 0.7 & 0.65 & 0.64 & 0.63 & 0.61 & 0.71 & 0.6 & & 0.6 & & 0.325 & 0.4 & & 0.47 & 0.55 \\
\hline$P C D G^{* *}$ & 0.1 & 0.11 & 0.12 & 0.12 & 0.14 & 0.07 & 0.08 & 0.09 & 0.1 & 0.13 & 0.1 & 0.12 & 0.13 & 0.13 & 0.15 \\
\hline PCND $\sigma^{* * *}$ & 0.6 & 0.57 & 0.55 & 0.54 & 0.51 & 0.73 & 0.7 & 0.68 & 0.67 & 0.61 & 0.6 & 0.55 & 0.555 & 0.55 & 0.515 \\
\hline PCSER ** & 0.3 & 0.32 & 0.33 & 0.34 & 0.35 & 0.2 & 0.22 & 0.23 & 0.24 & 0.26 & 0.3 & 0.33 & 0.315 & 0.32 & 0.335 \\
\hline
\end{tabular}

* For Regions 1, 1I, and III, minings of coal, oil, and gas is included in the energy sector and that of other materials is included under manufacturing of bas materials (see definition of sectors in Appendix C).

**The values for these variables do not directly affect the calculations of the version of the MEDEE 2 model used for the present assessment, but they as for projecting the evolu tion of other variables, outside the model calculations. 
change in this period was a decline of the agricultural share* from 32 to 15 percent and an increase in the industry (mining, manufacturing, and energy sectors) share from 41 to 57 percent.

The shifts in the structure of GDP formation assumed in the light of a retarding overall economic growth can be qualitatively described as follows. For Region I, the service sector share is assumed to increase slightly and the manufacturing share is assumed to decrease by roughly the same amount (the change is insignificant in the Low scenario). GDP formation structures assumed for Regions II and III gradually shift toward the pattern of Region I as these regions proceed to a higher level of economic development. All three regions are assumed to give higher emphasis to the development of machinery and equipment industries than to the basic materials and consumer goods industries. Only minor shifts are assumed in the GDP shares of construction and energy sectors in all the regions. The share of agriculture in GDP is assumed to decrease in all three regions in line with past trends. However, this decrease is large only in the case of Region II, whose share was large in the base year and which is projected to have a higher overall economic growth in each scenario than either of the two other developed regions.

\subsubsection{Energy Consumption in Sectors}

\section{Industry (Table 9.3.1)}

We have assumed that there will not be any significant changes in the energy intensity of agriculture and construction in the developed Regions I and III. This is because it was difficult to estimate the net effect of two oppositely acting factors: the likely improvements in the efficiencies of equipment used in these sectors, and a probable further, albeit small, increase in the mechanization of such activities. In Region II, the energy intensity of agriculture and construction activities are assumed to decrease slightly, with the sometimes inefficient use of the relatively heavy equipment currently employed. In the long term, therefore, efficiency improvements are expected to more than counterbalance the effect of increasing mechanization. As the mining sector in Regions I, II, and III is not considered separately but as part of the manufacturing and energy sector activities, its energy intensity is not given explicitly.

At present, agricultural activities in all the developing regions are largely carried out using traditional methods based on human and animal labor. The same is true for construction and nonpetroleum mining activities, at least in Regions V and VI. One may expect increasing mechanization of such activities with further development and a correspondingly greater demand for quality and quantity of sectoral products. In the case of agriculture, for example, considerable and rather rapid mechanization is necessary to obtain higher outputs from the limited resources of arable land required to supply a rapidly growing population with more and better food. The projected changes in energy intensity are based on our estimates of the energy requirements of field equipment (tractors and other appliances) and of irrigation water-pumping units, assuming that by 2030 agricultural

\footnotetext{
*These shares are based on values of GDP which do not include nonproductive services, e.g., social and administrative services. If the contribution of such nonproductive services is also included in GDP the shares of sectors will be somewhat different. It was estimated that the inclusion of nonproductive services in GDP of 1975 would lower the shares of agriculture and manufacturing by a factor of 1.35 , i.e., to 11 and 38 percent, respectively. These numbers can be compared to the GDP shares in market economy regions.
} 

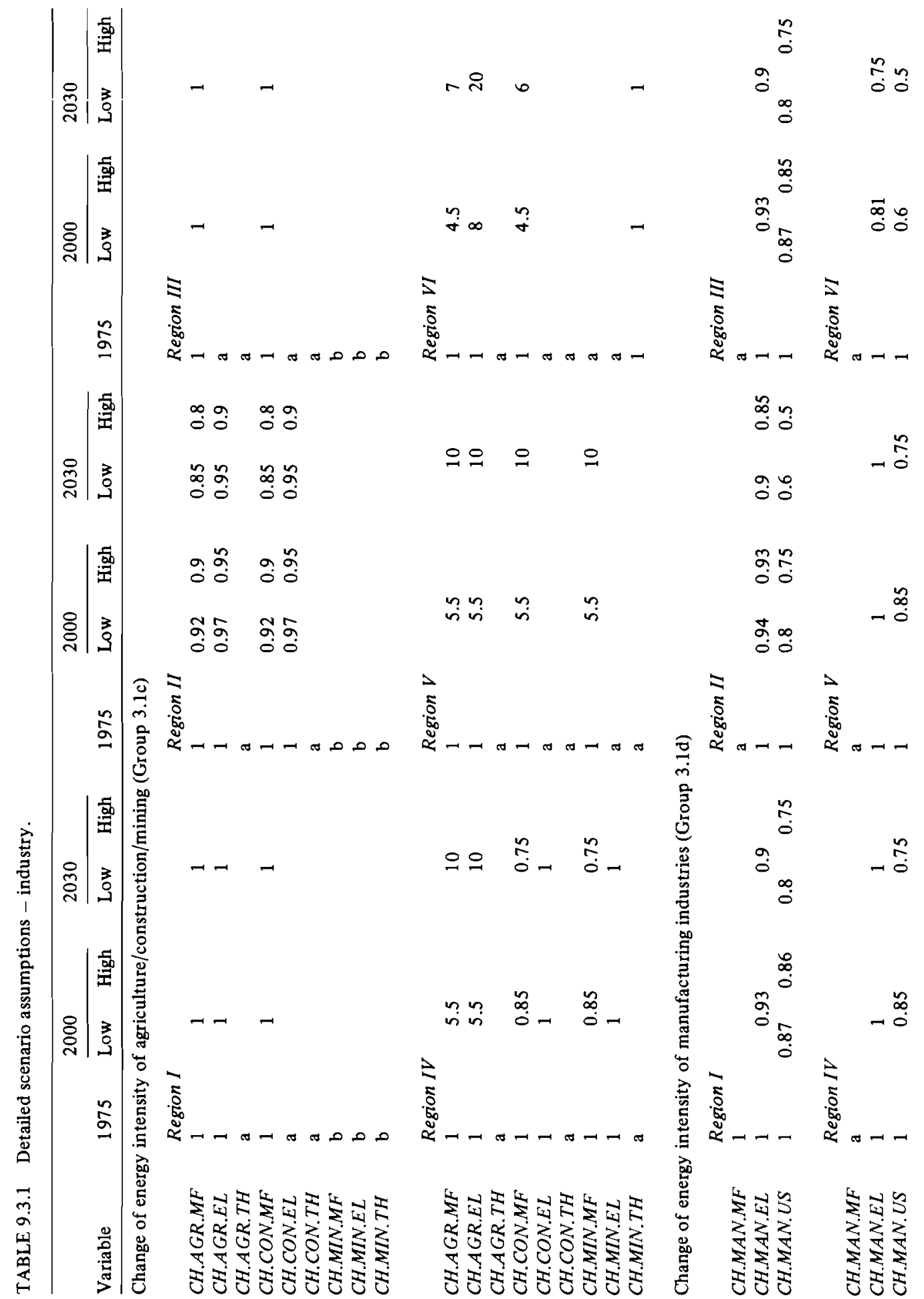


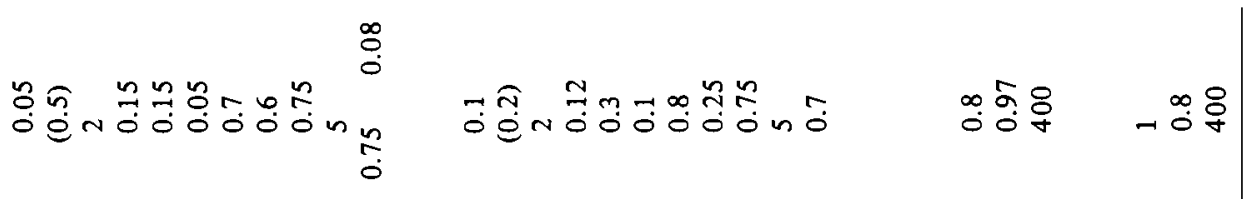

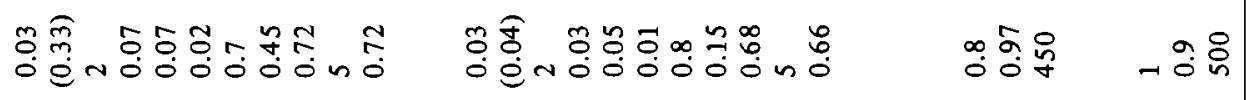

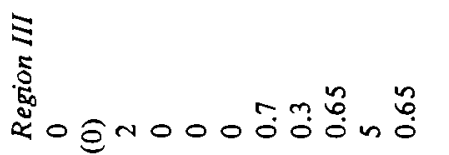
$\Sigma$

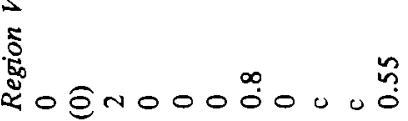

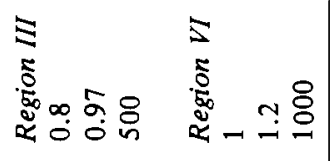
$\overline{0}$ 造

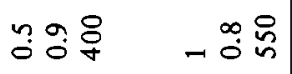
$\stackrel{\circ}{0}$

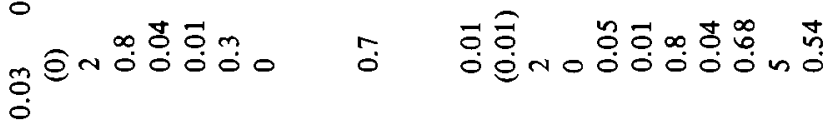

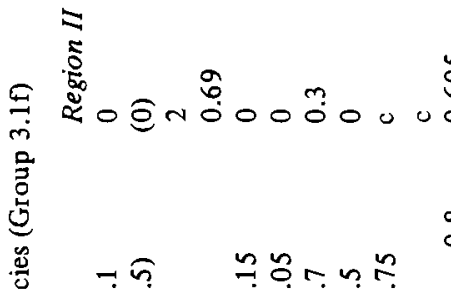<smiles>C#CCCCC</smiles>

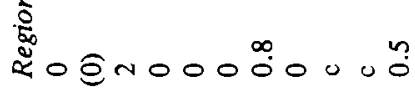

5 궁영영 - $\stackrel{0}{0}$

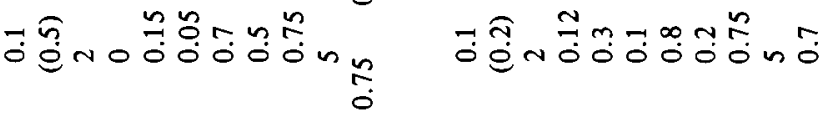

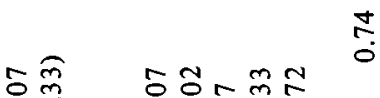
:0क्ष

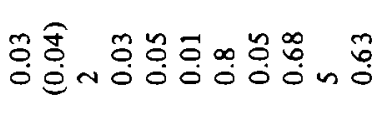
衰

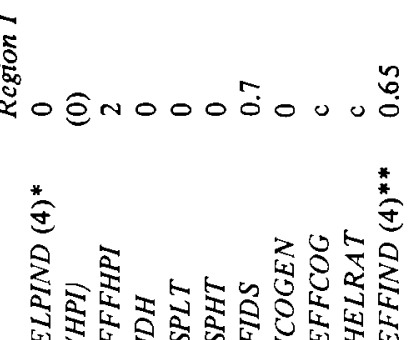

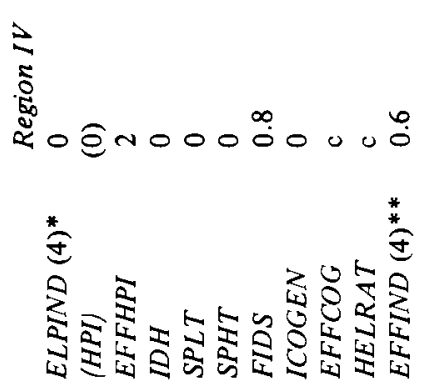

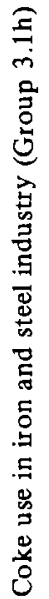
密

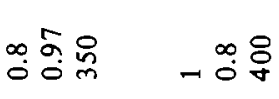

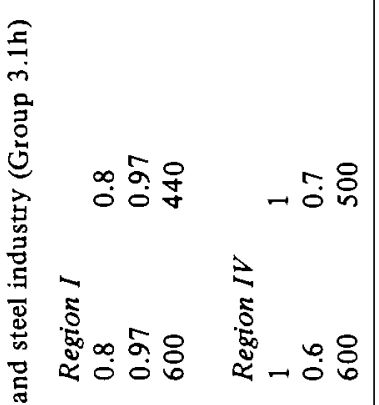

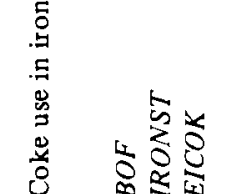

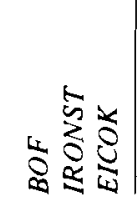

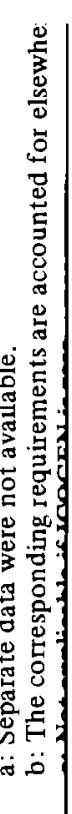


activities in the developing regions will be mechanized to an extent comparable to the present level of mechanization in the developed regions. Mechanization is also assumed to increase in the construction activities in Regions V and VI, but to relatively lower levels than those found in the developed regions. For the mining sector, the changes assumed take into account differences in the nature of mining activities and in the working conditions in the various regions, and reflect a likely future improvement.

It may be mentioned here that there are considerable uncertainties in the base year data of energy intensity of agriculture, construction, and mining activities of almost all regions, both developed and developing. The assumed changes in the energy intensity of these sectors should, therefore, be considered as qualitative indicators of a likely trend.

MEDEE-2 considers manufacturing activities by only three broad categories: basic materials industries, machinery and equipment industries, and consumer goods (nondurable) industries. Each category covers the manufacturing of a variety of products so that its composition is not uniform for all the regions; and even within a single region the composition cannot be assumed to remain constant all the time. The energy intensity of each category is thus affected by changes in composition as well as by changes and improvements in technology. The parameters of Group 3.1d in Table 3.9.1 are intended to project the changes in energy intensity of each category covering both the above aspects.

The data on energy consumption of various manufacturing industries in different countries over the last 15-20 years reveal a gradual reduction in energy intensity over time, e.g., for US, France, FRG, Austria, see Doblin (1978), Lapillonne (1978c), Schaefer et al. (1977), Foell et al. (1979). This is, in general, due to a reduction in the use of fossil fuels (per unit of output), while the specific use of electricity (per unit of output), by most of the industries, has actually been increasing.

The past increases in the use of electricity in the developing countries were generally due to increasing automation. As automation in the developed regions has already reached a high level and as electricity prices are expected to rise in the coming years, it is assumed that the use of electricity (per unit of output) for specific purposes will also decrease in the future, although not as fast as the use of fossil fuels. In the developing regions, where automation is expected to continue to rise, the energy intensity of manufacturing activities with respect to specific uses of electricity is assumed to be constant.

The projected changes in energy intensity of manufacturing activities in various regions are based, in general, on considerations of the present status of the technology in each region, rates of increase in industrialization (high growth allows more rapid incorporation of new technologies), and the prospects of technological improvement in line with past trends.

Thermal energy requirements of industry are, at present, normally met by direct use of fossil fuels (coal, oil, gas). The only exception is Region II, where a large fraction of the industrial steam demand is supplied by district heat systems based on both cogeneration plants and large boilers. This development has been due to central planning and considerable concentration of industry into just a few industrial centers. Application of such district heat systems in Region II is expected to grow further, because of the economic use of low-grade fuels in such systems. Other regions are also expected to employ such centralized heat supply systems to some extent, even though their industries are relatively more widely scattered. Similarly, the decentralized use of cogeneration systems in industrial plants is expected to increase in Region III and to be applied in other regions. Other energy-saving technologies, such as soft solar devices and (electric) heat 
pumps, are generally not in use now in any region. They, too, are expected to be applied more heavily as the capital cost of such systems reduces with research and development, and mass production. Electricity use for thermal processes is assumed to increase only modestly above present-day levels; although it is a very clean, efficient and easy-tohandle form of energy, the high losses incurred in the conversion from primary fuels to secondary energy would be in conflict with the need to conserve primary fuels. Despite the penetration of alternative energy sources assumed, a large share of the thermal energy for industry will have to come from the direct use of fossil fuels even by 2030 , so that improvements in efficiency of fossil fuel appear mandatory. Some such improvements have been assumed to materialize in line with past trends.

The present use of coke per ton of pig-iron produced varies considerably from country to country. So far, the lowest consumption was achieved by the Japanese steel industry where the consumption decreased to about $390 \mathrm{~kg}$ per ton of pig-iron in 1972 (see Doernberg 1977). However, after the oil crisis, coke consumption in Japan again increased as fuel oil injections were lowered; in 1975 the consumption was $440 \mathrm{~kg}$ per ton of pigiron. Despite this short-term reversal in the trend of the Japanese steel industry, we have assumed that future technological improvement will permit reduction in coke use to about $400 \mathrm{~kg}$ per ton of pig-iron in the various world regions. The changes assumed for other parameters related to steel production are based on discussions with technologists and on interregional comparison.

\section{Transportation (Table 9.3.2)}

The evolution of the modes of freight transportation assumed to occur in the various regions is based on consideration of past trends, regional characteristics, interregional comparison, existing infrastructure, relative costs of expanding road or railway networks, and the need to promote less energy intensive modes of transportation in the future. These essentially judgmental projections were developed in the light of the above considerations. No change has been assumed (except for Region II) in the energy intensity of various freight transportation modes. This does not mean that efficiency improvements will not occur but that their effect will largely be counterbalanced by lower capacity utilization resulting from the need for quicker service.

Data for passenger transportation in the US, 1950-74 (US 1976a), indicates that the total distance traveled per person and per year has been increasing somewhat faster than the increase in per capita private consumption expenditure. Such a rapid increase has apparently been due to the greater number of cars and the rapid expansion of air travel in recent years. With car ownership practically saturated, any further increase in the average distance traveled per person and per year will mainly depend on a further increase in air travel. This is a shift away from the past trend and toward a gradual development of saturation effects in personal travel in this region. In Regions II and III as well as in the developing regions, car ownership is still far from saturation and air travel is low. Both are expected to expand in the future, resulting in a high growth of passenger transportation activity. However, some saturation effects in Region III may become apparent toward the end of the study period. The past US trend has been taken as a general guideline for projecting passenger travel in the developed Regions II and III, although some adjustments were necessary in view of the differences in travel distances, settlement patterns, and other local conditions. As for the developing countries, intercity travel (parameter $D I$ ) is assumed to increase roughly in proportion to the per capita private 
TABLE 9.3.2 Detailed scenario assumptions - transportation.

\begin{tabular}{|c|c|c|c|c|c|c|c|c|c|c|c|c|c|c|c|}
\hline \multirow[b]{2}{*}{ Variable } & \multirow[b]{2}{*}{1975} & \multicolumn{2}{|l|}{2000} & \multicolumn{2}{|c|}{2030} & \multirow[b]{2}{*}{1975} & \multicolumn{2}{|l|}{2000} & \multicolumn{2}{|l|}{2030} & \multirow[b]{2}{*}{1975} & \multicolumn{2}{|l|}{2000} & \multicolumn{2}{|l|}{2030} \\
\hline & & Low & High & Low & High & & Low & High & Low & High & & Low & High & Low & High \\
\hline
\end{tabular}

Distribution of freight transportation by mode (Group $3.2 \mathrm{~b}$ )

$\begin{array}{llcc} & \text { Region I } & & \\ \text { TRU } & 0.234 & 0.239 & 0.242 \\ (T R U L) & (0.15) & (0.12) & (0.1) \\ \text { FTRA } & 0.39 & 0.379 & 0.373 \\ (T R A E F) & (0) & (0) & (0) \\ (T R A S T F) & (0) & (0) & (0) \\ B A & 0.164 & 0.165 & 0.165 \\ \text { PIP } & 0.212 & 0.217 & 0.22 \\ & & & \\ & \text { Region } I V & & \\ \text { TRU } & 0.615 & 0.6 & 0.56 \\ (T R U L) & (0) & (0) & (0) \\ F T R A & 0.175 & 0.21 & 0.28 \\ \text { (TRAEF) } & (0.01) & (0.05) & (0.2) \\ (T R A S T F) & (0) & (0) & (0) \\ B A & 0.15 & 0.13 & 0.1 \\ \text { PIP } & 0.06 & 0.06 & 0.06\end{array}$

Region II
0.025

$0.025 \quad 0.043$

(0)

(0)

0.775

0.757

$(0.35)$

0.757
$(0.55)$

$(0.055) \quad(0.02)$

$0.05 \quad 0.05$

0.05
0.15

\section{Region $V$}

$0.45 \quad 0.56$

(0)

0.35

$(0.15)$

$(0.55)$

$\begin{array}{ll}0.08 & 0.08 \\ 0.12 & 0.08\end{array}$

(0)

0.28

$(0.3)$

$(0.15)$

0.05
$(0)$
0.75
$(0.8)$
$(0)$
0.05
0.15

Region $I I I$
0.55

0.55

(0)

$\begin{array}{cc}(0) & (0) \\ 0.3 & 0.3\end{array}$

$\begin{array}{cc}0.3 & 0.3 \\ (0.3) & (0.4)\end{array}$

(0) $\quad(0)$

$(0)$
0.1

$(0)$
0.1

$0.05 \quad 0.05$

0.55

0.3

$(0.5)$

$0)$

Region VI

$\begin{array}{cccc} & \text { Region } V I & & \\ 0.6 & 0.426 & 0.56 & 0.51 \\ (0) & (0) & (0) & (0) \\ 0.27 & 0.024 & 0.07 & 0.18 \\ (0.5) & (0.05) & (0.12) & (0.3) \\ (0) & (0) & (0) & (0) \\ 0.08 & 0.03 & 0.04 & 0.06 \\ 0.06 & 0.52 & 0.33 & 0.25\end{array}$

Energy intensity of freight transportation modes (Group 3.2c)

\begin{tabular}{|c|c|c|}
\hline & Region I & \\
\hline$D T R U$ & 400 & \\
\hline$D T R U L$ & 1,100 & no \\
\hline$D T R A F$ & 100 & \\
\hline$D B A$ & 80 & change \\
\hline \multirow[t]{2}{*}{$D P I P$} & b & \\
\hline & Region IV & \\
\hline$D T R U$ & 800 & \\
\hline DTRUL & a & no \\
\hline$D T R A F$ & 200 & \\
\hline$D B A$ & 200 & change \\
\hline$D P I P$ & b & \\
\hline
\end{tabular}

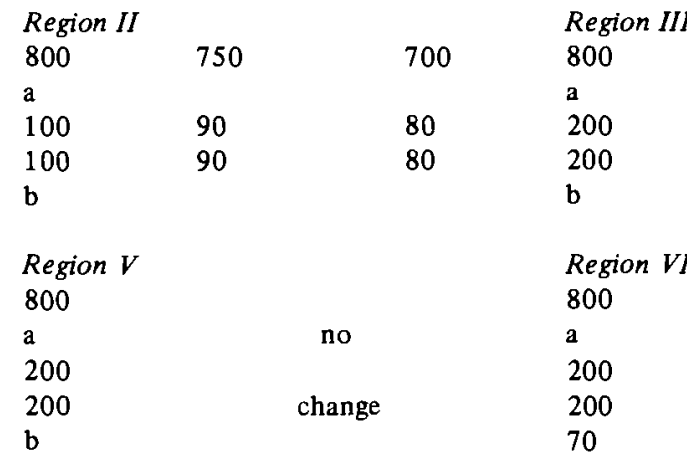

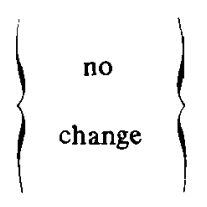

Region $V I$ 800

$\left\{\begin{array}{c}\text { no } \\ \text { change }\end{array}\right\}$




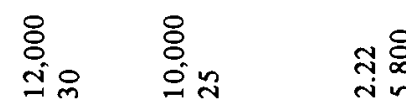

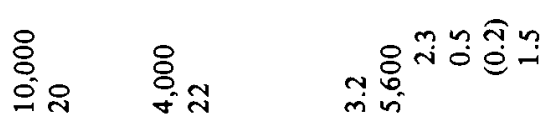

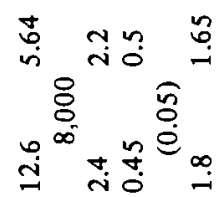

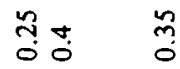

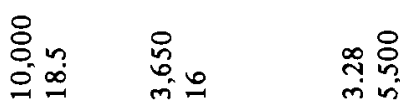

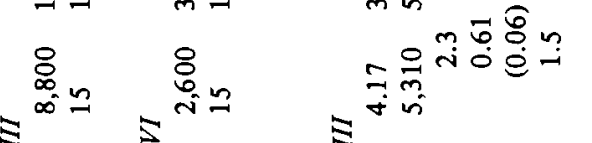

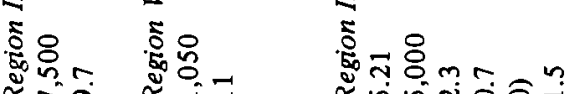

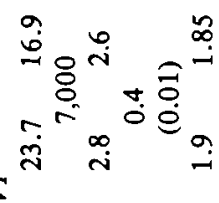

গุิ

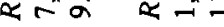

¿ัฐ

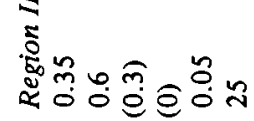

品

号

$\underset{8}{8} \stackrel{8}{=}=0$

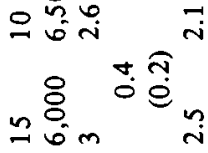

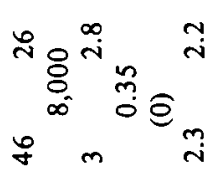

$\stackrel{n}{\sharp} \stackrel{n}{0}$

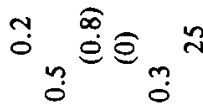

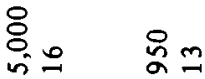

点

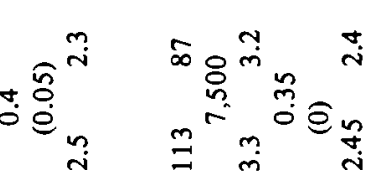

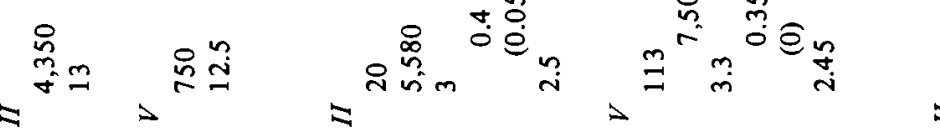

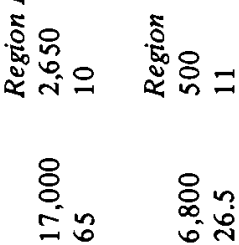

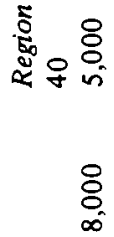

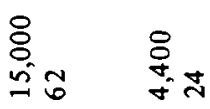

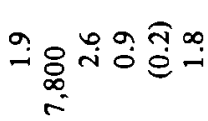

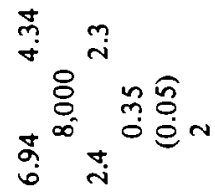

ำ

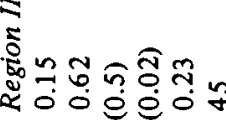

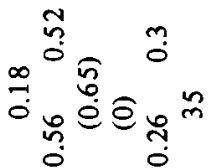

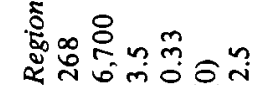

ตั

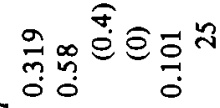


TABLE 9.3.2 Detailed scenario assumptions - transportation (continued).

\begin{tabular}{|c|c|c|c|c|c|c|c|c|c|c|c|c|c|c|c|}
\hline \multirow[b]{2}{*}{ Variable } & \multirow[b]{2}{*}{1975} & \multicolumn{2}{|l|}{2000} & \multicolumn{2}{|c|}{2030} & \multirow[b]{2}{*}{1975} & \multicolumn{2}{|l|}{2000} & \multicolumn{2}{|c|}{2030} & \multirow[b]{2}{*}{1975} & \multicolumn{2}{|c|}{2000} & \multicolumn{2}{|l|}{2030} \\
\hline & & Low & High & Low & High & & Low & High & Low & High & & Low & High & Low & High \\
\hline LFTRA & 140 & \multicolumn{2}{|c|}{140} & \multicolumn{2}{|c|}{140} & 400 & \multicolumn{2}{|c|}{300} & \multicolumn{2}{|c|}{200} & 140 & \multicolumn{2}{|c|}{140} & \multicolumn{2}{|c|}{140} \\
\hline$L F P$ & 0.5 & \multicolumn{2}{|c|}{0.57} & \multicolumn{2}{|c|}{0.6} & 0.9 & \multicolumn{2}{|c|}{0.8} & \multicolumn{2}{|c|}{0.7} & 0.6 & \multicolumn{2}{|c|}{0.6} & \multicolumn{2}{|c|}{0.6} \\
\hline$U M T$ & 0.034 & \multicolumn{2}{|c|}{0.074} & \multicolumn{2}{|c|}{0.1} & 0.6 & \multicolumn{2}{|c|}{0.6} & \multicolumn{2}{|c|}{0.6} & 0.3 & \multicolumn{2}{|c|}{0.39} & \multicolumn{2}{|c|}{0.5} \\
\hline (UMTE) & $(0.4)$ & \multicolumn{2}{|c|}{$(0.47)$} & \multicolumn{2}{|c|}{$(0.5)$} & $(0.8)$ & \multicolumn{2}{|c|}{$(0.8)$} & & & $(0.4)$ & & & & \\
\hline$L F M T B$ & 17.6 & & & & & 40 & 3 & & & & 20 & & & & \\
\hline LFMTE & 20.5 & & & & & 50 & 4 & & & & 30 & & & & \\
\hline & Region & & & & & Regior & & & & & Regior & & & & \\
\hline$P B U$ & 0.845 & 0.81 & 0.79 & 0.77 & 0.73 & 0.67 & 0.66 & 0.65 & 0.64 & 0.6 & 0.844 & 0.75 & 0.745 & 0.64 & 0.6 \\
\hline$P T R A$ & 0.107 & 0.085 & 0.09 & & & 0.314 & 0 & & & & 0.132 & & & & \\
\hline$(T R A E P)$ & $(0.01)$ & (0. & & & & $(0.15)$ & $(0$ & & & & $(0.05)$ & & & & \\
\hline (TRASTP) & $(0)$ & $(0)$ & & $(0$ & & $(0.55)$ & & & $(0$ & & $(0)$ & $(0$ & & (0 & \\
\hline$P L A$ & 0.048 & 0.105 & 0.12 & 0.16 & 0.2 & 0.016 & 0.04 & 0.05 & 0.06 & 0.1 & 0.024 & 0.04 & 0.055 & 0.06 & 0.1 \\
\hline$L F B U$ & 40 & 38 & 35 & 30 & 26 & 40 & 39 & 38 & 35 & 30 & 40 & 35 & 34 & 30 & 25 \\
\hline$L F T R A$ & 500 & 3 & & 250 & 200 & 500 & 480 & 450 & 400 & 350 & 500 & 375 & 350 & 250 & 200 \\
\hline$L F P$ & 0.6 & 0. & & & & 0.8 & 0 & & & & 0.75 & & & & \\
\hline (UMTE) & $(0.05)$ & $(0$ & & & & $(0.03)$ & & & & & $(0.02)$ & & 35) & & \\
\hline$L F M T B$ & 50 & 45 & 40 & 40 & 30 & 50 & 48 & 45 & 40 & 35 & 50 & 42 & 38 & 35 & 25 \\
\hline$L F M T E$ & 60 & 55 & 48 & 45 & 35 & 60 & 55 & 52 & 45 & 40 & 60 & 52 & 48 & 40 & 35 \\
\hline
\end{tabular}


Specific energy consumption of passenger transportation modes (Group 3.2g)

\begin{tabular}{|c|c|c|c|c|c|c|c|c|c|c|}
\hline & \multicolumn{3}{|c|}{ Region I } & \multicolumn{3}{|c|}{ Region II } & \multicolumn{4}{|c|}{ Region III } \\
\hline GIC & 14 & 6.5 & 6.2 & 12 & 7.5 & 8 & 9 & 8.5 & 6.2 & 6 \\
\hline$G U C$ & 19.6 & 8.9 & $8.5 \quad 7$. & 14 & $11.6 \quad 9.5$ & $10 \quad 8$ & 11 & 10 & 8.5 & 7.5 \\
\hline$E L U C$ & 0.25 & 0.25 & 0.25 & 0.25 & 0.25 & 0.25 & 0.25 & 0.25 & \multicolumn{2}{|c|}{0.25} \\
\hline$D B U$ & 39 & 39 & 39 & 35 & 33 & 30 & 40 & 40 & \multicolumn{2}{|c|}{40} \\
\hline$D T R A P$ & 42,790 & 42,790 & 42,790 & 22,750 & 20,000 & 18,000 & 20,000 & 20,000 & \multicolumn{2}{|c|}{20,000} \\
\hline$D P L A$ & 691 & 565 & 500 & 800 & 700 & 600 & 700 & 700 & \multicolumn{2}{|c|}{700} \\
\hline$D M T$ & 50 & 50 & 50 & 40 & 37 & 35 & 60 & 60 & \multicolumn{2}{|c|}{60} \\
\hline$E L M T$ & 3.4 & 3.4 & 3.4 & 3.4 & 3.4 & 3.4 & 3.4 & 3.4 & \multicolumn{2}{|c|}{3.4} \\
\hline & \multicolumn{3}{|c|}{ Region IV } & \multicolumn{3}{|c|}{ Region $V$} & \multicolumn{4}{|c|}{ Region VI } \\
\hline GIC & 9 & 8 & 8 & 9 & 8 & 8 & 11.5 & 8.5 & & \\
\hline$G U C$ & 12 & 10.5 & 10.5 & 12 & 10.5 & 10.5 & 14.5 & 10.7 & & \\
\hline$E L U C$ & 0.25 & 0.25 & 0.25 & 0.25 & 0.25 & 0.25 & 0.25 & 0.25 & & \\
\hline$D B U$ & 40 & 40 & 40 & 40 & 40 & 40 & 40 & 40 & 4 & \\
\hline$D T R A P$ & 20,000 & 20,000 & 20,000 & 20,000 & 20,000 & 20,000 & 20,000 & 20,000 & & \\
\hline$D P L A$ & 700 & 700 & 700 & 700 & 700 & 700 & 700 & 700 & & \\
\hline$D M T$ & 60 & 60 & 60 & 60 & 60 & 60 & 60 & 60 & 6 & \\
\hline$E L M T$ & 3.4 & 3.4 & 3.4 & 3.4 & 3.4 & 3.4 & 3.4 & 3.4 & & \\
\hline
\end{tabular}

NOTE: Values in parentheses are to be interpreted as fractions of the preceding category.

a: Separate data were not available.

b: Corresponding energy consumption accounted for elsewhere.

${ }^{a}$ Distance traveled per person per year, intercity (applies to the total population).

$b$ Distance traveled per person per day, intracity (applies only to the population of large cities). 
consumption expenditure. The relative increase in urban travel is assumed to be lower than that in intercity travel for all the regions, except for Region III where the current trend of suburban expansion is expected to continue.

Among the parameters related to car travel (Group 3.2e), car ownership (i.e., the inverse of parameter $C O$ ) is assumed to increase in the developing regions in proportion to both GDP per capita and the fraction of population living in urban areas. Relatively lower growth rates of car ownership are assumed for the developed regions where saturation effects are expected to play a varying role. The share of cars in urban travel is assumed to decrease or remain constant in the developed regions due to the promotion of mass transit systems. In the developing regions, the increase in car ownership would favor a heavier use of cars for urban travel, but road congestion in the overcrowded cities would have the opposite effect. Thus a significant increase in the use of cars for urban travel is assumed only for Region VI, where enough resources are available to modernize the road network. Load factors of cars are expected to decrease with increasing car ownership almost everywhere, particularly in the developing regions. Some use of electric cars for urban travel, to varying extents in different regions, is also envisaged in the future.

The scenario assumptions about various modes of intercity and urban travel (Groups $3.2 \mathrm{e}$ and $3.2 \mathrm{f}$ ) are based on considerations similar to those discussed in connection with modes of freight transportation. Additional factors, such as personal convenience, flexibility, and speed of travel were also accounted for by the mass transit modes chosen; the share of airplanes in intercity travel is assumed to increase everywhere. The share of intercity buses, on the other hand, is expected to decrease in all regions except in Region II. The load factors of mass transit modes (except for airplanes) are assumed to remain constant in Regions I and III, where they are already quite low. In all the other regions, they are assumed to decrease from the present high level to relatively more comfortable standards as the service will certainly be improved with further development in these regions.

The specific energy consumption of cars is expected to go down in all the regions, due to rising gasoline prices and the initiation of fuel economy standards in several countries. The assumed drop in future fuel consumption is most strongly pronounced in Region I, where present automobile fuel consumption is very high, compared to that in other regions. Significant reductions in the energy intensity of airplanes are also expected in Regions $I$ and II, in view of the importance of domestic air travel in these regions. Such reductions in other regions, though probable, have not been taken into account, since the share of air travel in intercity travel in Regions III through VI is much smaller than in Regions I and II. The specific energy consumption of other passenger transport modes in Regions I and III and the respective load factors were held constant in the present assessment. One should expect vehicle efficiencies to improve and the load factors to decline further; since the two effects would thus partly balance each other they were not considered separately. In the developing regions a trend towards larger vehicles was assumed to offset improvements in vehicle efficiencies. In Region II, improvements in these modes were considered after discussions with experts from this region, where reliance on mass transit and trains in particular, counts more heavily than in the other regions.

III Households and Services (Table 9.3.3)

As mentioned in Part III of Section 5.1.3, a large number of parameters are used in MEDEE-2 to conceptualize the likely evolution of energy consumption associated with various activities in the household/service sector. The scenario assumptions concerning 
TABLE 9.3.3 Detailed scenario assumptions - household/service sector.

\begin{tabular}{|c|c|c|c|c|c|c|c|c|c|c|c|c|c|c|c|}
\hline \multirow[b]{2}{*}{ Variable } & \multirow[b]{2}{*}{1975} & \multicolumn{2}{|l|}{2000} & \multicolumn{2}{|l|}{2030} & \multirow[b]{2}{*}{1975} & \multicolumn{2}{|l|}{2000} & \multicolumn{2}{|l|}{2030} & \multirow[b]{2}{*}{1975} & \multicolumn{2}{|l|}{2000} & \multicolumn{2}{|l|}{2030} \\
\hline & & Low & High & Low & High & & Low & High & Low & High & & Low & High & Low & High \\
\hline \multicolumn{16}{|c|}{ Factors affecting useful energy consumption (i) (Group 3.3b) } \\
\hline & \multicolumn{5}{|c|}{ Region I } & \multicolumn{5}{|c|}{ Region II } & \multicolumn{5}{|c|}{ Region III } \\
\hline$C O O K D W$ & 1,000 & \multicolumn{2}{|c|}{1,000} & \multicolumn{2}{|c|}{1,000} & 1,000 & \multicolumn{2}{|c|}{1,000} & \multicolumn{2}{|c|}{1,000} & 1,100 & \multicolumn{2}{|c|}{1,100} & \multicolumn{2}{|c|}{1,100} \\
\hline$D W H W$ & 1 & \multicolumn{2}{|c|}{1} & \multicolumn{2}{|c|}{1} & 0.6 & 0.75 & 0.8 & 0.9 & 1 & 0.7 & 0.9 & 1 & 1 & \\
\hline$H W C A P$ & 1,500 & \multicolumn{2}{|c|}{1,500} & & & 700 & \multicolumn{2}{|c|}{860} & \multicolumn{2}{|c|}{1,000} & 700 & 900 & 1,060 & 1,100 & 1,400 \\
\hline$D W A C$ & 0.39 & 0.46 & 0.51 & 0.5 & 0.6 & 0 & 0.05 & 0.1 & 0.15 & 0.2 & 0 & 0.1 & 0.14 & 0.2 & 0.3 \\
\hline$A C D W$ & 4,472 & & 60 & & & 2,000 & 2,0 & & 2,0 & & 3,000 & 3, & & 3,0 & \\
\hline$E L A P D W$ & 3,850 & 5,300 & 6,210 & 6,250 & 8,000 & 880 & 2,100 & 2,900 & 3,000 & 5,000 & 1,950 & 3,270 & 3,680 & 4,500 & 6,000 \\
\hline PREDW (1) & 0.48 & 0 & & 0. & & 0.05 & 0.0 & & 0. & & 0.1 & 0.2 & 0.26 & 0.3 & 0.4 \\
\hline PREDW (2) & 0.32 & 0 . & & 0. & & 0.35 & 0.4 & & 0.8 & & 0.2 & 0.36 & 0.38 & 0.5 & 0.55 \\
\hline PREDW (3) & 0.2 & 0 . & & 0 & & 0.6 & 0.5 & & 0.0 & & 0.7 & 0. & & 0.2 & 0.05 \\
\hline$A R E A H$ & 0.8 & 0 . & & 0 & & 1 & 1 & & 1 & & 0.7 & 0. & & 0.7 & \\
\hline$E L A R O$ & 120 & 126 & 131 & 130 & 150 & 40 & 50 & 60 & 60 & 80 & 40 & 50 & 60 & 60 & 80 \\
\hline$A R E A A C$ & 0.55 & 0.65 & 0.69 & 0.7 & 0.8 & 0 & 0.07 & 0.15 & 0.2 & 0.3 & 0.05 & 0.1 & 0.15 & 0.15 & 0.2 \\
\hline$A C A R E A$ & 70 & 70 & & 70 & & 70 & 70 & & 70 & & 70 & 70 & & 70 & \\
\hline$E F F A C$ & 2 & 2 & & 2 & & 2 & 2 & & 2 & & 2 & 2 & & 2 & \\
\hline & Region I & & & & & Region $V$ & & & & & Region & & & & \\
\hline COOKDW & 1,600 & & & & & 1,000 & 1,0 & & & & 1,600 & & & 1,8 & \\
\hline$D W H W$ & 0.2 & 0 & & 0 & & 0.1 & 0.12 & 0.13 & 0.14 & 0.16 & 0.6 & 0.9 & 0.95 & 1 & \\
\hline$H W C A P$ & 400 & 600 & 650 & 750 & 1,000 & 40 & 60 & 70 & 100 & 140 & 60 & 175 & 200 & 300 & 400 \\
\hline$D W A C$ & 0 & 0.04 & 0.05 & 0.12 & 0.2 & 0 & 0.002 & 0.004 & 0.006 & 0.012 & 0.01 & 0.06 & 0.1 & 0.2 & 0.3 \\
\hline$A C D W$ & 1,500 & 2,000 & 2,500 & 2,600 & 3,500 & 1,500 & 2,0 & & & & 2,000 & 2,600 & 3,000 & 3,000 & 4,000 \\
\hline$E L A P D W$ & 700 & 1,200 & 1,700 & 2,150 & 3,400 & 50 & 115 & 150 & 255 & 485 & 200 & 705 & 942 & 1,209 & 3,300 \\
\hline PREDW (1) & 0.08 & 0 & & 0. & & na & & & & & 0.01 & 0.014 & 0.018 & 0.02 & 0.03 \\
\hline PREDW (2) & 0.16 & 0. & & 0. & & na & & & & & 0.05 & 0.09 & 0.1 & 0.15 & 0.2 \\
\hline PREDW (3) & 0.56 & 0 & & 0 & & 0.35 & 0.4 & 0.45 & 0.55 & 0.65 & 0.4 & 0.6 & 0.75 & 0.82 & 0.77 \\
\hline$A R E A H$ & 0.8 & 0.85 & 0.87 & 0.95 & 1 & 0.35 & 0.45 & 0.6 & 0.65 & 0.95 & 0.7 & 0.9 & 0.95 & 1 & \\
\hline$E L A R O$ & 25 & 35 & 40 & 40 & 50 & 15 & 20 & 21 & 25 & 30 & 15 & 30 & 35 & 40 & 50 \\
\hline$A R E A A C$ & 0.05 & 0.12 & 0.15 & 0.35 & 0.4 & 0 & 0.005 & 0.01 & 0.02 & 0.05 & 0.04 & 0.15 & 0.2 & 0.3 & 0.5 \\
\hline$A C A R E A$ & 70 & 70 & & 70 & & 70 & 70 & & 70 & & 70 & 70 & & 70 & \\
\hline$E F F A C$ & 2 & 2 & & 2 & & 2 & 2 & & 2 & & 2 & 2 & & 2 & \\
\hline
\end{tabular}


TABLE 9.3.3 Detailed scenario assumptions - household/service sector (continued).

\begin{tabular}{|c|c|c|c|c|c|c|c|c|c|c|c|c|c|c|c|}
\hline \multirow[b]{2}{*}{ Variable } & \multirow[b]{2}{*}{1975} & \multicolumn{2}{|l|}{2000} & \multicolumn{2}{|l|}{2030} & \multirow[b]{2}{*}{1975} & \multicolumn{2}{|l|}{2000} & \multicolumn{2}{|l|}{2030} & \multirow[b]{2}{*}{1975} & \multicolumn{2}{|l|}{2000} & \multicolumn{2}{|l|}{2030} \\
\hline & & Low & High & Low & High & & Low & High & Low & High & & Low & High & Low & High \\
\hline
\end{tabular}

Factors affecting useful energy consumption (ii) (Group 3.3c)

\begin{tabular}{|c|c|c|c|c|c|c|c|c|c|c|c|c|c|c|c|c|}
\hline \multirow{3}{*}{$\begin{array}{l}\text { DEMDW } \\
N E W D W(1)\end{array}$} & \multicolumn{5}{|c|}{ Region I } & \multicolumn{5}{|c|}{ Region II } & \multicolumn{6}{|c|}{ Region III } \\
\hline & na & \multicolumn{2}{|c|}{0.02} & \multicolumn{2}{|c|}{0.02} & na & \multicolumn{2}{|c|}{0.045} & \multicolumn{2}{|c|}{0.045} & \multirow{2}{*}{ na } & \multirow{2}{*}{\multicolumn{2}{|c|}{$\begin{array}{l}0.03 \\
0.35\end{array}$}} & \multicolumn{3}{|c|}{0.03} \\
\hline & na & \multicolumn{2}{|c|}{0.6} & \multicolumn{2}{|c|}{0.6} & na & 0.2 & 0.25 & 0.2 & 0.3 & & & & \multicolumn{3}{|c|}{0.35} \\
\hline$N E W D W(2)$ & na & \multicolumn{2}{|c|}{0.4} & \multicolumn{2}{|c|}{0.4} & na & 0.6 & 0.63 & 0.6 & 0.65 & na & \multicolumn{2}{|c|}{$\begin{array}{l}0.35 \\
0.5\end{array}$} & \multicolumn{3}{|c|}{0.5} \\
\hline$N E W D W(3)$ & na & \multicolumn{2}{|c|}{ a } & \multicolumn{2}{|c|}{ a } & na & 0.2 & 0.12 & 0.2 & 0.05 & na & \multicolumn{2}{|c|}{0.15} & \multicolumn{3}{|c|}{0.15} \\
\hline$D W S(1)$ & na & & & & & na & \multicolumn{2}{|c|}{80} & \multicolumn{2}{|c|}{100} & na & \multicolumn{2}{|c|}{98} & 11 & & \\
\hline$D W S(2)$ & na & 8 & & 9 & & na & 62 & & 8 & & na & 7 & & 80 & & \\
\hline$D W S(3)$ & na & a & & $a$ & & na & 67 & & 8 & & na & 8 & & 95 & & \\
\hline$K(1)$ & na & 1 & & 1 & & na & 1.8 & & 1 & & na & 1 & & 1. & & \\
\hline$K(2)$ & na & 1 & & 1 & & na & 1. & & 1 & & na & 1 & & 1. & & \\
\hline$K(3)$ & na & a & & $a$ & & na & 0.8 & & 0 & & na & 0 & & 0. & & \\
\hline ISO (1) & 0 & & & 0 & & 0 & 0. & & 0 & & 0 & & & 0. & & \\
\hline ISO (2) & 0 & & & 0 & & 0 & 0. & & 0 & & 0 & & & 0. & & \\
\hline ISO (3) & 0 & 0 & & 0 & & 0 & 0. & & 0 & & 0 & & & 0. & & \\
\hline$A R E A L$ & na & 44 & 46.1 & 45 & 48 & na & 37 & 38 & 45 & 50 & na & 30 & 31 & 32 & 35 & \\
\hline$D E M A R$ & na & & & & & na & 0. & & & & na & & & 0 & & \\
\hline$H A R E A N$ & na & & & & & $\mathrm{na}$ & 17 & & & & na & & & 12 & & \\
\hline$E L A R N$ & na & 140 & 150 & 140 & 150 & na & 70 & 80 & 80 & 100 & na & 90 & 94 & 100 & 110 & \\
\hline$I S O S V$ & 0 & & & 0 & & 0 & 0 & & & & 0 & & & 0 & & \\
\hline & $\operatorname{Reg}$ & & & & & $\operatorname{Reg}$ & & & & & $R e_{\varepsilon}$ & & & & & \\
\hline$D E M D W$ & na & 0.01 & 0.015 & 0.015 & 0.025 & na & 0.007 & 0.01 & 0.012 & 0.02 & na & 0.01 & 0.02 & 0.025 & 0.03 & \\
\hline$N E W D W(1)$ & na & & & 0 & & na & a & & a & & na & 0.02 & 0.03 & 0.035 & 0.05 & $>$ \\
\hline$N E W D W(2)$ & na & 0.28 & 0.36 & 0.4 & 0.52 & na & $\mathbf{a}$ & & $\mathbf{a}$ & & na & 0.15 & 0.2 & 0.25 & 0.4 & 3 \\
\hline$N E W D W(3)$ & na & 0.36 & 0.32 & & & na & 0.5 & 0.6 & 0.8 & 1 & na & 0.65 & 0.75 & 0.715 & 0.55 & 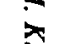 \\
\hline$D W S(1)$ & na & & & 1 & & na & a & & a & & па & & & 12 & & a \\
\hline$D W S(2)$ & na & 8 & & 9 & & na & a & & $\mathbf{a}$ & & na & 7 & & 90 & & 5 \\
\hline$D W S$ (3) & na & 4 & & 4 & & na & 26 & & 3 & & na & 3 & & 40 & & $?$ \\
\hline$K(1)$ & na & 2 & & 2 & & na & a & & a & & na & & & 2. & & s: \\
\hline$K(2)$ & na & 2 & & 2 & & na & $\mathbf{a}$ & & a & & na & & & 2 & & $\underline{N}$ \\
\hline$K(3)$ & na & 2 & & 2 & & na & 3 & & 3 & & na & 3 & & 3 & & \\
\hline
\end{tabular}


n̊ำ

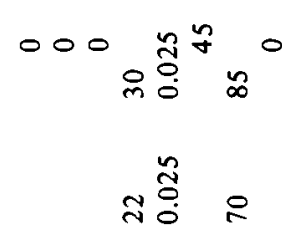

$000 \stackrel{4}{0}^{m} 8$

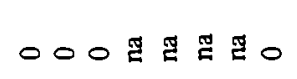

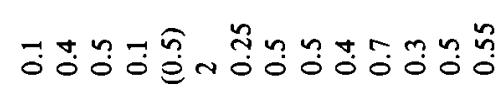

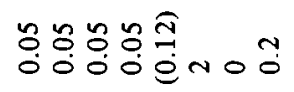

$\infty \stackrel{0}{0} 0$

- $\frac{0^{\circ}}{\pi}$

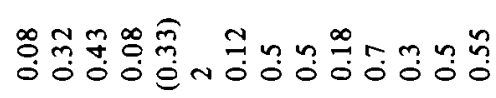

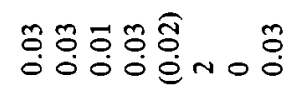

$\Xi$

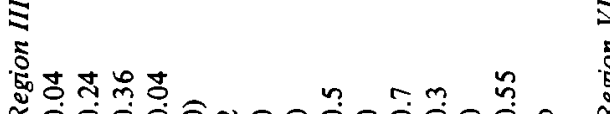

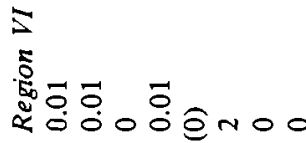

$=\ddot{\circ} \quad 8$

- ${ }_{1}^{\circ} \stackrel{0}{\circ}$

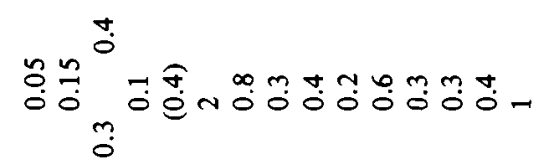

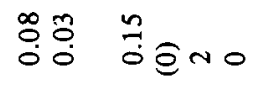

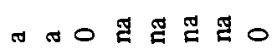

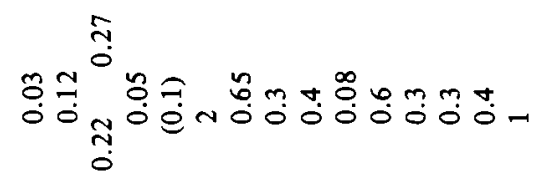

m̊̊

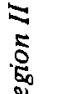

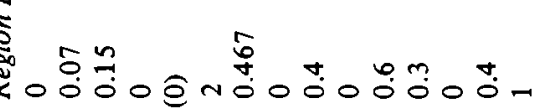

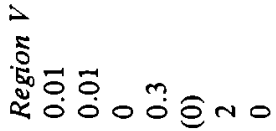

nn $\stackrel{0}{0} 8$

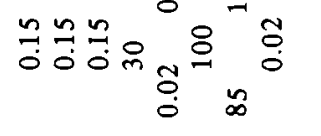

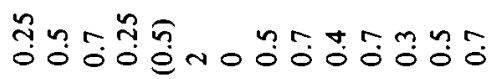

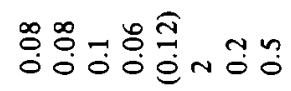

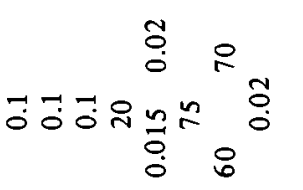

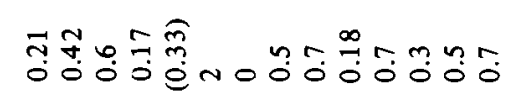

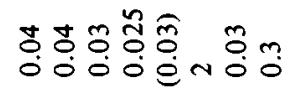

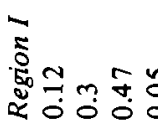

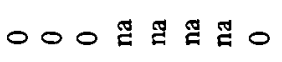

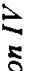

ชั่

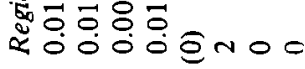

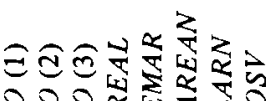

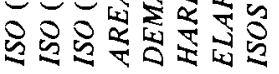

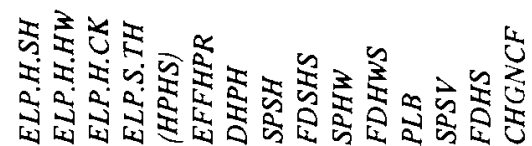

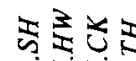

过这的的

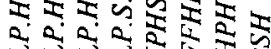

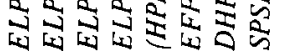


TABLE 9.3.3 Detailed scenario assumptions - household/service sector (continued).

\begin{tabular}{|c|c|c|c|c|c|c|c|c|c|}
\hline Variable & 1975 & 2000 & 2030 & 1975 & 2000 & 2030 & 1975 & 2000 & 2030 \\
\hline$F D S H S$ & 0.8 & 0.8 & 0.8 & 0.8 & 0.8 & 0.8 & 0.8 & 0.8 & 0.8 \\
\hline$S P H W$ & 0 & 0.2 & 0.3 & 0 & 0.1 & 0.3 & 0 & 0.02 & 0.15 \\
\hline$F D H W S$ & 0.8 & 0.8 & 0.8 & 0.8 & 0.8 & 0.8 & 0.8 & 0.8 & 0.8 \\
\hline$P L B$ & 0.3 & 0.3 & 0.3 & 0.7 & 0.6 & 0.5 & 0.7 & 0.6 & 0.5 \\
\hline$S P S V$ & 0 & 0.3 & 0.5 & 0 & 0.2 & 0.5 & 0 & 0.03 & 0.2 \\
\hline$F D H S$ & 0.8 & 0.8 & 0.8 & 0.8 & 0.8 & 0.8 & 0.8 & 0.8 & 0.8 \\
\hline$C H G N C F$ & 1 & 1 & 1 & 1 & 1 & 1 & 1 & 1 & 1 \\
\hline \multicolumn{10}{|c|}{ Fossil fuel efficiencies (relative to electricity) (Group 3.3e) } \\
\hline & Region I & & & Region & & & Regior & & \\
\hline EFF.H.SH & 0.63 & 0.73 & 0.8 & 0.59 & 0.63 & 0.65 & 0.63 & 0.665 & 0.7 \\
\hline EFF.H.HW & 0.57 & 0.65 & 0.7 & 0.49 & 0.53 & 0.55 & 0.57 & 0.585 & 0.6 \\
\hline EFF.H.CK & 0.41 & 0.46 & 0.5 & 0.4 & 0.45 & 0.5 & 0.51 & 0.529 & 0.55 \\
\hline EFF.S.TH & 0.7 & 0.76 & 0.8 & 0.59 & 0.63 & 0.65 & 0.7 & 0.725 & 0.75 \\
\hline \multirow[t]{2}{*}{ EFFNCF } & $\mathbf{a}$ & & & 0.3 & & & $\mathbf{a}$ & & \\
\hline & Region IV & & & Region & & & Regior & & \\
\hline$E F F . H . S H$ & 0.6 & 0.63 & 0.7 & 0.5 & 0.53 & 0.6 & 0.6 & 0.63 & 0.7 \\
\hline EFF.H.HW & 0.55 & 0.58 & 0.65 & 0.5 & 0.53 & 0.6 & 0.55 & 0.58 & 0.65 \\
\hline EFF.H.CK & 0.5 & 0.51 & 0.55 & 0.5 & 0.51 & 0.55 & 0.5 & 0.51 & 0.55 \\
\hline EFF.S.TH & 0.65 & 0.68 & 0.75 & 0.55 & 0.58 & 0.65 & 0.6 & 0.63 & 0.7 \\
\hline EFFNCF & 0.075 & 0.09 & 0.15 & 0.075 & 0.085 & 0.12 & 0.075 & 0.085 & 0.12 \\
\hline
\end{tabular}

na: Not applicable.

a: Category not included for this region.

b: Noncommercial fuels not considered in Regions I and III.

NOTE: Values in parentheses are to be interpreted as fractions of the preceding category. 
the changes in the values of the various parameters in 2000 and 2030 in relation to those in 1975 are detailed in Table 9.3.3 for both the High and the Low scenarios. Some general considerations underlying these assumptions and largely applicable to all the regions are:

(1) A continued trend towards a relatively more comfortable living (e.g., larger houses, more central heating, more air-conditioning, more hot water, additional electrical appliances in households, etc.) and provision of better amenities in the service sector (e.g., through increased supply of space/water heating, air-conditioning, lighting, and electrical equipment) with increasing levels of GDP per capita.

(2) Increasing shares of electricity with time (and affluence) in the provision of thermal energy requirements (cooking, space/water heating) of households and services, in line with past trends.

(3) Increasing emphasis on improved insulation of buildings, both new and old, in regions where space heating is an important energy-consuming activity.

(4) Gradual introduction of soft solar devices for space and water heating in both households and service sector buildings leading to a considerable buildup by 2030 .

(5) Some improvement in the fossil fuel efficiencies of various thermal devices and, in addition, gradual introduction of heat pumps in places where electricity is to be used for supplying thermal energy.

(6) Introduction or increased use of district heat in regions where settlement patterns and energy requirements favor district heating systems.

(7) Saturation of energy requirements of certain activities, e.g., of cooking energy per dwelling, or of useful thermal energy per $\mathrm{m}^{2}$ of floor area under given climatic conditions.

Although regional characteristics, such as climatic conditions, people's cooking and living habits, construction styles of buildings, etc., have to be taken into account in projecting the likely evolution of various parameters, considerable insight, at least in respect of regions at lower levels of GDP per capita, may be obtained by comparing the base year data (or estimated base year values of various parameters) of different regions at various stages of development. Our projections of scenario parameters draw heavily upon such interregional comparisons.

Noncommercial fuels play an important role in meeting the household energy requirements of the developing regions, particularly of Regions IV and V. Among the developed regions, only Region II has a significant contribution of noncommercial fuels. Although the use of such fuels, particularly that of firewood obtained by indiscriminate cutting of forests, has recently been increasing in the developing regions, we believe that measures will soon be adopted to check this deforestation problem. Accordingly, it has been assumed that the use of noncommercial fuels in the various regions, including Region II, will not be significantly different in 2000 and 2030 from 1975 . However, the efficiency in using such fuels is assumed to increase in the developing regions by as much as a factor of 2 , due to the introduction of better stoves and other devices in rural areas.

\subsection{Projected Final Energy Demand}

This section is devoted to the salient features of the final energy demand projected for the years 2000 and 2030 in the various world regions, resulting from the detailed scenario assumptions spelled out in Tables 9.1-9.3 and briefly reviewed in Section 5.2. 
The evolution of final energy demand in Regions I through VI in the High and the Low scenarios is shown in the projections in Table 10, also incorporating the share of electricity in final energy demand. It is worth noting that the demand for final energy rises much more rapidly in the developing regions than in the developed regions. In the

TABLE 10 Final energy in the two scenarios (TWyr/yr).

\begin{tabular}{|c|c|c|c|c|c|}
\hline \multirow[b]{3}{*}{ Region } & \multirow[b]{3}{*}{1975} & \multicolumn{4}{|c|}{ Projections } \\
\hline & & \multicolumn{2}{|c|}{ High scenario } & \multicolumn{2}{|c|}{ Low scenario } \\
\hline & & 2000 & 2030 & 2000 & 2030 \\
\hline $\begin{array}{l}\text { I (NA) } \\
\text { (\% elec.) }\end{array}$ & $\begin{array}{l}1.87 \\
(12)\end{array}$ & $\begin{array}{l}2.63 \\
(18)\end{array}$ & $\begin{array}{l}3.67 \\
(20)\end{array}$ & $\begin{array}{l}2.26 \\
(18)\end{array}$ & $\begin{array}{l}2.64 \\
(21)\end{array}$ \\
\hline $\begin{array}{r}\text { II (SU/EE) } \\
\text { (\% elec.) }\end{array}$ & $\begin{array}{l}1.28 \\
(10)\end{array}$ & $\begin{array}{l}2.39 \\
(17)\end{array}$ & $\begin{array}{l}4.11 \\
(23)\end{array}$ & $\begin{array}{l}2.17 \\
(16)\end{array}$ & $\begin{array}{l}2.95 \\
(20)\end{array}$ \\
\hline $\begin{array}{c}\text { III (WE/JANZ) } \\
(\% \text { elec.) }\end{array}$ & $\begin{array}{l}1.59 \\
(13)\end{array}$ & $\begin{array}{l}3.04 \\
(17)\end{array}$ & $\begin{array}{l}4.38 \\
(21)\end{array}$ & $\begin{array}{l}2.39 \\
(17)\end{array}$ & $\begin{array}{l}2.99 \\
(21)\end{array}$ \\
\hline $\begin{array}{l}\text { IV (LA) } \\
\text { (\% elec.) }\end{array}$ & $\begin{array}{l}0.25 \\
(10)\end{array}$ & $\begin{array}{l}1.00 \\
(12)\end{array}$ & $\begin{array}{l}2.64 \\
(15)\end{array}$ & $\begin{array}{l}0.73 \\
(12)\end{array}$ & $\begin{array}{l}1.66 \\
(16)\end{array}$ \\
\hline $\begin{array}{c}\mathrm{V}(\mathrm{Af} / \mathrm{SEA}) \\
\text { (\% elec.) }\end{array}$ & $\begin{array}{r}0.25 \\
(9)\end{array}$ & $\begin{array}{l}1.06 \\
(13)\end{array}$ & $\begin{array}{l}3.17 \\
(16)\end{array}$ & $\begin{array}{l}0.80 \\
(12)\end{array}$ & $\begin{array}{l}1.88 \\
(15)\end{array}$ \\
\hline $\begin{array}{l}\text { VI (ME/NAf) } \\
\text { (\% elec.) }\end{array}$ & $\begin{array}{r}0.11 \\
(4)\end{array}$ & $\begin{array}{l}0.58 \\
(12)\end{array}$ & $\begin{array}{l}1.64 \\
(17)\end{array}$ & $\begin{array}{l}0.43 \\
(12)\end{array}$ & $\begin{array}{l}0.87 \\
(15)\end{array}$ \\
\hline I $+{ }_{(\% \text { elec. })}^{\text {IlI }}$ & $\begin{array}{l}3.46 \\
(12)\end{array}$ & $\begin{array}{l}5.66 \\
(17)\end{array}$ & $\begin{array}{l}8.04 \\
(21)\end{array}$ & $\begin{array}{l}4.65 \\
(17)\end{array}$ & $\begin{array}{l}5.62 \\
(21)\end{array}$ \\
\hline $\begin{array}{c}\mathrm{IV}+\mathrm{V}+\mathrm{VI} \\
\text { (\% elec.) }\end{array}$ & $\begin{array}{r}0.61 \\
(8)\end{array}$ & $\begin{array}{l}2.65 \\
(12)\end{array}$ & $\begin{array}{l}7.45 \\
(16)\end{array}$ & $\begin{array}{l}1.97 \\
(12)\end{array}$ & $\begin{array}{l}4.40 \\
(15)\end{array}$ \\
\hline $\begin{array}{l}\text { Total } \\
\text { (\% elec.) }\end{array}$ & $\begin{array}{l}5.35 \\
(11)\end{array}$ & $\begin{array}{l}10.69 \\
(16)\end{array}$ & $\begin{array}{l}19.61 \\
(19)\end{array}$ & $\begin{array}{l}8.79 \\
(16)\end{array}$ & $\begin{array}{l}12.98 \\
(19)\end{array}$ \\
\hline
\end{tabular}

High scenario, 1975-2030, the demand is projected to increase by factors of 10.6 to 14.9 for the developing regions IV, V, and VI, but by factors of only 2.0 to 3.2 for the developed regions I, II, and III. The corresponding increases in the Low scenario are by factors of 6.6 to 7.9 and 1.4 to 2.3 , respectively. Among the developing regions, the highest increase in final energy consumption in both the scenarios is projected to occur in Region VI, which had also been assigned higher economic growth (relative to the 1975 level) than Regions IV and V (see Table 3). Similarly, among the developed regions, Region II which was assigned the highest relative increases in economic development in the basic scenario definitions of Table 3 - is the region projected to have the largest increases in final energy consumption as shown in Table 10.

The share of electricity in final energy is projected to grow in all the world regions in both scenarios, reaching by $203020-23$ percent in the developed regions (10-13 percent in 1975) and 15-17 percent in the developing regions (4-10 percent in 1975). The evolutions over time of the fractional shares of electricity, district heat, soft solar, substitutable fossil fuels, etc., in the final energy demand of different regions, are shown in Figure 6 for the High scenario. The distributions for the Low scenario are very similar 


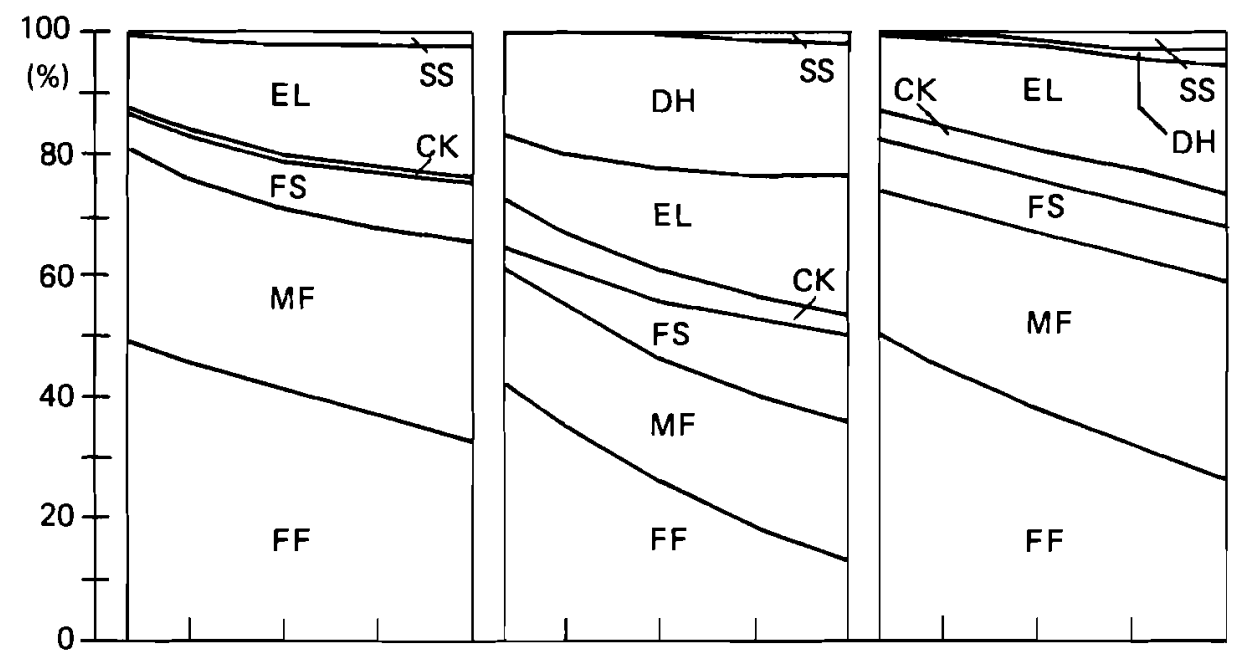

$\begin{array}{lll}\text { Region } 1 & \text { Region II } & \text { Region III }\end{array}$

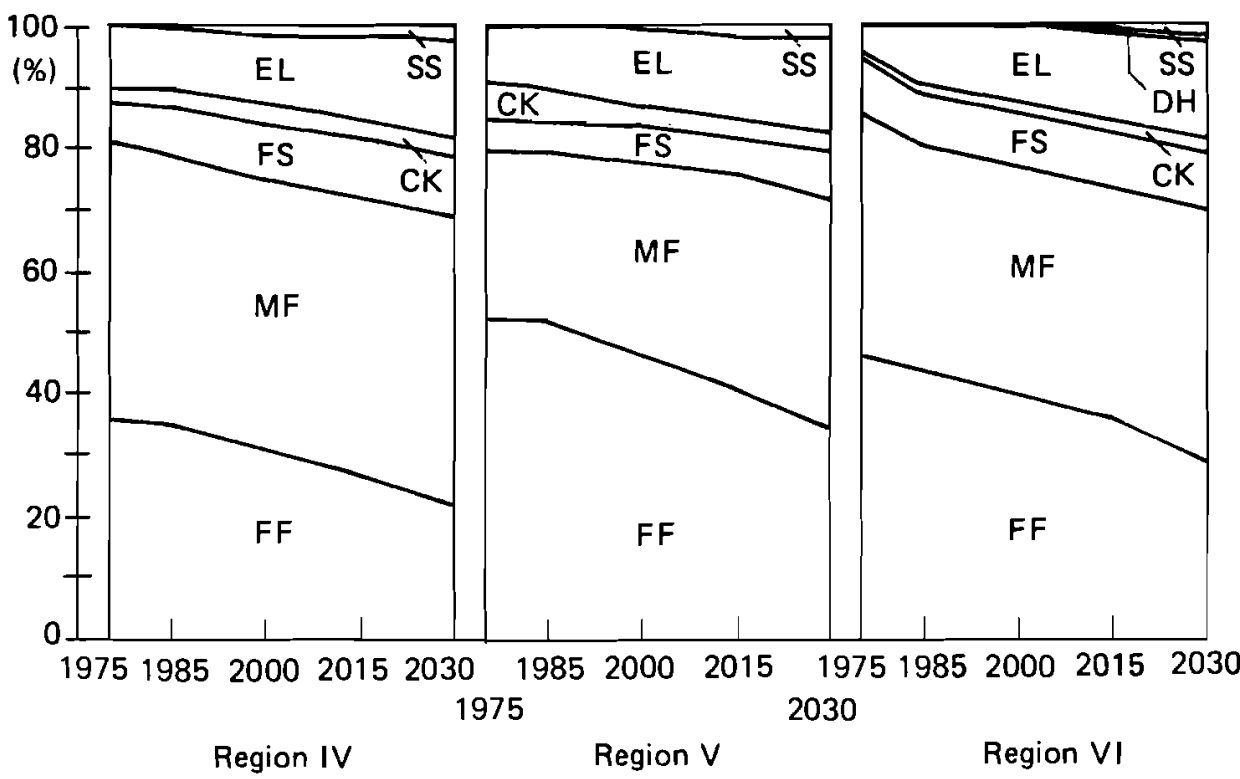

FIGURE 6 Shares of energy forms in final energy demand, 1975-2030 (High scenario). FF $=$ substitutable fossil fuels; $\mathrm{CK}=$ specific uses of coal (ess. coke); $\mathrm{MF}=$ motorfuel; $\mathrm{EL}=$ electricity; $\mathrm{SS}=$ soft solar; $F S=$ feedstocks; $D H=$ district heat.

to those in the High scenario and have been omitted. It may be mentioned here that the allocation of substitutable fossil fuels to solids, liquids, and gases is made subsequently to the MEDEE-2 analysis, in the light of expected changes in the fuel prices. These allocations are discussed in Energy Systems Program Group (1981). Further, in the case of 
developing regions, a significant fraction of the substitutable fossil fuel demand may be met by charcoal and biogas. Estimates for this have been made by Khan (1981).

Although the relative increases in final energy consumption appear large, particularly in the developing regions, they are not as dramatic if seen on a per capita basis (Table 11).

TABLE 11 Per capita final (commercial) energy consumption, two scenarios 1975 to 2030 (kW/cap)*

\begin{tabular}{|c|c|c|c|c|c|}
\hline \multirow[b]{2}{*}{ Region } & \multirow[b]{2}{*}{1975} & \multicolumn{2}{|c|}{ High scenario } & \multicolumn{2}{|c|}{ Low scenario } \\
\hline & & 2000 & 2030 & 2000 & 2030 \\
\hline I (NA) & 7.89 & 9.25 & 11.63 & 7.95 & 8.37 \\
\hline I (SU/EE) & 3.52 & 5.47 & 8.57 & 4.98 & 6.15 \\
\hline III (WE/JANZ) & 2.84 & 4.46 & 5.70 & 3.52 & 3.90 \\
\hline IV (LA) & 0.80 & 1.75 & 3.31 & 1.28 & 2.08 \\
\hline $\mathrm{V}(\mathrm{Af} / \mathrm{SEA})$ & 0.18 & 0.42 & 0.89 & 0.32 & 0.53 \\
\hline VI (ME/NAf) & 0.80 & 2.34 & 4.64 & 1.76 & 2.46 \\
\hline I + III & 4.34 & 5.87 & 7.43 & 4.82 & 5.20 \\
\hline$I V+V+V I$ & 0.33 & 0.79 & 1.59 & 0.59 & 0.94 \\
\hline I through VI & 1.76 & 2.25 & 3.13 & 1.85 & 2.07 \\
\hline
\end{tabular}

NOTE: The figures are average rates of final energy use, averaged over the population and the year.

*For electricity share: see Table 10.

The per capita consumption of final energy in the developing world regions is projected to increase, by 2030 , only by a factor of $2.6-3.1$ in the Low scenario and of $4.2-5.8$ in the High scenario. Accordingly, in 2030, Region V, the poorest among the developing regions, would have a per capita final energy consumption of only $0.5-0.9 \mathrm{kWyr} / \mathrm{yr}$, whereas for the other two developing regions relatively more comfortable levels of 2.4 $4.6 \mathrm{kWyr} / \mathrm{yr}$ are to be expected. The projected ranges of per capita final energy consumption for the developed regions, in 2030, in the High and Low scenarios, are 5.7-11.6 $\mathrm{kWyr} / \mathrm{yr}$ and $3.9-8.4 \mathrm{kWyr} / \mathrm{yr}$, respectively, as compared to $2.8-7.9 \mathrm{kWyr} / \mathrm{yr}$ in 1975 . Thus two out of the three developing market economy regions, i.e., Regions IV and VI, are expected by 2030 to reach levels of per capita final energy consumption comparable to those currently found in some developed regions.

\subsubsection{Shares of Sectors in Final Energy Demand}

The distribution of final energy demand across three broad sectors: transport, industry (agriculture, construction, mining, and manufacturing), and buildings (household and services) is shown in Table 12 for the year 2030 for each world region, together with the corresponding distribution in 1975. Regional differences in sectoral energy use are apparent. These differences seem to persist in spite of the fact that economic and demographic structures in some of the regions have been assumed to undergo considerable changes over the next 50 years.

Table 12 illustrates that the share of final energy used in buildings is, throughout, much higher in the developed regions than in the developing regions, as one would expect. In addition to low space heating requirements in developing regions, this is also due to the considerable dependence of these regions on noncommercial fuels for domestic 
TABLE 12 Shares of sectors in final energy demand (\% of final energy).

\begin{tabular}{|c|c|c|c|}
\hline Region & Transport & Industry* & Buildings** \\
\hline \multicolumn{4}{|l|}{1975} \\
\hline I (NA) & 29 & 40 & 31 \\
\hline II (SU/EE) & 18 & 59 & 23 \\
\hline III (WE/JANZ) & 20 & 51 & 29 \\
\hline IV (LA) & 41 & 47 & 12 \\
\hline V (Af/SEA) & 30 & 59 & 11 \\
\hline VI (ME/NAf) & 39 & 47 & 14 \\
\hline \multicolumn{4}{|c|}{2030 - High scenario } \\
\hline 1 (NA) & 28 & 52 & 20 \\
\hline II (SU/EE) & 19 & 64 & 17 \\
\hline III (WE/JANZ) & 25 & 52 & 23 \\
\hline IV (LA) & 44 & 46 & 10 \\
\hline V (Af/SEA) & 29 & 62 & 9 \\
\hline VI (ME/NAf) & 37 & 52 & 11 \\
\hline \multicolumn{4}{|c|}{2030 - Low scenario } \\
\hline I (NA) & 26 & 50 & 24 \\
\hline II (SU/EE) & 19 & 63 & 18 \\
\hline III (WE/JANZ) & 23 & 49 & 28 \\
\hline IV (LA) & 44 & 43 & 13 \\
\hline V (Af/SEA) & 32 & 55 & 13 \\
\hline VI (ME/NAf) & 36 & 50 & 14 \\
\hline
\end{tabular}

*Industry includes agriculture, manufacturing, mining, and construction.

**Buildings in the household and service sectors.

NOTE: ltalic figures highlight the most visible of regional differences.

use. Also, building energy use is low in these projections due to saturation effects, which can be seen in almost all world regions.

Transportation activities in the developing regions make up a relatively high share of final energy in 1975 and the trend, in general, shows a slight increase in both scenarios. This is due to a considerable increase in freight transportation, projected to grow with industrial output, as well as to an expected increase in personal travel and a reduction of average load factors. Among the developed regions the relative shares of transportation and industrial activities are markedly different in Regions I plus III (essentially OECD countries) and Region II, mirroring the differing emphasis on industrial activity and personal transportation in the two types of economies.

\section{Energy Demand of Industries}

Industrial energy use is a major portion of the total consumption in every world region today; the scenario assumptions do not lead to major departures from this. Energy as a factor of production, as an "input" to productive output, is an indispensable commodity - qualitatively different from the energy used by households or that consumed in transportation activities. Yet, despite its firm footing in virtually all of the world's economies, industrial energy demand trends and possibilities span an impressively wide range. The scenario assumptions of Section 5.3.2 (see also Table 9.3.1) were based on 
considerations of such trends and appropriate possibilities in the technoeconomic environment of the various world regions.

Manufacturing activities account for a major share of the industrial energy consumption (Table 13). In 1975 the share of manufacturing activities, including coke use in the steel industry and feedstock inputs to petrochemical industries, out of total industrial energy consumption was 90 to 97 percent for Regions I to $\mathrm{V}$ in spite of considerable differences in the composition of their economic structure. In Region VI this share was relatively smaller - about 62 percent - due to the exceptionally low level of manufacturing

TABLE 13 Final energy projections for industry, including coke and feedstocks (TWyr/yr).

\begin{tabular}{clllll}
\hline & \multicolumn{3}{c}{ High scenario } & \multicolumn{2}{l}{ Low scenario } \\
\cline { 5 - 6 } Region & 1975 & 2000 & 2030 & 2000 & 2030 \\
\hline I (NA) & 0.76 & 1.31 & 1.91 & 1.08 & 1.31 \\
(\% manuf.) & $(92)$ & $(91)$ & $(89)$ & $(91)$ & $(90)$ \\
II (SU/EE) & 0.76 & 1.49 & 2.64 & 1.35 & 1.85 \\
(\% manuf.) & $(92)$ & $(91)$ & $(90)$ & $(90)$ & $(88)$ \\
III (WE/JANZ) & 0.81 & 1.55 & 2.27 & 1.18 & 1.46 \\
(\% manuf.) & $(91)$ & $(89)$ & $(89)$ & $(90)$ & $(89)$ \\
IV (LA) & 0.12 & 0.48 & 1.23 & 0.33 & 0.72 \\
(\% manuf.) & $(90)$ & $(91)$ & $(90)$ & $(89)$ & $(87)$ \\
V (Af/SEA) & 0.15 & 0.67 & 1.97 & 0.47 & 1.02 \\
(\% manuf.) & $(97)$ & $(88)$ & $(82)$ & $(85)$ & $(76)$ \\
VI (ME/NAf) & 0.05 & 0.32 & 0.85 & 0.24 & 0.43 \\
(\% manuf.) & $(62)$ & $(83)$ & $(86)$ & $(85)$ & $(80)$ \\
\hline
\end{tabular}

activity and the dominance of oil and gas production activity in the industrial sector of this region. The scenario assumptions of changes in economic structure, composition of manufacturing activities, and technological coefficients result in projections for the years 2000 and 2030 for which the share of manufacturing in the industrial energy consumption varies between 76 and 90 percent in all world regions.

Table 14 lists the present and projected final energy demand of the manufacturing sector in different world regions and also indicates the shares of electricity and coke plus feedstocks (essentially liquid fuel based, used in petrochemical industries) in this demand. It is seen that the share of electricity in manufacturing energy demand increases in all regions, reaching levels of $20-25$ percent in 2030 as against $11-15$ percent at present. The share of coke plus feedstocks also increases in all the regions (except in Region VI where petrochemical feedstock production for export purposes is currently an important activity from 13-28 percent in 1975 to $20-33$ percent in 2030 . Various factors are responsible for these changes. Some of the more important ones are assumed to be the following: (1) a greater reduction in the energy intensity of manufacturing activities with respect to useful thermal energy than with respect to specific uses of electricity (e.g., motive power, electrolysis, lighting); (2) penetration of electricity in the useful thermal energy market of the manufacturing processes; (3) a relatively small reduction in the demand of coke per ton of pig-iron production in the developed regions, and (4) increasing importance of the basic materials industries in the manufacturing sectors of the developing countries. 
TABLE 14 Final energy projections for manufacturing, including coke and feedstocks (TWyr/yr).

\begin{tabular}{|c|c|c|c|c|c|}
\hline \multirow[b]{2}{*}{ Region } & \multirow[b]{2}{*}{1975} & \multicolumn{2}{|c|}{ High scenario } & \multicolumn{2}{|c|}{ Low scenario } \\
\hline & & 2000 & 2030 & 2000 & 2030 \\
\hline I (NA) & 0.70 & 1.19 & 1.70 & 0.98 & 1.19 \\
\hline (\% elec.) & (13) & (18) & $(21)$ & (18) & (20) \\
\hline (\% coke + feedst.) & (18) & (21) & (23) & (21) & (22) \\
\hline II (SU/EE) & 0.70 & 1.35 & 2.37 & 1.22 & 1.62 \\
\hline (\% elec.) & (12) & (18) & (24) & (16) & (21) \\
\hline (\% coke + feedst.) & (20) & (26) & (31) & (24) & (26) \\
\hline UI (WE/JANZ) & 0.73 & 1.39 & 2.01 & 1.05 & 1.30 \\
\hline (\% elec.) & (15) & (19) & (24) & (19) & (21) \\
\hline (\% coke + feedst. $)$ & (28) & (32) & (33) & (31) & (32) \\
\hline IV (LA) & 0.11 & 0.44 & 1.10 & 0.29 & 0.63 \\
\hline (\% elec.) & (14) & (16) & (21) & (17) & (21) \\
\hline (\% coke + feedst. $)$ & (22) & (28) & (33) & (27) & (33) \\
\hline $\mathrm{V}(\mathrm{Af} / \mathrm{SEA})$ & 0.14 & 0.59 & 1.62 & 0.40 & 0.77 \\
\hline (\% elec.) & (11) & (15) & (21) & (15) & (20) \\
\hline (\% coke + feedst. $)$ & (13) & (16) & (20) & (15) & (18) \\
\hline VI (ME/NAf) & 0.03 & 0.26 & 0.73 & 0.20 & 0.35 \\
\hline (\% elec.) & (12) & (20) & (25) & $(20)$ & (25) \\
\hline (\% coke + feedst. $)$ & (33) & (22) & (25) & (23) & (26) \\
\hline
\end{tabular}

We now look at the changes in energy intensity of the manufacturing industries (excluding the use of coke in steel industry, and the use of liquid fuels for feedstock production) that result from our scenario assumptions of Table 9.31. Also we indicate to what extent the shifts, assumed to occur in the great variety of manufacturing activities in the world regions, are responsible for these changes. The requirements of energy for a given mix of manufacturing activities can be reduced in various ways: (1) by incorporating better machinery and processes (which reduces the energy intensity of these activities) (2) by increasing the shares of electricity, district heat, and soft solar energy in meeting the demand for thermal processes (which reduces conversion losses), (3) by making increased use of cogeneration and heat pumps (which reduces the requirements of final energy); and (4) by improving the efficiency of fossil fuel conversion to process heat (which also reduces conversion losses). Tables 15 and 16 summarize some of our previously described assumptions (see Tables 9.2 and 9.3.1) for the year 2030 according to the High scenario, in aggregated and/or more transparent form. The data for 1975 (column 1, Table 15) show considerable differences in the average useful energy intensity of manufacturing activities in the various world regions. These differences are partly due to different mixes of component activities and partly due to differences in processes, technologies, and the extent of automation.

These projections (Table 15) in general indicate a greater potential for reduction of energy intensity in the developed regions than in the developing regions. These reductions - which are in part due to structural changes in manufacturing - are especially large in Regions II and I, but not so large in Region III where manufacturing activities have already undergone considerable modernization. The largest structural changes in the manufacturing sector are assumed for the developing regions (see Table 9.2), where both the most energy-intensive basic materials industries and the least energy-intensive 
TABLE 15 Projected reduction in average useful energy intensity of manufacturing industries, High scenario.

\begin{tabular}{|c|c|c|c|c|}
\hline \multirow[b]{2}{*}{ Region } & \multicolumn{2}{|c|}{$\begin{array}{l}\text { Useful energy intensity } \\
\text { (kWhr(e)/\$VA }\end{array}$} & \multirow{2}{*}{$\begin{array}{l}\% \text { reduction in } \\
2030 \text { relative } \\
\text { to } 1975\end{array}$} & \multirow{2}{*}{$\begin{array}{l}\text { Of which }(\%) \text { due } \\
\text { to structural } \\
\text { change* }\end{array}$} \\
\hline & 1975 & 2030 & & \\
\hline I (NA) & 8.66 & 6.06 & 30 & 8 \\
\hline II (SU/EE) & 10.86 & 6.12 & 44 & 1 \\
\hline III (WE/JANZ) & 4.20 & 3.21 & 24 & 4 \\
\hline IV (LA) & 5.81 & 4.51 & 22 & 4 \\
\hline$V(A f / S E A)$ & 11.06 & 9.29 & 16 & -3 \\
\hline VI (ME/NAf) & 7.68 & 4.96 & 35 & -8 \\
\hline
\end{tabular}

*Structural changes are the result of modernization in the manufacturing activities.

NOTE: Useful energy is expressed as equivalent electricity requirement. Data are for manufacturing industries, excluding coke and petrochemical feedstock use.

TABLE 16 Assumed penetration of electricity, district heat, cogeneration, heat pump and soft solar in their potential industrial heat markets in 2030 , High scenario (\% of potential industrial heat markets)*

\begin{tabular}{lllllll} 
& & & & & \multicolumn{3}{c}{ Soft solar } \\
\cline { 5 - 7 } Region & Electricity & $\begin{array}{l}\text { District } \\
\text { heat }\end{array}$ & Cogeneration & $\begin{array}{l}\text { Heat } \\
\text { pump }\end{array}$ & $\begin{array}{l}\text { Low } \\
\text { temp. }\end{array}$ & $\begin{array}{l}\text { High } \\
\text { temp. }\end{array}$ \\
\hline I (NA) & 0.10 & 0 & 0.50 & 0.50 & 0.15 & 0.05 \\
II (SU/EE) & 0.10 & $0.85^{* *}$ & 0 & 0 & 0.10 & 0.03 \\
III (WE/JANZ) & 0.05 & 0.15 & $0.60^{* *}$ & 0.50 & 0.15 & 0.05 \\
IV (LA) & 0.10 & 0.12 & 0.20 & 0.20 & 0.30 & 0.10 \\
V (Af/SEA) & 0.04 & 0.05 & 0.15 & 0.10 & 0.30 & 0.10 \\
VI (ME/NAf) & 0.10 & 0.12 & 0.25 & 0.20 & 0.30 & 0.10 \\
\hline
\end{tabular}

*Potential industrial heat markets: electricity, all process heat; district heat, steam and hot water; cogeneration, low temperature steam and hot water; heat pump, steam and hot water demand met by electricity; and soft solar, steam and hot water.

**In Region II district heat and in Region III on-site cogeneration were already supplying 69 percent and 30 percent of their respective potential markets in 1975.

machinery and equipment industries grow relatively faster than the nondurable goods industries; this has a balancing effect on the overall energy intensity of manufacturing.

As mentioned in Section 5.2.3, Part I, the penetration of various more efficient energy forms as well as of cogeneration and heat pumps in the industrial heat market was projected in the light of regional differences in settlement patterns, past practices, current technological trends, geographical conditions, etc. All these technological changes essentially aim at reducing the demand of fossil fuels for industrial process heat. Yet, in spite of our rather optimistic assumptions of Table 16, more than 80 percent of the industrial process heat requirements in all the regions except in Region II would still have to be met by fossil fuels in 2030 in the High scenario (Table 17). Note again that improvements in the average efficiency of fossil fuel use of the order of 20 percent are also assumed to be possible over the next 50 years (see Table 9.3.1, Group 3.1f). Table 17 lists the shares of various energy sources (fossil fuels, electricity, district heat, soft solar) in the heat demand of manufacturing industries resulting from the assumptions of the High scenario. 
TABLE 17 Shares of energy sources in the heat market of the manufacturing sector, High scenario (\% of total useful thermal energy).

\begin{tabular}{|c|c|c|c|c|c|c|c|c|c|c|c|c|}
\hline \multirow[b]{2}{*}{ Region } & \multicolumn{6}{|c|}{2000} & \multicolumn{6}{|c|}{2030} \\
\hline & FF & (COG) & $\mathrm{EL}$ & (HP) & $\mathrm{DH}$ & SS & FF & (COG) & $\mathbf{E L}$ & (HP) & DH & SS \\
\hline I (NA) & 92 & $(5.9)$ & 7 & $(1.2)$ & 0 & 1 & 87 & $(9.0)$ & 10 & $(2.5)$ & 0 & 3 \\
\hline II (SU/EE) & 39 & $(0.0)$ & 5 & $(0.0)$ & 55 & 1 & 30 & $(0.0)$ & 10 & $(0.0)$ & 59 & 1 \\
\hline III (WE/JANZ) & 92 & $(8.1)$ & 3 & $(0.5)$ & 4 & 1 & 85 & $(10.8)$ & 5 & (1.3) & 8 & 2 \\
\hline IV (LA) & 95 & $(0.4)$ & 3 & $(0.1)$ & 1 & 1 & 80 & (1.6) & 10 & $(0.8)$ & 5 & 5 \\
\hline$V($ Af/SEA) & 99 & $(0.2)$ & 1 & $(0.0)$ & 0 & 0 & 90 & $(0.9)$ & 4 & $(0.2)$ & 2 & 4 \\
\hline VI (ME/NAf) & 95 & $(0.9)$ & 3 & $(0.0)$ & 1 & 1 & 81 & $(1.5)$ & 10 & $(0.8)$ & 5 & 4 \\
\hline
\end{tabular}

NOTE: $F F=$ fossil fuels; $C O G=$ with cogeneration of electricity (included in FF); EL = electricity; $\mathrm{HP}=($ electric) heat pumps (included in $\mathrm{EL}) ; \mathrm{DH}=\operatorname{district}$ heat $; \mathrm{SS}=$ soft solar.

In 1975, the fossil fuel share is 100 percent in all regions except Regions II (48 percent district heat); in Region III, cogeneration was estimated to be 5 percent.

The overall effect of these technological developments, better practices, and structural changes is a reduction in the average final energy intensity of manufacturing activities (excluding feedstocks and the use of coke in the steel industry) by about 35 to 55 percent in the regions for the High scenario, as is shown in Table 18. The effects of structural changes are not very large (see Table 15) due to the high sectoral aggregation. A larger reduction in final energy intensity, as compared to that in useful energy intensity, is due to higher final-to-useful energy conversion efficiency, assumed to improve by 20 30 percent.

At present, use of coke in the steel industry amounts to 2-11 percent of the final energy requirements of manufacturing activities in the various world regions. The consumption of coke per ton of pig-iron produced varies considerably from country to country. Estimated regional averages for 1975 are between $500 \mathrm{~kg}$ in Region III (WE/JANZ) and $1,000 \mathrm{~kg}$ in Region VI (ME/NAf). The scenario assumptions of Table 9.3.1, Group $3.1 \mathrm{~h}$, imply reduction in coke consumption of 20-60 percent in the various world regions. The share of coke for the steel industry in the industrial final energy demand of the regions changes only slightly (except for Region II) over a period of 50 years and stays within a range of $2-10$ percent in both the High and the Low scenarios. In Region II, this share would fall from 11 percent in 1975 to about 4.5 percent in 2030.

TABLE 18 Average final energy intensity of manufacturing activities, excluding feedstocks and coke.

\begin{tabular}{lcclll}
\hline & $\begin{array}{l}\text { Energy intensity, High } \\
\text { scenario (kWhr(e)/\$VA) }\end{array}$ & & $\begin{array}{l}\text { Relative } \\
\text { decrease (\%) }\end{array}$ & $\begin{array}{l}\text { Reduction due } \\
\text { to structural } \\
\text { change (\%) }\end{array}$ \\
\cline { 2 - 5 } & 1975 & 2030 & & 43 & 6 \\
I (NA) & 12.3 & 7.0 & 54 & 1 \\
II (SU/EE) & 13.9 & 6.4 & 37 & 4 \\
III (WE/JANZ) & 5.7 & 3.6 & 36 & 3 \\
IV (LA) & 8.6 & 5.5 & 36 & -2 \\
V (Af/SEA) & 19.6 & 12.6 & 50 & -7 \\
VI (ME/NAf) & 12.2 & 6.1 & & 50 \\
\hline
\end{tabular}


We consider here the share of agriculture in the industrial energy demand. Agriculture in developing regions, based largely on traditional farming practices, is currently far less energy intensive than that in developed regions. According to the economic projections of the scenarios (see Table 9.2), the agricultural GDP in Regions IV, V, and VI is expected to increase by a factor of 3.7 to 4.5 over the next 50 years; the expected increase would be 2.2 to 2.5 times in Regions I, II, and III. The implications of these projections in energy terms can be seen in the parameters of Table 19.

TABLE 19 Agricultural patterns in different world regions in 1975.

\begin{tabular}{llllc}
\hline & $\begin{array}{l}\text { Arable land } \\
\text { per capita } \\
\text { (ha/cap) }\end{array}$ & $\begin{array}{l}\text { lrigation } \\
\text { (\% of } \\
\text { arable land) }\end{array}$ & $\begin{array}{l}\text { Mechanical } \\
\text { appliances } \\
\text { (per 1,000 ha) }\end{array}$ & $\begin{array}{l}\text { Fertilizer } \\
\text { use } \\
\text { (kg/ha) }\end{array}$ \\
\hline I (NA) & 1.07 & 7 & 22 & 80 \\
II (SU/EE) & 0.77 & 7 & 15 & 96 \\
III (WE/JANZ) & 0.34 & 9 & 45 & 117 \\
IV (LA) & 0.45 & 9 & 7 & 32 \\
V (Af/SEA) & 0.32 & 14 & 1 & 14 \\
VI (ME/NAf) & 0.33 & 25 & 4 & 27 \\
VII (C/CPA) & 0.15 & 61 & 2 & 50 \\
\hline
\end{tabular}

NOTE: All data refer to arable land including land under permanent crops. Mechanical appliances included here are tractors and harvesters. Fertilizer use refers to consumption in terms of $\mathrm{N}_{2}, \mathrm{P}_{2} \mathrm{O}_{5}$ and $K_{2} O$.

SOURCES: FAO 1977, UN $1977 \mathrm{~b}$.

Consider arable land in developing regions. There is little potential for expanding arable land area in Regions IV, V, and VI where the present per capita availability of arable land is about 0.34 ha compared to 0.62 ha in the developed Regions I, II, and III. If no significant new area is brought under cultivation, the per capita availability will decrease over the next 50 years to 0.14 ha in the developing regions and 0.46 ha in the developed regions.

The limits on arable land expansion imply that essential agricultural productivity improvements must come from increases in the use of fertilizers, irrigation, and farm mechanization. But surface water is in short supply and precipitation is not adequate in most areas; increasing use will therefore have to be made of underground water.

Taking these factors into account, the energy intensity of agriculture - including mechanization and irrigation, but not including energy used to produce fertilizers - in Regions IV, V, and VI was assumed to increase by a factor of 10 over the next 50 years (see Table 9.3.1, Group 3.1 c). Thus by 2030 the average energy intensity in these regions would be about the same $\left(2.8 \mathrm{kWhr} / \$ \mathrm{VA}^{*}\right)$ as the present average value for the developed regions. The final energy used in agriculture would increase for the High and Low scenarios by about 45 and 37 times the 1975 level in the developing regions, and by just 2.4 and 2.0 times in the developed regions. The share of agricultural activities in industrial energy consumption in 2030 is thus found to lie in the range of 3 to 5 percent in all regions

* $\$$ VA $=\$$ value added 
except $\mathrm{V}$ where it amounts to 10 percent for the High scenario and 15 percent for the Low scenario. (The shares in all the regions in 1975 were in the range of 1 to 4 percent.)

Energy needed for fertilizer production is counted in this analysis in the basic materials manufacturing sector. For Regions IV and V those sectors are projected to increase in output by 2030 to about 10 to 20 times their 1975 levels. These increases should easily encompass the energy demand for chemical fertilizer, which may increase by a factor of 5 to 10 in the same period.

\section{Energy Demand of Transportation}

Transportation activities take an appreciable share of the total final energy (see Table 12). In 1975 this share was about 20 percent in Regions II and III, 30 percent in Regions I and V, and 40 percent in Regions IV and VI; for the world as a whole, the share was about 24 percent. Of course, the ways in which this energy is used (the mix of transport modes - cars, buses, trains, trucks, planes - and the fuels used) vary considerably from country to country. The end result is usually a large share of energy use in transport; and one that has been growing.

The analysis reported here foresees some changes in this picture: relatively slower growth in personal travel in developed regions (except for air travel); moderately increased use of public transportation for urban travel (a consequence of growing urban traffic congestion); and greater economies of gasoline consumption (see Table 9.3.2). These assumed changes are due to relative price increases, changes in public perceptions about energy availability (which may or may not be accompanied quickly by price changes), and government mandates.

The results are strikingly different in different parts of the world, as is shown in Table 20. Region I (NA) evidences the smallest relative increase in transportation energy use, although the high mobility, great distances, and large (but slowly shrinking) cars of the US and Canada, keep the absolute level of energy use high. However, the share of passenger travel in transportation activity declines considerably - from 75 percent in 1975 , to $40-50$ percent in 2030 . In Regions II and III, demand of energy for both passenger travel and freight transportation continues to increase steadily with only minor changes in the relative shares of these two activities in total transportation energy. It may be pointed out here that in Region II (SU/EE), transportation energy use is currently low compared to both NA and WE/JANZ, despite large distances. The main factors for this contrast are the high share of rail in both freight and passenger transportation, and the emphasis on urban mass transit. Although a certain increase in car ownership and attendant increase in energy use for personal transportation is envisaged in SU/EE, the total increase is not so marked because in freight transportation no significant shift towards trucks is expected.

In the developing Regions IV, V, and VI, growth in transport energy demand is significantly higher, owing to greater freight transport accompanying growth in industrial and agricultural output, and to the fact that personal travel is far from the saturation mark. Further, the share of passenger travel in transportation energy demand increases in all developing regions, although the change is not as large in Region IV (LA) as in the other two regions.

Table 20 also shows the share of electricity in transportation energy demand resulting from the scenario assumptions of Table 9.3.2. In Regions I, IV, V, and VI, this share 
TABLE 20 Projections of transportation final energy demand (TWyr/yr).

\begin{tabular}{|c|c|c|c|c|c|}
\hline \multirow[b]{2}{*}{ Region } & \multirow[b]{2}{*}{1975} & \multicolumn{2}{|c|}{ High scenario } & \multicolumn{2}{|c|}{ Low scenario } \\
\hline & & 2000 & 2030 & 2000 & 2030 \\
\hline I (NA) & 0.54 & 0.65 & 1.01 & 0.56 & 0.68 \\
\hline (\% elec.) & $(0.1)$ & $(0.6)$ & (1.1) & $(0.7)$ & (1.5) \\
\hline (\% passenger) & (74) & $(48)$ & (39) & (54) & (49) \\
\hline II (SU/EE) & 0.22 & 0.42 & 0.79 & 0.38 & 0.55 \\
\hline (\% elec.) & $(4.0)$ & $(6.4)$ & $(8.9)$ & $(6.3)$ & (9.2) \\
\hline (\% pass.) & $(25)$ & $(30)$ & (27) & (28) & (28) \\
\hline III (WE/JANZ) & 0.31 & 0.71 & 1.11 & 0.53 & 0.69 \\
\hline (\% elec.) & (1.9) & $(2.2)$ & (3.1) & $(2.6)$ & (3.9) \\
\hline (\% pass.) & $(60)$ & (59) & $(54)$ & $(58)$ & (56) \\
\hline IV (LA) & 0.11 & 0.41 & 1.15 & 0.30 & 0.73 \\
\hline (\% elec.) & $(0.2)$ & $(0.4)$ & (1.4) & $(0.4)$ & (1.5) \\
\hline (\% pass.) & (31) & (33) & $(35)$ & $(35)$ & (38) \\
\hline V (Af/SEA) & 0.08 & 0.27 & 0.91 & 0.22 & 0.61 \\
\hline (\% elec.) & $(0.5)$ & $(0.8)$ & $(1.5)$ & $(0.8)$ & (1.6) \\
\hline (\% pass.) & $(40)$ & (45) & $(55)$ & $(47)$ & (59) \\
\hline $\mathrm{VI}$ (ME/NAf) & 0.04 & 0.20 & 0.61 & 0.14 & 0.31 \\
\hline (\% elec.) & $(0.1)$ & $(0.2)$ & $(0.9)$ & $(0.2)$ & $(1.0)$ \\
\hline (\% pass.) & (20) & (23) & (34) & (26) & (34) \\
\hline
\end{tabular}

increases from a very low level of $0.1-0.5$ percent in 1975 to a modest level of 1.0 1.5 percent in 2030. The same share in Region III would increase from about 2 percent in 1975 to 3-4 percent in 2030; whereas for Region II, the projected increase over the same period, is from an already high level of 4 percent to a still higher level of 9 percent.

Passenger travel. Consider the relative levels of passenger transport activity around the world in 1975. Total passenger travel (intercity plus urban) in North America in 1975 was some 4,100 billion $\left(10^{9}\right)$ passenger-kilometers (population 237 million, $10^{6}$ ); in Region II it was 1,700 billion (population 363 million); in Region III over 5,000 billion (population 560 million). The total activity for developing Regions IV, V, and VI together was only 3,000 billion passenger-kilometers, for 1,874 million people. But this seems sure to change. Passenger travel in the developed regions is expected to be nearing saturation levels - further increases will probably be relatively modest. (There are limits, of income and time, to how much one can travel.) This effect is especially pronounced in Region I. Regions I and III together show only a 1.2 to 1.6 percent per year growth in total passenger travel according to the MEDEE-2 runs for the two scenarios to 2030. The developing Regions IV, V, and VI together increase their personal travel amount by 3.9 to 4.4 percent per year. The Region II growth rate is projected at 1.9 to 2.4 percent per year.

But the types or modes of travel and relative load factors are also to be considered. Table 21 summarizes, for the High scenario, the results of an array of assumptions for urban and intercity mobility, relative growth of different transport modes, and expected changes in load factors around the world (see Table 9.3.2). It is apparent in Table 21 that passenger travel in NA is assumed to shift away from automobiles and towards airplanes in the scenarios. Still, by 2030 the car would account for 73 percent of total passengerkilometers, compared to 50 percent or less in other regions. In general, developed regions 
TABLE 21 Assumptions on passenger travel (intercity and urban) and its distribution by mode of transportation, High scenario.

\begin{tabular}{|c|c|c|c|c|c|}
\hline \multirow[b]{2}{*}{ Region } & \multirow{2}{*}{$\begin{array}{l}\text { Activity level } \\
\left(10^{9} \mathrm{~km} / \mathrm{per} / \mathrm{yr}\right)\end{array}$} & \multicolumn{4}{|c|}{ Modal split (\%) } \\
\hline & & Plane & Car & Train* & Bus \\
\hline \multicolumn{6}{|l|}{1975} \\
\hline I (NA) & 17.4 & 4 & 93 & 1 & 2 \\
\hline II (SU/EE) & 4.8 & 11 & 26 & 51 & 12 \\
\hline III (WE/JANZ) & 9.2 & 3 & 37 & 37 & 23 \\
\hline IV (LA) & 4.1 & 1 & 37 & 5 & 57 \\
\hline V (Af/SEA) & 1.0 & 1 & 25 & 14 & 60 \\
\hline VI (ME/NAf) & 2.2 & 1 & 29 & 5 & 65 \\
\hline \multicolumn{6}{|l|}{2000} \\
\hline I (NA) & 21.7 & 12 & 83 & 2 & 3 \\
\hline II (SU/EE) & 9.1 & 13 & 29 & 45 & 13 \\
\hline III (WE/JANZ) & 13.5 & 9 & 44 & 27 & 20 \\
\hline IV (LA) & 7.5 & 3 & 45 & 5 & 47 \\
\hline $\mathrm{V}(\mathbf{A f} / \mathrm{SEA})$ & 2.0 & 2 & 32 & 11 & 55 \\
\hline VI (ME/NAf) & 6.3 & 2 & 34 & 9 & 55 \\
\hline \multicolumn{6}{|l|}{2030} \\
\hline I (NA) & 25.9 & 20 & 73 & 3 & 4 \\
\hline II (SU/EE) & 13.3 & 15 & 30 & 41 & 14 \\
\hline III (WE/JANZ) & 18.0 & 12 & 50 & 20 & 18 \\
\hline IV (LA) & 13.5 & 4 & 49 & 9 & 38 \\
\hline $\mathrm{V}(\mathrm{Af} / \mathrm{SEA})$ & 4.6 & 2 & 39 & 10 & 49 \\
\hline VI (ME/NAf) & 15.9 & 4 & 38 & 15 & 43 \\
\hline
\end{tabular}

*Train includes urban electric mass transit.

SOURCES: UN (1977c); IRF (1976); Europa (1976); CMEA (1976).

are projected to continue observed tendencies toward relatively more air and (except NA) car travel; developing regions reflect expected shifts towards cars (noticeably) and trains (less noticeably), and away from the current large fraction of bus travel (roughly 60 percent in developing regions and less than 20 percent in developed regions).

Automobiles. Cars consume prodigious amounts of energy. More precisely, they consume prodigious amounts of petroleum - a particularly important distinction.

In North America, total automobile travel (intercity and urban) is assumed to grow from 3,800 billion passenger-kilometers in 1975 (that is equivalent to four automobile trips coast to coast across the US per person per year) to about 6,000 billion by 2030 . This average growth rate of just 0.8 percent per year indicates a leveling-off in the so-far continuously increasing automobile use in this region. The Region III growth in total car travel, by contrast, is assumed to be $1.6-2.4$ percent per year; while in Region II it is assumed to be 2.1-2.7 percent per year. In the developing Regions IV, V, and VI the corresponding rates are between 4 and 6 percent per year - even though the assumptions restrict urban car travel because of city traffic congestion to $35-50$ percent of all urban passenger travel.

Assumptions for car ownership and usage vary widely among regions, as recorded in Table 9.3.2. Group 3.2e. Car ownership, and the distance traveled per car are thought 
to be nearing limits in North America. Region IV, Latin America, is assumed to approach the present statistics of Region III by 2030, whereas the figure for Region V in 2030 may be comparable to Region IV today. In Regions IV, V, and VI the relatively high growth of car ownership in the scenarios results from assumed higher growth in GDP per capita and anticipated increases in urbanization.

Region II (SU/EE), has now low car ownership and high distance traveled per car figures more typical of developing regions. The scenarios for this region maintain that automobile ownership will continue to be low, reaching only half of the present WE/JANZ level by 2030 . This reflects the explicit desire in this region to develop public transport facilities, to minimize the need for private automobile use, and thus to minimize liquid fuel requirements.

Energy use in vehicles can be reduced significantly by increasing load factors average number of passengers per trip, or passenger-kilometers divided by vehicle-kilometers - and by improving the vehicle's energy-using efficiency (see Table 9.3.2, Groups 3.2f and $3.2 \mathrm{~g}$ ). Load factors for automobiles are assumed to be constant in the scenario cases in the developed regions, but are reduced somewhat in the developing regions as cars become more common and family sizes decrease. However, the largest factor in reducing potential per-kilometer energy use in cars is efficiency improvement. The major share of this potential is found, not surprisingly, in North America.

Electric cars offer a potential for reduction of motor fuel use in automobiles. Electric cars are assumed to be three times as efficient as internal combustion engine automobiles, but nevertheless would consume about the same total primary energy as conventional cars if the electricity came from central station sources. It is assumed here (see Table 9.3.2, Group 3.2e) that by 2030 about 20 percent of urban car travel in the developed regions I, II, and III and perhaps 5 percent of urban car travel in the developing regions IV and VI might be accounted for by electric cars.

As a result of these and other assumptions, automobile energy use declines sharply in Region I, and shows a modest decline (as a share of total transportation energy use) in Region II and III. Regions IV, V, and VI contrast sharply with these results, with marked increases in total automobile energy use, largely because of the current low level of use.

Table 22 shows these projections for automobile energy use in the scenarios. The quantities are large, as can be seen. The gasoline consumption in cars in 2030 in Regions 1 through VI would amount to about 0.9 to $1.1 \mathrm{TWyr} / \mathrm{yr}$ of oil. One must ask the extent to which alternative transport modes could replace the car, and with what energy consequences.

Mass transit. In the projections over 50 years, North Americans travel relatively less by car for intercity trips, than currently. One reason is an assumed modest shift away from cars and toward mass transit for intercity travel. In other regions, the shift assumed is actually toward cars for intercity travel, but trains continue to play a very significant role in Regions II, III, V, and VI - by 2030, 35 to 40 percent in Region II, 20 to 35 percent in Region III, 16 percent in Region V, and 20 percent in Region VI, from 53 percent, 42 percent, 26 percent, and 10 percent in 1975. In Regions I and IV, train intercity travel is assumed to remain low -1 and 6 percent, respectively, of all intercity travel in 1975 to about 2 and 3 percent, respectively, in 2030 (see Table 21). 
TABLE 22 Energy use by automobiles in six world regions (GWyr/yr).

\begin{tabular}{|c|c|c|c|c|c|}
\hline \multirow[b]{2}{*}{ Region } & \multirow[b]{2}{*}{1975} & \multicolumn{2}{|c|}{ High scenario } & \multicolumn{2}{|c|}{ Low scenario } \\
\hline & & 2000 & 2030 & 2000 & 2030 \\
\hline \multicolumn{6}{|l|}{ I (NA) } \\
\hline Energy used by cars & 364 & 205 & 194 & 203 & 201 \\
\hline As $\%$ of total transportation energy & (67) & (32) & (19) & (36) & (29) \\
\hline \multicolumn{6}{|l|}{ II (SU/EE) } \\
\hline Energy used by cars & 26 & 45 & 63 & 42 & 50 \\
\hline As $\%$ of total transportation energy & (11) & (11) & (8) & (11) & (9) \\
\hline \multicolumn{6}{|l|}{ III (WE/J ANZ) } \\
\hline Energy used by cars & 111 & 214 & 249 & 168 & 179 \\
\hline As $\%$ of total transportation energy & (35) & (30) & (22) & (32) & (26) \\
\hline \multicolumn{6}{|l|}{ IV (LA) } \\
\hline Energy used by cars & 20 & 82 & 238 & 67 & 179 \\
\hline As $\%$ of total transportation energy & (19) & (20) & (21) & (22) & (25) \\
\hline \multicolumn{6}{|l|}{$V($ Af/SEA) } \\
\hline Energy used by cars & 17 & 67 & 277 & 60 & 216 \\
\hline As $\%$ of total transportation energy & (22) & (25) & (30) & (27) & (36) \\
\hline \multicolumn{6}{|l|}{ VI (ME/NAf) } \\
\hline Energy used by cars & 6 & 27 & 108 & 22 & 67 \\
\hline As $\%$ of total transportation energy & (13) & (13) & (18) & (16) & (21) \\
\hline
\end{tabular}

Travelers take to the air in greatly increasing numbers in these scenario projections for the developed market economies, both High and Low cases. The rate of growth is also high for developing regions, but from a much smaller starting amount. In Region IV intercity air travel would grow from 2.6 percent in 1975 to $6-8$ percent by 2030 ; in Regions V and VI the increase would be from 1.5 percent in 1975 to 3-7 percent by 2030 in the scenarios. In North America, airplane flights would account for as much as 30 percent of all intercity travel in 2030 (from 7 percent currently), while Region III would increase air travel from 3.5 percent currently to as much as 18 percent of all intercity travel by 2030 . In Region II, air travel may account for as much as 27 percent of all intercity movements by 2030 , from 20 percent currently.

In most cases load factors for trains, planes, and buses, are assumed to be approximately constant or increase only marginally in Regions I and III. This is not the case in the developing regions - overcrowding on buses and trains is the norm, not the exception. High population growth, coupled with the high mobility preferences accompanying income increases, keep the Regions IV and V load factors high, although a gradual relaxation of the present overcrowding is assumed to occur in parallel with increasing per capita income and slowing down of population growth. Load factors of 20 and 25 passengerkilometers per vehicle-kilometer for buses and about 140 for trains are common for Regions I and III. In Regions IV, V, and VI the bus load factors of 40-50 currently, fall to $20-40$ by 2030 in the scenarios, while train load factors fall from 500 to $200-400^{*}$. The bus and train load factors in Region II are also assumed to fall by a factor of 2 over the next 50 years and become comparable to those in Regions I and III (see Table 9.3.2, Group 3.2f). *Of course, varying "vehicle" size among and even within regions increases the difficulties of drawing
comparisons. 
Freight transportation. Freight transport is assumed to grow significantly in all world regions roughly in parallel with the activity levels in the agriculture, mining manufacturing, and energy sectors. It is a big business: some 5 trillion $\left(10^{12}\right)$ ton-kilometers of freight in 1975 reaches, by 2030, 11 trillion in the Low scenario and 19 trillion in the High scenario for the developed Regions I and III. Energy use increases by a factor of 2.4 to 3.9 over the 50-year period. (See Tables 20 and 23.) Freight transportation activity is much lower in Regions IV, V, and VI. These regions together had only about 2 trillion ton-kilometers of freight movement in 1975; an increase of 6 to 10 times that level is projected by 2030 . Gradual shifts toward increasing freight transportation on trains in Regions IV and VI and with trucks in Region V are assumed. No significant change is assumed in the present distribution of freight transportation modes in the developed regions I, II, and III. As a result of these assumptions, together with those concerning passenger travel, the share of freight movement in transportation energy would increase in Regions I and III and decrease, to varying extents, in other regions (see Table 20).

TABLE 23 Projections of freight transportation activity $\left(10^{12}\right.$ ton-km).

\begin{tabular}{llccllr}
\hline & & \multicolumn{2}{c}{ High scenario } & & \multicolumn{2}{c}{ Low scenario } \\
Region & 1975 & 2000 & 2030 & & 2000 & 2030 \\
\hline I (NA) & 3.1 & 7.0 & 12.5 & & 5.5 & 7.4 \\
II (SU/EE) & 4.6 & 10.0 & 21.8 & & 9.2 & 15.2 \\
III (WE/JANZ) & 1.5 & 3.5 & 6.0 & & 2.7 & 3.7 \\
IV (LA) & 0.9 & 3.4 & 9.9 & & 2.5 & 5.9 \\
V (Af/SEA) & 0.5 & 1.8 & 4.8 & & 1.4 & 2.9 \\
VI (ME/NAf) & 0.6 & 2.0 & 5.3 & & 1.4 & 2.8 \\
\hline
\end{tabular}

III Energy Demand of the Household/Service Sector

Table 24 lists the commercial final energy, demand projections of the household/ service sector in various regions. The evolution of energy demand in this sector markedly differs between the regions. According to these projections, the demand would increase by a factor of 7 to 12 in the developing regions IV, V, and VI, by a factor of about 2 in Regions II (SU/EE) and III (WE/JANZ); and by less than 30 percent in Region I (NA) over the next 50 years. The share of services in the final energy demand of the household/ service sector as a whole seems to increase in all the regions, with the largest increase occurring in Region VI and the smallest one in Region I. The use of electricity grows quite rapidly in both households and services so that an increasingly larger fraction of the demand of this sector will, in the future, have to be met by electricity in all the world regions. The share of electricity, in 2030 , for various world regions, is projected to be in the range of 30-50 percent for the High scenario as against 7-28 percent in 1975. These projections are the net outcome of our assumptions concerning likely changes in the values of a large number of parameters (see Table 9.3.3) that were considered necessary to describe the evolution of energy demand of this sector. In order to put these projections in proper perspective we give here a brief overview of the above-mentioned scenario assumptions in a relatively more aggregated form. 
TABLE 24 Projections of final energy demand* in the household/service sector (TWyr/yr).

\begin{tabular}{|c|c|c|c|c|c|}
\hline \multirow[b]{2}{*}{ Region } & \multirow[b]{2}{*}{1975} & \multicolumn{2}{|c|}{ High scenario } & \multicolumn{2}{|c|}{ Low scenario } \\
\hline & & 2000 & 2030 & 2000 & 2030 \\
\hline I (NA) & 0.57 & 0.66 & 0.74 & 0.62 & 0.64 \\
\hline (\% elec.) & (23) & (39) & $(50)$ & (37) & (46) \\
\hline (\% serv.) & (28) & (30) & (33) & (27) & (28) \\
\hline II (SU/EE) & 0.29 & 0.48 & 0.69 & 0.44 & 0.55 \\
\hline (\% elec.) & (7) & (21) & (33) & (17) & (26) \\
\hline (\% serv.) & (25) & (28) & (35) & (26) & (29) \\
\hline III (WE/JANZ) & 0.47 & 0.78 & 1.00 & 0.69 & 0.84 \\
\hline (\% elec.) & (18) & (28) & $(41)$ & $(28)$ & (37) \\
\hline (\% serv.) & $(14)$ & (15) & (19) & (15) & (17) \\
\hline IV (LA) & 0.031 & 0.11 & 0.26 & 0.10 & 0.21 \\
\hline (\% elec.) & (23) & (33) & (48) & (28) & (43) \\
\hline (\% serv.) & $(10)$ & (12) & (15) & (12) & (20) \\
\hline V (Af/SEA) & 0.028 & 0.12 & 0.30 & 0.11 & 0.25 \\
\hline (\% elec.) & (14) & (19) & (32) & (16) & (22) \\
\hline (\% serv.) & (9) & (12) & (16) & (10) & (12) \\
\hline VI (ME/NAf) & 0.015 & 0.06 & 0.18 & 0.05 & 0.12 \\
\hline (\% elec.) & (7) & (22) & (43) & (19) & (31) \\
\hline (\% serv.) & (7) & (19) & (32) & (18) & (29) \\
\hline
\end{tabular}

*The figures in this table refer only to the demand of commercial energy. These figures have been arrived at after taking into account the requirements of households that are/would be met by noncommercial fuels.

In 1975 there were 266 million homes in Regions I and III, 45 percent of which were centrally heated houses and apartments. There were on average 3.0 persons per household. Housing construction in the scenarios is assumed to be tied to the low population growth, allowing for further reductions in the assumed average number of persons per household by 2030: to 2.24 in Region I, and to 2.56 in Region III. Almost all new residential dwellings are assumed to be centrally heated; many are also air-conditioned. In these two regions by 2030 about 90 percent of dwellings will be centrally heated in the scenarios, compared to 45 percent currently. Air-conditioning will be available for $30-40$ percent of dwellings, as against 12 percent in 1975 .

In Regions IV, V, and VI taken together, the number of residential dwellings reaches about 1,130 million by 2030 , from 360 million in 1975 , with persons per household dropping from 5.22 to 4.16 . As most of these regions are warm, space heating requirements are relatively small; only about 25 percent of dwellings require space heat. By 2030, 17 to 19 percent are assumed to use space heat, compared to 11 percent in 1975 .

Service sector floor area increases fairly rapidly in Regions I and III, reflecting the high growth of the total service sector. By 2030, these regions will have from 1.7 to 2.1 times as much building area in use, and to be energy-serviced, as in 1975. In Region II the increase is even larger, from 3.2 to 4.0 times. Two main factors - higher population growth, and improvement in the working conditions of service sector employees - cause the growth in service sector activity in developing regions to be even greater than in developed regions. By 2030 service sector floor area in these regions is about 6.0 to 7.5 times that in 1975 . 
TABLE 25 Projected useful energy requirements in households $\left(10^{3} \mathrm{kWhr}(\mathrm{e}) /\right.$ household/year $)$.

\begin{tabular}{|c|c|c|c|c|}
\hline Region & Cooking & $\begin{array}{l}\text { Space/ } \\
\text { water } \\
\text { heating }\end{array}$ & $\begin{array}{l}\text { Air- } \\
\text { conditioning }\end{array}$ & $\begin{array}{l}\text { Misc. } \\
\text { elec. } \\
\text { appl. }\end{array}$ \\
\hline \multicolumn{5}{|l|}{1975} \\
\hline I (NA) & 1.2 & 25.3 & 1.0 & 3.9 \\
\hline II (SU/EE) & 1.2 & 11.9 & 0 & 0.9 \\
\hline III (WE/JANZ) & 1.3 & 9.5 & 0 & 2.0 \\
\hline IV (LA) & 1.9 & 1.0 & 0 & 0.7 \\
\hline$V($ Af/SEA) & 1.2 & 0.05 & 0 & 0.05 \\
\hline VI (ME/NAf) & 1.9 & 0.8 & 0.01 & 0.2 \\
\hline \multicolumn{5}{|c|}{2030 - High scenario } \\
\hline I (NA) & 1.2 & 18.2 & 2.0 & 8.0 \\
\hline II (SU/EE) & 1.2 & 14.4 & 0.2 & 5.0 \\
\hline III (WE/JANZ) & 1.3 & 12.8 & 0.5 & 6.0 \\
\hline IV (LA) & 2.1 & 2.9 & 0.4 & 3.4 \\
\hline $\mathrm{V}(\mathrm{Af} / \mathrm{SEA})$ & 1.4 & 0.2 & 0.02 & 0.5 \\
\hline VI (ME/NAf) & 2.1 & 3.8 & 0.7 & 3.3 \\
\hline \multicolumn{5}{|c|}{2030 - Low scenario } \\
\hline I (NA) & 1.2 & 18.2 & 1.7 & 6.3 \\
\hline II (SU/EE) & 1.2 & 13.6 & 0.2 & 3.0 \\
\hline III (WE/JANZ) & 1.3 & 11.4 & 0.4 & 4.5 \\
\hline IV (LA) & 2.1 & 2.3 & 0.2 & 2.2 \\
\hline$V(A f / S E A)$ & 1.4 & 0.1 & 0.01 & 0.3 \\
\hline VI (ME/NAf) & 2.1 & 3.1 & 0.4 & 1.2 \\
\hline
\end{tabular}

NOTE: Useful energy is expressed as electricity equivalent. Figures here are averages for all dwellings within a region.

Tables 25,26 , and 27 report some of the energy consumption figures associated with the household/service sector activity levels just cited. It is readily apparent from these tables that the largest energy-using device in buildings in developed regions is the space itself. Space heating, and to a lesser extent, air-conditioning, overwhelm other needs in residences; in service sector buildings, energy consumption due to electrical appliances is also very high. In Regions I and III, about 60 percent of useful energy in buildings goes to heating the inside air; in the scenario projections here this number decreases to $40-50$ percent, as various energy-reducing measures are introduced.

Improved insulation in homes, old and new, can reap substantial reductions in energy use. In the scenarios insulation improvements in new buildings and retrofit of pre1975 dwellings are assumed to reduce the heat losses in dwellings in Regions I, II, and III quite significantly. Retrofitting of the pre-1975 housing stock is assumed to reduce their heat losses by $20-30$ percent over the next 50 years. Post-1975 dwellings are already designed to have 10-15 percent lower heat losses today; according to the assumptions used here, by 2030 the average heat losses of all post. 1975 dwellings would be only 50 percent of those in 1975. Further gains are difficult beyond certain initial savings. Rising prices and an assumed increasing public awareness of energy uncertainties (plus a fair measure of government-instituted standards) are assumed to lead to these results. 
TABLE 26 Household use of electricity, 1975 and scenario assumptions $\left(10^{3} \mathrm{kWhr}(\mathrm{e}) /\right.$ household $)$.

\begin{tabular}{|c|c|c|c|c|c|}
\hline \multirow[b]{2}{*}{ Region } & \multirow[b]{2}{*}{1975} & \multicolumn{2}{|c|}{ High scenario } & \multicolumn{2}{|c|}{ Low scenario } \\
\hline & & 2000 & 2030 & 2000 & 2030 \\
\hline $\begin{array}{l}\text { I (NA) total electricity } \\
\text { (\% thermal uses) }\end{array}$ & $\begin{array}{l}9.4 \\
(59)\end{array}$ & $\begin{array}{l}13.0 \\
(52)\end{array}$ & $\begin{array}{l}15.0 \\
(47)\end{array}$ & $\begin{array}{l}11.9 \\
(56)\end{array}$ & $\begin{array}{l}12.9 \\
(52)\end{array}$ \\
\hline $\begin{array}{l}\text { II (SU/EE) total electricity } \\
\text { (\% thermal uses) }\end{array}$ & $\begin{array}{l}1.2 \\
(25)\end{array}$ & $\begin{array}{r}3.9 \\
(26)\end{array}$ & $\begin{array}{r}6.5 \\
(23)\end{array}$ & $\begin{array}{r}3.0 \\
(29)\end{array}$ & $\begin{array}{r}4.3 \\
(30)\end{array}$ \\
\hline $\begin{array}{l}\text { III (WE/JANZ) total electricity } \\
\text { (\% thermal uses) }\end{array}$ & $\begin{array}{l}3.1 \\
(38)\end{array}$ & $\begin{array}{r}6.0 \\
(39)\end{array}$ & $\begin{array}{r}9.1 \\
(34)\end{array}$ & $\begin{array}{r}5.3 \\
(38)\end{array}$ & $\begin{array}{r}7.1 \\
(36)\end{array}$ \\
\hline $\begin{array}{l}\text { IV (LA) total electricity } \\
\text { (\% thermal uses) }\end{array}$ & $\begin{array}{l}0.7 \\
(3)\end{array}$ & $\begin{array}{r}1.9 \\
(11)\end{array}$ & $\begin{array}{r}4.2 \\
(20)\end{array}$ & $\begin{array}{r}1.4 \\
(13)\end{array}$ & $\begin{array}{r}2.7 \\
(21)\end{array}$ \\
\hline $\begin{array}{l}\mathrm{V} \text { (Af/SEA) total electricity } \\
\text { (\% thermal uses) }\end{array}$ & $\begin{array}{r}0.05 \\
(1)\end{array}$ & $\begin{array}{l}0.2 \\
(4)\end{array}$ & $\begin{array}{l}0.5 \\
(8)\end{array}$ & $\begin{array}{l}0.1 \\
(3)\end{array}$ & $\begin{array}{r}0.3 \\
(11)\end{array}$ \\
\hline $\begin{array}{l}\text { VI (ME/NAf) total electricity } \\
\text { (\% thermal uses) }\end{array}$ & $\begin{array}{l}0.2 \\
(9)\end{array}$ & $\begin{array}{r}1.2 \\
(22)\end{array}$ & $\begin{array}{r}4.3 \\
(23)\end{array}$ & $\begin{array}{r}0.9 \\
(19)\end{array}$ & $\begin{array}{r}1.8 \\
(33)\end{array}$ \\
\hline
\end{tabular}

*Thermal uses include air-conditioning.

NOTE: Only for Region I (NA) were sufficient statistics available; for other regions estimates come from partial data and/or data for selected countries.

Consumption of electricity per household for specific uses (lighting, electrical appliances) is a direct assumption; consumption for thermal uses results from separate assumptions on useful energy consumption for space heating, water heating, cooking, and air-conditioning and from assumed penetration of electricity into these markets.

Electricity used for appliances has grown by great leaps and bounds in recent years, usually much faster than rises in real income. Increased disposable income has to date seemed to go in rather large shares to "extras" such as dishwashers, color televisions, clothes dryers. In Region I, and to some extent in Regions II and III, some flattening of this growth curve is postulated - appliance ownership saturates, and their energy efficiencies improve in response to rising prices.

Relative increases in electricity consumption for household appliances (see Table 25) are much higher by 2030 in developing regions - 3 to 5 times 1975 levels in Region IV, 5 to 10 times in Region V, and 6 to 17 times in Region VI - mainly because the present levels are so low. Most houses which use electricity at all in these regions today use it only for lighting and a bare minimum of other activities.

Another factor which is expected to play an important role in the future energy requirements of buildings in both the developed and developing regions is air-conditioning. Until now the extensive use of air-conditioning has been limited to Region I; scenario assumptions here project by 2030 considerable use of air-conditioning in several other world regions as well (see Tables 25 and 27).

At present the useful thermal energy requirements in the household/service sector are met essentially by fossil fuels and electricity in the developed regions and by fossil fuels and noncommercial energy in the developing regions. The scenario assumptions of Table 9.3.3 (Groups 3.3d and 3.3e) concerning the future use of noncommercial fuels; efficiency improvements in the use of all fuels; and penetration of electricity, soft solar, district heat, and heat pumps lead to the final energy demand patterns shown in Table 28. There, the large reliance on district heat in Region II is simply a logical extension of the present situation. Also, the higher fossil, and low electric, shares in developing regions 
TABLE 27 Useful energy * projections for service sector.

\begin{tabular}{|c|c|c|c|c|}
\hline Region & $\begin{array}{l}\text { Service sector } \\
\text { working area }\left(10^{9} \mathrm{~m}^{2}\right)\end{array}$ & $\begin{array}{l}\text { Space/water } \\
\text { heating }\end{array}$ & $\begin{array}{l}\text { Air- } \\
\text { conditioning }\end{array}$ & $\begin{array}{l}\text { Misc. } \\
\text { elec. } \\
\text { appl. }\end{array}$ \\
\hline \multicolumn{5}{|l|}{1975} \\
\hline I (NA) & 2.72 & 270 & 22 & 120 \\
\hline II (SU/EE) & 1.50 & 256 & 0 & 40 \\
\hline III (WE/JANZ) & 3.00 & 110 & 2 & 40 \\
\hline IV (LA) & 0.60 & 12 & 2 & 25 \\
\hline V (Af/SEA) & 1.25 & 1 & 0 & 15 \\
\hline VI (ME/NAf) & 0.18 & 20 & 2 & 15 \\
\hline \multicolumn{5}{|c|}{2030 - High scenario } \\
\hline I (NA) & 5.00 & 227 & 33 & 150 \\
\hline II (SU/EE) & 6.65 & 186 & 12 & 100 \\
\hline III (WE/JANZ) & 7.26 & 96 & 8 & 104 \\
\hline IV (LA) & 3.20 & 19 & 16 & 65 \\
\hline V (Af/SEA) & 9.40 & 2 & 2 & 38 \\
\hline VI (ME/NAf) & 2.54 & 52 & 20 & 100 \\
\hline \multicolumn{5}{|c|}{2030 - Low scenario } \\
\hline I (NA) & 3.79 & 225 & 28 & 136 \\
\hline II (SU/EE) & 4.75 & 186 & 8 & 80 \\
\hline III (WE/JANZ) & 5.99 & 95 & 6 & 89 \\
\hline IV (LA) & 3.41 & 22 & 14 & 66 \\
\hline V (Af/SEA) & 6.90 & 2 & 1 & 33 \\
\hline VI (ME/NAf) & 1.84 & 52 & 12 & 85 \\
\hline
\end{tabular}

*Useful energy is expressed as electricity equivalent $\left(\mathrm{kWhr}(\mathrm{e}) / \mathrm{m}^{2}\right)$.

TABLE 28 Shares of energy sources in the household/service sector heat market (\% of total useful thermal energy).

\begin{tabular}{|c|c|c|c|c|c|c|c|c|c|c|}
\hline \multirow[b]{3}{*}{ Region } & \multicolumn{10}{|c|}{ High scenario } \\
\hline & \multicolumn{5}{|l|}{2000} & \multicolumn{5}{|l|}{2030} \\
\hline & $\mathrm{NCE}^{*}$ & $\mathrm{FF}$ & EL & $\mathrm{DH}^{* *}$ & SS & $\mathrm{NCE}$ & FF & EL & $\mathrm{DH}$ & SS \\
\hline I (NA) & 0 & 68 & 24 & 0 & 8 & 0 & 56 & 31 & 0 & 13 \\
\hline Ш (SU/EE) & 4 & 44 & 6 & 43 & 3 & 3 & 22 & 10 & 60 & 5 \\
\hline III (WE/JANZ) & 0 & 73 & 15 & 6 & 6 & 0 & 55 & 21 & 13 & 11 \\
\hline IV (LA) & 18 & 72 & 3 & 1 & 6 & 14 & 57 & 9 & 8 & 12 \\
\hline V (Af/SEA) & 37 & 63 & 0 & 0 & 0 & 26 & 70 & 2 & 0 & 2 \\
\hline VI (ME/NAf) & 3 & 94 & 2 & 0 & 1 & 2 & 86 & 5 & 2 & 5 \\
\hline
\end{tabular}

*In 1975, noncommercial energy share is estimated to be 7, 39, 68, and 9 percent in Regions II, IV, V, and VI, respectively. The Low scenario shares are quite similar to those in the High scenario.

* The share of district heat in Region II was already 25 percent in 1975 .

$\mathrm{NCE}=$ noncommercial energy sources; FF $=$ fossil fuels (for Regions IV, V, and VI, this column includes the fossil fuel equivalent of charcoal/wood and biogas to be supplied as commercial fuel); EL = electricity; $\mathrm{DH}=$ district heat; $\mathrm{SS}=$ soft solar. 
than in developed reflect the end-use patterns typical in buildings in these two kinds of regions.

The extent of conservation implied in these projections may be judged from the fact that use of heat pumps in electrical heating to the extent of 40-50 percent in Regions I, II, and III and 12 percent in Regions IV and VI as well as efficiency improvements of 10 to 25 percent in the use of fossil fuels in different world regions, have been assumed possible by 2030 .

In spite of the unfavorable cost economics of present soft solar devices, we have introduced fairly aggressive buildup rate assumptions for soft solar systems in the household/service sector in both the developed and the developing regions (see Table 9.3.3, Group 3.3d). For example, it has been assumed that 50 percent of all new (post-1975) single-family centrally heated homes and low rise service sector buildings will install solar heating systems (the assumptions are 30 percent for Region II and 20 percent for Region VI). These systems will be 50 to 80 percent solar - that is, requiring backup (oil, electric, gas) for 20 to 50 percent of the time. Further, it is assumed that by $203030-40$ percent of all the households in Regions I, III, IV, and V, and 15-20 percent in Regions II and VI, would be using solar water heating systems. With these assumptions one finds by 2030 that soft solar devices would support 10-11 percent of the household/service sector's space and water heating demand in the developed Regions I, II, and III and about 14 percent of the corresponding demand in the developing Regions IV, V, and VI, in both the High and the Low scenarios. The shares of soft solar in the total useful thermal energy demand (including cooking and air-conditioning requirements) will be even lower, as shown in Table 28 for the High scenario.

The rather optimistic buildup rate assumptions for soft solar used in this assessment serve to explore a reasonable upper bound to what they could contribute in the energy mix. However, the ultimate soft solar contribution seems to be constrained by the size of the market - the demands for space and water heat in detached houses or low-rise service sector buildings are not excessive. Moreover, in the developing regions, a large fraction of the useful heat demand of the household/service sector originates from cooking requirements. This fraction was about 82 percent in 1975 and remains as high as 59-64 percent by 2030 . Further, in these regions most of the dwellings that need space heating are heated with only detached room heaters and this practice is expected to continue although at a lower level - in spite of increased income levels, as the heating seasons and requirements are generally small.

\subsubsection{Electricity Demand}

In the developed regions, electricity demand has been growing rapidly - significantly faster than GDP and faster than the demand for other energy forms. High end-use efficiency, flexibility, and ease of control make this energy form economically more attractive than other energy carriers, such as coal or even oil and gas, which in general require a larger technological effort at the point of end-use. On the other hand, thermal generation of electricity involves large conversion losses, and the expected price rises for primary fuels will make it necessary to economize its use* - to restrict it as much as possible to essential uses.

*The impact of higher generation costs can be judged from the significantly lower levels of electrification in countries with predominantly thermal generation (typically $10-14$ percent) than in countries with great hydropower potential (e.g., Norway with about 20 percent of final energy consumption). 
In view of these considerations, our assumptions concerning penetration of electricity in the household/service sector heat market have been fairly conservative. In the marketeconomy developed regions $I+I I I$, it is assumed that price increases for electricity in general and the problem of large peaks in the winter season in particular would discourage consumers to use electricity as the main energy carrier for heating. In the centrally planned Region II, the emphasis has been, and probably will be, to provide space heat and hot water with district heat, either from combined heat and power plants, or from boiler plants which allow an economical use of low-grade fuels. As a result of the various assumptions, specific uses of electricity in the household/service sector in the developed regions grow by a factor of 4.8 and 3.4 between 1975 and 2030 in the High and Low scenarios, respectively; with respect to thermal uses of electricity, the two scenarios differ only modestly, with factors of growth between 1975 and 2030 of 3.1 and 2.8 , respectively (Table 29).

In industry, the differences in the level of electrification between the three developed regions are not as great as in the household/service sector (see Vigdorchik 1976). Unfortunately, the lack of data does not permit a separation of thermal uses (furnaces, small boilers, etc.) from specific uses (lighting, electric drives, electrolysis, etc.). As indicated in Table 29, only the incremental electricity penetration into thermal uses above the present levels is considered. Data for France and Austria indicate that about 10 percent of the useful thermal energy demand is supplied by electricity. If this figure is applied to the developed regions I + II + III, the resulting estimates of thermal and specific uses of electricity in industry are 94 and $217 \mathrm{GWyr} / \mathrm{yr}$ in 1975, which corresponds to a ratio of 1:2.3.

For the scenarios, no change was assumed in the energy intensity of industry with respect to specific electricity requirements. While in the past there was an increase in almost all industry sectors, mainly as a result of increasing automation. However, the refined control mechanisms that are possible through the use of microprocessors will help to rationalize processes better and perhaps allow a reduction in energy use despite more automation. No significant further penetration into thermal uses was assumed following the general guideline to minimize the use of primary fuels. However, the situation in industry is different from that in the household/service sector. In the latter sector the major share of thermal energy demand is in the low-temperature range, where electricity offers more convenience, but requires a larger amount of primary fuels than direct combustion of fossil fuels. In industry, about 40 percent of the thermal energy demand is in the high-temperature range, and in these applications electricity is in some cases even superior from an energetic point of view, in addition to being economically advantageous. In the light of these considerations, the projections of industrial electricity demand are probably on the conservative side. "Specific uses" in the three developed regions increase by factors of 4.2 and 3.7 in the High and Low scenarios, respectively, while the total industrial electricity use increases by factors of 4.9 and 3.0 , respectively. Assuming that about one-third of the electricity demand for the so-called "specific uses" would actually be for thermal uses, electricity would cover about 21-24 percent of the useful thermal energy demand in 2030 . Since it would mainly be used in the hightemperature range, this means that by 2030 about 50-60 percent of the high-temperature demand would be supplied by electricity.

The situation of the developing regions (IV $+\mathrm{V}+\mathrm{VI}$ ) could be compared to that in the developed regions several decades previous, when large areas had no access to 
TABLE 29 Thermal energy and electricity demand in the two scenarios (GWyr $/ \mathrm{yr})$.

\begin{tabular}{|c|c|c|c|c|c|c|c|c|c|c|}
\hline & \multicolumn{5}{|c|}{ Developed regions $(\mathrm{I}+\mathrm{II}+\mathrm{III})$} & \multicolumn{5}{|c|}{ Developing regions (IV + V + VI) } \\
\hline & \multirow[b]{2}{*}{1975} & \multicolumn{2}{|c|}{ High scenario } & \multicolumn{2}{|c|}{ Low scenario } & \multirow[b]{2}{*}{1975} & \multicolumn{2}{|c|}{ High scenario } & \multicolumn{2}{|c|}{ Low scenario } \\
\hline & & 2000 & 2030 & 2000 & 2030 & & 2000 & 2030 & 2000 & 2030 \\
\hline $\begin{array}{l}\text { Useful thermal energy demand: } \\
\text { Industry } \\
\text { Household/service }\end{array}$ & $\begin{array}{l}939 \\
781\end{array}$ & $\begin{array}{l}1,775 \\
1,170\end{array}$ & $\begin{array}{l}2,672 \\
1,457\end{array}$ & $\begin{array}{l}1,504 \\
1,091\end{array}$ & $\begin{array}{l}1,894 \\
1,306\end{array}$ & $\begin{array}{r}105 \\
67\end{array}$ & $\begin{array}{l}484 \\
163\end{array}$ & $\begin{array}{r}1,351 \\
344\end{array}$ & $\begin{array}{l}339 \\
157\end{array}$ & $\begin{array}{l}694 \\
316\end{array}$ \\
\hline Total & 1,720 & 2,945 & 4,129 & 2,595 & 3,200 & 172 & 647 & 1,695 & 496 & 1,010 \\
\hline $\begin{array}{l}\text { Of which supplied by electricity: } \\
\text { Industry* } \\
\text { Household/service }\end{array}$ & $\begin{array}{r}0 \\
75\end{array}$ & $\begin{array}{r}85 \\
164\end{array}$ & $\begin{array}{l}215 \\
234\end{array}$ & $\begin{array}{r}60 \\
152\end{array}$ & $\begin{array}{l}113 \\
210\end{array}$ & $\begin{array}{l}0 \\
0\end{array}$ & $\begin{array}{r}10 \\
3\end{array}$ & $\begin{array}{l}93 \\
16\end{array}$ & $\begin{array}{l}7 \\
3\end{array}$ & $\begin{array}{l}48 \\
14\end{array}$ \\
\hline Total & 75 & 249 & 449 & 212 & 323 & 0 & 13 & 109 & 10 & 62 \\
\hline $\begin{array}{l}\text { Specific uses of electricity: } \\
\text { Industry } \\
\text { Household/service }\end{array}$ & $\begin{array}{l}311 \\
153\end{array}$ & $\begin{array}{l}694 \\
397\end{array}$ & $\begin{array}{r}1,305 \\
738\end{array}$ & $\begin{array}{l}563 \\
328\end{array}$ & $\begin{array}{l}828 \\
520\end{array}$ & $\begin{array}{l}39 \\
11\end{array}$ & $\begin{array}{r}235 \\
68\end{array}$ & $\begin{array}{l}763 \\
264\end{array}$ & $\begin{array}{r}168 \\
51\end{array}$ & $\begin{array}{l}409 \\
161\end{array}$ \\
\hline Total & 464 & 1,091 & 2,043 & 891 & 1,340 & 50 & 303 & 1,027 & 219 & 570 \\
\hline Electricity use for transportation & 16 & 46 & 116 & 41 & 87 & 1 & 4 & 35 & 3 & 24 \\
\hline
\end{tabular}

* Only electricity penetration into thermal uses above the present level is considered, because a separation of thermal and specific uses in 1975 was not possible due to lack of data. A very rough estimate for the developed regions could be 10 percent of useful thermal energy demand, or $90-100 \mathrm{GWyr} / \mathrm{yr}$. 
electricity and many households used electricity for lighting. As a result of increasing rural electrification and higher levels of per household electricity consumption as well as due to high population and industrial growth rates assumed for the developing regions, the two scenarios imply a rapid increase of electricity demand during the study period:

Specific uses, household/service sector: $\quad \times 24(\mathrm{H}) / \times 15(\mathrm{~L})$

Total uses, household/service sector: $\quad \times 25(\mathrm{H}) / \times 16(\mathrm{~L})$

Specific uses, industry: $\quad \times 20(\mathrm{H}) / \times 10(\mathrm{~L})$

Total uses, industry: $\quad \times 22(\mathrm{H}) / \times 12(\mathrm{~L})$

In the case of developing regions, air-conditioning could cause a rapid increase in electricity demand. Most of the population in the developing Regions IV, V, and VI lives in warm climatic zones and the use of comfort air-conditioning may be expected to increase with increasing per capita income. In the scenarios considered here the average use of airconditioning per dwelling and per square meter of service sector floor area in 2030 in Regions IV (LA) and VI (ME/NAf) is assumed to become comparable to that envisaged for the developed Regions I, II, and III (see Tables 25 and 27). However the air-conditioning requirements (per dwelling or per square meter of service sector floor area) of Region $\mathrm{V}$ (Af/SEA) are assumed to be an order of magnitude smaller, despite a latent demand, in view of the low income levels that will persist in this region even 50 years from now.

\section{CONCLUDING REMARKS}

The projections of final energy demand till 2030 for six out of the seven comprehensive world regions considered in IIASA's energy study (Energy Systems Program Group 1981) and the various underlying assumptions have been discussed at some length. In evaluating them one has to appreciate that projecting energy demand in a medium- to long-term frame is a fundamentally complex issue - full of uncertainties and pitfalls.

One gets a feeling of the difficulties and uncertainties involved in such an undertaking by looking at the various medium- to long-term energy demand projections available for one country, i.e., the US, whose present pattern of energy consumption is best understood and the relevant historical data of which are best documented. A number of recent primary energy projections for the US are plotted in Figure 7. The wide variation in these projections aptly illustrates the difficulties involved. Obviously, the uncertainties increase as the projections extend to larger world regions covering several countries, given an availability of data that is much less satisfactory than for the US. Nonetheless, estimates of future energy requirements of the various world regions are essential for us to appreciate the kind and size of problems the world may have to face in the wake of dwindling global conventional fuel resources and in order to be prepared to meet the challenge.

The assessments of final energy demand reported here represent such an effort. Of course, they are not predictions or forecasts; in our judgment, they simply describe a range of realistic evolutions of future energy demand in various world regions that are consistent with a plausible range of world economic development and population growth.

The world's energy demand increased more or less exponentially between 1950 and 1975 at an average growth rate of 5 percent per year (see e.g., Doblin 1979). Obviously, 


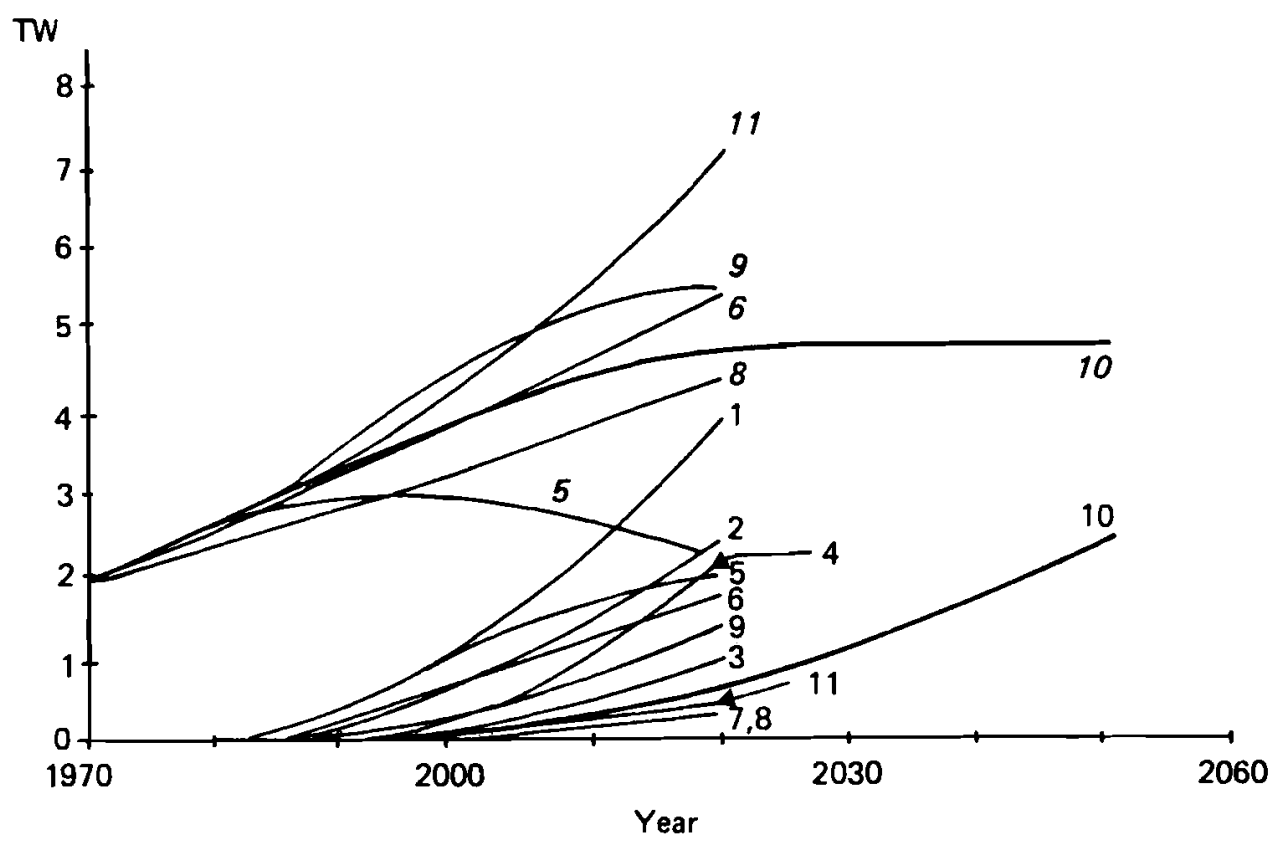

FIGURE 7 Some recent projections of primary energy demand and potential solar shares ofr the US. Italic numbers describe projections of total energy demand; roman numbers indicate total energy demand potentially available from solar energy sources: (1) MITRE (1973), (2) Morrow (1973) "maximum solar", (3) Morrow (1973) "minimum solar", (4) Wolf (1974), (5) Lovins (1976), (6, 7, 8) Renyl et al. (1976), (9) ERDA 49 (1975), CONAES (1977), (10) Weingart and Nakicenovic (1979), (11) Beller ed. (1975) "future energy reference system".

this trend cannot continue in view of the limited resources of conventional fuels. Although there are sources of energy - solar and nuclear (through breeding and fusion) - that promise virtually unlimited supply, the present status and cost economics of these sources is such that they may, at best, be expected to play only a minor role in the next 15-50 year period. Therefore, energy conservation leading to a shift away from the exponential energy growth trend of the last 30 years is indispensible. However, significant energy conservation is possible only in the most highly developed countries; most of the population in the developing world still lives at levels of energy consumption close to subsistence and will need increasing amounts of energy to improve. The assessment of energy demand reported here is based on what we would consider optimistic, though not unrealistic, assumptions about measures of energy conservation and possible technological improvements.

The extent of energy savings embodied in the two scenarios can be seen in Figures $8 \mathrm{a}$ and $8 \mathrm{~b}$, where final energy per unit of GDP is plotted against GDP per capita for Regions I through VI. There the ratio of final energy demand to GDP is seen to continue to decrease for the developed Regions 1 , II, and III in line with the historical trends. On the other hand, the ratio continues to increase, at least initially, for all the developing regions, again in line with the historical trends, but flattens off later and even starts to fall in Regions IV and VI. These different trends in the developed and the developing regions are characteristic of economies that have already reached a high level of industrialization, but are still in the process of building up their industrial infrastructure. 


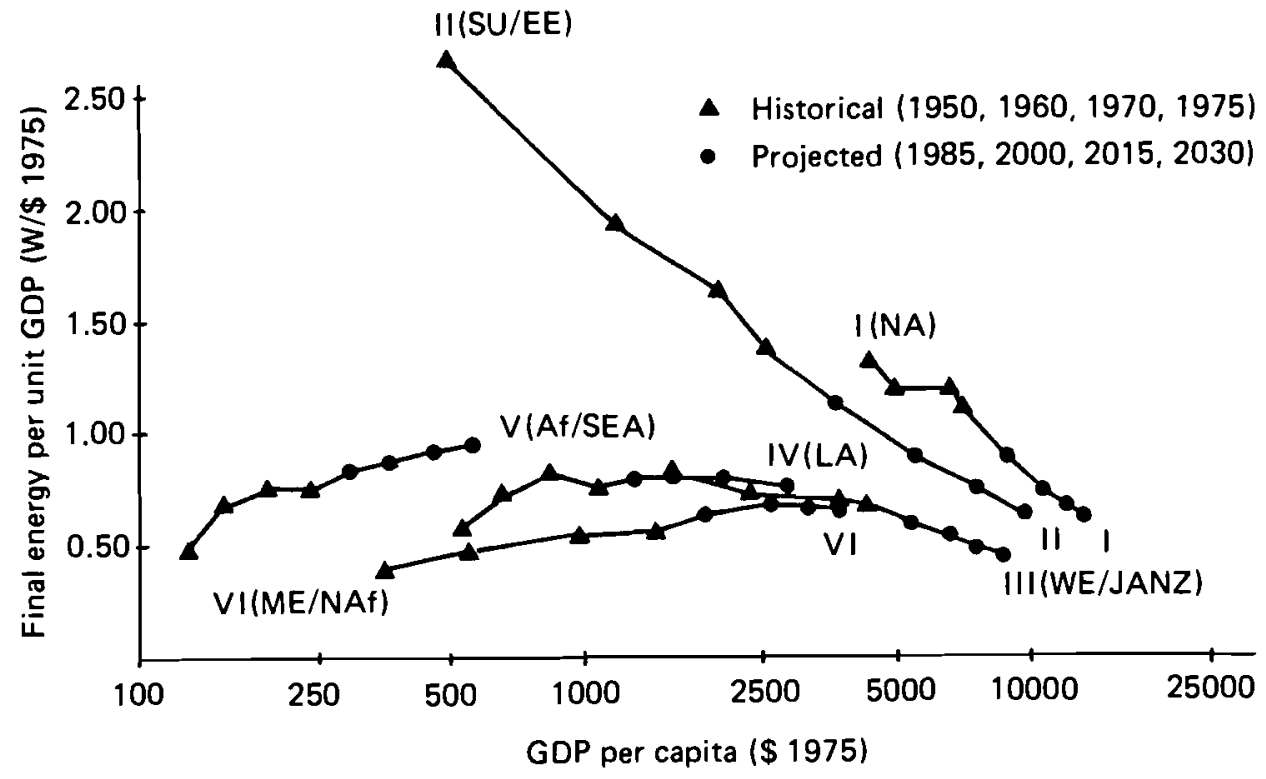

FIGURE 8a Energy intensity in different world regions (High scenario).

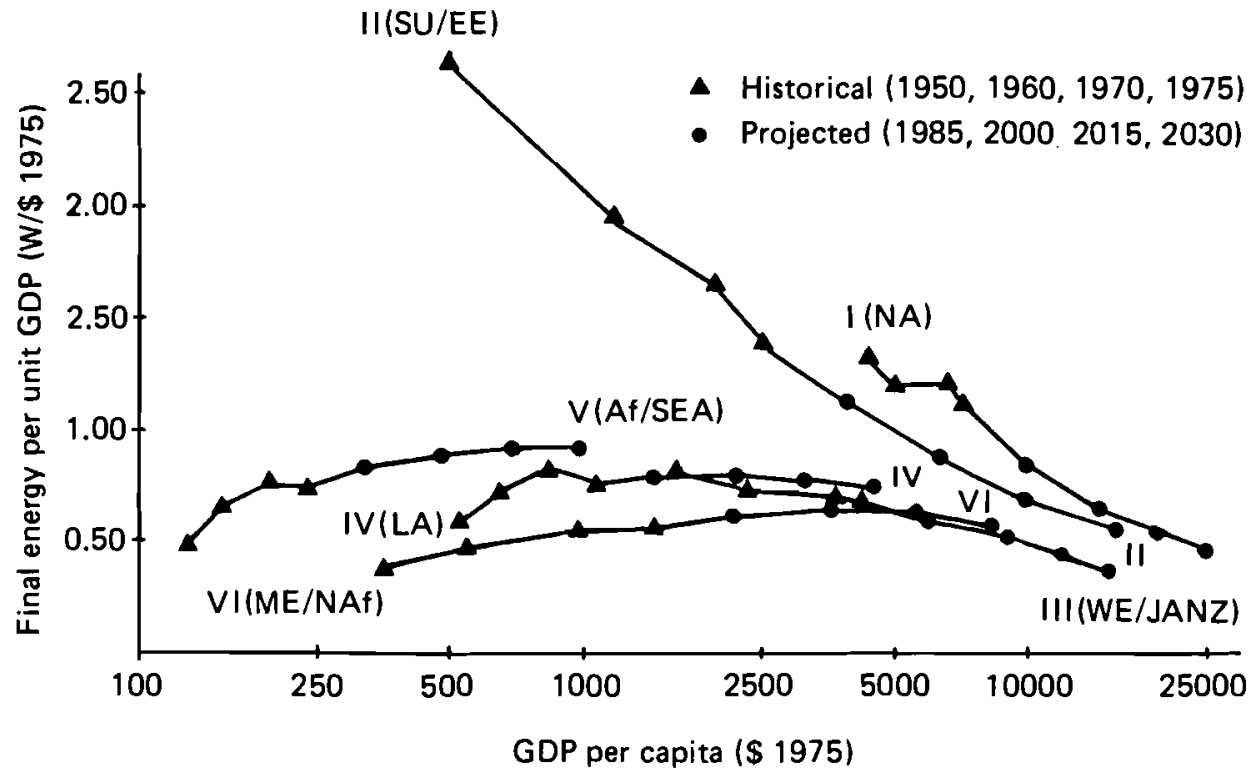

FIGURE 8b Energy intensity in different world regions (Low scenario). 
Globally speaking, the curves of Figures $8 \mathrm{a}$ and $8 \mathrm{~b}$ imply a reduction of final energy per dollar of GDP from 0.91 in 1975 to 0.53 and 0.62 in 2030 for the High and the Low scenarios, respectively. If only the developed Regions I, II, and III are considered, the improvement is even more impressive: final energy per dollar of GDP decreases from 0.95 in 1975 to 0.45 and 0.55 over a period of 55 years. By far the largest improvement is seen in Region II (SU/EE), where the overall conservation resulting from various scenario assumptions amounts to 61 and 54 percent. The corresponding figures for Region I are 59 and 44 percent and for Region III (WE/JANZ) 45 and 33 percent. These improve ments, seen in the light of real price increases of 3.0 and 2.4 times the prices in the recent past (see Energy Systems Program Group 1981, Chant 1981) appear quite pronounced but not unrealistic. Some measures behind this trend have been reported here in detail. Indicators such as automobile efficiency, average transport load factors, home insulation, structural changes in industry and others have been cited to illustrate the extent of the energy-using improvements assumed.

Another measure of the efficiency improvements assumed in the scenarios can be derived by calculating the final energy that would result by 2030 if the historical 1950 1975 final energy-to-GDP elasticity were applied for 1975 to 2030 . Table 30 shows the differences between final energy calculated in this way and the final energy projections of the High and the Low scenarios.

TABLE 30 Final energy in the two scenarios compared to final energy calculated with historical elasticities (2030).

\begin{tabular}{lllllll}
\hline & $\begin{array}{l}\text { High } \\
\text { scenario } \\
(\mathrm{GWyr} / \mathrm{yr})\end{array}$ & $\begin{array}{l}\text { With } \\
\text { historical } \epsilon_{\mathrm{f}} \\
(\mathrm{GWyr} / \mathrm{yr})\end{array}$ & $\begin{array}{l}\text { Difference** } \\
(\%)\end{array}$ & $\begin{array}{l}\text { Low } \\
\text { scenario } \\
(\mathrm{GWyr} / \mathrm{yr})\end{array}$ & $\begin{array}{l}\text { With } \\
\text { historical } \epsilon_{\mathrm{f}}^{*} \\
(\mathrm{GWyr} / \mathrm{yr})\end{array}$ & $\begin{array}{l}\text { Difference** } \\
(\%)\end{array}$ \\
\hline I (NA) & 3,665 & 6,921 & 47 & 2,636 & 4,036 & 35 \\
II (SU/EE) & 4,114 & 5,355 & 23 & 2,952 & 3,850 & 23 \\
III (WE/JANZ) & 4,375 & 6,037 & 28 & 2,987 & 3,761 & 21 \\
IV (LA) & 2,641 & 4,385 & 40 & 1,656 & 2,481 & 33 \\
V (Af/SEA) & 3,175 & 6,900 & 54 & 1,876 & 3,121 & 40 \\
VI (ME/NAf) & 1,620 & 2,590 & 37 & 850 & 1,015 & 16 \\
& & & & & & \\
Total of I to VI & 19,590 & 32,188 & 39 & 12,957 & 18,264 & 29 \\
\hline
\end{tabular}

*Calculated using historical (1950-1975) final energy-to-GDP elasticity $\left(\epsilon_{\mathrm{f}}\right)$ for each region.

** Calculated as final energy using historical $\epsilon_{\mathrm{f}}$ minus IIASA scenario projection divided by final energy using historical $\epsilon_{\mathrm{f}}$.

Savings of roughly 20 to 50 percent occur in each region. The demand reductions in Regions I to VI through conservation measures embodied in the two IIASA scenarios thus represent a net final energy saving of 5.3 to $12.6 \mathrm{TWyr} / \mathrm{yr}$ by 2030 .

These amounts are certainly substantial. They underscore the aggressive conservation measures assumed in the scenarios. They reflect the belief that vigorous action to increase energy efficiency and to improve energy productivity is a necessity in any energy strategy - short-, medium- or long-term. Without such improvements, the adequate supply of energy necessary to meet the demand at the levels of world economic and 
population growth assumed would probably run into serious difficulties, and the two IIASA energy supply scenarios (Energy Systems Program Group 1981) might not have proved to be feasible.

The appropriate energy supply strategies corresponding to the two final energy demand scenarios discussed in this report have been described in detail in the Energy Systems Program Group (1981). They indicate that meeting the global requirements of energy will become increasingly more difficult with time. Still the demand can be met with the help of technologies which are either in hand or expected to be commercially available (at economical costs) in the near future. The two IIASA supply scenarios imply provision of $22.4 \mathrm{TW}$ to $35.7 \mathrm{TW}$ of primary energy globally in the year 2030 . This is by mining 6.5 to $12.0 \mathrm{TWyr} / \mathrm{yr}$ of coal, as against $2.3 \mathrm{TWyr}$ in 1975 , (of which 52 percent to 56 percent will be required for making synthetic liquid fuel), by exploiting 1.6 to 3.5 $\mathrm{TWyr} / \mathrm{yr}$ of unconventional oil reserves of tar sand, shale, heavy crude, and by generating 1.8 to $2.9 \mathrm{TWyr}$ of electricity through nuclear reactors (of which 1.2 to $1.8 \mathrm{TWyr}$ will be from fast breeder reactors). All this would call for tremendous efforts and heavy investments - the investment required for building the energy supply infrastructure will increase to a level of about 4.5 percent of the gross world product (as against 2.5 percent in 1975). One, therefore, wonders if it is possible to cut down the energy demand for a given economic growth much beyond the level envisaged in the present assessment by invoking additional conservation. In order to assess the implications of extreme conservation measures, a scenario was developed for Regions I (NA) and III (WE/JANZ) (see Energy Systems Program Group 1981) that gave final energy demand in 2030. This was lower by 32 percent than the Low scenario demand of Region I and 45 percent lower than Region III (implying zero final energy growth between 1975 and 2030 for Regions I and III taken together) for the same economic growth as in the case of the Low scenario. Possible percentage reductions in total and sectoral final energy demand as well as in demand by fuel types for the two regions, resulting from incorporating extreme conservation in the Low scenario, are listed in Table 31.

What such an extreme conservation would imply may be judged to a certain extent by comparing some major assumptions of the Low scenario and the Extreme Conservation scenario listed in Table 32. The Extreme Conservation scenario differs from the Low scenario essentially in the following features: a large shift in the structure of GDP formation towards services and within the manufacturing sector away from energyintensive heavy industries and towards less energy-intensive construction of machinery and equipment; reduced activity level projections, particularly in the transportation sector; higher efficiency improvements, particularly for activities pertaining to the industry and household/service sectors; reduced or phased out penetration of electricity into thermal uses; and finally, reduced use of electrical appliances in dwellings, and of comfort heating and air-conditioning in the household/service sector buildings.

In some cases, changes in important energy-using activities were rather modest because, it was felt, sufficiently aggressive changes were already incorporated into the Low scenario. For example, automobiles were assumed to reach an average efficiency of $7.41 / 100 \mathrm{~km}(32 \mathrm{mpg})$ in Region I by 2030 in the Low scenario, from a 1975 average

*Including the primary energy requirements of Region VII (China and Centrally Planned Asian Economies) which are projected as $2-3 \mathrm{TW}$ and $4.5 \mathrm{TW}$ for the Low and High scenarios, respectively. 
TABLE 31 Percentage reduction in an Extreme Conservation scenario compared to the Low scenario final energy demand in 2030, Regions I (NA) and III (WE/JANZ).

\begin{tabular}{llll}
\hline & \multicolumn{2}{l}{ Percent reduction requircd in } & \\
\cline { 2 - 3 } & Region I & Region III & Regions I and III \\
\hline Total final energy & -32 & -45 & -39 \\
By sector & & & \\
Transportation & -40 & -45 & -43 \\
Industry & -38 & -54 & -47 \\
Household/service & -8 & -28 & -19 \\
By energy form & & & \\
Substitutable fossil fuels* & -18 & -40 & -29 \\
Centrally supplied heat** & na & -34 & -34 \\
Soft solar & -18 & -35 & -26 \\
Electricity & -52 & -55 & -54 \\
Motor fuel & -37 & -40 & -38 \\
Coke and feedstocks & -27 & -56 & -45 \\
\hline
\end{tabular}

* Substitutable fossil fuels are thermal uses of oil, gas, and coal.

** Centrally supplied heat is steam and hot water from district heat or cogeneration plants. na: Not applicable.

TABLE 32 Some major assumptions for an Extreme Conservation case compared to those of the Low scenario.

\begin{tabular}{|c|c|c|c|c|c|c|}
\hline & \multicolumn{3}{|c|}{ Region I } & \multicolumn{3}{|c|}{ Region III } \\
\hline & \multirow[b]{2}{*}{1975} & \multicolumn{2}{|l|}{2030} & \multirow[b]{2}{*}{1975} & \multicolumn{2}{|l|}{2030} \\
\hline & & $\begin{array}{l}\text { Low } \\
\text { scenario }\end{array}$ & $\begin{array}{l}\text { Extreme } \\
\text { Conservation }\end{array}$ & & $\begin{array}{l}\text { Low } \\
\text { scenario }\end{array}$ & $\begin{array}{l}\text { Extreme } \\
\text { Conservation }\end{array}$ \\
\hline \multicolumn{7}{|l|}{ Macroeconomics, lifestyle } \\
\hline Manufacturing (\% of GDP) & 24.5 & 23.8 & 20 & 33.6 & 29.7 & 20 \\
\hline Services (\% of GDP) & 64.8 & 65.8 & 69.6 & 48.5 & 55 & 64.7 \\
\hline \multicolumn{7}{|l|}{ Basic materials (\% of } \\
\hline manufacturing-VA) & 24.8 & 23.2 & 20 & 33 & 29.4 & 20 \\
\hline $\begin{array}{l}\text { Machinery and equipment (\% of } \\
\text { manufacturing-VA) }\end{array}$ & 43.2 & 47 & 50.2 & 42 & 47.1 & 55 \\
\hline \multicolumn{7}{|l|}{ Intercity passenger transportation } \\
\hline year $(1,000 \mathrm{~km})$ & 10 & 15 & 10 & 7.5 & 10 & 7.5 \\
\hline Persons per car & 2 & 1.9 & 2 & 5.21 & 3.20 & 4 \\
\hline \multicolumn{6}{|l|}{ Distance driven per car per year, } & 5 \\
\hline Bus (\% of public transportation) & 15 & 12 & 30 & 35 & 29 & 35 \\
\hline Train (\% of public transportation) & 5 & 5 & 20 & 50 & 56 & 60 \\
\hline Plane (\% of public transportation) & 80 & 83 & 50 & 5 & 15 & 5 \\
\hline \multicolumn{7}{|l|}{ Dwellings } \\
\hline $\begin{array}{l}\text { Electrical use for appliances } \\
(1,000 \mathrm{kWhr}(\mathrm{e}) / \mathrm{d} \text { welling })\end{array}$ & 3.85 & 6.25 & 3.85 & 1.95 & 4.50 & 2.20 \\
\hline $\begin{array}{l}\text { Useful energy for air-conditioning } \\
\text { per dwelling }(1,000 \mathrm{kcal})\end{array}$ & 4,472 & 5,800 & 4,472 & & 3,000 & \\
\hline Dwelling with air-conditioning (\%) & 39 & 50 & 20 & 0 & 20 & 0 \\
\hline
\end{tabular}

NOTE: These assumptions are selected from an array of changes. They both represent the largest changes and have the most energy-reducing impact. In some instances (e.g., automobile efficiency or home insulation) the assumptions for the Low scenario were regarded as sufficiently rigorous so that only rather minor further improvements could be introduced into the Extreme Conservation case. 
of $17.11 / 100 \mathrm{~km}$ (14 mpg). This projection to 2030 was unchanged for the Extreme Conservation scenario. In Region III, automobile efficiency was assumed to improve from about $9.91 / 100 \mathrm{~km}$ in 1975 to about $7.21 / 100 \mathrm{~km}$ in 2030 in the Low scenario and to about $5.51 / 100 \mathrm{~km}$ in the Extreme Conservation scenario. Similarly, improvements in the technical efficiency of fossil fuel use from the Low scenario to the Extreme Conservation scenario could not be too substantial, given the already high efficiencies assumed for the former.

Whereas this exercise indicates that reduction of energy demand, at least in the developed regions, by some 30-45 percent below the levels envisaged in the present assessment may be possible through extreme conservation measures, it is not clear as to what actions (energy price increases, tax benefits, early amortization allowances etc.) would be required to spur such changes. In our opinion, therefore, it will not be prudent to rely for future energy planning on such extreme conservation possibilities which are rather unlikely to happen.

\section{ACKNOWLEDGMENTS}

Many members of the IIASA Energy Systems Program have helped during the course of work described in this report. The authors would like to acknowledge all such help and useful discussions with various members of the Program although it would be difficult to name all of them individually. Still, we feel that our special thanks are due to:

$P$. Basile and V. Chant for many useful suggestions at various stages of this work and for carrying out a critical evaluation of the MEDEE-2 results in economic terms in general, and in relation to expected rising costs of different fuels in particular. Such an evaluation and subsequent feedback were very necessary to remove certain inconsistencies in the results at early stages of the MEDEE-2 runs.

B. Lapillonne, who implemented the MEDEE-2 model at IIASA, established the base year data set for the US (about 90 percent of Region I), and also helped establish the base year values for Region III (Western Europe, Japan, Australia, and New Zealand).

H. Maier, A. Papin, and Y. Sinyak for providing useful information on Region II (Soviet Union and Eastern Europe) and for reviewing the energy demand projections for this region.

J.C. di Primio for advising on various aspects of the study on Region IV (Latin America) in particular, and on important considerations relevant to all the developing regions in general.

Finally, we are most grateful to Professor W. Häfele, Leader of the Energy Systems Program at IIASA, for his guidance, suggestions, and encouragement throughout the course of this work. In fact, without his advice and critical assessment, this work could not have been completed in its present form.

\section{REFERENCES}

APS (American Physical Society) (1975) Efficient use of energy: The APS studies on the technical aspects of the more efficient use of energy. AIP Conference Proceedings 25. New York: American Institute of Physics.

Arab Fund (1979) Private communications with M. Badawi, Arab Fund for Economic and Social Development, Kuwait. Data was supplied concerning cconomic and transportation activitics in several Arab countries. 
AT A (American Transit Association) (1975) Transit Fact Book 1973/74.

Basile, P. (1980) The IIASA Set of Energy Models: Its Design and Application. RR-80-31. Laxenburg, Austria: International Institute for Applied Systems Analysis.

Beschinsky, A.A., and Y.M. Kogan (1976) Economic Problems of Electrification. (Russian; selected parts translated by A. Papin.) Moscow: Energiya Press.

Beller, M., Ed. (1975) Sourcebook for Energy Assessment. BNL 50483. New York: Brookhaven National Laboratory, Upton.

Canada (1975) Canada Yearbook 1975. Statistics Canada. Ottawa.

CEC (Commission of the European Communities) (1978) Document No. 4 of the Working Group Meeting on Energy R\&D Strategies, June 1978. Dept. XII/C-1, Brussels: CEC.

Cecelski, M., J. Dunkerley, and W. Ramsey (1979) Household Energy and the Poor in the Third World. Research Paper R-15. Washington, DC: Resources for the Future.

Chant, V.G. (1981) Two Global Scenarios: Evolution of Energy Use and the Economy to 2030. RR-81-35. Laxenburg, Austria: International Institute for Applied Systems Analysis.

Chapman, P.F., and D.F. Hemming (1976) Energy Requirements of Some Energy Sources, in Proceedings 9th International TNO Conference: The Energy Accounting of Materials, Products, Processes and Services, Rotterdam. February, 1976.

Chateau, B., and B. Lapillonne (1977) La prévision a long terme de la demande d'energie: Propositions methodologiques. Paris: Éditions du CNRS.

Chenery, H., and M. Syrquin (1975) Patterns of Development 1950-1970. London: For the World Bank by Oxford University Press.

CMEA (Council for Mutual Economic Assistance) (1976) Statistical Yearbook (1976) of the Member States of the Council for Mutual Economic Assistance, London: IPC Industrial Press Ltd.

CONAES (Committee on Nuclear and Alternative Energy Systems) (1977) Report of the Solar Resource Group, Washington, DC: National Academy of Sciences.

Doblin, C. (1978) Energy Demand by U.S. Manufacturing Industries: Past Performance and Review of Various Projections up to the Year 2000. RM-78-44. Laxenburg, Austria: International Institute for Applied Systems Analysis.

Doblin, C. (1979) Historical Data Series 1950-1976. WP-79-87. Laxenburg, Austria: International Institute for Applied Systems Analysis.

Doernberg, A. (1977) Energy Use in Japan and the United States BNL 50713. New York: Brookhaven National Laboratory, Upton.

ECE (Economic Commission for Europe) (1976) Increased Energy Economy and Efficiency in the ECE Region. Document No. E/ECE/883/Rev. 1. New York: United Nations.

ECE (Economic Commission for Europe) (1977) Annual Bulletin of General Energy Statistics for Europe 1975. New York: United Nations.

ECE (Economic Commission for Europe) (1978a) A Statistical Survey of the Housing Situation in the ECE Countries around 1970. New York: United Nations.

ECE (Economic Commission for Europe) (1978b) Annual Bulletin of Housing and Building Statistics for Europe 1977. New York: United Nations.

Elshafei, A.N. (1978) Energy Assessment in Egypt and Implications of Industrial Development until 2000. Paper presented at the Conference on Policies and Strategies for Industrial Development in Africa, Cairo 23-26 Sept., 1978. (The data given in this paper were based on the work of the Egypt/US Energy Assessment Committee.)

Energy Research and Development Administration (1975) ERDA49. Definition Report. Washington, DC: National Solar Energy Research Development and Demonstration.

Energy Systems Program Group (of the International Institute for Applied Systems Analy sis). W. Häfele, Program Leader. (1981) Energy in a Finite World - A Global Systems Analysis. Cambridge, Massachusetts: Ballinger Publishing Co.

Europa (1974) The Middle East and North Africa, 1974-75. 21 st Edition. London: Europa Publications Ltd.

Eurostat (1978) Nutzenergiebilanzen 1975. Statistical Office of the European Communities, Brussels. (The data refers to France and the FRG.)

FAO (Food and Agriculture Organization) (1977) FAO Production Yearbook, Vol. 30, 1976. Rome: FAO. 
FEA (Federal Energy Administration) (1974a) Project Independence and Energy Conservation: Transport Sector. Washington, DC: FEA.

FEA (Federal Energy Administration) (1974b) Residential and Commercial Energy Use Patterns 1970-1990. Project Independence Blueprint, Vol. I, Washington, DC: FEA.

Foell, W.K., R.L. Dennis, M.E. Hanson, L.A. Hervey, A. Hölzl, J.P. Peerenboom, and E. Poenitz (1979) Assessment of Alternative Energy/Environment Futures of Austria: 1977-2015. RR-79-7. Laxenburg, Austria: International Institute for Applied Systems Analysis.

Goen, R.L. (1975) Comparison of Energy Consumption between West Germany and the United States. SRI-EGU-3519. Menlo Park, California: Stanford Research Institute.

Häfele, W. (1977) On Energy Demand, Invited Paper XXI. General Conference of the International Atomic Energy Agency, Vienna, September, 1977.

Henderson, P.D. (1975) India: The Energy Sector. Delhi: Oxford University Press.

Hirst, E. (1974a) Direct and Indirect Energy Requirements for Automobiles. ORNL-NSF-EP-64. Oakridge, Tennessee: Oak Ridge National Laboratory.

Hirst, E. (1974b) Transportation energy use and conservation potential. Bulletin of the Atomic Scientists 14(9):34.

Hirst, E., and J. Jackson (1977) Historical patterns of residential and commercial energy use. Energy $2: 113$.

Hittman (1974) Environmental Impacts, Efficiency and Cost of Energy Supply and End Use. Final Report, Vol. I, 1974. Columbia, USA: Hittman Associates.

IBRD (International Bank for Reconstruction and Development) (1976) World Tables 1976. Baltimore: The John Hopkins University Press.

IEA (International Energy Agency) (1976) Analysis of Energy Consumption and Conservation Potential: The Transport Sector. IEA/SLT(71)51. Paris: IEA.

ILO (International Labour Office) (1976) Yearbook of Labour Statistics. Geneva: ILO.

IRF (International Road Federation) (1976) World Road Statistics 1971-1975. See also earlier editions. Washington, DC: IRF.

Japan (1978) Energy in Japan: Facts and Figures. Tokyo: Agency of Natural Resources and Energy, Ministry of International Trade and Industry.

Keyfitz, N. (1977) Population of the World and Its Regions 1975-2050. WP-77-7. Laxenburg, Austria: International Institute for Applied Systems Analysis.

Khan, A. (1981) The Possible Share of Soft/Decentralized Renewables in Meeting the Future Energy Demands of Developing Regions. RR-81-18. Laxenburg, Austria: International Institute for Applied Systems Analy sis.

Lapillonne, B. (1978a) MEDEE-2: A Model for Long-Term Energy Demand Evaluation. RR-78-17. Laxenburg, Austria: International Institute for Applied Systems Analysis.

Lapillonne, B. (1978b) Long term perspectives of the U.S. energy demand: Application of the MEDEE-2 modeI to the U.S. Energy 5:231-257.

Lapillonne, B. (1978c) Private communication concerning data given in a doctoral thesis (Chateau, B., and B. Lapillonne, Essai de prévision de la demande d'énergie en France d̀ l'an 2000, Institute Economique et Juridique de l'Énergie, Grenoble, 1977) and three scenarios for France using the MEDEE approach (Chateau, B. et al., La demande d'énergie finale de la France à 1'horizon 2000. Institut Economique et Juridique de 1'Énergie, Grenoble, 1979).

Leach, G., Ch. Lewis, A. Buren, F. Romig, and G. Foley (1979) A Low Energy Strategy for the United Kingdom. The International Institute for Environment and Development. London: Science Reviews Ltd.

Lovins, A.B. (1976) Energy strategy: The road not taken? Foreign Affairs 55:65-96.

Lovins, A.B. (1977) Soft Energy Paths. London: Penguin Books Ltd.

Makhijani, A., and A. Poole (1975) Energy and Agriculture in the Third World. Cambridge, Massachusetts: Ballinger Publishing Company.

McGranahan, G., and M. Taylor (1977) Patterns of Urban Household Energy Use in Developing Countries: The Case of Mexico City. Report No. 111. State University of New York at Stony Brook: Institute for Energy Research.

Melentiev, L.A. (1977) Principal objective tendencies in the development of power engineering in the USSR during the second half of the twentieth century. Power Engineering 15(5) (Translation of article in Izvestiya Akademii Nauk SSR: Energetika i Transport 15(5)). 
MITRE (1973) Systems analy sis of solar energy programs. Report prepared by the MITRE Corporation for the National Science Foundation, Project No. NSF/C831, Project No. 2950. Washington, DC: NSF.

Morrow, W.E. (1973) Solar energy - its time is near. Technology Review 76:30.

OECD (Organization for Economic Cooperation and Development) (1977) Energy Statistics 1973/ 1975. Paris: OECD.

OECD (Organization for Economic Cooperation and Development) (1979a) Main Economic Indicators 1979. Monthly Series. Paris: OECD.

OECD (Organization for Economic Cooperation and Development) (1979b) Workshop on Energy Data of Developing Countries: Vol. II, Basic Energy Statistics and Energy Balances of Developing Countries 1967-1977. Paris: OECD.

Pakistan (1977) Pakistan Economic Survey 1976-77, Islamabad: Government of Pakistan, Finance Division.

Parikh, K. (1976) Second India Studies: Energy. Delhi: The Macmillan Company of India Ltd.

Parikh, J. (1978) Energy Systems and Development. (1980) Delhi: Oxford University Press.

Petro Studies (1978) Soviet Oil, Gas and Energy Databook. Petro Studies Co., Stavanger: Noroil Publishing House Ltd.

Paxton, J., Ed. (1976) The Statesman's Yearbook. Statistical and Historical Annual of the World, 1976 and 1977. London: Macmillan.

Reuyl, J.S., W.W. Harman, R.C. Carlson, M.D. Levine, Th.F. Mandel, and J.G. Widwer (1976) A Preliminary Social and Environmental Assessment of the ERDA Solar Energy Program 19752020. Vol. I (Final Draft Report). Prepared for the Environmental and Resources Study Branch, Division of Solar Energy, ERDA, Washington, DC. Menlo Park, California: Stanford Research Institute.

Revelle, R. (1976) Energy use in rural India. Science 192: 969.

Salter, R.G., R.O. Petruschell, and K. Wolf (1976) Energy Conservation in Nonresidential Buildings. R-1623-NSF, Santa Monica, California: Rand Corporation.

Saudi Arabia (1977) Petroleum Statistical Bulletin 1977. Economics Department, Saudi Arabia.

Schaefer, H., H. Bouillon, K.F. Ebersbach, R. Frister, J. Poschenrieder, and B. Rössle (1977) Technologien zur Einsparung von Energie im Endverbrauchssek tor Industrie (Teil 1), FfE - Schriftenreihe 77-04, Forschungsstelle für Energiewirtschaft, München.

Schipper, L., and A.J. Lichtenberg (1976) Efficient energy use and well being: The Swedish example. Science 194(4269).

SPP (Science and Public Policy) (1975) Energy Alternatives: A Comparative Analysis. Science and Public Policy Program, University of Oklahoma. Washington, DC: Government Printing Office.

SRI (Stanford Research Institute) (1972) Patterns of Energy Consumption in the United States PB-212776, Menlo Park, California: Stanford Research Institute.

Styrikovich, M. (1979) Private communication to W. Häfele: Data prepared by Soviet experts from the Committee for Systems Analysis, Presidium of the Academy of Sciences of the USSR, Moscow.

UN (United Nations) (1974) World Comprehensive Demographic Projections 1965-85. UN Population Division's Working Paper ESA/P/WP.52. New York: UN.

UN (United Nations) (1975) The Growth of World Industry 1973. New York: UN.

UN (United Nations) (1976a) Population by Sex and Age for Regions and Countries 1950-2000. UN Population Division's Working Paper ESA/P/SP.60. New York: UN.

UN (United Nations) (1976b) Compendium of Housing Statistics 1972-74. New York: UN.

UN (United Nations) (1977a) World Energy Supplies 1971-1975. New York: UN.

UN (United Nations) (1977b) Statistical Yearbook 1976. New York: UN.

UN (United Nations) (1977c) Yearbook of National Accounts Statistics 1976. New York: UN.

UN (United Nations (1977d) Yearbook of Industrial Statistics 1975. New York: UN.

UN (United Nations) (1978a) World Energy Supplies 1972-1976. New York: UN.

UN (United Nations) (1978b) Monthly Bulletin of Statistics, January 1978. New York: UN.

US (1976a) Statistical Abstract of the United States 1976. (97th edition). Washington, DC: US Bureau of the Census.

US (1976b) Historical Statistics, Colonial Times to 1970. Washington, DC: US Bureau of the Census. USSR (1976) The USSR in Figures for 1975. Central Statistical Board. Moscow: Statistika Publishers. 
Vieira, A.H.G. (1978) (Coordinator) Consumo Energético no Brasil: Perspectivos Para 1990. Sao Paulo: CESP.

Vigdorchik, A.G. (1976) On certain patterns in the development of the energy balance of the USSR. Power Engineering 14(5) (Translation of article in Izvestiya Akademii Nauk SSR: Energetika i Transport 14(5):3.

WAES (Workshop on Alternative Energy Strategies) (1976) First Technical Report on Energy Demand Studies: Major Consuming Countries. Cambridge, Massachusetts: MIT Press.

Weingart, J.M., and N. Nakicenovic (1982) Market Penetration Dynamics and the Large-Scale Use of Solar Energy. Laxenburg, Austria: International Institute for Applied Systems Analysis (forthcoming).

WFB (World Fact Book) (1974) A Handbook of Economic, Political, and Geographic Intelligence. Acton: Publishing Science Group Inc.

Wolf, M. (1974) Solar energy utilization by physical methods. Science 184(4134):382-386.

World Bank (1977) World Bank Atlas. 12th Edition. Washington, DC. 


\section{APPENDIXES}

\section{APPENDIX A: THE SEVEN WORLD REGIONS OF THE IIASA ENERGY SYSTEMS PROGRAM}

\section{Region I: North America (NA)}

Highly developed market economies with energy resources

Canada

United States of America

Region II: The Soviet Union and Eastern Europe (SU/EE)

Highly developed centrally-planned economies with energy resources

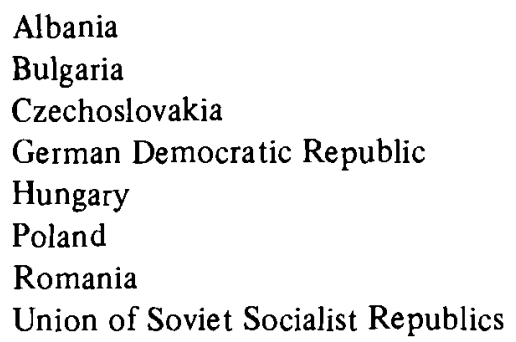

Region III: Western Europe, Japan, Australia, New Zealand, South Africa, and Israel (WE/JANZ)

Highly developed market economies with relatively low energy resources

$\begin{array}{cl}\begin{array}{c}\text { Member Countries of the European Community } \\ \text { Belgium }\end{array} & \\ \text { Denmark } & \text { Italy } \\ \text { France } & \text { Luxembourg } \\ \text { Germany, Federal Republic of } & \text { Netherlands } \\ \text { Ireland } & \text { United Kingdo } \\ \text { Other Western European Countries } & \\ \text { Austria } & \\ \text { Cyprus } & \text { Portugal } \\ \text { Finland } & \text { Spain } \\ \text { Greece } & \text { Sweden } \\ \text { Iceland } & \text { Switzerland } \\ \text { Norway } & \text { Turkey } \\ & \text { Yugoslavia }\end{array}$


Others

Australia

Israel

Japan

New Zealand

South Africa

\section{Region IV: Latin America (LA)}

Developing economies with some energy resources and significant population growth

Argentina
Bahamas
Belize
Bolivia
Brazil
Chile
Colombia
Costa Rica
Cuba
Dominican Republic
Ecuador
El Salvador
Guadeloupe
Guatemala
Guyana
Haiti

Honduras

Jamaica

Martinique

Mexico

Netherlands Antilles

Nicaragua

Panama

Paraguay

Peru

Puerto Rico

Surinam

Trinidad and Tobago

Uruguay

Venezuela

Other Caribbean

\section{Region V: Africa (Except Northern Africa and South Africa), South and Southeast} Asia (Af/SEA)

Slowly developing economies with some energy resources and significant population growth Africa

Angola
Benin
Botswana
Burundi
Cameroon
Cape Verde
Central African Republic
Chad
Congo
Ethiopia
Gabon
Gambia
Ghana

Guinea
Guinea Bissau
Ivory Coast
Kenya
Lesotho
Liberia
Madagascar
Malawi
Mali
Malta
Mauritania
Mauritius
Morocco


Mozambique

Namibia

Niger

Nigeria

Reunion

Rwanda

Senegal

Sierra Leone

Somalia

Sudan

Asia

Afghanistan

Bangladesh

Brunei

Burma

Comoros

Hong Kong

India

Indonesia

Korea, Republic of South

Macau

Malaysia
Swaziland

Tanzania, United Republic of

Togo

Tunisia

Uganda

Upper Volta

Western Sahara

Zaire

Zambia

Zimbabwe

Nepal

Pakistan

Papua New Guinea

Philippines

Singapore

Sri Lanka

Taiwan

Thailand

East Timor

West South Asia n.e.s.

\section{Region VI: Middle East and Northern Africa (ME/NAf)}

Developing economies with large energy resources

Member Countries of the Organization of Arab Petroleum Exporting Countries (OAPEC)

$\begin{array}{ll}\text { Algeria } & \text { Libyan Arab Republic } \\ \text { Bahrain } & \text { Qatar } \\ \text { Egypt } & \text { Saudi Arabia } \\ \text { Iraq } & \text { Syrian Arab Republic } \\ \text { Kuwait } & \text { United Arab Emirates }\end{array}$

Others

$\begin{array}{ll}\text { Iran } & \text { Oman } \\ \text { Jordan } & \text { Yemen } \\ \text { Lebanon } & \text { Yemen, People's Republic of }\end{array}$

\section{Region VII: China and Centrally-Planned Asian Economies (C/CPA)}

Developing centrally-planned economies with energy resources

China, People's Republic of

Kampuchea, Democratic (formerly Cambodia)

Korea, People's Republic of North
Laos, People's Democratic Republic of Mongolia

Vietnam, People's Republic of 


\section{APPENDIX B: EQUATIONS AND VARIABLE DEFINITIONS OF MEDEE-2 (IIASA VERSION)}

\section{APPENDIX B1: CALCULATION OF ENERGY DEMAND IN MEDEE-2}

An outline of MEDEE-2 has already been presented in the main text of this report (see Section 3). In general, the overview given is sufficient to understand the approach. The computer model itself is just one part of a three-stage process, which includes (1) a detailed analysis of the present energy consumption pattern in the country or region under consideration; (2) an analysis of past trends in economic, social and technological factors with an important influence on energy demand; and (3) the construction of scenarios describing alternative future evolutions of these factors and the calculation of energy demand implied by these scenarios*. The last step is facilitated by the computer model which serves both as a framework to formulate scenarios and as an accounting tool to evaluate the energy demand evolution corresponding to a given scenario.

The computer model is rather simple and mechanistic. It relies almost exclusively on exogenous information, and dependencies between the various factors are in general not formalized - it is left to the user to ensure that his projections are reasonable and consistent. This is certainly a major shortcoming of the model, and in any application to a single country efforts will have to be made to reduce the number of exogenous variables and to internalize the projection of their future evolution by means of structural assumptions. It is doubtful, however, that such a formal approach would have been successful in this global study which considers world regions rather than individual countries; available statistics would probably not allow the estimation and validation of complex relations with any statistical significance. Although the equations are mostly trivial they are summarized here in order to clarify how the various parameters affect the results**. This may also help to remove ambiguities about the scope of the model. A listing of both parameter and derived variables is added at the end of this Appendix; the parameter variables appear in the same sequence as in Tables 8 and 9 , which contain a cross-regional comparison of the specific values assigned in the two scenarios.

\section{Definition of Energy Use Categories}

MEDEE-2 distinguishes three broad "sectors" of energy use which are defined from a functional rather than from an institutional point of view; energy use for the production of goods is aggregated under the label "industry" - this includes agriculture, construction, and mining as well as manufacturing; energy used to transport goods or passengers is summarized under the label "transportation" - this includes commercial and public transportation as well as private transportation by car; energy used in dwellings and service sector buildings is summarized under the heading "household/service sector". Since MEDEE-2 deals only with final energy, it excludes by definition any internal energy

\footnotetext{
*In order to limit the number of scenarios, only one trajectory needs to be considered for those factors showing a heavy trend that is likely to continue into the future. For other factors, that could depart significantly from past trends and/or present expectations - for example, due to saturation, or in reaction to higher energy prices, or as a result of regulations - a range of values must be considered if the uncertainty of future energy demand is to be captured.

** Parameter variables are typed in italics, other variables in roman.
} 
use by energy production industries; energy use for such purposes is determined in the course of the energy supply calculation.

An important aspect for the assessment of future energy demand by form is the degree of substitutability between various sources. Therefore, a distinction is made between "specific uses", where substitutions are rather unlikely (e.g., electricity for lighting, motive power in stationary applications, electrolysis, etc.; liquid fuels for networkindependent transportation; coke for pig-iron production; liquid fuels or natural gas as feedstocks), and thermal energy use where various energy sources can be used to meet the demand (e.g., fossil fuels, such as coal, oil, and gas; district heat; electricity; solar energy; other commercial fuels such as charcoal and biogas). Energy demand for specific uses is directly calculated in terms of final energy; thermal energy demand is first calculated in terms of useful energy* and then converted to final energy taking into account the fuel mix and the end-use efficiencies of the various energy sources.

\section{Macroeconomic Indicators}

MEDEE-2 requires a fairly detailed picture of the expected macroeconomic situation as a background for the energy demand scenarios. Energy demand for the production and transportation of goods is directly linked to the value added (at constant prices) of the various sectors. Energy demand for "consumptive uses" such as in passenger transportation or in the household/service sector is not directly linked to monetary indicators but rather to physical factors; nevertheless relationships between activity levels in these sectors and macroeconomic indicators do exist, although they are not formalized within the computer model.

Six major economic sectors are distinguished in the model, namely agriculture, construction, mining, manufacturing, energy, and services; the manufacturing sector is further divided into four subsectors, namely basic materials, machinery and equipment, nondurables, and a miscellaneous category. The model allows calculation of the GDP formation, i.e., the value added generated by each sector, in either of two ways: (1) by specifying the structure of GDP formation directly; or (2) by estimating coefficients for a set of (linear) equations which determine the GDP contribution of each sector as a function of GDP expenditure.

The second approach can be chosen if time series of national accounts statistics are available which allow an estimation of the various coefficients. For the six world regions considered in this study, the available statistics were generally poor, and therefore the sectoral shares were entered directly as a scenario. Exports, imports and import duties, and government expenditures are not explicitly considered. On the level of world regions, this is not a serious simplification; for individual countries, however, foreign trade usually represents large shares of total GDP and should therefore be treated explicitly.

\footnotetext{
*The term is used here in the sense of "equivalent electricity requirements". Efficiencies are expressed relative to those of electricity. By definition, electricity, district heat, and solar energy are accounted for with an end-use efficiency of 1 .
} 
Variant (a)

The GDP formation is entered exogenously:

- GDP formation by economic sector:

$\left[\begin{array}{l}\text { YAG } \\ \text { YB } \\ \text { YMIN } \\ \text { YMAN } \\ \text { YEN } \\ \text { YSER }\end{array}\right]=Y \quad \cdot\left[\begin{array}{l}P Y A G \\ P Y B \\ P Y M I N \\ P Y M A N \\ P Y E N \\ P Y S E R\end{array}\right]$

\section{VAMAN $=$ YMAN}

- Value added by manufacturing subsectors:

$\left[\begin{array}{l}\text { VAIG } \\ \text { VAM } \\ \text { VAC } \\ \text { VAMIS }\end{array}\right] \quad=$ VAMAN $\quad \cdot\left[\begin{array}{l}P V A I G \\ P V A M \\ P V A C \\ P V A M I S\end{array}\right]$

where

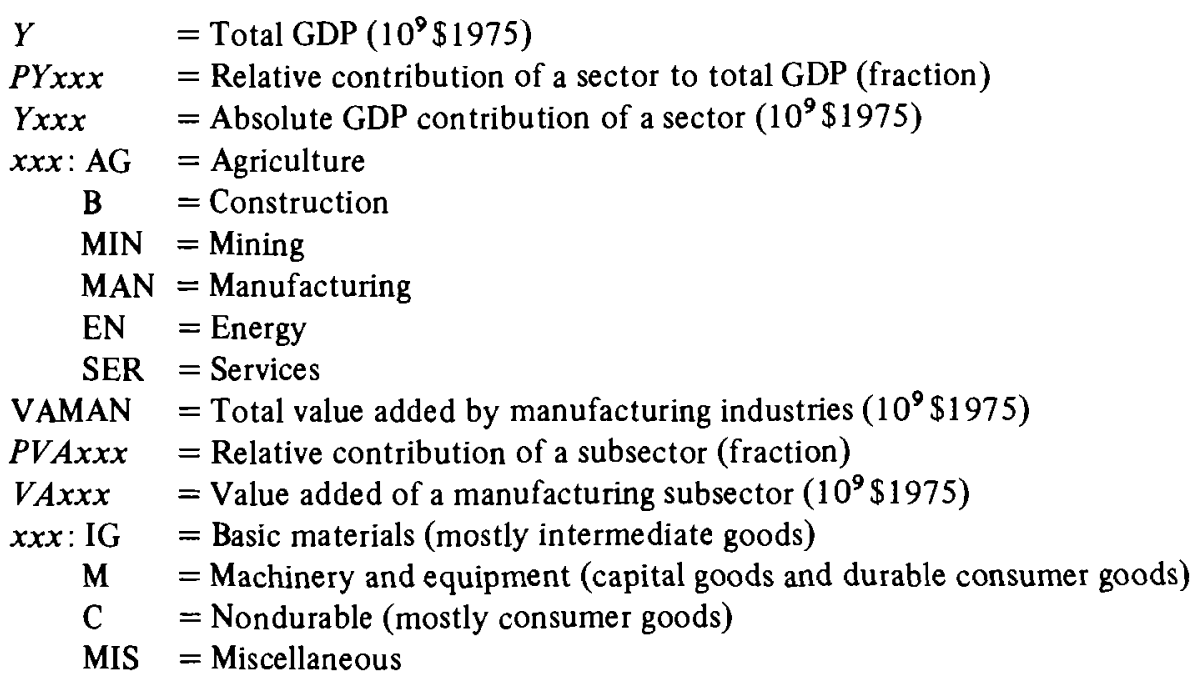

Variant (b)

The GDP formation is determined as a function of private consumption expenditures on durables, nondurables and services, and of investment expenditures on construction and 
machinery and equipment. This option is chosen if $(P Y A G, \ldots, P Y S E R)$ or $(P V A I G$, $\ldots, P V A M I S)$ are all zero.

- GDP expenditure:

$\mathrm{GCF}=Y \cdot I$

$\left[\begin{array}{l}\mathrm{GCFB} \\ \mathrm{GCFM}\end{array}\right]=\mathrm{GCF} \quad \cdot\left[\begin{array}{l}I B \\ I M\end{array}\right]$

$\mathrm{PC}=Y \cdot P$

$\left[\begin{array}{l}\text { TPCDG } \\ \text { TPCNDG } \\ \text { TPCSER }\end{array}\right] \quad=\mathrm{PC} \quad \cdot\left[\begin{array}{l}P C D G \\ P C N D G \\ P C S E R\end{array}\right]$

$\mathrm{TPCG}=\mathrm{TPCDG}+\mathrm{TPCNDG}$

- GDP formation by economic sector:

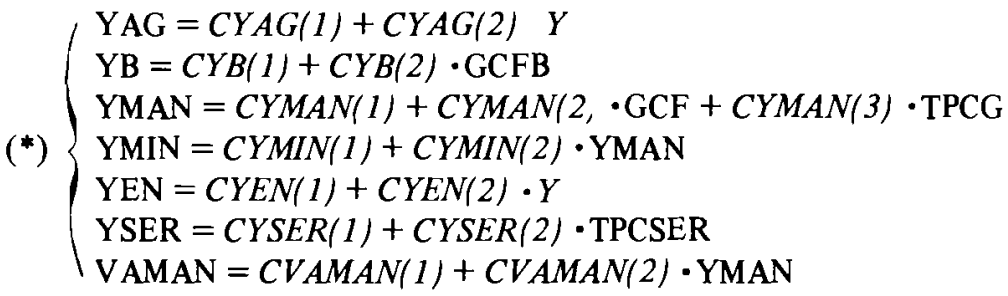

- Value added by manufacturing:

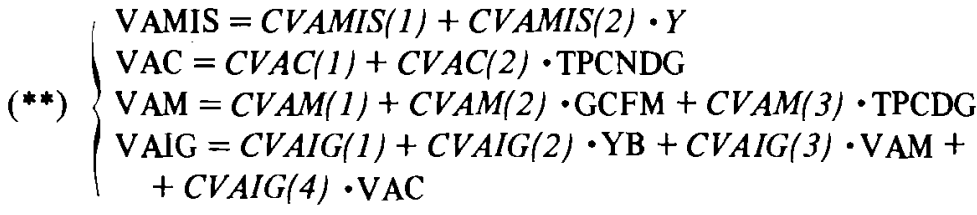

(*) These components have to be normalized with respect to $Y$.

(**) These components have to be normalized with respect to VAMAN.

where

$I \quad=$ Investment share in total GDP (fraction)

$\mathrm{GCF}=$ Gross fixed capital formation $\left(10^{9} \$ 1975\right)$ 
$I B, I M \quad=$ Relative shares of investment spent on construction, and on machinery and equipment, respectively (fractions)

GCFB = Gross fixed capital formation expenditures for construction, and for machinery and equipment, respectively $\left(10^{9} \$ 1975\right)$

$P \quad=$ Private consumption share in total GDP (fraction)

PC = Private consumption expenditures $\left(10^{9} \$ 1975\right)$

$\left.\begin{array}{l}P C D G \\ P C N D G\end{array}\right\}=$ Relative shares of private consumption spent on durable goods, nondurable $\left.\begin{array}{l}P C N D G \\ P C S E R\end{array}\right\}=$ goods, and services, respectively (fractions)

$T P C D G\}$ Private consumption expenditures on durable goods, nondurable goods, and

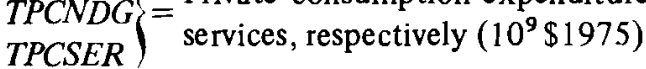

$T P C G=$ Private consumption expenditures spent on goods $\left(10^{9} \$ 1975\right)$

For the variables relating to GDP formation, the definitions are given under Variant (1). The prefix "C" is used for the coefficients of the various econometric equations. The dimension of the constant terms in these equations is $10^{9} \$ 1975$; the other terms are scalars.

The equations do not ensure that the individual components of GDP and of manufacturing value added sum up to the respective totals, so that a subsequent normalization is required. Additivity could not be forced by constrained parameter estimation alone; constraints would also have to be imposed on the structure of GDP formation which is entered exogenously.

\section{Energy Demand Calculations by Sector}

\section{(1) Industry}

As mentioned earlier, industrial energy demand is defined here as energy demand for the production of goods. For each economic sector belonging to this group, its value added is used as activity level indicator, or in other words, value added is used as the main driving variable for calculating energy demand of the corresponding industrial subsector. Monetary rather than physical indicators are chosen because of the diversity of goods that are produced. For a detailed energy demand projection, however, the energy intensive group of basic materials industries should be further disaggregated and the energy demand for certain products such as steel, aluminium, cement, glass, paper, fertilizers should be analyzed in physical terms, taking into account substitution possibilities between various production technologies.

The demand calculations for each economic sector in this group are very simple. The basic energy demand of a sector (final energy in the case of specific uses such as motor fuel and electricity, useful energy in the case of thermal uses) is calculated as the product of value added and current energy intensity, which is in turn the product of the base year energy intensity and an exogenously specified index. Useful thermal energy demand of all sectors combined is then converted to final energy demand based on exogenous specification of fuel mix and efficiencies.

Specifically, energy demand of agriculture, construction, and mining is calculated only in final energy terms even for thermal uses, based on the assumption that the decentralized energy use pattern would make the substitution of fossil fuels (mainly oil) by alternative energy sources difficult: 


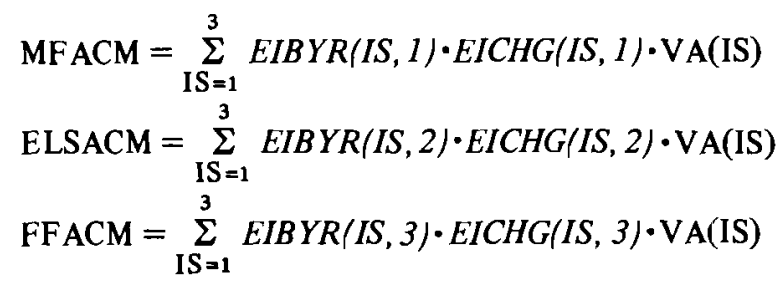

where

VA(IS) $=$ Value added of sector IS $\left(10^{9} \$ 1975\right)$, with

IS $=1:$ Agriculture

IS $=2:$ Construction

IS $=3:$ Mining

$\operatorname{EIBYR}(I S, J)=$ Base year energy intensity for energy form $\mathrm{J}$, with

$\mathrm{J}=1:$ Motor fuel $\left(10^{3} \mathrm{kcal} / \$ 1975\right)$

$\mathrm{J}=2$ : Electricity $(\mathrm{kWhr}(\mathrm{e}) / \$ 1975)$

$\mathrm{J}=3$ : Thermal energy $\left(10^{3} \mathrm{kcal} / \$ 1975\right.$; final energy $)$

$E I C H G(I S, J)=$ Index of energy intensity, i.e., factor of change in energy intensity between the base year and the current model year

MFACM $=$ Total motor fuel use in agriculture/construction/mining (pcal)

ELSACM = Total electricity use in agriculture/construction/mining (TWhr(e))

FFACM $=$ Total thermal energy use in agriculture/construction/mining (pcal)

In the case of manufacturing industries, the demand for motor fuel and for specific uses of electricity (such as lighting, motive power, and electrolysis) is again calculated directly in final energy terms.

For the manufacturing sector, motor fuel and specific electricity demand is calculated in the same way:

$$
\begin{aligned}
& \text { MFMAN }=\sum_{I S=4}^{7} E I B Y R(I S, 1) \cdot \operatorname{EICHG}(4,1) \cdot \mathrm{VA}(\mathrm{IS}) \\
& \text { ELSMAN }=\sum_{\mathrm{IS}=4}^{7} \operatorname{EIBYR}(I S, 2) \cdot E I C H G(4,2) \cdot \mathrm{VA}(\mathrm{IS})
\end{aligned}
$$

where

VA(IS) $=$ Value added of sector IS $\left(10^{9} \$ 1975\right)$, with

IS $=4:$ Basic materials

IS $=5:$ Machinery and equipment

IS $=6:$ Nondurables

IS $=7:$ Miscellaneous

$\operatorname{EIBYR}(I S, J)=$ Base year energy intensity for energy form $\mathrm{J}$, with

$J=1:$ Motor fuel $\left(10^{3} \mathrm{kcal} / \$ 1975\right)$

$\mathrm{J}=2$ : Electricity for specific uses $(\mathrm{kWhr}(\mathrm{e}) / \$ 1975)$

$E I C H G(4, J)=$ Index of energy intensity (only specified for the manufacturing sector as a whole)

MFMAN = Total motor fuel use in manufacturing (Pcal)

ELSMAN = Total electricity use in manufacturing (TWhr(e)) 
The demand for thermal energy is first calculated in terms of useful energy and then converted to final energy based on assumptions about the penetration of alternative energy sources in their potential markets and their efficiency relative to the use of electricity with conventional technologies. The potential markets are very broadly defined by three process temperature ranges, namely low-temperature (space heat, hot water, and steam for process temperatures between 80 and $120^{\circ} \mathrm{C}$ ), medium-temperature (steam for process temperatures above $120^{\circ} \mathrm{C}$ ), and high-temperature (furnace/direct heat, excluding iron ore reduction by coke which is accounted for as a specific use). The breakdown of thermal energy demand by type of use, namely space/water heating, steam generation, and furnace/direct heat can either be specified for each manufacturing subsector (in the array PUSIND) or for the manufacturing sector as a whole (through the parameters $S T S H I$ and $S T I$ ). In the first case, electricity penetration rates and fossil fuel efficiencies must be specified for each potential market (namely temperature range) (in $\operatorname{ELPIND}(J)$, $\operatorname{EFFIND}(J), \mathrm{J}=1,2,3)$; in the second case they need to be specified only for the aggregate thermal energy demand (in $\operatorname{ELPIND}(4), E F F I N D(4)$ ). The low-temperature share of the steam demand is specified by the parameter $L T H$ in both cases.

(a) The breakdown of thermal energy demand by type of use is specified for each manufacturing subsector (i.e., PUSIND(. , .) $\neq 0$ ):

- useful energy demand by type of use:

$$
\begin{aligned}
\operatorname{USMAN}(\mathrm{J})= & \sum_{\mathrm{IS}=4}^{7} \operatorname{EIBYR}(I S, 3) \cdot \operatorname{EICHG}(4,3) \cdot \mathrm{VA}(\mathrm{IS}) \cdot \operatorname{PUSIND}(I S-3, J) \\
& (\mathrm{J}=1,2,3) \\
\operatorname{USMAN}(4)= & \sum_{\mathrm{J}=1}^{3} \operatorname{USMAN}(\mathrm{J})
\end{aligned}
$$

where

VA(IS) $=$ Value added of sector IS $\left(10^{9} \$ 1975\right)$

$E I B Y R(I S, 3)=$ Base year thermal energy intensity of sector IS $\left(10^{3} \mathrm{kcal} / \$ 1975\right)$

$\operatorname{EICHG}(4,3)=$ Index of thermal energy intensity in manufacturing

$\operatorname{PUSIND}(I S-3, J)=$ Share of useful thermal energy demand of sector IS for process category $\mathbf{J}$, with

$\mathrm{J}=1:$ Steam generation

$\mathrm{J}=2:$ Furnace/direct heat

$\mathrm{J}=3:$ Space/water heating

USMAN $(\mathrm{J})=$ Useful thermal energy demand in manufacturing for process category $\mathrm{J}$, with $\mathrm{J}=4$ : Total for all process categories as follows:

The penetration of energy sources in the thermal energy market is then determined

- electricity (conventional):

PMEL $(1)=E L P I N D(1) \cdot(1-H P I)$

PMEL(2) $=E L P I N D(2)$

$\operatorname{PMEL}(3)=E L P I N D(3) \cdot(1-H P I)$ 
- electricity (heat pump):

$\operatorname{PMHP}(1)=H P I \cdot E L P I N D(1)$

$\operatorname{PMHP}(2)=0$

$\operatorname{PMHP}(3)=H P I \cdot E L P I N D(3)$

- district heat:

$\operatorname{PMDH}(1)=I D H$

$\operatorname{PMDH}(2)=0$

$\mathrm{PMDH}(3)=I D H$

- soft solar systems:

$\operatorname{PMSS}(1)=[L T H \cdot S P L T+(1-L T H) \cdot S P H T] \cdot F I D S$

$\operatorname{PMSS}(2)=0$

PMSS $(3)=S P L T \cdot F I D S$

- cogeneration (within industrial plants, as opposed to cogeneration in central power plants)

PMCG(1) $=L T H \cdot I C O G E N$

$\operatorname{PMCG}(2)=0$

$\operatorname{PMCG}(3)=I C O G E N$

- fossil fuels (remainder):

$\operatorname{PMFF}(\mathrm{J})=1-[\operatorname{PMEL}(\mathrm{J})+\operatorname{PMHP}(\mathrm{J})+\operatorname{PMDH}(\mathrm{J})+\operatorname{PMSS}(\mathrm{J})+\operatorname{PMCG}(\mathrm{J})]$ $(\mathrm{J}=1,2,3)$

If $\operatorname{PMFF}(\mathrm{J})$ would be negative, the other penetration rates are normalized and PMFF(J) set to zero.

Finally, PMxx(4) (where $\mathrm{xx}=\mathrm{EL}, \mathrm{HP}, \mathrm{DH}, \mathrm{SS}, \mathrm{CG}, \mathrm{FF}$ ) and $E F F I N D(4)$ are calculated as weighted averages.

where

$\operatorname{ELPIND}(J)=$ Share of useful thermal energy demand in manufacturing for process category J (USMAN(J)) that is supplied by electricity (must be specified if PUSIND $\neq 0$ )

$H P I=$ Contribution of heat pumps to low-temperature use of electricity

$\operatorname{PMEL}(\mathrm{J})=$ Share of electricity (conventional) in USMAN $(\mathrm{J})$

$\operatorname{PMHP}(\mathrm{J})=$ Share of electricity (heat pump) in USMAN(J)

$I D H=$ Share of the manufacturing demand for steam and hot water that is supplied by district heat

$\operatorname{PMDH}(\mathrm{J})=$ Share of district heat in $\operatorname{USMAN}(\mathrm{J})$

$L T H=$ Share of low-temperature steam in the total steam demand of the manufacturing sector

$S P L T=$ Share of the manufacturing demand for low-temperature steam and for hot water which is supplied by solar systems

$S P H T=$ Share of the manufacturing demand for high-temperature steam that is supplied by solar systems

FIDS = Approximate share of useful thermal energy demand that can be met by a solar installation (i.e., 1.FIDS determines the backup requirements)

PMSS $(\mathrm{J})=$ Share of soft solar systems in USMAN(J)

ICOGEN = Share of the manufacturing demand for low-temperature steam and hot water which is supplied by fossil fuels, but with cogeneration of electricity 
PMCG $(J)=$ Share of on-site cogeneration in USMAN $(\mathrm{J})$

$\operatorname{PMFF}(\mathrm{J})=$ Share of fossil fuels in USMAN $(\mathrm{J})$

(b) The breakdown of thermal energy demand by type of uses is specified only for the manufacturing sector as a whole (i.e., $\operatorname{PUSIND}(.,)=0$.$) ):$

- useful energy demand by type of use:

$$
\begin{aligned}
& \text { USMAN(4) }=\sum_{I S=4}^{?} E I B Y R(I S, 3) \cdot E I C H G(4,3) \cdot \mathrm{VA}(\mathrm{IS}) \\
& \text { USMAN }(1)=\operatorname{USMAN}(4) \cdot S T I \\
& \text { USMAN }(2)=\operatorname{USMAN}(4) \cdot(1-S T S H I) \\
& \text { USMAN(3) }=\operatorname{USMAN}(4) \cdot(S T S H I-S T I)
\end{aligned}
$$

where

STSHI, STI = Share of useful thermal energy demand in manufacturing for steam generation and space/water heating together (STSHI) and for steam generation only $(S T I)$. (Note: 1 - STSHI represents the share of useful energy demand for furnace/direct heat, but excluding the use of coke for iron ore reduction and electrolysis.) The definitions of the other variables are given above under Variant (a).

The penetration of the various energy sources in the thermal energy market in manufacturing is in this case calculated only for the aggregate, not for each temperature range:

$$
\begin{aligned}
& \text { PMEL(4) }=E L P I N D(4) \cdot(1-S T S H I \cdot H P I) \\
& \text { PMHP(4) }=H P I \cdot S T S H I \cdot E L P I N D(4) \\
& \text { PMDH(4) }=I D H \cdot S T S H I \\
& \text { PMSS(4) }=\{[S T S H I-S T I \cdot(1-L T H)] S P L T+S T I \cdot(1-L T H) \cdot S P H T\} F I D S \\
& \text { PMCG(4) }=[S T I \cdot L T H+(S T S H I-S T I)] I C O G E N \\
& \text { PMFF(4) }=1-[\operatorname{PMEL}(4)+\operatorname{PMHP}(4)+\operatorname{PMDH}(4)+\operatorname{PMSS}(4)+\operatorname{PMCG}(4)]
\end{aligned}
$$

If PMFF(4) would be negative, the other penetration rates are normalized and PMFF(4) is set to 0.

The definitions of the variables are given above under Variant (a).

Conversion of useful thermal to final energy demand:

$[\mathrm{JL}=1, \mathrm{JU}=3$ in Variant (a), $\mathrm{JL}=\mathrm{JU}=4$ in Variant (b)]

$$
\begin{aligned}
& \text { DHMAN }=\sum_{\mathrm{J}=\mathrm{JL}}^{\mathrm{JU}} \operatorname{PMDH}(\mathrm{J}) \cdot \operatorname{USMAN}(\mathrm{J}) \\
& \text { SOLMAN }=\sum_{\mathrm{J}=\mathrm{JL}}^{\mathrm{JU}} \operatorname{PMSS}(\mathrm{J}) \cdot \operatorname{USMAN}(\mathrm{J}) \\
& \text { COGSTH }=\sum_{\mathrm{J}=\mathrm{JL}}^{\mathrm{JU}} \operatorname{PMCG}(\mathrm{J}) \cdot \operatorname{USMAN}(\mathrm{J})
\end{aligned}
$$




$$
\begin{aligned}
& \text { FFMAN }=\left\{\sum_{\mathrm{J}=\mathrm{JL}}^{\mathrm{JU}} \operatorname{PMFF}(\mathrm{J}) \cdot \operatorname{USMAN}(\mathrm{J}) / \text { EFFIND }(\mathrm{J})\right\}+\text { COGSTH/EFFCOG } \\
& \begin{aligned}
\text { ELHMAN }=\left\{\sum_{\mathrm{J}=\mathrm{JL}}^{\mathrm{JU}}[\operatorname{PMEL}(\mathrm{J})+\operatorname{PMHP}(\mathrm{J}) / E F F H P I] \cdot \mathrm{USMAN}(\mathrm{J})\right\} \\
-\mathrm{COGSTH} / \mathrm{HELRAT}
\end{aligned} \\
& \text { COGEL }=\text { COGSTH } / \text { HELRAT }
\end{aligned}
$$

where

DHMAN = District heat demand in manufacturing (Pcal)

SOLMAN = Useful energy demand replaced by soft solar systems in manufacturing (Pcal)

COGSTH $=$ Total useful energy demand provided with cogeneration of electricity (lowtemperature steam or hot water; Pcal)

EFFIND $(J)=$ Average efficiency of fossil fuel use for thermal process $\mathrm{J}$ in manufacturing relative to the efficiency of electricity

$E F F C O G=$ System efficiency of cogeneration, i.e., (heat + electricity output)/(heat content of fuels used)

FFMAN = Thermal use of fossil fuels in manufacturing (Pcal)

$E F F H P I=$ Coefficient of performance of (electric) heat pumps in industry

HELRAT = Ratio of heat to electricity in the output of cogeneration systems

ELHMAN = Thermal use of electricity in manufacturing (Pcal) net of byproduct electricity

COGEL = Byproduct electricity from cogeneration in manufacturing (Pcal)

Coke used for pig-iron production currently accounts for the bulk of fossil fuel demand in the iron and steel industry, and in countries with a large steel industry it represents a major item of industrial energy demand. There has been a gradual penetration of electric steel production from scrap (the share in industrialized countries is currently in the range of 10-20 percent of total steel production with some exceptions), but in general steel is produced via the blast furnace route. The coke rate in blast furnaces could be considerably reduced in the past, partly through technological improvements, but to a large extent at the expense of fuel oil and gas injections. With an expected further increase in the relative price of these fuels, such a substitution is not very likely in the future. The alternative route of prereduction of iron ore with natural gas followed by electric smelting seems promising only for countries with indigenous natural gas resources. One can therefore expect that blast furnaces would be only slowly replaced by other technologies, and this is the reason why the alternatives were not explicitly considered.

Specifically, steel production is projected as a function of value added by basic materials industries (which include the iron and steel industry). Coke use for pig-iron production is then calculated based on assumptions about the share of nonelectric steelmaking, the amount of pig-iron required to produce one ton of steel in nonelectric furnaces (which depends on scrap additions), and of the coke rate.

PSTEEL $=C P S T(1)+C P S T(2) \cdot \mathrm{VAIG}$

COKE $=$ PSTEEL $\cdot$ BOF $\cdot I R O N S T \cdot(E I C O K / 1000) \cdot 7$ 
where

$C P S T(1)$ and $C P S T(2)$ are constants with the dimensions $10^{6}$ tons and tons $/ 10^{3} \$$ value added (VA), respectively

VAIG $=$ Value added of basic materials industries $\left(10^{9} \$ 1975\right)$

PSTEEL $=$ Total amount of steel production $\left(10^{6}\right.$ tons $)$

$B O F=$ Share of steel produced in nonelectric furnaces

IRONST $=$ Tons of pig-iron input per ton of steel produced (the residual is assumed to be scrap)

$E I C O K=$ Coke input in blast furnaces per unit output of pig-iron

$\mathrm{COKE}=$ Coke demand for pig-iron production (Pcal)

Electricity use in the iron and steel industry is accounted for under specific electricity uses of basic materials industries. Thermal energy uses in this industry is also included under the basic materials sector.

The "feedstocks" category should in principle include all uses of energy sources as a raw material; here it applies mainly to certain oil products such as naphtha, lubricants, and bitumen. The demand for these products has been linked in a simplistic form to the value added of basic materials industries (which include the petrochemical industry):

$$
\operatorname{FEED}=[C F E E D(1)+C F E E D(2) \cdot \mathrm{VAIG}] \cdot 10
$$

where

$C F E E D(1)$ and $C F E E D(2)$ are constants with the dimensions $10^{6}$ tons and tons $/ 10^{3} \$$ VA, respectively

VAIG $=$ Value added of basic materials industries $\left(10^{3} \$ 1975\right)$

FEED $=$ Demand for feedstocks (Pcal)

Finally, some aggregates of industrial energy demand (i.e., energy demand for the production of goods) are calculated:

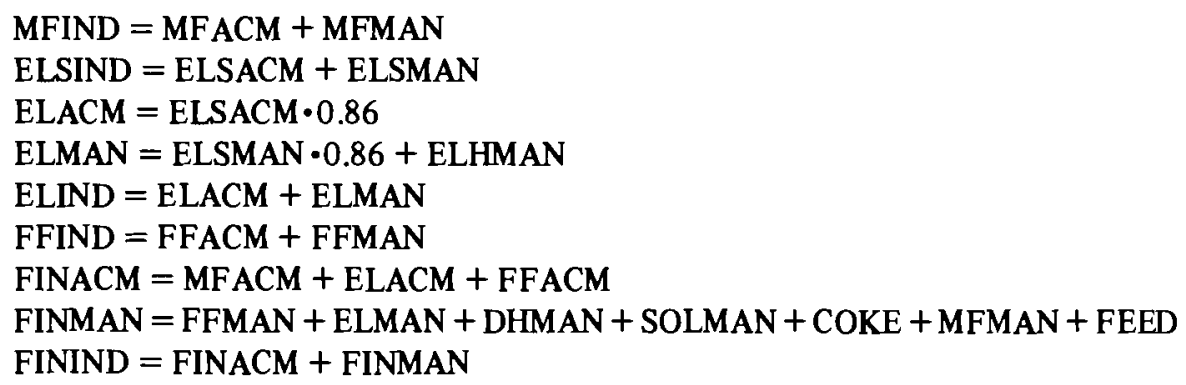

where

MFIND $=$ Motor fuel demand in industry (Pcal)

ELSIND = Electricity demand for specific uses, industry (TWhr(e)) 
ELACM $=$ Electricity demand, agriculture/construction/mining (Pcal)

ELMAN = Electricity demand in manufacturing (Pcal)

ELIND $=$ Total electricity demand, industry $(\mathrm{Pcal})$

FFIND $=$ Thermal use of fossil fuels, industry (Pcal)

FINACM $=$ Final energy demand agriculture/construction $/$ mining $(P c a l)$

FINMAN $=$ Final energy demand in manufacturing (Pcal)

FININD = Final energy demand, industry $($ Pcal $)$

The definitions of the variables on the right-hand side of the equations have been given above.

\section{(2) Transportation}

Transportation energy demand is calculated directly in final energy terms, because it is mainly demand for motor fuel; only railways and urban mass transit are presently operated with other energy sources (electricity, or in the case of railways also coal), but the total amount if relatively small. The penetration of electric cars in urban traffic will probably not be able to change the heavy dependence on liquid fuels in the near future.

Three broad categories of transportation are considered: freight, passenger, and a miscellaneous category which includes international and military transportation. The latter category is treated very simplistically; energy demand for these purposes is treated as a function of GDP, i.e.

$$
\mathrm{TMISMF}=\operatorname{CMISM}(1)+\operatorname{CMISMF}(2) \cdot Y
$$

where

CMISMF(1) and CMISMF(2) are constants with dimensions Pcal/ $\$ 1975$ and Mcal/ $\$ 1975$, respectively

$Y=$ Total GDP $\left(10^{9} \$ 1975\right)$

TMISMF $=$ Motor fuel demand for international and military transportation

In the case of domestic freight transportation, the total demand (in terms of ton-kilometers) is treated as a function of the GDP contribution of the goods-producing sectors*:

$$
\mathrm{TKFRT}=C T K F R T(1)+C T K F R T(2) \cdot[Y-(\mathrm{YB}-\mathrm{YSER})]
$$

where

CTKFRT(1) and CTKFRT(2) are constants with dimensions $10^{9} \mathrm{tkm} / \$ 1975$ and $\mathrm{tkm} /$ $\$ 1975$, respectively

$Y=$ Total GDP $\left(10^{9} \$ 1975\right)$

$Y B=G D P$ contribution of the construction sector $\left(10^{9} \$ 1975\right)$

YSER $=$ GDP contribution of the service sectors $\left(10^{9} \$ 1975\right)$

TKFRT $=$ Demand for domestic freight transportation $\left(10^{9} \mathrm{tkm}\right)$

*Excluding construction, where transportation services are usually supplied by the furms themselves and motor fuel demand for these purposes can hardly be isolated since it is usually local transportation. 
The model split, i.e., the contribution of the various modes of transportation, are exogenously specified:

$\left[\begin{array}{l}\text { TKTRUL } \\ \text { TKTRU } \\ \text { TKTRA } \\ \text { TKBA } \\ \text { TKPIP }\end{array}\right]$

$=$ TKFRT $\quad\left[\begin{array}{l}T R U \cdot T R U L \\ T R U \cdot(1-T R U L) \\ F T R A \\ B A \\ P I P\end{array}\right]$

where

$T R U=$ Share of trucks in the total demand for freight transportation $T R U L=$ Share of local truck transportation in the total freight transportation performed by trucks (the residual is assumed to be long-distance hauls)

$F T R A=$ Share of rail in the total demand for freight transportation

$F B A=$ Share of inland waterways or coastal shipping in the total demand for freight transportation

$F P I P=$ Share of pipelines in the total demand for freight transportation

$T K x x x x=$ Freight transportation service by mode $x x x x\left(10^{9} \mathrm{tkm}\right)$

The energy intensities must also be supplied exogenously, except the intensities of electric and steam locomotives, which are linked to the intensity of diesel locomotives by factors of 0.33 and 3.0 , respectively. With these specifications, the energy demand of the various modes is calculated as follows:

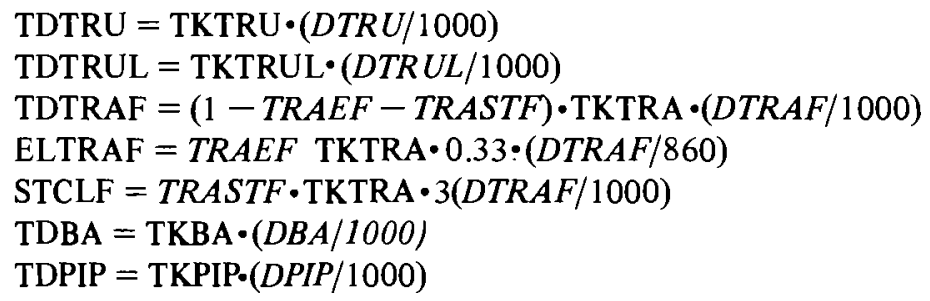

where

$D T R U=$ Energy intensity of trucks (average or, if $T R U L \neq 0$, long distance)

$D T R U L=$ Energy intensity of trucks for short hauls (only relevant if $T R U L \neq 0$ )

$D T R A F=$ Energy intensity of diesel freight trains

$T R A E F=$ Share of electric freight trains in the total freight transportation by rail

$T R A S T F=$ Share of steam freight trains in the total freight transportation by rail

$D B A=$ Energy intensity of inland waterways and coastal shipping (only motor fuel considered)

$D P I P=$ Energy intensity of pipelines (only motor fuel considered)

TDxxxx = Energy demand for freight transportation by mode $\mathrm{xxxx}$ (Pcal)

ELTRAF $=$ Electricity demand by electric railways $(\mathrm{TWhr}(\mathrm{e}))$ 
Total motor fuel demand for freight transportation is the sum of the following components:

$$
\text { TDFT }=\text { TDTRU + TDTRUL }+ \text { TDTRAF + TDBA + TDPIP }
$$

i.e., truck (long-distance and local), rail (diesel locomotives), barge, and pipeline.*

Two points should be brought to attention at this point: first, the exogenous specification of the modal split independent of the total demand and independent of the product mix can lead to unrealistic results, and second, it is dangerous to look at transportation from the point of view of energy intensity only. Other aspects, such as costs to provide the necessary infrastructure, speed, unit size, etc. are probably still the dominant factors in the choice of mode, despite the significant increase in energy costs.

For passenger transportation, the main indicators are annual travel distance and car ownership. These indicators can be exogenously linked to monetary indicators such as GDP or private consumption per capita, but such relations are not built into the model. A distinction is made between intercity and intracity transportation; the latter category is linked to the population in large cities, where mass transportation is feasible.

Car is assumed to be the preferred mode for intercity passenger travel, and the residual is assigned to public modes:

$$
\begin{aligned}
& \mathrm{PKI}=P O \cdot(D I / 1000) \\
& \mathrm{PIC}=(P O / C O) \cdot D I C \cdot(L F I C / 1000) \\
& \mathrm{PCT}=\mathrm{PKI}-\mathrm{PIC}
\end{aligned}
$$

where

$P O=$ Total population $\left(10^{6}\right.$ people $)$

$D I=$ Average annual intercity travel distance per person $(\mathrm{km} / \mathrm{p})$

$\mathrm{PKI}=$ Total intercity travel $\left(10^{9} \mathrm{pkm}\right)$

$C O=$ Ratio of population to number of cars

$D I C=$ Average annual distance driven per car in intercity traffic $(\mathrm{km} / \mathrm{car})$

$L F I C=$ Average load factor of cars in intercity traffic $(\mathrm{p} / \mathrm{car})$

PIC $=$ Passenger-kilometers by car, intercity $\left(10^{9} \mathrm{pkm}\right)$

PCT $=$ Passenger-kilometers by public transportation, intercity $\left(10^{9} \mathrm{pkm}\right)$

The shares of the various modes of public transportation must be exogenously specified:

$\left[\begin{array}{l}\text { TPBU } \\ \text { TPTRA } \\ \text { TPLA }\end{array}\right] \quad=$ PCT $\quad \cdot\left[\begin{array}{l}P B U \\ P T R A \\ P L A\end{array}\right]$

where

$P B U=$ Share of buses in intercity passenger travel excluding travel by car

$P T R A=$ Share of trains in intercity passenger travel excluding travel by car

*Since pipelines transport mostly oil and gas, they were considered explicitly only for Region VI; in the other regions, energy use of pipelines is included under transportation losses. 
$P L A=$ Share of airplanes in intercity passenger travel excluding travel by car $\mathrm{TPxxx}=$ Passenger kilometers by mode $\mathrm{xxx}\left(10^{9} \mathrm{pkm}\right)$

To calculate the energy consumption associated with each mode of transportation, average load factors, and energy in tensities are required. These factors are in general specified per vehicle, except for airplanes where energy intensity and capacity utilization are specified per seat-km. For gasoline, an energy content of $8,500 \mathrm{kcal} / 1$ is assumed; for diesel, a factor of $9,000 \mathrm{kcal} / 1$ is applied. As in the case of freight transportation, the energy intensity of electric and steam locomotives is related to that of diesel locomotives by factors of 0.33 and 3.0 , respectively.

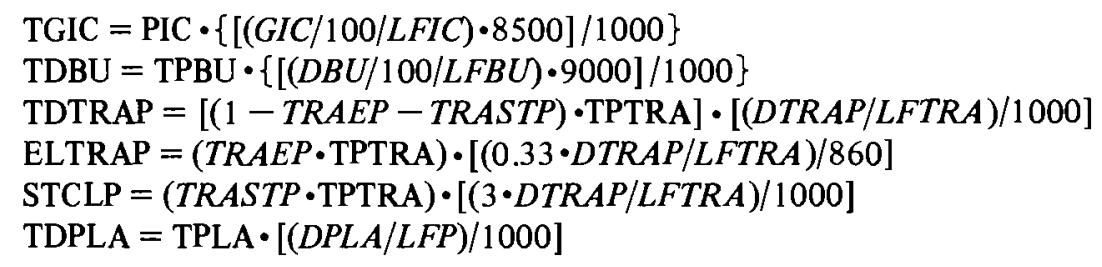

where

$\mathrm{PIC}=$ Passenger-kilometers by car, intercity $\left(10^{9} \mathrm{pkm}\right)$

$G I C=$ Specific gasoline consumption of cars in intercity traffic $(1 / 100 \mathrm{~km})$

$L F I C=$ Average load factor of cars in intercity traffic $(\mathrm{p} / \mathrm{car})$

TGIC $=$ Total gasoline consumption of cars, intercity traffic (Pcal)

TPBU $=$ Passenger-kilometers by bus, intercity $\left(10^{9} \mathrm{pkm}\right)$

$D B U=$ Specific diesel consumption of buses in intercity traffic $(1 / 100 \mathrm{~km})$

$L F B U=$ Average load factor of buses in intercity traffic (p/bus)

TDBU $=$ Total diesel consumption of buses, intercity (Pcal)

TPTRA $=$ Passenger-kilometers by train $\left(10^{9} \mathrm{pkm}\right)$

$T R A E P=$ Share of electric trains in the total intercity travel by train

$T R A S T P=$ Share of steam trains in the total intercity travel by train

$D T R A P=$ Energy intensity of diesel passenger trains $(\mathrm{kcal} / \mathrm{train}-\mathrm{km})$

$L F T R A=$ Average load factor of passenger trains ( $\mathrm{p} / \mathrm{train}$ )

TDTRAP $=$ Total diesel consumption of railways for passenger transportation (Pcal)

ELTRAP = Total electricity consumption of railways for passenger transportation (TWhr(e))

STCLP = Total coal consumption of railways for passenger transportation (Pcal)

$D P L A=$ Energy intensity of airplanes ( $\mathrm{kcal} / \mathrm{seat}-\mathrm{km})$

$L F P=$ Average capacity utilization of airplanes (fraction of seats occupied)

TDPLA $=$ Total fuel consumption by airplanes

Total motor fuel consumption for intercity passenger transportation is then:

$$
\text { TMFIP }=\text { TGIC + TDBU + TDTRAP + TDPLA }
$$

For intercity passenger transportation, total demand is related to the population living in large cities and an average daily distance traveled per person in these areas: 


$$
\begin{aligned}
& \mathrm{POU}=(1-P O L C) \cdot P O \\
& \mathrm{PKU}=(D U \cdot 365) \cdot(\mathrm{POU} / 1000)
\end{aligned}
$$

where

$P O=$ Total population $\left(10^{6}\right.$ people $)$

$P O L C=$ Share of population in large cities

POU $=$ Population living in large cities $\left(10^{6}\right.$ people $)$

$D U=$ Average daily travel distance

$\mathrm{PKU}=$ Total passenger kilometers, intracity $\left(10^{9} \mathrm{pkm}\right)$

The distribution between travel by car and mass transit must be exogenously specified:

$$
\left[\begin{array}{l}
\text { PUC } \\
\text { PUMT }
\end{array}\right]
$$$$
=\mathrm{PKU} \quad \cdot \quad\left[\begin{array}{l}
U C \\
U M T
\end{array}\right]
$$

where

$U C=$ Share of cars in the total demand for intracity passenger transportation

$U M T=$ Share of mass transportation systems in the total demand for intracity passenger transportation

Pxxx are the corresponding absolute figures $\left(10^{9} \mathrm{pkm}\right)$

Together with average load factors and energy intensities, and introducing a split between electric and other modes, energy consumption is calculated as follows:

$$
\begin{aligned}
& \text { TGUC }=[(1-U C E) \cdot \mathrm{PUC}] \cdot\{[(G U C / 100) L F U C] \cdot 8500\} / 1000 \\
& \text { TELUC }=(U C E \cdot \mathrm{PUC}) \cdot(E L U C / L F U C) \\
& \text { TDMT }=[(1-U M T E) \cdot \mathrm{PUMT}] \cdot\{[(D M T / 100 / L F T M B) 9000] / 1000\} \\
& \text { TELMT }=(U M T E \cdot \mathrm{PUMT}) \cdot(E L M T / L F M T E)
\end{aligned}
$$

where

$U C E=$ Share of electric cars in the total intracity car travel $L F U C=$ Average load factor of cars in intracity travel $G U C=$ Specific gasoline consumption of cars in intracity travel TGUC $=$ Gasoline consumption of cars in intracity traffic (Pcal) $E L U C=$ Specific electricity consumption $(\mathrm{kWhr}(\mathrm{e}) / \mathrm{vkm})$ of electric cars (intracity travel) TELUC $=$ Electricity consumption by electric cars $(\mathrm{TWhr}(\mathrm{e}))$ $U M T E=$ Share of electric mass transit in the total intracity mass transportation $D F M T B=$ Average load factor of nonelectric mass transit systems $D M T=$ Specific diesel consumption of buses $(1 / 100 \mathrm{~km})$ TDMT $=$ Motor fuel consumption for intracity mass transportation (Pcal) $E L M T=$ Specific electricity consumption of intracity mass transportation systems $L F M T E=$ Average load factor of electric mass transit systems 
Total energy consumption for intracity transportation is then:

$$
\begin{aligned}
& \text { TMFUP }=\text { TDMT }+ \text { TGUC } \\
& \text { TELUP }=\text { TELMT }+ \text { TELUC }
\end{aligned}
$$

where

TMFUP $=$ Total motor fuel consumption $(\mathrm{Pcal})$

TELUP $=$ Total electricity consumption (TWhr(e))

The sector totals are formed from the following components:

$$
\begin{aligned}
& \text { TELTR }=\text { TELFT + TELIP + TELUP } \\
& \text { TMFTR }=\text { TDFT + TMFIP + TMFUP + TMSMF } \\
& \text { TCLTR }=\text { STCLF + STCLP } \\
& \text { ELTR }=\text { TELTR } 0.86 \\
& \text { FINTR = ELTR + TMFTR + TCLTR }
\end{aligned}
$$

where

TELTR $=$ Total electricity consumption for transportation (TWhr(e)) with components: freight, passenger/intercity, passenger/intracity

TMFTR = Total motor fuel consumption for transportation (Pcal) with components: freight, passenger/intercity, passenger/intracity, and miscellaneous

TCLTR $=$ Total coal consumption by railways (Pcal)

ELTR = Same as TELTR, but converted to Pcal

FINTR $=$ Total final energy consumption for transportation (Pcal)

In the course of applying MEDEE-2 to the six regions and later in various country studies, various points turned out in the context of travel demand projections, which should be improved. One of these problem areas is the independent projection of travel distance and modal split: the amount which a person can afford to travel depends both on income and time. Modes with higher speed will therefore tend to increase the total demand for travel more than modes with low average speed.* E.g., the rapid increase of travel demand in the last decades would hardly have been possible without the availability of cars to a majority of the population. And although a saturation is in sight for this mode in some industrialized countries a large increase in air travel would be compatible with the time budget of people, if the money budget of the majority of the population were sufficiently increased. The second problem area is the exogenous specification of load factors. It is true that transportation energy demand could be significantly reduced by improving

\footnotetext{
*An interesting study of these relationships was made by Y. Zahavi (1977) Equilibrium between travel demand system supply and urban structure. Transport Decisions in an Age of Uncertainty. Proceedings of the Third World Conference on Transport Research, Rotterdam, 26-28 April 1977. The HagueBoston: Martinus Nijhoff.
} 
the load factors; in reality however the desire for quicker service often counteracts attempts in this direction. This is especially true for mass transportation modes with their typically large unit sizes. Finally, energy consumption is not the only aspect that has to be considered in projecting travel demand. Other and probably still dominant factors are income and desire for convenience, and speed on one hand, and congestion and pollution on the other hand. It is doubtful whether there is enough empirical evidence to formalize the interaction of all these factors in a model.

\section{(3) Household/Service Sector}

Energy demand for accommodation of people in the household/service sector is divided into five basic categories in the MEDEE-2 model, namely space heating, water heating, cooking (these three categories are called "thermal uses"), air-conditioning*, and specific electricity uses. In the service subsector, thermal energy uses are treated in aggregate, since space heating is the single most important category (there are of course exceptions such as hospitals, public swimming pools, hotels, and restaurants).

Space heating is treated in some detail, i.e., by distinguishing between existing stock and new construction, and also by distinguishing between single family houses and apartments.

The stock of dwellings is calculated as follows:

- Initialization for the base year:

$$
\begin{aligned}
& \text { TDEMDW }=0 \\
& \text { DWINCR }=0 \\
& \text { CONSDW }=0 \\
& \text { TPREDW }=D W \\
& \text { TPSTDW }=0 \\
& \text { TDWSH }=\text { TPREDW } \cdot D W S H
\end{aligned}
$$

- Change in later years:

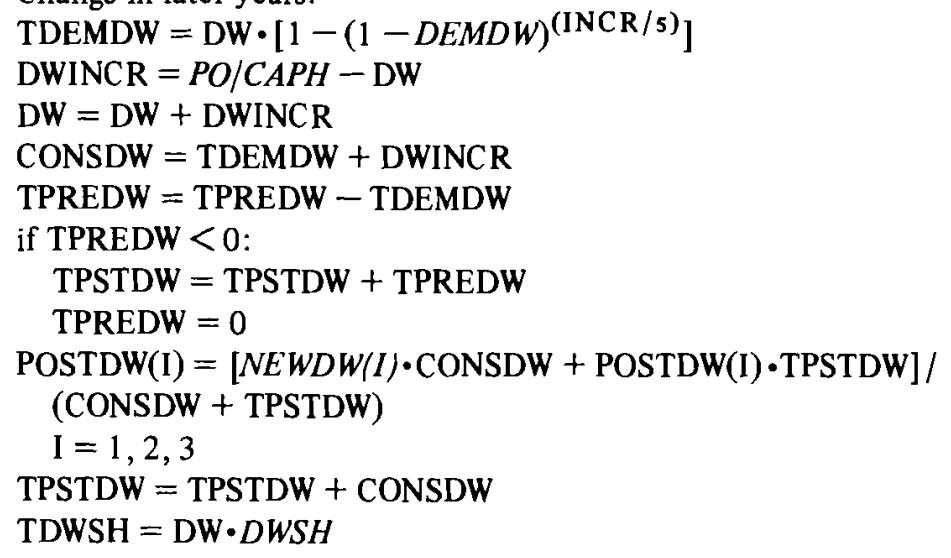

\footnotetext{
*In this study, air-conditioning is also treated like a specific electricity use, i.e., no other energy source (gas, solar) is considered.
} 
where

TDEMDW $=$ Dwellings demolished between previous and current model year $\left(10^{6}\right.$ dwellings)

DWINCR $=$ Net addition of dwellings between previous and current model year $\left(10^{6}\right.$ dwellings)

CONSDW $=$ New constructed dwellings between previous and current model year $\left(10^{6}\right.$ dwellings)

TPREDW $=$ Stock of pre-1975 dwellings $\left(10^{6}\right.$ dwellings $)$

$D W S H=$ Share of dwellings in climatic conditions where space heating is required

TDWSH $=$ Total stock of dwellings in areas where space heating is required $\left(10^{6} \mathrm{dwellings}\right)$

$D E M D W=$ Average demolition rate of dwellings during a 5-year period between the previous and current model years (fraction)

INCR = Length of the period between previous and current model year

$P O=$ Total population $\left(10^{6}\right.$ people $)$

$C A P H=$ Average number of persons per dwelling

$\mathrm{DW}=$ Total stock of dwellings $\left(10^{6}\right.$ dwellings $)$

$N E W D W(I)=$ Share of dwellings, constructed between the previous and the current model years, which are of type I

I $=1$ : single family house with central heating

$\mathrm{I}=2:$ apartment with central heating

$\mathrm{I}=3$ : no central heating available

POSTDW $(I)=$ Share of dwellings constructed after the base year which are of type $I$ as defined above $(I=1,2,3)$

The useful thermal energy demand for space heating is in the case of dwellings constructed before the base year calculated from the average heat loss in the base year after allowing for a reduction of this level due to improved insulation.

$$
\operatorname{PRESH}(\mathrm{I})=[P R E D W(I) \cdot \mathrm{TPREDW} \cdot D W S H] \cdot\{[S H D W O(I) \cdot(1-I S O(I))] / 1000\}
$$

where

PREDW(I) = Share of dwellings constructed before the base year which are of type I as defined above $(I=1,2,3)$; the distribution can change due to differential demolition rates and due to installation of central heating in existing buildings

TPREDW $=$ Stock of dwellings constructed before the base year $\left(10^{6}\right.$ dwellings $)$

$D W S H=$ Share of dwellings in climatic conditions where space heating is required

$S H D W O(I)=$ Average heat loss in a dwelling of type $\mathrm{I}(\mathrm{I}=1,2,3)$ in the base year $\left(10^{3}\right.$ $\mathrm{kcal} / \mathrm{dwelling} / \mathrm{yr}$ )

$I S O(I)=$ reduction of the average heat loss of dwellings constructed before the base year until the current model year, expressed as a fraction of the average heat loss in the base year $(\mathrm{I}=1,2,3)$

$\operatorname{PRESH}(I)=$ Useful energy demand for space heating in dwellings of type $\mathrm{I}(\mathrm{I}=1,2,3)$ which were constructed before the base year

In the case of dwellings constructed after the base year, energy demand for space heating is calculated taking into account the climatic conditions (as expressed by heating 
degree-days), the average size of dwellings (which tends to increase), and an average heat loss factor (which tends to decrease due to better insulation and heat management practices). The heat loss factor is normalized to the floor area and should include all losses through walls and windows as well as ventilation losses. Free heat gains are taken care of in a crude form by calculating the heating degree-days based on a reference temperature of $18^{\circ} \mathrm{C}$ and assuming that the difference between this temperature and a standard indoor temperature of $21^{\circ} \mathrm{C}$ would come from lights, electrical equipment, people, etc.

$\operatorname{POSTSH}(\mathrm{I})=[\operatorname{POSTDW}(\mathrm{I}) \cdot \operatorname{TPSTDW} \cdot D W S H] \cdot\{[(D W S(I) \cdot K(I) \cdot D D \cdot 24) / 1000] / 1000\}$

where

POSTDW $(I)=$ Share of dwellings constructed after the base year which are of type $\mathrm{I}(\mathrm{I}=$ $1,2,3)$

TPSTDW $=$ Stock of dwellings constructed after the base year $\left(10^{6}\right.$ dwellings $)$

$D W S H=$ Share of dwellings in climatic conditions where space heating is required

$D W S(I)=$ Average size of dwellings of type $I(I=1,2,3)$ which have been constructed after the base year $\left(\mathrm{m}^{2}\right)$

$K(I)=$ Average heat loss factor of such dwellings $(I=1,2,3)\left(\mathrm{kcal} / \mathrm{m}^{2} \mathrm{~h}^{\circ} \mathrm{C}\right)$

$D D=$ Average number of heating degree-days per year, weighted by the population.*

Total useful energy demand for space heating is then given by:

$$
\mathrm{SH}=\sum_{\mathrm{I}=1}^{3}[\mathrm{PRESH}(\mathrm{I})+\operatorname{POSTSH}(\mathrm{I})]
$$

Useful energy demand for the other four categories is projected in a very simple way:

- Water heating:

$$
\mathrm{HW}=(\mathrm{DW} \cdot D W H W) \cdot[(H W C A P \cdot C A P H) / 1000]
$$

where

$\mathrm{DW}=$ Total stock of dwellings $\left(10^{6}\right.$ units $)$

$D W H W=$ Share of dwellings where hot water supply is provided

*For a particular site, degree-days can be calculated as follows:

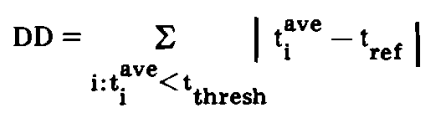

where

$i=1$ to 365

$t_{i}^{\text {ave }}=$ Mean temperature of day $i$

$t_{\text {ref }}=$ Indoor temperature level to be maintained by the heating system $\left(18^{\circ} \mathrm{C}\right)$

$t_{\text {thresh }}=$ Threshold value; a day counts as a heating degree-day only if the mean daily temperature falls below this threshold value - smaller differences are compensated by the storage capacity of the walls. This threshold value varies from $12^{\circ} \mathrm{C}$ in Scandinavia, $15^{\circ} \mathrm{C}$ in countries like FRG and Austria, and even $18^{\circ} \mathrm{C}$ in the USA, reflecting the different building standards in these countries. 
$H W C A P=$ Useful energy demand for water heating per person per year $\left(10^{3} \mathrm{kcal} / \mathrm{p} / \mathrm{yr}\right)$

$C A P H=$ Average number of persons per dwelling

$\mathrm{HW}=$ Total useful energy demand for water heating (Pcal)

- Cooking:

$\mathrm{COOK}=\mathrm{DW} \cdot(C O O K D W / 1000)$

where

DW $=$ Total stock of dwellings $\left(10^{6}\right.$ units $)$

COOKDW $=$ Useful energy demand for cooking per dwelling per year $\left(10^{3} \mathrm{kcal} / \mathrm{dw} / \mathrm{yr}\right)$

COOK $=$ Total useful energy demand for cooking (Pcal)

- Air-conditioning:

$\mathrm{ACH}=(\mathrm{DW} \cdot D W A C) \cdot(A C D W / 1000)$

where

DW $=$ Total stock of dwellings ( $10^{6}$ units)

$D W A C=$ Share of dwellings with air-conditioning

$A C D W=$ Specific cooling requirements per dwelling $\left(10^{3} \mathrm{kcal} / \mathrm{dw} / \mathrm{yr}\right)$

$\mathrm{ACH}=$ Total demand for cooling (Pcal)

- Electricity demand for purposes other than space and water heating, cooking and water heating, cooking and air-conditioning:

$\mathrm{ELAP}=\mathrm{DW} \cdot E L A P D W / 1000$

where

$\mathrm{DW}=$ Total stock of dwellings $\left(10^{6}\right.$ units $)$

$E L A P D W=$ Average annual electricity consumption per dwelling $(\mathrm{kWhr}(\mathrm{e}))$

$E L A P=$ Total electricity consumption of household for "specific uses" (TWhr(e))

In the service sector, energy demand is related to the floor area, which is in turn derived from the GDP contribution and an average floor area per worker. A distinction between old and new buildings is made both for thermal and for specific electricity uses, because of significantly different standards in new buildings. The labor force is calculated as follows:

$$
\begin{aligned}
& \text { PLSER }=P Y S E R C P L S E R * \\
& \text { LSER }=P O \cdot P L F \cdot P A R T L F \cdot P L S E R
\end{aligned}
$$

\footnotetext{
*It would be better to calculate the service sector labor force from GDP contribution and relative productivity. At constant prices, the productivity of the service sector tends to increase less than that of industry, so that in recent years in several developed countries the GDP share remained almost constant despite a strong increase in the share of labor force employed in the service sector.
} 
where

PYSER = Relative GDP contribution of the service sector (fraction)

$C P L S E R=$ Constant, to be calculated from the equation: $C P L S E R=\ln$ PLSER $/ \ln P Y S E R$ for the base year (or by regression from a number of years)

PLSER = Service sector share of labor force (fraction)

$P O=$ Total population $\left(10^{6}\right.$ people $)$

$P L F=$ Potential labor force (share of population in the age group 15-64)

$P A R T L F=$ Labor force participation (ratio of actual labor force to potential labor force) LSER $=$ Service sector labor force $\left(10^{6}\right.$ workers $)$

The floor area is calculated in a similar way as the stock of dwellings:

- Initialization for the base year:

TDEMAR $=0$

ARINCR $=0$

CONSAR $=0$

AREAO $=T A R E A$

AREAN $=0$

$\mathrm{TARSH}=\mathrm{AREAO} \cdot A R S H$

where

TDEMAR = Service sector floor area demolished between previous and current model year $\left(10^{6} \mathrm{~m}^{2}\right)$

ARINCR $=$ Net addition of service sector floor area between previous and current model year $\left(10^{6} \mathrm{~m}^{2}\right)$

$T A R E A=$ Total service sector floor area $\left(10^{6} \mathrm{~m}^{2}\right)$

CONSAR $=$ New constructed service sector floor area between previous and current model year $\left(10^{6} \mathrm{~m}^{2}\right)$

AREAO $=$ Pre -1975 service sector floor area $\left(10^{6} \mathrm{~m}^{2}\right)$

AREAN $=$ Post -1975 service sector floor area $\left(10^{6} \mathrm{~m}^{2}\right)$

$A R S H=$ Share of floor area in climatic conditions where heating is required

TARSH $=$ Total service sector floor area, where space heating is required $\left(10^{6} \mathrm{~m}^{2}\right)$

- Change in later years:

$$
\begin{aligned}
& \text { TDEMAR }=\text { TAREA } \cdot\left[1-(1-D E M A R)^{(\mathrm{INCR} / 5)}\right] \\
& \text { ARINCR }=\text { AREAL } \cdot \text { LSER }- \text { TAREA } \\
& \text { TAREA }=\text { TAREA }+ \text { ARINCR } \\
& \text { CONSAR }=\text { TDEMAR + ARINCR } \\
& \text { AREAO }=\text { AREAO }- \text { TDEMAR } \\
& \text { if AREAO }<0: \\
& \text { AREAN }=\text { AREAN + AREAO } \\
& \text { AREAO =0 } \\
& \text { TARSH }=\text { TAREA } \cdot A R S H
\end{aligned}
$$

where

$D E M A R=$ Average demolition rate of the floor area of service sector buildings over a 5 year period between the previous and the current model year 
$A R E A L=$ Average floor area per worker in the service sector. (The definition of the other variables has been given above.)

Energy demand for thermal uses, specific electricity uses and air-conditioning is then calculated in the following way:

- Thermal uses:

$$
\begin{aligned}
& \text { HSERVO }=(\text { AREAO } \cdot A R S H \cdot A R E A H) \cdot\{[H A R E A O \cdot(1-I S O S V)] / 1000\} \\
& \text { HSERVN }=(\text { AREAN } \cdot A R S H \cdot A R E A H) \cdot(H A R E A N / 1000) \\
& \text { THSERV }=\text { HSERVO }+ \text { HSERVN }
\end{aligned}
$$

where

AREAO = Floor area in service sector buildings constructed before the base year $\left(10^{6} \mathrm{~m}^{2}\right)$ $A R S H=$ Share of floor area in climatic conditions where space heating is required AREAH $=$ Share of that area which is actually heated

$H A R E A O$ = Average annual useful energy demand for thermal uses in the base year $\left(10^{3} \mathrm{kcal} / \mathrm{m}^{2} / \mathrm{yr}\right)$

ISOSV = Reduction of this rate in the current year relative to the base year level (fraction) HSERVO = Total useful thermal energy demand of old service sector buildings (Pcal)

The definition of variables to calculate the demand for new service sector buildings is similar and therefore omitted. The total thermal energy demand, THSERV (Pcal), is just the sum of the demand in old and new buildings.

- Specific electricity uses

$$
\begin{aligned}
& \text { ELSVO }=\text { AREAO } \cdot(E L A R O / 1000) \\
& \text { ELSVN }=\text { AREAN } \cdot(E L A R N / 1000) \\
& \text { ELSV }=\text { ELSVO }+ \text { ELSVN }
\end{aligned}
$$

where

AREAO = Floor area in service sector buildings constructed before the base year $\left(10^{6} \mathrm{~m}^{2}\right)$ $E L A R O=$ Average annual electricity consumption for nonthermal uses in such buildings $\left(\mathrm{kWhr}(\mathrm{e}) / \mathrm{m}^{2} / \mathrm{yr}\right)$

ELSVO $=$ Specific electricity demand in old service sector buildings (TWhr(e)

The definition of the variables to calculate the demand in new service sector buildings is similar. ELSV(TWhr(e)) is the total service sector electricity demand for specific uses.

- Air-conditioning

$$
\mathrm{ACSV}=(\mathrm{TAREA} \cdot A R E A A C) \cdot(A C A R E A / 1000)
$$

where

TAREA $=$ Total service sector floor area $\left(10^{6} \mathrm{~m}^{2}\right)$

$A R E A A C=$ Share of service sector floor area with air-conditioning 
$A C A R E A=$ Average annual cooling demand in service sector buildings $\left(10^{3} \mathrm{kcal} / \mathrm{m}^{2} / \mathrm{yr}\right)$ $\mathrm{ACSV}=$ Total cooling demand of the service sector

Conversion of useful thermal to final energy demand: the four thermal/energy demand categories in the household service sector, for which alternative energy sources are con. sidered, are

$$
\begin{aligned}
\operatorname{USHS}(1) & =\text { SH } \\
\operatorname{USHS}(2) & =\text { HW } \\
\operatorname{USHS}(3) & =\text { COOK } \\
\operatorname{USHS}(4) & =\text { THSERV }
\end{aligned}
$$

i.e., useful thermal energy demand (in Pcal) for

- space heating in households (SH)

- water heating in households (HW)

- cooking in households (COOK)

- all thermal uses in the service sector (THSERV).

It is assumed that a certain amount of noncommercial fuels would be used by households (the service sector is concentrated in urban areas so that noncommercial fuel use would be rather unlikely):

$\mathrm{FINNCF}=B Y R N C F \cdot C H G N C F \cdot 7$

$\mathrm{USNCF}=\mathrm{FINNCF} \cdot E F F N C F$

$\mathrm{PNCFH}=\mathrm{USNCF} /\left[\sum_{\mathrm{J}=1}^{3} \operatorname{USHS}(3)\right]$

$\operatorname{PHSNCF}(\mathrm{J})=\operatorname{PNCFH}(\mathrm{J}=1,2,3)$

$\operatorname{PHSNCF}(\mathrm{J})=0(\mathrm{~J}=4)$

where

$B Y R N C F=$ Amount of noncommercial fuels used in the base year $\left(10^{6} \mathrm{tce}\right)$

$C H G N C F=$ Index of the amount used in the current model year relative to the base year level

FINNCF = Amount of noncommercial fuels used in the current model year $\left(10^{6}\right.$ tce $)$

$E F F N C F=$ Average end-use efficiency of noncommercial fuels

USNCF $=$ Total useful energy supplied by noncommercial fuels (Pcal)

PNCFH = Share of useful thermal energy demand in households which is supplied by noncommercial fuels

$\operatorname{PHSNCF}(J)=$ Share of useful thermal energy demand for category $\mathbf{J}$ as defined above $(\mathrm{J}=1, \ldots, 4)$ which is supplied by noncommercial fuels

Electricity penetration must be exogenously specified for each category. For space and water heating in households and for thermal uses in the service sector, a certain fraction of this electricity market is assumed to be replaced by heat pumps. (Other energy sources for heat pumps, such as gas or solar energy, are not considered.) 
- Electricity (conventional):

$$
\begin{aligned}
& \text { PHSEL(1) }=E L P H S(1) \cdot(1-H P H S) \\
& \text { PHSEL(2) }=E L P H S(2) \cdot(1-H P H S) \\
& \text { PHSEL(3) }=E L P H S(3) \\
& \text { PHSEL(4) }=E L P H S(4) \cdot(1-H P H S)
\end{aligned}
$$

- Electricity (heat pump):

$$
\begin{aligned}
& \text { PHSHP(1) }=H P H S \cdot E L P H S(1) \\
& \text { PHSHP(2) }=H P H S \cdot E L P H S(2) \\
& \text { PHSHP(3) }=0 \\
& \text { PHSHP(4) }=H P H S \cdot E L P H S(4)
\end{aligned}
$$

where

$E L P H S(\mathrm{~J})=$ Electricity penetration into thermal energy demand category $\mathrm{J}$ (as defined above)

$H P H S=$ Average contribution of heat pump to electric space and water heating in the household/service sector

PHSEL(J) = Share of thermal energy demand for category J [USHS(J), as defined above] supplied by resistive use of electricity

PHSHP(J) = Share of USHS(J) supplied by heat pumps.

For space and water heating in the household/service sector, district heat is also considered as a possible energy source, but only in large cities:

$$
\begin{aligned}
& \operatorname{PHSDH}(\mathrm{J})=(1-P O L C) \cdot D H P H(\mathrm{~J}=1,2,4) \\
& \operatorname{PHSDH}(\mathrm{J})=0(\mathrm{~J}=3)
\end{aligned}
$$

where

$P O L C=$ Share of population living outside large cities

$D H P H=$ District heat penetration into space and water heating of dwellings and thermal uses in the service sector (large cities only)

$\operatorname{PHSDH}(\mathrm{J})=$ Share of USHS(J) supplied by district heat

Soft solar systems are assumed to be potentially used for space heating in single-family houses with central heating which are constructed after the base year and for water heating. In the service sector, their use is assumed to be restricted to low-rise buildings constructed after the base year.

- Soft solar systems:

$$
\begin{aligned}
& \text { PHSSS }(1)=\text { POSTSH }(1) \cdot F D S H S \cdot S P S H / \text { USHS }(1) \\
& \text { PHSSS }(2)=S P H W \cdot F D H W S \\
& \text { PHSSS }(3)=0 \\
& \text { PHSSS }(4)=P L B \cdot H S E R V N \cdot F D H S \cdot S P S V / \text { USHS(4) }
\end{aligned}
$$

where

POSTSH(1) = Total energy demand for space heating in single-family houses with central heating constructed after the base year (Pcal) 
USHS(1) = Total energy demand for space heating in households (Pcal)

SPSH = Solar penetration into space heating in post-1975 single-family houses with central heating

FDSHS = Approximate share of space heat demand in households that can be met by a solar installation (the residual must be covered by a backup system)

$S P H W=$ Solar penetration into water heating in dwellings (total demand)

$F D H W S=$ Approximate share of the hot water demand that can be met by a solar installation (the residual must be covered by a backup system)

HSERVN = Total heat demand in service sector buildings constructed after the base year (Pcal)

USHS(4) = Total heat demand in service sector buildings (Pcal)

$P L B=$ Share of low-rise buildings (e.g., up to 3 floors) in the total service sector floor area $S P S V=$ Solar penetration into thermal uses in post-1975 low-rise buildings of the service sector

$F D H S=$ Approximate share of thermal energy demand in the service sector that can be met by a solar installation (the residual must be covered by a backup system)

PHSSS $(J)=$ Share of USHW(J) (as defined above) which is effectively replaced by solar energy systems

The shares of USHS(J) which are not supplied by one of the energy sources mentioned above must be supplied by commercial fossil fuels, i.e.:

$$
\begin{aligned}
\operatorname{PHSFF}(J)= & 1-(\operatorname{PHSNCF}(\mathbf{J})+\operatorname{PHSEL}(\mathrm{J})+\operatorname{PHSHP}(\mathrm{J})+\operatorname{PHSDH}(\mathrm{J})+\operatorname{PHSSS}(\mathrm{J})) \\
& (\mathrm{J}=1,2,3,4)
\end{aligned}
$$

If $\operatorname{PMFF}(J)$ would be negative, the other penetration rates are normalized and $\operatorname{PMFF}(J)$ set to zero. follows:

The final energy demand of the household/service sector can now be calculated as

- Thermal uses:

$$
\begin{aligned}
& \text { ELHHS }=\sum_{\mathbf{J}=1}^{4} \operatorname{USHS}(\mathrm{J}) \cdot[\operatorname{PHSEL}(\mathrm{J})+\operatorname{PHSHP}(\mathrm{J}) / E F F H P R] \\
& \text { DHHS }=\sum_{\mathbf{J}=1}^{4} \operatorname{USHS}(\mathrm{J}) \cdot \operatorname{PHSDH}(\mathrm{J}) \\
& \text { SOLHS }=\sum_{\mathbf{J}=1}^{4} \operatorname{USHS}(\mathrm{J}) \cdot \operatorname{PHSSS}(\mathrm{J}) \\
& \text { FFHS }=\sum_{\mathrm{J}=1}^{4} \operatorname{USHS}(\mathrm{J}) \cdot[\operatorname{PHSFF}(\mathrm{J}) / E F F H S(J)]
\end{aligned}
$$

where

$E F F H P R=$ Coefficient of performance of (electric) heat pumps in the household/service sector 
$E F F H S(\mathrm{~J})=$ Efficiency of fossil fuel use relative to that of electricity use for thermal energy use category $\mathrm{J}(\mathrm{J}=1,2,3,4)$ in the household/service sector.

(The definitions of USHS(J) and PHSxx(J) for $\mathrm{xx}=\mathrm{EL}, \mathrm{HP}, \mathrm{DH}, \mathrm{SS}$, FF have been given above.)

ELHHS = Electricity consumption for thermal uses in the household/service sector (Pcal)

DHHS = District heat consumption in the household/service sector (Pcal)

SOLHS = Useful energy demand replaced by soft solar systems in the household/service sector (Pcal)

FFHS $=$ Commercial fossil fuel consumption in the household/service sector (Pcal)

- Specific uses of electricity:

ELSPHS $=$ ELAP + ELSV

where

ELAP $=$ Specific uses by households $(\mathrm{TWh}(\mathrm{e}))$

ELSV $=$ Specific uses in the service sector $(\mathrm{TWh} r(\mathrm{e}))$

ELSPHS = Total specific uses of electricity in the household/service sector (TWhr(e))

- Electricity for air-conditioning:

$\mathrm{USCOOL}=\mathrm{ACH}+\mathrm{ACSV}$

$\mathrm{ELAC}=\mathrm{USCOOL} / E F F A C$

where

ACH $=$ Total cooling demand of households (Pcal)

ACSV $=$ Total cooling demand of the service sector (Pcal)

USCOOL $=$ Total cooling demand of the household/service sector (Pcal)

$E F F A C=$ Coefficient of performance of (electric) air-conditioners

$\mathrm{ELAC}=$ Total electricity use for air-conditioning in the household/service sector

- Sector totals are given by:

$\mathrm{ELHS}=\mathrm{ELAC}+\mathrm{ELHHS}+\mathrm{ELSPHS} \cdot 0.86$

FINHS $=$ FFHS + ELHS + DHHS + SOLHS

FHSPNC $=$ FINHS + FINNCF

where

ELHS $=$ Total electricity consumption of the household/service sector (Pcal) (air-conditioning + specific + thermal uses)

FINHS = Commercial final energy demand of the household/service sector (Pcal)

FHSPNC $=$ Commercial plus noncommercial final energy demand of the household/service sector (Pcal)

The main problem in projecting energy demand for the household/service sector along the framework presented above seems to be the lack of relations indicating whether the costs to build an infrastructure as assumed in a scenario are plausible within the macroeconomic background, since these costs in general still dominate energy costs. Such problem areas are for instance housing construction, construction of electricity networks (in 
developing countries) and of district heating systems, purchase of household equipment, etc. Another shortcoming is the superficial treatment of air-conditioning, the demand for which should also be linked to the particular climatic conditions, like the demand for space heating. The definition of the potential markets for the various energy sources is rough, but has tumed out helpful. A problem area is, however, the independent calculation of total demand for, say, space heating and of the market shares of various energy sources. Electric heating, for example, can only be installed if the insulation level meets certain standards which are stricter than for other energy sources; demand for space and water heating in apartments with district heat connection tends to be higher than in other dwellings; installation of solar systems may not give the expected savings if at the same time the comfort level increases, etc. Despite these problems, the framework was helpful for the broad assessment required in this global study.

Total final energy demand is calculated in MEDEE-2 for the following energy sources/categories (unit: Pcal):

$$
\begin{aligned}
& \text { FF = FFHS + FFIND } \\
& \text { DH = DHHS + DHIND } \\
& \text { SOL = SOLHS + SOLIND } \\
& \text { ELEC = ELTR + ELHS + ELIND } \\
& \text { TMF = TMFTR + MFIND } \\
& \text { COALSP = TCLTR + COKE } \\
& \text { ENERGY = FF + DH + SOL + ELEC + TMF + COALSP + FEED } \\
& \text { ENPNCF = ENERGY + FINNCF }
\end{aligned}
$$

where

$\mathrm{FF}=$ Total thermal use of fossil fuels (household/service, industry)

$\mathrm{DH}=$ Total district heat demand (household/service, industry)

SOL $=$ Total solar energy demand (household/service, industry)

ELEC $=$ Total electricity demand (transportation, household/service, industry)

TMF = Total motor fuel demand (transportation, industry)

COALSP $=$ Specific uses of coal (transportation, industry)

ENERGY = Total commercial final energy demand (including feedstocks)

ENPNCF $=$ Total commercial plus noncommercial final energy demand

In this study, only oil products were considered for motor fuels and feedstocks, although in the long run they could be substituted by other sources. For the thermal use of fossil fuels, coal, oil, and gas were considered in all regions; in developing regions, charcoal and biogas were also considered as alternatives, although their use would be more restricted. Charcoal is also treated as a substitute for coke in pig-iron production. These fuel allocations together with assumptions about transportation/distribution losses and internal consumption by energy producing industries is a necessary step to convert the MEDEE-2 output in to the input suitable for the supply model MESSAGE, i.e., into secondary energy demand. The assumptions entering in this intermediate step are described in Part IV of Energy in a Finite World - A Global Systems Analysis by the Energy Systems Program Group (1981). Attempts are currently being made by the Energy Systems Program of IJASA to formalize this step and to treat energy end-use also in an optimization framework. 


\section{APPENDIX B2: DEFINITION OF PARAMETER VARIABLES*}

Variable
PO
PLF
PARTLF

POLC

PRUR

CAPH

$Y$

Group (a):

PYAG[YREL(1)]

$P Y B[Y R E L(2)]$

$P Y M I N[Y R E L(3)]$

$P Y M A N[Y R E L(4)]$

PYEN[YREL(5)]

PYSER [ YREL(6)]

PVAIG/VAREL(1)]

PVAM[VAREL(2)]

PVACIVAREL(3)]

PVAMIS/VAREL(4)]

Group (b):

$I$

(IB)

(IM)

$P$

(PCDG)

(PCNDG)

(PCSER)

\section{Unit Explanation}

$10^{6} \quad$ Total population

fraction Share of population of age 15-64 in the total population (potential labor force)

fraction Share of potential labor force actually working fraction Share of population living outside large cities (the definition in terms of city size varies from region to region; the variable is used to determine the approximate potential market for district heating and mass transportation systems)

fraction Share of rural population (according to UN definition), the variable was not used in the present version of MEDEE-2, but was considered outside the model for estimating some other parameters

persons per Average household size (the number of dwelhousehold lings is calculated as $P O / C A P H$, i.e., the term household is used in the sense "persons living together in one dwelling"')

$10^{9} \$ 1975$ Total GDP

Distribution of GDP formation by kind of economic activity. Sectors considered: agriculture, construction, mining, manufacturing, energy, services

Distribution of manufacturing value added. Sectors considered: basic materials, machinery and equipment, nondurables, and miscellaneous industries

Share of GDP spent on investments (I), and distribution of investments among construction (IB), and machinery and equipment (IM) Share of private consumption expenditures in total GDP $(P)$, and distribution of private consumption among durable goods $(P C D G)$, nondurable goods (PCNDG), and services (PCSER)

${ }^{*}$ Constants and initial values are marked by ${ }^{c}$ and ${ }^{i}$, respectively; the values of all other variables have to be specified for each point in time considered. The names correspond in general to those used in the MEDEE-2 code; if not, the name used in the program is shown in brackets. 


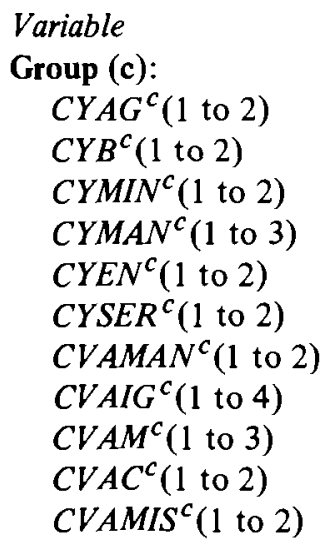

EI.AGR.MF. ${ }^{i}[E I B Y R(1,1)] 10^{3} \mathrm{kcal} / \$ V A$ EI.AGR.EL ${ }^{i}[E I B Y R(1,2)]$ (for MF, TH); EI.AGR.TH. ${ }^{i}[E I B Y R(1,3)] \mathrm{kWhr}(\mathrm{e}) / \$ \mathrm{VA}$ EI.CON.MF ${ }^{i}[E I B Y R(2,1)]$ (for EL) EI.CON.EL $\left.{ }^{i} / E I B Y R(2,2)\right]$ EI.CON.TH ${ }^{l}[E I B Y R(2,3)]$ EI.MIN.MF ${ }^{i}[E I B Y R(3,1)]$ EI.MIN.EL ${ }^{i}$ EIBYR $\left.(3,2)\right]$ EI.MIN.TH ${ }^{l}[E I B Y R(3,3)]$

EI.BM.MF ${ }^{i}[E I B Y R(4,1)]$ EI.BM.EL ${ }^{i}[E I B Y R(4,2)]$ EI.BM.US ${ }^{i}[E I B Y R(4,3)]$ EI.ME.MF ${ }^{l}[E I B Y R(5,1)]$ EI.ME.EL ${ }^{i}[\operatorname{EIBYR}(5,2)]$ EI.ME.US ${ }^{i}[E I B Y R(5,3)]$ EI.ND.MF ${ }^{l}[E I B Y R(6,1)]$ EI.ND.EL ${ }^{i}[E I B Y R(6,2)]$ EI.ND.US ${ }^{i}[E I B Y R(6,3)]$ EI.MS.MF ${ }^{l}[E I B Y R(7,1)]$ EI.MS.EL ${ }^{i}[E I B Y R(7,2)]$ EI.MS.US [EIBYR(7, 3)] CH.AGR.MF[EICHG $(1,1)]$ CH.AGR.EL/EICHG $(1,2)]$ CH.AGR.TH[EICHG $(1,3)]$ CH.CON.MF[EICHG $(2,1)]$ CH.CON.EL[EICHG $(2,2)]$ CH.CON.TH[EICHG $(2,3)]$ CH.MIN.MF[EICHG $(3,1)]$ CH.MIN.EL[EICHG $(3,2)]$ CH.MIN.TH[EICHG $(3,3)]$

CH.MAN.MF[EICHG $(4,1)]$ CH.MAN.EL[EICHG $(4,2)]$
Unit

Explanation

Coefficients of linear equations to determine the GDP formation of 6 major economic sectors, the value added by manufacturing, and the value added contributions of 4 aggregated manufacturing sectors as a function of total GDP and the structure of GDP expenditure; the parameters in group (b) and (c) need only be specified if the parameters in group (a) are not specified.

Specific energy consumption per dollar value added by sector and energy form in the base year.

Sectors: $A G R=$ agriculture, CON $=$ construction, $\mathrm{MIN}=$ mining.

Energy forms: $M F=$ motor fuel, $E L=$ electricity, $\mathrm{TH}=$ thermal uses (final energy).

$10^{3} \mathrm{kcal} / \$ \mathrm{VA}$

(for MF, US); kWhr(e)/\$VA (for EL)

Specific energy consumption per dollar value added by manufacturing subsector and energy form in the base year.

Sectors: $\mathrm{BM}=$ basic materials, $\mathrm{ME}=$ machinery and equipment, $N D=$ nondurables, $\mathrm{MS}=$ miscellaneous industries.

Energy forms: $\mathrm{MF}=$ motor fuel, $\mathrm{EL}=$ electricity, US = thermal uses (useful energy).

Ratio of energy intensity in the current year relative to the base year by sector and by energy forms (same sectors and energy forms as above)

Ratio of energy intensity in the current year relative to the base year in the 


\begin{tabular}{|c|c|}
\hline Variable & Unit \\
\hline $\operatorname{PUSIND}^{c}(I, J)$ & fractions \\
\hline $\begin{array}{r}\text { Sectors: } \\
\qquad \begin{array}{r}I=1 \\
I=2 \\
I=3 \\
I=4\end{array}\end{array}$ & \\
\hline $\begin{array}{l}\text { Process } \\
\text { Categories: } \\
\qquad \begin{array}{l}\mathrm{J}=1 \\
\mathrm{~J}=2 \\
\mathrm{~J}=3\end{array}\end{array}$ & \\
\hline $\begin{array}{l}\text { STSHI } \\
S T I\end{array}$ & fractions \\
\hline
\end{tabular}

$L T H$

$\operatorname{ELPIND}(J)$

ELPIND(4) fraction

(HPI) fraction

EFFHPI thermal energy extracted/electric energy input

IDH fraction

SPLT fraction

SPHT fraction

\section{Explanation}

manufacturing sector, by energy form (same energy forms as above; the same factor is applied to all manufacturing subsectors).

Share of useful thermal energy demand of manufacturing sector I for process category $\mathrm{J}$

Basic materials

Machinery and equipment

Nondurables

Miscellaneous manufacturing industries

Steam generation

Furnace/direct heat

Space/water heating

Share of useful thermal energy demand in manufacturing for steam generation and space/water heating together (STSHI) and for steam generation only (STI). (Note: $1-S T S H I$ represent the share of useful energy demand for furnace/direct heat, but excluding the use of coke for iron ore reduction and electrolysis.) These two variables must be specified only if the array PUSIND is zero.

Share of low-temperature steam in the total steam demand of the manufacturing sector.

Share of useful thermal energy demand in manuffacturing for process category $\mathrm{J}(\mathrm{J}=1,2,3)$ that is supplied by electricity (must be specified if PUSIND $\neq 0$ )

Average electricity penetration into thernal uses in manufacturing (must be specified only if PUSIND $=0$ )

Contribution of heat pumps to low-temperature use of electricity

Coefficient of performance of (electric) heat pumps in industry

Share of the manufacturing demand for steam and hot water that is supplied by district heat

Share of the manufacturing demand for lowtemperature steam and for hot water which is supplied by solar systems

Share of the manufacturing demand for hightemperature steam that is supplied by solar systems 


$\begin{array}{ll}\begin{array}{l}\text { Variable } \\ \text { FIDS }\end{array} & \begin{array}{l}\text { Unit } \\ \text { fraction }\end{array} \\ \text { ICOGEN } & \text { fraction } \\ \text { EFFCOG } & \text { fraction } \\ \text { HELRAT } & \begin{array}{l}\mathrm{kWh}(\mathrm{e}) \text { steam/ } \\ \mathrm{kWh}(\mathrm{e}) \text { electricity } \\ \text { fraction }\end{array} \\ \end{array}$

Explanation

Approximate share of useful thermal energy demand that can be met by a solar installation (i.e., 1 - FIDS determines the backup requirements) Share of the manufacturing demand for lowtemperature steam and hot water which is supplied by fossil fuels, but with cogeneration of electricity

System efficiency of cogeneration, i.e., (heat + electricity output)/(heat content of fuels used) Ratio of heat to electricity in the output of cogeneration systems

Average efficiency of fossil fuel use for thermal process $\mathbf{J}(\mathrm{J}=1,2,3)$ in manufacturing relative to the efficiency of electricity (must be specified if $P U S I N D \neq 0$ )

EFFIND(4) fraction

$\begin{array}{ll}C F E E D(1)^{c} & 10^{6} \text { tons } \\ C F E E D(2)^{c} & \text { tons } / 10^{3} \text { \$VA } \\ C P S T(1)^{c} & 10^{6} \text { tons } \\ C P S T(2)^{c} & \text { tons } / 10^{3} \text { \$VA } \\ B O F & \text { fraction }\end{array}$

Average efficiency of fossil fuel use in thermal processes relative to the efficiency of electricity (must be specified only if PUSIND =0)

Constants used to project the feedstock requirements of the petrochemical industry

Constants used to project the amount of steel produced

Share of steel produced in nonelectric furnaces (the electricity requirements for electric steelmaking must be reflected in EI.BM.EL for the base year, and in CH.MAN.EL for the projections)

IRONST tons of pig-iron/ Tons of pig-iron input per ton of steel produced (the residual is assumed to be scrap)

EICOK $\mathrm{kg}$ coke/ton of pig-iron

CTKFRT(1) $10^{9}$ ton $-\mathrm{km}$

CTKFRT(2) ton $-\mathrm{km} / \$ 1975$

CMISMF(1) $\quad 10^{12} \mathrm{kcal}$

CMISMF $(2) \quad 10^{3} \mathrm{kcal} / \$ 1975$

Coke input in blast furnaces per unit output of pig-iron

Constants used to project the total demand for freight transportation

Constants used to project the total motor fuel demand for international, military, and miscellaneous transportation

$T R U \quad$ fraction

(TRUL) fraction (relative to $T R U$ )

FTRA fraction

Share of trucks in the total demand for freight transportation

Share of local truck transportation in the total freight transportation performed by trucks (the residual is assumed to be long-distance hauls)

Share of rail in the total demand for freight transportation

(TRAEF) fraction

Share of electric freight trains in the total freight (relative to FTRA) transportation by rail 


\begin{tabular}{|c|c|c|}
\hline Variable & Unit & Explanation \\
\hline$(T R A S T F)$ & $\begin{array}{l}\text { fraction (rela- } \\
\text { tive to } F R T R A \text { ) }\end{array}$ & $\begin{array}{l}\text { Share of steam freight trains in the total freight } \\
\text { transportation by rail }\end{array}$ \\
\hline$B A$ & fraction & $\begin{array}{l}\text { Share of inland waterways or coastal shipping } \\
\text { in the total demand for freight transportation }\end{array}$ \\
\hline$P I P$ & fraction & $\begin{array}{l}\text { Share of pipelines in the total demand for freight } \\
\text { transportation }\end{array}$ \\
\hline$D T R U$ & $\mathrm{kcal} /$ ton $\cdot \mathrm{km}$ & $\begin{array}{l}\text { Energy intensity of trucks (average or, if } T R U L \neq \\
0, \text { long-distance) }\end{array}$ \\
\hline DTRUL & $\mathrm{kcal} /$ ton-km & $\begin{array}{l}\text { Energy intensity of trucks for short hauls (only } \\
\text { relevant if } T R U L \neq 0 \text { ) }\end{array}$ \\
\hline$D T R A F$ & $\mathrm{kcal} /$ ton-km & Energy intensity of diesel freight trains \\
\hline (STDTRA) & factor & $\begin{array}{l}\text { Ratio between the energy intensities of steam and } \\
\text { diesel trains }\end{array}$ \\
\hline (ELDTRA) & factor & $\begin{array}{l}\text { Ratio between the energy intensities of electric } \\
\text { and diesel trains }\end{array}$ \\
\hline$D B A$ & $\mathrm{kcal} / \mathrm{ton}-\mathrm{km}$ & $\begin{array}{l}\text { Energy intensity of inland waterways and coastal } \\
\text { shipping (only motor fuel considered) }\end{array}$ \\
\hline$D P I P$ & $\mathrm{kcal} /$ ton-km & $\begin{array}{l}\text { Energy intensity of pipelines (only motor fuel } \\
\text { considered) }\end{array}$ \\
\hline$D I$ & $\mathrm{~km} / \mathrm{yr} /$ person & $\begin{array}{l}\text { Average intercity distance traveled per year per } \\
\text { person (applies to the total population) }\end{array}$ \\
\hline$D U$ & $\mathrm{~km} /$ day/person & $\begin{array}{l}\text { Average intracity distance traveled per day per } \\
\text { person (applies only to the population living in } \\
\text { large cities) }\end{array}$ \\
\hline$C O$ & $\begin{array}{l}\text { population/ } \\
\text { number of cars }\end{array}$ & Inverse of car ownership \\
\hline$D I C$ & $\mathrm{~km} / \mathrm{yr} / \mathrm{car}$ & $\begin{array}{l}\text { Average intercity distance driven per year per car } \\
\text { (one must be careful that the average distance } \\
\text { driven in intracity travel as implied by the assump- } \\
\text { tions on } P O, P O L C, D U, U C, L F U C \text { together with } \\
\text { the assumption on } D I C \text {, matches the total average } \\
\text { distance driven per year per car) }\end{array}$ \\
\hline$L F I C$ & persons per car & Average load factor of cars in intercity travel \\
\hline$U C$ & fraction & $\begin{array}{l}\text { Share of cars in the total demand for intracity } \\
\text { passenger transportation }\end{array}$ \\
\hline$(U C E)$ & $\begin{array}{l}\text { fraction } \\
\text { (relative to } U C \text { ) }\end{array}$ & $\begin{array}{l}\text { Share of electric cars in the total intracity car } \\
\text { travel }\end{array}$ \\
\hline LFUC & persons per car & Average load factor of cars in intracity travel \\
\hline$P B U$ & fraction & $\begin{array}{l}\text { Share of buses in intercity passenger travel exclud- } \\
\text { ing travel by car }\end{array}$ \\
\hline$P T R A$ & fraction & $\begin{array}{l}\text { Share of trains in intercity passenger travel exclud- } \\
\text { ing travel by car }\end{array}$ \\
\hline$(T R A E P)$ & $\begin{array}{l}\text { fraction } \\
\text { (relative to } P T R A \text { ) }\end{array}$ & $\begin{array}{l}\text { Share of electric trains in the total intercity travel } \\
\text { by train }\end{array}$ \\
\hline
\end{tabular}




\begin{tabular}{|c|c|}
\hline $\begin{array}{l}\text { Variable } \\
\text { (TRASTP) }\end{array}$ & $\begin{array}{l}\text { Unit } \\
\text { fraction (relative } \\
\text { to } P T R A \text { ) } \\
\text { fraction }\end{array}$ \\
\hline$L F B U$ & persons per bus \\
\hline$L F T R A$ & persons per train \\
\hline$L F P$ & fraction \\
\hline$U M T$ & fraction \\
\hline (UMTE) & $\begin{array}{l}\text { fraction (relative } \\
\text { to } U M T \text { ) }\end{array}$ \\
\hline L.FMTB & persons per bus \\
\hline LFMTE & $\begin{array}{l}\text { persons per } \\
\text { vehicle }\end{array}$ \\
\hline$G I C$ & liter/100 veh-km \\
\hline$G U C$ & liter/100 veh-km \\
\hline$E L U C$ & kWhr(e)/veh-km \\
\hline$D B U$ & liter/ 100 veh-km \\
\hline$D T R A P$ & $\mathrm{kcal} / \mathrm{train}-\mathrm{km}$ \\
\hline$D P L A$ & $\mathrm{kcal} / \mathrm{seat}-\mathrm{km}$ \\
\hline$D M T$ & liter $/ 100$ veh-km \\
\hline$E L M T$ & $\mathrm{kWhr}(\mathrm{e}) / \mathrm{veh}-\mathrm{km}$ \\
\hline$D D^{c}$ & egree-day \\
\hline
\end{tabular}

$D W S H^{c} \quad$ fractions

\section{Explanation}

Share of steam trains in the total intercity travel by train

Share of airplanes in intercity passenger excluding travel by car

Average load factor of buses (intercity)

Average load factor of trains (intercity)

Average capacity utilization factor of airplanes

Share of mass transportation systems in the total demand for intracity passenger transportation

Share of electric mass transit in the total intracity mass transportation ( $1-U M T E$ is the share of buses)

Average load factor of nonelectric mass transit systems (intracity)

Average load factor of electric mass transit systems (intracity)

Specific gasoline consumption of cars in intercity travel

Specific gasoline consumption of cars in intracity travel

Specific electricity consumption of electric cars (intracity travel)

Specific diesel consumption of buses (intercity)

Specific fuel consumption of diesel passenger trains (intercity)

Specific energy consumption of airplanes

Specific diesel consumption of buses (intracity)

Specific electricity consumption of intracity mass transportation systems

The definition in the US Statistical Abstract (see US (1976a), p. 178) is as follows: "A unit, based upon temperature difference and time, used in estimating fuel consumption and specifying nominal heating load in winter. For any one day, when the mean temperature is less than $65^{\circ} \mathrm{F}$ there exist as many degree days as there are Fahrenheit degrees difference in the temperature between the average temperature for the day and $65^{\circ} \mathrm{F}$." The definition used here differs in that it is (i) based on degrees Celsius, with the threshold being $18^{\circ} \mathrm{C}$; (ii) based on monthly average temperature; (iii) averaged over a region (weighted by population) by selection of a few representative cities. Our values are therefore rough approximations.

Share of dwellings (service sector floor area) which is in climatic conditions where heating is required 


\begin{tabular}{|c|c|}
\hline Variable & Unit \\
\hline$D W-75^{i}(D W)$ & $10^{6}$ dwellings \\
\hline SHDWO $(1)^{i}$ & $10^{3} \mathrm{kcal} / \mathrm{yr} /$ \\
\hline$S H D W O(2)^{i}$ & dwelling \\
\hline$S H D W O(3)^{i}$ & \\
\hline $\begin{array}{r}T A R E A-75^{i} \\
{[T A R E A]}\end{array}$ & $10^{6} \mathrm{~m}^{2}$ \\
\hline$C P L S E R^{c}$ & \\
\hline$H A R E A O^{i}$ & $10^{3} \mathrm{kcal} / \mathrm{yr} / \mathrm{m}^{2}$ \\
\hline$B Y R N C F^{i}$ & $10^{6} \mathrm{tce}$ \\
\hline COOKDW & $10^{3} \mathrm{kcal} / \mathrm{yr} / \mathrm{dw}$ \\
\hline$D W H W$ & fraction \\
\hline$H W C A P$ & $\begin{array}{l}10^{3} \mathrm{kcal} / \mathrm{yr} / \\
\text { person }\end{array}$ \\
\hline$D W A C$ & fraction \\
\hline$A C D W$ & $10^{3} \mathrm{kcal} / \mathrm{yr} / \mathrm{dw}$ \\
\hline$E L A P D W$ & $\mathrm{kWhr}(\mathrm{e}) / \mathrm{yr} / \mathrm{dw}$ \\
\hline $\operatorname{PREDW}(1)$ & fractions \\
\hline PREDW(2) & \\
\hline $\operatorname{PREDW}(3)$ & \\
\hline$A R E A H$ & fraction \\
\hline$E L A R O$ & $\mathrm{kWhr}(\mathrm{e}) / \mathrm{yr} / \mathrm{m}^{2}$ \\
\hline$A R E A A C$ & fraction \\
\hline$A C A R E A$ & $10^{3} \mathrm{kcal} / \mathrm{yr} / \mathrm{m}^{2}$ \\
\hline$E F F A C$ & thermal energy \\
\hline & energy input \\
\hline$D E M D W$ & fraction \\
\hline
\end{tabular}

$\begin{array}{ll}N E W D W(1) & \text { fractions } \\ N E W D W(2) & \\ N E W D W(3) & \\ D W S(1) & \mathrm{m}^{2} / \mathrm{dw}\end{array}$

$D W S(2)$

$D W S(3)$

\section{Explanation}

Total stock of dwellings in the base year

Specific space heat requirements of pre-75 dwellings (useful energy); 1 = single family house with central heating; 2 = apartment with central heating; $3=$ dwelling with room heating only

Total floor area of service sector buildings in the base year

Constant to calculate service sector labor force from the GDP-share of the service sector

Specific heat requirements of pre-1975 service sector buildings (useful energy)

Amount of noncommercial fuels used in the base year; noncommercial fuel use is considered only in the household sector in the model

Specific energy consumption for cooking in dwellings (useful energy)

Share of dwellings with hot water facilities

Specific energy consumption for water heating per person (useful energy)

Share of dwellings with air-conditioning

Specific cooling requirements per dwelling

Specific electricity consumption per dwelling (for uses other than space heating, water heating, cooking and air-conditioning)

Distribution of pre-1975 dwellings per type (definition of dwelling types as for SHDWO above)

Share of service sector floor area (in cold climates) actually heated

Specific electricity consumption in pre-1975 service sector buildings

Share of air-conditioned service sector floor area Specific cooling requirements in the service sector Coefficient of performance of (electric) air-conditioners

Average demolition rate of dwellings over a 5-year period between the previous and the current model years

Distribution of dwellings, constructed between the previous and the current model years by type (definition of dwelling types as for SHDWO above) Average floor area heated in post-1975 dwellings (definition of dwelling types as for SHDWO above) 


$\begin{array}{ll}\begin{array}{l}\text { Variable } \\ K(1)\end{array} & \begin{array}{l}\text { Unit } \\ \mathrm{kcal} / \mathrm{hr} / \\ K(2)\end{array} \\ \mathrm{m}^{2} /{ }^{\circ} \mathrm{C} \\ I S O(1) & \text { fractions } \\ I S O(2) & \\ I S O(3) & \\ & \\ \text { AREAL } & \mathrm{m}^{2} / \text { worker } \\ D E M A R & \text { fraction }\end{array}$

HAREAN

ELARN

ISOSV

ELP.H.SH[ELPHS(1)]

ELP.H.HW[ELPHS(2)]

ELP.H.CK[ELPHS(3)]

ELP.S.TH[ELPHS(4)]

(HPHS)

EFFHPR

DHPH

SPSH

FDSHS fractions

fraction

thermal energy extracted/ electric energy input fraction

fraction

fraction

\section{Explanation}

Specific heat loss rate in dwellings built after 1975 (definition of dwelling types as for SHDWO above)

Reduction of the average space heat demand of pre-1975 dwellings in the current year relative to that in the base year due to better insulation (definition of dwelling types as for $S H D W O$ above)

Average floor area per worker in the service sector

Average demolition rate of the floor area of service sector buildings over a 5-year period between the previous and the current model year

$10^{3} \mathrm{kcal} / \mathrm{yr} / \quad$ Specific heat requirements of post $1975 \mathrm{ser}$ vice sector buildings

Specific electricity consumption in post1975 service sector buildings

Reduction of the average heat demand in pre1975 service sector buildings in the current year relative to that in the base year due to better insulation

Electricity penetration into thermal uses in the household/service sector. The categories are: $H . S H=$ space heating (households); $H . H W=$ water heating (households); $H . C K$ = cooking (households); $S . T H=$ thermal uses (service sector)

Contribution of heat pump to electric space and water heating in the household/service sector

Coefficient of performance of (electric) heat pumps in the household/service sector

District heat penetration into space and water heating of dwellings and thermal uses in the service sector (large cities only)

Solar penetration into space heating in post1975 single family houses with central heating

Approximate share of space heat demand in households that can be met by a solar installation (the residual must be covered by a backup system) 


\begin{tabular}{|c|c|c|}
\hline Variable & Unit & Explanation \\
\hline$S P H W$ & fraction & $\begin{array}{l}\text { Solar penetration into water heating in dwel- } \\
\text { lings (total demand) }\end{array}$ \\
\hline$F D H W S$ & fraction & $\begin{array}{l}\text { Approximate share of the hot water demand } \\
\text { that can be met by a solar installation (the } \\
\text { residual must be covered by a backup system) }\end{array}$ \\
\hline$P L B$ & fraction & $\begin{array}{l}\text { Share of low-rise buildings (e.g., up to } 3 \text { floors) } \\
\text { in the total service sector floor area }\end{array}$ \\
\hline SPSV & fraction & $\begin{array}{l}\text { Solar penetration into thermal uses in post- } \\
1975 \text { low-rise buildings of the service sector }\end{array}$ \\
\hline$F D H S$ & fraction & $\begin{array}{l}\text { Approximate share of thermal energy demand } \\
\text { in the service sector that can be met by a solar } \\
\text { installation (the residual must be covered by a } \\
\text { backup system) }\end{array}$ \\
\hline CHGNCF & & $\begin{array}{l}\text { Ratio of the amount of noncommercial fuels } \\
\text { used in the current year relative to that in the } \\
\text { base year }\end{array}$ \\
\hline $\begin{array}{l}\text { EFF.H.SH[EFFHS }(1)] \\
\text { EFF.H.HW(EFFHS(2)] } \\
\text { EFF.H.CK[EFFHS(3)] } \\
\text { EFF.S.TH[EFFHS(4)] }\end{array}$ & fraction & $\begin{array}{l}\text { Efficiency of fossil fuel use relative to that of } \\
\text { electricity use for thermal uses in the house- } \\
\text { hold/service sector (definition of categories } \\
\text { as for ELP.X.YY above) }\end{array}$ \\
\hline EFFNCF & fraction & $\begin{array}{l}\text { Efficiency of noncommercial fuel use relative } \\
\text { to that of thermal electricity uses }\end{array}$ \\
\hline
\end{tabular}

\section{APPENDIX B3: DEFINITION OF DERIVED VARIABLES}

$\begin{array}{lll}\text { Variable } & \text { Unit } & \text { Explanation } \\ \text { GCF } & 10^{9} \$ 1975 & \text { Gross fixed capital formation } \\ \text { GCFB } & 10^{9} \$ 1975 & \text { Gross fixed capital formation, buildings } \\ \text { GCFM } & 10^{9} \$ 1975 & \text { Gross fixed capital formation, machinery } \\ \text { PC } & 10^{9} \$ 1975 & \text { Private consumption expenditure } \\ \text { TPCG } & 10^{9} \$ 1975 & \text { Private consumption, durable and nondurable goods } \\ \text { TPCDG } & 10^{9} \$ 1975 & \text { Private consumption, durable goods } \\ \text { TPCNDG } & 10^{9} \$ 1975 & \text { Private consumption, nondurable goods } \\ \text { TPCSER } & 10^{9} \$ 1975 & \text { Private consumption, services } \\ \text { YAG } & 10^{9} \$ 1975 & \text { GPD contribution, agriculture } \\ \text { YB } & 10^{9} \$ 1975 & \text { GDP contribution, construction } \\ \text { YMIN } & 10^{9} \$ 1975 & \text { GDP contribution, mining } \\ \text { YMAN } & 10^{9} \$ 1975 & \text { GDP contribution, manufacturing } \\ \text { YEN } & 10^{9} \$ 1975 & \text { GDP contribution, energy sector (electricity/gas/water) } \\ \text { YSER } & 10^{9} \$ 1975 & \text { GDP contribution, service sectors } \\ \text { VAMAN } & 10^{9} \$ 1975 & \text { Value added, manufacturing } \\ \text { VAIG } & 10^{9} \$ 1975 & \text { Value added contribution, basic material industries } \\ \text { VAM } & 10^{9} \$ 1975 & \text { Value added contribution, machinery and equipment } \\ & & \text { industries }\end{array}$




\begin{tabular}{|c|c|c|}
\hline Variable & Unit & Explanation \\
\hline VAC & $10^{9} \$ 1975$ & $\begin{array}{l}\text { Value added contribution, nondurable goods } \\
\text { industries }\end{array}$ \\
\hline VAMIS & $10^{9} \$ 1975$ & Value added contribution, miscellaneous industries \\
\hline $\mathrm{VA}(1)$ & $10^{9} \$ 1975$ & $=\mathrm{YAG}$ \\
\hline $\mathrm{VA}(2)$ & $10^{9} \$ 1975$ & $=\mathrm{YB}$ \\
\hline $\mathrm{VA}(3)$ & $10^{9} \$ 1975$ & $=\mathrm{YMIN}$ \\
\hline $\mathrm{VA}(4)$ & $10^{9} \$ 1975$ & $=\mathrm{VAIG}$ \\
\hline $\mathrm{VA}(5)$ & $10^{9} \$ 1975$ & $=\mathrm{VAM}$ \\
\hline $\mathrm{VA}(6)$ & $10^{9} \$ 1975$ & $=\mathrm{VAC}$ \\
\hline $\mathrm{VA}(7)$ & $10^{9} \$ 1975$ & $=$ VAMIS \\
\hline MFACM & Pcal & $\begin{array}{l}\text { Motor fuel demand, agriculture/construction/ } \\
\text { mining }\end{array}$ \\
\hline ELSACM & TWhr(e) & $\begin{array}{l}\text { Electricity demand, agriculture/construction/ } \\
\text { mining }\end{array}$ \\
\hline FFACM & Pcal & $\begin{array}{l}\text { Thermal use of fossil fuels, agriculture/construc- } \\
\text { tion/mining }\end{array}$ \\
\hline MFMAN & Pcal & Motor fuel demand, manufacturing \\
\hline ELSMAN & TWhr(e) & Electricity demand for specific uses, manufacturing \\
\hline $\operatorname{USMAN}(J), J=1-4$ & Pcal & $\begin{array}{l}\text { Useful thermal energy demand in manufacturing } \\
\text { for steam generation }(\mathrm{J}=1) \text {, furnace/direct heat } \\
(\mathrm{J}=2) \text {, space/water heating }(\mathrm{J}=3) \text {, and total }(\mathrm{J}= \\
\text { 4) }\end{array}$ \\
\hline $\operatorname{PMFF}(J), J=1-4$ & fraction & Share of fossil fuels in USMAN(J) \\
\hline $\operatorname{PMEL}(\mathrm{J}), \mathrm{J}=1-4$ & fraction & Share of electricity (conventional) in $\operatorname{USMAN}(\mathrm{J})$ \\
\hline $\operatorname{PMHP(J),~J~=~} 1-4$ & fraction & Share of electricity (heat pump) in USMAN(J) \\
\hline $\operatorname{PMDH}(J), J=1-4$ & fraction & Share of district heat in USMAN(J) \\
\hline $\operatorname{PMSS}(\mathrm{J}), \mathrm{J}=1-4$ & fraction & Share of soft solar systems in USMAN(J) \\
\hline $\operatorname{PMCG}(J), J=1-4$ & fraction & Share of onsite cogeneration in USMAN(J) \\
\hline FFMAN & Pcal & Thermal use of fossil fuels in manufacturing \\
\hline ELHMAN & Pcal & Thermal use of electricity in manufacturing \\
\hline DHMAN & Pcal & District heat demand in manufacturing \\
\hline SOLMAN & Pcal & $\begin{array}{l}\text { Useful energy demand replaced by soft solar sys- } \\
\text { tems in manufacturing }\end{array}$ \\
\hline COGSTH & Pcal & $\begin{array}{l}\text { Total useful energy demand provided with cogen- } \\
\text { eration of electricity }\end{array}$ \\
\hline COGEL & Pcal & $\begin{array}{l}\text { Byproduct electricity from cogeneration in manu- } \\
\text { facturing }\end{array}$ \\
\hline PSTEEL & $10^{6}$ tons & Total steel production \\
\hline COKE & Pcal & Coke demand for pig-iron production \\
\hline FEED & Pcal & $\begin{array}{l}\text { Total feedstock consumption (i.e., use of energy } \\
\text { sources as raw material) }\end{array}$ \\
\hline MFIND & Pcal & Motor fuel demand in industry \\
\hline ELACM & Pcal & $\begin{array}{l}\text { Electricity demand, agriculture/construction/ } \\
\text { mining }\end{array}$ \\
\hline ELMAN & Pcal & Electricity demand in manufacturing \\
\hline
\end{tabular}




$\begin{array}{ll}\text { Variable } & \text { Unit } \\ \text { ELSIND } & \text { TWhr(e) } \\ \text { ELIND } & \text { Pcal } \\ \text { FFIND } & \text { Pcal } \\ \text { FINACM } & \text { Pcal } \\ \text { FINMAN } & \text { Pcal } \\ \text { FININD } & \text { Pcal } \\ \text { TKFRT } & 10^{9} \text { ton-km } \\ \text { TKTRU } & 10^{9} \text { ton-km } \\ \text { TKTRUL } & 10^{9} \text { ton-km } \\ \text { TKTRA } & 10^{9} \text { ton-km } \\ \text { TKBA } & 10^{9} \text { ton-km } \\ \text { TKPIP } & 10^{9} \text { ton-km } \\ \text { TDTRU } & \text { Pcal } \\ \text { TDTRUL } & \text { Pcal } \\ \text { TDTRAF } & \text { Pcal } \\ \text { ELTRAF } & \text { TWhr(e) } \\ \text { STCLF } & \text { Pcal } \\ \text { TDBA } & \text { Pcal } \\ \text { TDPIP } & \text { Pcal } \\ \text { TDFT } & \text { Pcal } \\ \text { TELFT } & \text { TWhr(e) } \\ \text { PKI } & 10^{9} \mathrm{pkm} \\ \text { PIC } & 10^{9} \mathrm{pkm} \\ \text { PCT } & 10^{9} \mathrm{pkm} \\ \text { TPLA } & 10^{9} \mathrm{pkm} \\ \text { TPTRA } & 10^{9} \mathrm{pkm} \\ \text { TPBU } & 10^{9} \mathrm{pkm} \\ \text { TGIC } & \text { Pcal } \\ \text { TDBU } & \text { Pcal } \\ \text { TDPLA } & \text { Pcal } \\ \text { TDTRAP } & \text { Pcal } \\ \text { ELTRAP } & \text { TWhr(e) } \\ \text { STCLP } & \text { Pcal } \\ \text { TELIP } & \text { TWhr(e) } \\ \text { TMFIP } & \text { Pcal } \\ \text { POU } & 10^{6} \mathrm{persons} \\ \text { PKU } & 10^{9} \mathrm{pkm} \\ \text { PUC } & 10^{9} \mathrm{pkm} \\ 10^{9} \mathrm{pkm} \\ \text { Pcal } & \text { TWhr(e) } \\ & \end{array}$

Explanation

Electricity demand for specific uses, industry

Total electricity demand, industry

Thermal use of fossil fuels, industry

Final energy demand, agriculture/contruction/mining

Final energy demand in manufacturing

Final energy demand, industry

Total ton-kilometers, freight (domestic)

Ton-kilometers by truck, long-distance traffic

Ton-kilometers by truck, local traffic

Ton-kilometers by train

Ton-kilometers by barge (or coastal shipping)

Ton-kilome ters by pipelines

Diesel consumption by trucks, long-distance traffic

Diesel consumption by trucks, local traffic

Diesel consumption by freight trains

Electricity consumption by freight trains

Coal consumption by freight trains

Diesel consumption by barges or for coastal shipping

Diesel consumption by pipelines

Total motor fuel consumption, freight transportation

Total electricity consumption, freight transportation

Total passenger-kilometers, intercity

Passenger-kilometers by car, intercity

Passenger-kilometers by public transportation, intercity

Passenger-kilometers by plane (domestic)

Passenger-kilometers by train, intercity

Passenger-kilometers by bus, intercity

Gasoline consumption of cars, intercity traffic

Diesel consumption by buses, intercity traffic

FueI consumption by planes (domestic flights)

Diesel consumption by passenger trains

Electricity consumption by passenger trains (intercity)

Coal consumption by passenger trains

Total electricity consumption, intercity passenger transportation

Total motor fuel consumption, intercity passenger transportation

Total population in large cities (where mass transportation and district heating is feasible)

Total passenger-kilometers, intercity

Passenger-kilometers by car, intercity

Passenger-kilometers by public transportation, intracity

Gasoline consumption by cars, intracity traffic

Electricity consumption by electric cars (only considered for intracity traffic) 


\begin{tabular}{|c|c|c|}
\hline Variable & Unit & Explanation \\
\hline TDMT & Pcal & Diesel consumption for public transportation, intracity \\
\hline TELMT & TWhr(e) & Electricity consumption for public transportation, intracity \\
\hline TMFUP & Pcal & Total motor fuel consumption, intracity traffic \\
\hline TELUP & TWhr(e) & Total electricity consumption, intracity traffic \\
\hline TMISMF & Pcal & $\begin{array}{l}\text { Fuel consumption, international and military transporta- } \\
\text { tion }\end{array}$ \\
\hline TELTR & TWhr(e) & Total electricity consumption for transportation \\
\hline TMFTR & Pcal & Total motor fuel consumption for transportation \\
\hline TCLTR & Pcal & Total coal consumption for transportation \\
\hline ELTR & Pcal & $\begin{array}{l}\text { Total electricity consumption for transportation, but } \\
\text { with electricity expressed as thermal equivalent }\end{array}$ \\
\hline FINTR & Pcal & Final energy consumption for transportation \\
\hline TDEMDW & $10^{6} \mathrm{dwell}$ & $\begin{array}{l}\text { Dwellings demolished between previous and current model } \\
\text { year }\end{array}$ \\
\hline DWINCR & $10^{6} \mathrm{dwell}$ & $\begin{array}{l}\text { Net addition of dwellings between previous and current } \\
\text { model year }\end{array}$ \\
\hline DW & $10^{6}$ dwell & Total stock of dwellings \\
\hline CONSDW & $10^{6}$ dwell & $\begin{array}{l}\text { New constructed dwellings between previous and current } \\
\text { model year }\end{array}$ \\
\hline TPREDW & $10^{6}$ dwell & Stock of pre-1975 dwellings \\
\hline TPSTDW & $10^{6}$ dwell & Stock of post-1975 dwellings \\
\hline TDWSH & $10^{6}$ dwell & $\begin{array}{l}\text { Total stock of dwellings in areas, where space heating is } \\
\text { required }\end{array}$ \\
\hline POSTDW(1) & fraction & $\begin{array}{l}\text { Share of single family homes with central heating in post- } \\
1975 \text { dwellings }\end{array}$ \\
\hline POSTDW(2) & fraction & $\begin{array}{l}\text { Share of apartments with central heating in post-1975 } \\
\text { dwellings }\end{array}$ \\
\hline POSTDW(3) & fraction & $\begin{array}{l}\text { Share of dwellings without central heating in post-1975 } \\
\text { dwellings }\end{array}$ \\
\hline $\operatorname{PRESH}(1)$ & Pcal & $\begin{array}{l}\text { Useful energy demand for space heating, pre-1975 single } \\
\text { family homes with central heating }\end{array}$ \\
\hline $\operatorname{PRESH}(2)$ & Pcal & $\begin{array}{l}\text { Useful energy demand for space heating, pre-1975 apart- } \\
\text { ments with central heating }\end{array}$ \\
\hline PRESH(3) & Pcal & $\begin{array}{l}\text { Useful energy demand for space heating, pre-1975 dwel- } \\
\text { lings without central heating }\end{array}$ \\
\hline POSTSH(1) & Pcal & $\begin{array}{l}\text { Useful energy demand for space heating, post-1975 single } \\
\text { family homes with central heating }\end{array}$ \\
\hline $\operatorname{POSTSH}(2)$ & Pcal & $\begin{array}{l}\text { Useful energy demand for space heating, post-1975 apart- } \\
\text { ments with central heating }\end{array}$ \\
\hline POSTSH(3) & Pcal & $\begin{array}{l}\text { Useful energy demand for space heating, post-1975 dwel- } \\
\text { lings without central heating }\end{array}$ \\
\hline $\mathrm{SH}$ & Pcal & Useful energy demand for space heating \\
\hline HW & Pcal & Useful energy demand for water heating \\
\hline COOK & Pcal & Useful energy demand for cooking \\
\hline $\mathrm{ACH}$ & Pcal & Useful energy demand for air-conditioning \\
\hline
\end{tabular}


Variable

ELAP

PLSER

LSER

TDEMAR

ARINCR

TAREA

CONSAR

AREAO

AREAN

TARSH

HSERVO

HSERVN

THSERV

ACSV

ELSVO

ELSVN

ELSV

$\operatorname{USHS}(\mathrm{J}), \mathrm{J}=1-4$

FINNCF

USNCF

PNCFH

$\operatorname{PHSNCF}(\mathrm{J}), \mathrm{J}=1-4$

$\operatorname{PHSFF}(\mathrm{J}), \mathrm{J}=1-4$

$\operatorname{PHSEL}(\mathrm{J}), \mathrm{J}=1-4$

$\operatorname{PHSHP(J),~J~}=1-4$
Unit

TWhr(e)

fraction

$10^{6}$ workers

$10^{6} \mathrm{~m}^{2}$

$10^{6} \mathrm{~m}^{2}$

$10^{6} \mathrm{~m}^{2}$

$10^{6} \mathrm{~m}^{2}$

$10^{6} \mathrm{~m}^{2}$

$10^{6} \mathrm{~m}^{2}$

$10^{6} \mathrm{~m}^{2}$

Pcal

Pcal

Pcal

Pcal

TWhr(e)

TWhr(e)

TWhr(e)

Pcal

Pcal

Pcal

fraction

fraction

fraction

fraction

fraction

\section{Explanation}

Specific electricity consumption in dwellings (i.e., for purposes other than space and water heating, cooking, and air-conditioning)

Service sector share of labor force

Numbers of workers in the service sector

Service sector floor area demolished between previous and current model years

Net addition of service sector floor area between previous and current model years

Total service sector floor area

Newly constructed service sector floor area between previous and current model years

Pre-1975 service sector floor area

Post-1975 service sector floor area

Total service sector floor area, where space heating is required

Useful energy demand for thermal uses, pre1975 service sector buildings

Useful energy demand for thermal uses, post1975 service sector buildings

Total useful energy demand for thermal uses in the service sector

Useful energy demand for air-conditioning in the service sector

Specific electricity demand, pre-1975 service sector buildings

Specific electricity demand, post-1975 service sector buildings

Total specific electricity demand of the service sector

Useful energy demand for space heating ( $\mathrm{J}=$ $1)$, water heating $(\mathrm{J}=2)$, cooking $(\mathrm{J}=3)$ in households and thermal uses in the service sector $(\mathrm{J}=4)$

Final energy from noncommercial fuels (e.g., fuelwood, wastes)

Useful energy from noncommercial fuels

Fraction of useful energy demand for space and water heating and cooking in households supplied by noncommercial fuels Share of noncommercial fuels in USHS(J) Share of commercial fossil fuels in USHS(J) Share of electricity (conventional) in USHS(J) Share of electricity (heat pumps) in USHS(J) 


\begin{tabular}{|c|c|c|}
\hline $\begin{array}{l}\text { Variable } \\
\text { PHSDH(J), } \\
\operatorname{PHSSS}(\mathrm{J}), \mathrm{J}\end{array}$ & $\begin{array}{l}\text { Unit } \\
=1-4 \\
=1-4\end{array}$ & $\begin{array}{ll}\text { Explanation } & \\
\text { fraction } & \text { Share of district heat in USHS(J) } \\
\text { fraction } & \text { Share of soft solar systems in USHS(J) }\end{array}$ \\
\hline ELHHS & Pcal & $\begin{array}{l}\text { Electricity consumption for thermal uses in the household/ } \\
\text { service sector }\end{array}$ \\
\hline DHHS & Pcal & District heat consumption in the household/service sector \\
\hline SOLHS & Pcal & $\begin{array}{l}\text { Useful energy demand replaced by soft solar systems in the } \\
\text { household/service sector }\end{array}$ \\
\hline FFHS & Pcal & $\begin{array}{l}\text { Commercial fossil fuel consumption in the household/service } \\
\text { sector }\end{array}$ \\
\hline USCOOL & Pcal & $\begin{array}{l}\text { Useful energy demand for cooling in the household/service sec- } \\
\text { tor }\end{array}$ \\
\hline ELAC & Pcal & $\begin{array}{l}\text { Electricity demand for air-conditioning in the household/ser- } \\
\text { vice sector }\end{array}$ \\
\hline ELSPHS & TWhr(e) & $\begin{array}{l}\text { Electricity demand for specific uses in the household/service } \\
\text { sector }\end{array}$ \\
\hline ELHS & Pcal & Total electricity consumption of the household/service sector \\
\hline FINHS & Pcal & $\begin{array}{l}\text { Commercial final energy demand of the household/service sec- } \\
\text { tor }\end{array}$ \\
\hline FHSPNC & Pcal & $\begin{array}{l}\text { Commercial plus noncommercial final energy demand of the } \\
\text { household/service sector }\end{array}$ \\
\hline FF & Pcal & Total thermal use of fossil fuels \\
\hline DH & Pcal & Total district heat demand \\
\hline SOL & Pcal & Total solar energy demand \\
\hline ELEC & Pcal & Total electricity demand \\
\hline TMF & Pcal & Total motor fuel demand \\
\hline COALSP & Pcal & Specific uses of coal \\
\hline ENERGY & Pcal & Total commercial final energy demand \\
\hline ENPNCF & Pcal & Total commercial plus noncommercial final energy demand \\
\hline
\end{tabular}


APPENDIX C: DEFINITIONS OF MACROECONOMIC SECTORS IN TERMS OF ISIC* CATEGORIES

\begin{tabular}{|c|c|c|}
\hline & Regions I, II, III & Regions IV, V, VI \\
\hline Agriculture & ISIC 1 & ISIC 1 \\
\hline Construction & ISIC 5 & ISIC 5 \\
\hline Mining & - & ISIC 2 \\
\hline Manufacturing & $\begin{array}{l}\text { ISIC } 3 \\
\text { - ISIC } 353,354 \\
+ \text { ISIC } 2 \\
- \text { ISIC } 21,22\end{array}$ & ISIC 3 \\
\hline Energy & $\begin{aligned} & \text { ISIC } 4 \\
+ & \text { ISIC } 21,22 \\
+ & \text { ISIC } 353,354\end{aligned}$ & ISIC 4 \\
\hline $\begin{array}{l}\text { Services** } \\
\text { Manufacturing subsectors: }\end{array}$ & ISIC $6,7,8,9$ & ISIC $6,7,8,9$ \\
\hline Basic materials & $\begin{aligned} & \text { ISIC } 341,351,352,36,37 \\
+ & \text { ISIC } 2 \\
- & \text { ISIC } 21,22\end{aligned}$ & $\begin{aligned} & \text { ISIC } 341,351,352 \\
+ & \text { ISIC } 353,354 \\
+ & \text { ISIC } 36,37\end{aligned}$ \\
\hline $\begin{array}{l}\text { Machinery and equipment } \\
\text { Nondurables }\end{array}$ & $\begin{array}{l}\text { ISIC } 38 \\
\text { ISIC } 31,32,33,342,355,356,39\end{array}$ & $\begin{array}{l}\text { ISIC } 38 \\
\text { ISIC } 31,32,33 \\
+ \text { ISIC } 342,355,356 \\
+ \\
+ \text { ISIC } 39\end{array}$ \\
\hline
\end{tabular}

* International Standard Industrial Classification of all Economic Activities, Statistical Paper Series No. 4 Rev. 2, UN New York (1968).

**For Region II, a rough estimate of services belonging to the nonmaterial sphere has been included. 


\section{THE AUTHORS}

Arshad $M$. Khan gained his Ph.D. in physics at the University of Birmingham, UK in 1964. In 1968 he joined the Pakistan Institute of Nuclear Science and Technology and did experimental work on the nuclear physics of neutron capture reactions. At the same time, Dr. Khan was closely associated with the science and technology planning activities in Pakistan. He joined IIASA's Energy Systems Program in 1978 to study the long-term energy requirements of developing countries, and the options and alternative strategies that could be applied to their particular circumstances. He is now Head of the Applied Systems Analysis Group at the Pakistan Atomic Energy Commission.

Alois Hölzl received his diploma in Applied Mathematics from the Technical University in Vienna, in 1976. He joined IIASA's Resources and Environment Area in 1975 as a research assistant. In 1978 he became a research scholar and joined the Energy Systems Program. His activity was devoted to energy demand modeling, first on a case study for Austria, and later for the developed world regions as part of the Energy Systems Program. He is now a member in the organizing department of the Austrian National Oil and Gas Company. 


\section{SELECTED ENERGY-RELATED PUBLICATIONS BY IIASA}

ENERGY IN A FINITE WORLD: PATHS TO A SUSTAINABLE FUTURE Report by the Energy Systems Program Group of IIASA, Wolf Häfele, Program Leader. 225 pp. \$16.50.

Written by Jeanne Anderer with Alan McDonald and Nebojకa Nakićenović

ENERGY IN A FINITE WORLD: A GLOBAL SYSTEMS ANALYSIS

Report by the Energy Systems Program Group of IIASA, Wolf Häfele, Program Leader. 837 pp. $\$ 45.00$.

Both of the above volumes are available from Ballinger Publishing Company, 17 Dunster Street, Cambridge, Massachusetts 02138, USA.

\section{ENERGY IN A FINITE WORLD: EXECUTIVE SUMMARY}

Report by the Energy Systems Program Group of IIASA, Wolf Häfele, Program Leader. 74 pp. Written by Alan McDonald.

Free copies available from IIASA.

The other publications listed here are divided into five subject areas:

1 Global, regional, and sectoral energy models - whether for energy demand, energy supply and conversion, or for economic, resource, or environmental impacts of energy technologies.

2 The analysis of different energy sources - i.e., fossil fuels, nuclear power, solar power and other renewables - and the conversion, storage, and transportation technologies associated with them.

3 The analysis of energy demand patterns.

4 Environmental and safety risks of energy technologies.

5 The analysis of total energy systems and energy strategies including all the dimensions of the first four categories taken together.

Books in the International Series on Applied Systems Analysis (Wiley) can be ordered from John Wiley \& Sons Ltd., Baffins Lane, Chichester, Sussex PO19 2UD, United Kingdom.

Books published by Pergamon Press can be ordered from Pergamon Press Ltd., Headington Hill Hall, Oxford OX3 OBW, United Kingdom, or Pergemon Press, Inc., Fairview Park, EImstord, N.Y. 10523, USA.

All other publications can be ordered from the Office of Communications (Distribution), Laxenburg, Austria. 


\section{Energy Models}

RR-80-31. The IIASA Set of Energy Models: Its Design and Application. P.S. Basile. December 1980.65 pp. $\$ 7.00$

RR-78-17. MEDEE-2: A Model for Long-Term Energy Demand Evaluation. B. Lapillonne. November 1978.45 pp. $\$ 6.00$

RR-79-8. The Economic IMPACT Model. Yu.D. Kononov, A. Por. October 1979. 72 pp. $\$ 8.50$

RR-81-31. The Energy Supply Model MESSAGE. L. Schrattenholzer. December 1981. 39 pp. $\$ 5.00$

RR-82-13. A Long-Term Macroeconomic Equilibrium Model for the European Community, H.H. Rogner. April 1982.

Modeling of Large-Scale Energy Systems. Proceedings of the IIASA-IFAC Symposium on Modeling of Large-Scale Energy Systems. W. Häfele, Editor, L.K. Kirchmayer, Associate Editor. 1981.462 pp. (Available from Pergamon Press.) $\$ 72.00$

CP.74-3. Proceedings of IIASA Working Seminar on Energy Modeling, May 28-29, 1974. May 1974.342 pp. $\$ 13.00$

RR-74-10. A Review of Energy Models: No. 1 - May 1974. J.-P. Charpentier, Editor. July 1974. 102 pp. $\$ 8.50$

RR-75-35. A Review of Energy Models: No. 2 - July 1975. J.P. Charpentier, Editor. October 1975. 133 pp. $\$ 10.00$

RR-76-18. A Review of Energy Models: No. 3 (Special Issue on Soviet Models). J.-M. Beaujean, J.P. Charpentier, Editors. December 1976. 33 pp. $\$ 4.00$

RR-78-12. A Review of Energy Models: No. 4 - July 1978. J.-M. Beaujean, J.P. Charpentier, Editors. July 1978. 48 pp. $\$ 6.00$

CP-77-2. Methods of Systems Analysis for Long-Term Energy Development. Yu.D. Kononov, Editor. March 1977. 38 pp. $\$ 5.00$

RR-76-11. Modeling of the Influence of Energy Development on Different Branches of the National Economy. Yu.D. Kononov. October 1976. 15 pp. (Microfiche only.) $\$ 4.00$ RR-79-13. The Dynamics of Energy Systems and the Logistic Substitution Model. C. Marchetti, N. Nakićenović. December 1979. 73 pp. $\$ 8.50$

RR-79-12. Software Package for the Logis tic Substitution Model. N. Nakićnovic. December 1979.69 pp. $\$ 7.00$

RR-77-22. Macrodynamics of Technological Change: Market Penetration by New Technologies. V. Peterka. November 1977. 128 pp. (Microfiche only.)

RR-80-28. Market Substitution Models and Economic Parameters. B.I. Spinrad. July 1980. 26 pp. $\$ 4.00$

RR-81-5. Economic Evolutions and Their Resilience: A Model. M. Breitenecker, H.R. Grümm. April 1981.38 pp. $\$ 5.00$

RR-81-14. Dynamic Linear Programming Models of Energy, Resource, and Economic Development Systems. A Propoi, 1. Zimin. July 1981. 67 pp. $\$ 7.00$

RR-81-35. Two Global Scenarios: The Evolution of Energy Use and the Economy to 2030. V.G. Chant. December 1981.49 pp. $\$ 6.00$

\section{Energy Sources}

North Sea Oil. Resource Requirements for Development of the U.K. Sector. J.K. Klitz. 1980. 260 pp. (Available from Pergamon Press.) $\$ 36.00$

Future Supply of Nature-Made Petroleum and Gas. R. Meyer, Editor. IIASA, UNITAR. 1977. 1046 pp. (Available from Pergamon Press.) Hard cover $\$ 60.00$, soft cover $\$ 40.00$ 
Conventional and Unconventional World Gas Resources. M. Grenon, C. Delahaye, Editors. 1981. (Forthcoming from Pergamon Press.)

Future Coel Supply for the World Energy Balance. M. Grenon, Editor. :979. 720 pp. (Available from Pergamon Press.) $\$ 90.00$

RR-80-20. Energy and Entropy Fluxes in Coal Gesification and Liquefaction Proceseses. H. Voigt. April 1980. 25 pp. $\$ 4.00$

CP.77-6. Modium-Term Aspects of a Coal Revival: Two Cese Studies. Report of the IIASA Cosi Task Force. W. Sessin, F. Hoffmann, M. Sednicki. Editors. August 1977. 90 pp. \$8.50 Methods and Models for Assessing Energy Resources. M. Grenon, Editor. 1979. 605 pp. (Available from Pergamon Press.) $\$ 75.00$

RM-78-36. On Fossil Fuel Reserves and Resources. M. Grenon. June 1978. 37 pp. \$5.00

RR-75-2. Studies on Energy Resources in the IIASA Energy Project. M. Grenon. Jenuary 1975. 42 pp. (Microfiche only.) $\$ 4.00$

RR-76-38. Traneport and Storege of Energy. C. Marchetti. November 1975. 33 pp. $\$ 5.00$

AR-77-8. Fusion and Fast Breeder Reactors. W. Häfele, J.P. Holdren, G. Kesaler, G.L. Kulcinksi. July 1977. 506 pp. $\$ 24.00$

AR-75-38. Considerations on the Large-Scale Development of Nuclear Fuel Cycles. R. Avenhaus, W. Hëfele, P.E. McGrath. October 1975. 98 pp. $\$ 8.50$

RR-75-40. Application of Nuclear Power Other Than for Electricity Generation. W. Häfele. W. Sessin. November 1975. 120 pp. (Microfiche only.) $\$ 6.00$

AR-73-14. Hypotheticality and the New Challenges: The Pathfinder Role of Nuclear Energy. W. Hz̈fole. December 1973. 20 pp. $\$ 4.00$

AR-73-5. The Fast Breeder a Cornerstone for Future Large Supplies of Energy. W. Hăfele. September $1973.60 \mathrm{pp} . \$ 7.00$

RA-81-18. The Possible Share of Soft/Decentralized Renewables in Meeting the Future Eneryy Dernends of Developing Regions. A.M. Khan. September 1981. 40 pp. $\$ 5.00$ AM-77-28. Mobilization and Impacts of Bio-Ges Technologies. J.K. Parikh, K.S. Parikh. November 1977. 19 pp. $\$ 3.00$

RR-81-10. The Helios Strategy: A Heretical View of the Potential Role of Solar Energy in the Future of a Small Planet. J.M. Weingart. Reprinted from Technological Forecasting and Social Change, Volume 12 (14), pp. 273-315 (1978)

RA-77-20. Power from Glaciers: The Hydropower Potential of Greenland's Glacial Waters. R. Partl. November 1977. 52 pp. $\$ 7.00$

AA-78-7. On Hydrogen and Energy Systems. C. Marchetti. March 1976. 10 pp. (Microfiche only.) $\$ 4.00$

RM-78-62. Genetic Engineering and the Energy System: How to Make Ends Meet. C. Marchetti. December 1978. 11 pp. $\$ 4.00$

\section{Energy Demand}

RR-79-15. Simulation of Macroeconomic Scenarios to Assess the Energy Demand for India (SIMA). J.K. Parikh, K.S. Parikh. December 1979. 59 pp. $\$ 7.00$

The Growth of Energy Consumption and Prices in the USA, FRG, France, and the UK, 1950-1980. C.P. Doblin. 1982. Forthcoming.

RM-78-46. Energy Demand by US Manufacturing Industries. C.P. Doblin. September 1978. 43 pp. $\$ 6.00$ 
RM-76-43. German Democratic Republic: Energy Demand Data. C.P. Doblin. June 1976. 29 pp. (Microfiche only.) $\$ 4.00$

CP-76-1. Proceedings of the Workshop on Energy Demand. W.D. Nordhaus, Editor. January 1976. 880 pp. (Microfiche only.) $\$ 16.00$

RM-76-18. Data Provided for W.D. Nordhaus Study: The Demand for Energy: An International Perspective. C.P. Doblin. March 1976. 72 pp. $\$ 8.50$

\section{Environmental and Safety Risks}

Climate and Energy Systems. J. Jäger. 1982. (Forthcoming.)

Climatic Constraints and Human Activities. Task Force on the Nature of Climate and Society Research, February 4-6, 1980. J. H. Ausubel, A.K. Biswas, Editors. 1980. 214 pp. (Avaitable from Pergamon Press.) $\$ 30.00$

CP.77-9. Climate and Solar Energy Conversion: Proceedings of a IIASA Workshop, Decem. ber 8-10, 1976. J. Williams, G. Krömer, J.M. Weingart, Editors. December 1977. $\$ .50$

Carbon Dioxide, Climate and Society. J. Williams, Editor. 1978. 332 pp. (Available from Pergamon Press.) $\$ 30.00$

RM-76-17. On Geoengineering and the $\mathrm{CO}_{2}$ Problem. C. Marchetti. March 1976. 13 pp. $\$ 4.00$

RR-75-45. The Carbon Cycle of the Earth - A Material Balance Approach. R. Avenhaus, G. Hartmann. December 1975. 27 pp. $\$ 4.00$

RR 80-30. Possible Climatic Consequences of a Man-Made Global Warming. H. Flohn. December 1980. 92 pp. $\$ 8.50$

RA-80-21. The Impect of Weste Heat Release on Climate: Experiments with a General Circulation Model. J. Williams, G. Krömer. A. Gilchrist. Reprinted from Joumal of Applied Meteorology, Volume 18,pp. 1501-1511 (1979)

RR-80-15. A Comparative Study of Public Beliefs About Five Energy Systems. K. Thomas, D. Mouer, M. Fishbein, H.J. Otway, R. Hinkle, D. Simpson. April 1980. 32 pp. $\$ 5.00$

RR 80-25. The Value of Human Life: A Review of the Models. J. Linnerooth. Reprinted from Economic Enquiry, Volume 17,pp. 52-74 (1979)

RM-78-69. What Are We Talking About When We Talk About "Risk"? A Critical Survey of Risk and Risk Preference Theories. R.E. Schsefer. December 1978. 54 pp. $\$ 7.00$

RR-75-14. Avoidence Response to the Risk Environment: A Cross-Cultural Comparison. H.J. Otway, R. Maderthaner, G. Guttmann. June 1975. 29 pp. (Microfiche only.) \$4.00

AR-80-18. Nucleer Energy: The Accuracy of Policy Makers' Perceptions of Public Beliefs. K. Thomas, E. Swaton, M. Fishbein, H.J. Otway. April 1980. 37 pp. $\$ 5.00$

Material Accountability: Theory, Verification, and Applications. R. Avenhaus. 1977. $188 \mathrm{pp}$. (Availeble from John Wiley and Sons Ltd.) $\$ 32.85$

RR-76-19. The WELMM Approach to Energy Strategies and Options. M. Grenon, B. Lapillone. December 1976. 41 pp. \$6.00

RR-76-13. Environmental Impacts of Electrical Generation: A Systemwide Approach. W.K. Foell, W.A. Buenring. April 1976. 32 pp. (Microfiche only.) $\$ 4.00$

\section{Energy Systems and Energy Strategies}

RM-78-18. Energy Systems - The Broader Context. C. Marchetti, April 1978. 14 pp. $\$ 4.00$ 
CP.76-7. Energy Systems: Global Options and Strategies. W. Häfele, 1976, in IIASA Conference '76. 574 pp. $\$ 10.00$

AR-76-8. Energy Strategies. W. Häfele, W. Sassin. March 1976. 37 pp. (Microfiche only.) $\$ 4.00$

RR-73-1. Energy Systems. W. Häfele. July 1973.45 pp. IMicrofiche only.l $\$ 4.00$

RA-78-7. On 10'2 : A Check on Earth Carrying Capacity for Man. C. Marchetti. May 1978. 11 pp. $\$ 4.00$

RR-76-5. Definitions of Resilience. H.R. Grümm. March 1976. 20 pp. (Microfiche only.) $\$ 4.00$

Management of Energy/Environment Systems: Methods and Case Studies. W.K. Foell, Editor. 1979. 488 pp. (Available from John Wiley and Sons Ltd.) $\$ 39.50$

RR-79-10. On Energy and Agriculture: From Hunting-Gathering to Landless Farming. C. Marchetti. December 1979. 13 pp. $\$ 4.00$

RR-74-20. Future, Energy Resources. W. Häfele. November 1974. 28 pp. (Microfiche only.) $\$ 4.00$

The Nuclear Apple and the Solar Orange. Alternatives in World Energy. M. Grenon. 1981. 156 pp. (Available from Pergamon Press.) $\$ 36.00$

RA-76-10. Energy Strategies and the Case of Nuclear Power. W. Häfole. May 1976. 30 pp. $\$ 3.00$

RA-74-7. Strategies for a Transition from Fossil to Nuclear Fuels. W. Häfole. A.S Manne. June 1974. 70 pp. (Microfiche only.) $\$ 4.00$

RR-75-47. An Extension of the Häfele-Manne Model for Assessing Strategies for a Transition from Fossil to Nuclear and Solar Alternatives. A. Suzuki. December 1975 179 pp. (Microfiche only.) $\$ 6.00$

RR-80-27. Effects of Accounting Rules on Utility Choices of Energy Technologies in the United States. B.I. Spinrad. July 1980.32 pp. $\$ 5.00$

RR-76-6. A Systems Approsch to Development Planning of the Fuel Power Industry of a Planned-Economy Country. L.S. Belyaev. March 1976. 23 pp. (Microfiche only.) $\$ 4.00$

CP-76-12. Systems Studies of Nuclear Energy Development in the USSR. L.A. Melentiev, A.A. Makarov, A. Belostotsky. December 1976. 40 pp. $\$ 5.00$

RR-74-6. Energy Choices that Europe Faces: A European View of Energy. W. Häfele. March 1974. 37 pp. (Microflche only.) $\$ 4.00$

RR-81-8. A Global and Long-Range Picture of Energy Developments. W. Häfele. May 1981. 11 pp. Reprinted from Science Vol. 209. 4 July (1980). Single copies available froe of charge. 